FREDDY ARMANDO FRANCO GRIJALBA

DESENVOLVIMENTO DE ENSAIO NÃO DESTRUTIVO BASEADO NO RUÍDO MAGNÉTICO DE BARKHAUSEN PARA CARACTERIZAÇÃO DE TENSÕES ELÁSTICAS E DEFORMAÇÕES PLÁSTICAS EM AÇOS 


\section{DESENVOLVIMENTO DE ENSAIO NÃO DESTRUTIVO BASEADO NO RUÍDO MAGNÉTICO DE BARKHAUSEN PARA CARACTERIZAÇÃO DE TENSÕES ELÁSTICAS E DEFORMAÇÕES PLÁSTICAS EM AÇOS}

Tese apresentada à Escola Politécnica da Universidade de São Paulo, para obtenção do título de Doutor em Engenharia.

Área de Concentração:

Engenharia Mecânica, Projeto e fabricação.

Orientador: Prof. Livre-Docente Linilson Rodrigues Padovese 
Este exemplar foi revisado e alterado em relação à versão original, sob responsabilidade única do autor e com a anuência de seu orientador.

São Paulo, 10 de maio de 2010.

Assinatura do autor

Assinatura do orientador

\section{FICHA CATALOGRÁFICA}

Grijalba, Freddy Armando Franco

Desenvolvimento de ensaio não destrutivo baseado no ruído magnético de barkhausen para caracterização de tensões elasticas e deformações plásticas em aços / F.A.F. Grijalba. -- São Paulo, 2010.

$161 \mathrm{p}$.

Tese (Doutorado) - Escola Politécnica da Universidade de São Paulo. Departamento de Engenharia Mecânica.

1. Ensaios não destrutivos 2. Deformação e estresses I. Universidade de São Paulo. Escola Politécnica. Departamento de Engenharia Mecânica II. t. 
A mi princesa y amada esposa, Adriana. Por Clenar de felicidad cada uno de mis días.

A mi querida familia, especialmente a mis padres Luis y Cecilia, que me dieron no solamente la vida, sino también mi educación y siempre, han estado ahí.... para $m i$. 


\section{AGRADECIMENTOS}

Em primeiro lugar, agradeço a Deus por me iluminar, guiar, e conceder saúde, paz e força para conseguir culminar este trabalho.

Ao senhor orientador, Prof. Dr. Linilson Rodrigues Padovese, pela oportunidade oferecida, pela amizade, apoio e pela confiança depositada em mim.

A Fundação de Amparo a Pesquisa do Estado de São Paulo - FAPESP- pela concessão da bolsa e pelo apoio financeiro, o que possibilitou a minha permanência em Brasil, e conseguir realizar meus estudos de Doutorado.

Aos colegas do Laboratório LADIN, Dra. Márcia Maru, Dr. Julio Capó, Dr José Benitez, Alexander Alvarez, Manuel Caldas e em especial a Manuel Alberteris, pela alegre convivência, pelas conversas e sugestões.

Ao Senhor Álvaro Fontes, pelo seu excelente trabalho na fabricação e usinagem das diferentes amostras e equipamentos projetados no desenvolvimento do trabalho.

A mis amigos Colombianos, Loer F, Ediguer F, Adriana G, Leonardo V, Ricardo S, Mario G, John A, Carlos A, Sandra R, Alexander A, Wilfredo M, Belky, Dairo M, Cristian $\mathrm{D}, \mathrm{y}$ todos aquellos que de alguna forma me colaboraron y ayudaron, además de hacerme la vida mas amena durante estos años de estadía en Brasil.

E a todas as outras pessoas que direta o indiretamente colaboraram com a realização desta tese, meu agradecimento. 


\section{RESUMO}

Neste trabalho se estuda a aplicação de um método de Ensaio Não Destrutivo, baseado no Ruído Magnético de Barkhausen (RMB), na medição de falhas superficiais em aços. O RMB é gerado por abruptas mudanças na magnetização de materiais quando submetidos a campos magnéticos variáveis. Essas mudanças são afetadas pela microestrutura e a presença e distribuição de tensões elásticas (compressão e tração). Inicialmente apresenta-se um estudo de medições de tensões produzidas por flexão, e perfis de dureza, via RMB. Analisa-se a influência de parâmetros de medição e analise dos sinais, na qualidade do diagnostico. Analisou-se a sensibilidade dos sinais de RMB na medição de tensão a parâmetros tais como direção de laminação da chapa, intensidade e frequência de campo magnético de excitação. Nos estudos da aplicação do RMB em medições de dureza, se usaram amostras de ensaio Jominy, com variação contínua de dureza. Utilizou-se dois tipos de materiais e foram feitas medidas de dureza HRC, RMB e análise metalográfica. O comportamento de diferentes parâmetros dos sinais de RMB se correlacionou com as medições de Dureza e as micrografias obtidas. As amplitudes do RMB mostraram ser inversamente proporcionais aos níveis de dureza. Também se apresenta uma nova tecnologia para inspeção de superfícies, baseado no conceito do Barkhausen Contínuo. São apresentadas análises de parâmetros de medição e de configuração de sonda, na inspeção sob três situações: presença de defeitos volumétricos, deformação plástica, e tensões mecânicas aplicadas. Estudou-se a influência de parâmetros como, amplitude do campo aplicado, velocidade de varredura, posicionamento e características do sensor, no nível de detecção do dano. Métodos de processamento de sinais específicos foram desenvolvidos. Os resultados mostraram, que para cada um dos casos estudados, é possível detectar a posição e nível do dano produzido. Essa nova tecnologia aumenta o espectro de soluções de Ensaios Não Destrutivos para problemas não contemplados pelos métodos existentes.

\section{Palavras chaves:}

Ruído de Barkhausen, Ensaio Não Destrutivo, Dureza, Deformação Plástica, Tensão, Barkhausen Contínuo, Mapeamento de superfícies 


\section{ABSTRACT}

This work studies the application of a non-destructive testing method, based on the Magnetic Barkhausen Noise (MBN). MBN is generated by abrupt changes in magnetization of ferromagnetic materials subjected to variable magnetic fields. These changes are affected by the presence and distribution of elastic stresses (compression and traction) in the material and by its microstructure. At first, the present study describes MBN measurements of stresses produced by bending and MBN measurements of hardness profiles, in steel samples. The influence of both, measurement parameters and signal analysis, in the quality of fault diagnosis is also analysed. In this context, regarding stress measurements, the MBN signal sensitivity to parameters like surface lamination direction, intensity and frequency of magnetic excitation field is studied. On the other hand, application of MBN to hardness measurements used Jominy essay samples presenting continuous hardness variation. In this case, samples of two different materials were employed and hardness measurements were obtained by HRC, MBN as well as by metallographic analysis techniques. Behaviour of different MBN signal parameters were correlated with obtained hardness measurements and micrography. MBN amplitudes were shown to be inversely proportional to hardness levels. Finally, the work describes a new surface inspection technology, based on the concept of Continuous Barkhausen. In this context, the study analyses probe configuration and measurement parameters, concerning inspection of surface fault from three different origins: volumetric, plastic deformation, applied mechanical stress. The influence of parameters like applied field amplitude, probe velocity, sensor position and characteristics, in detecting damage level was also evaluated. In particular, specific signal processing methods were developed. Results showed that, for each studied case, it is possible to detect damage position and level. This new technology increases the range of NDT essay solutions for problems not yet contemplated by existing methods. .

\section{Key words:}

Barkhausen noise, Non-destructive testing, hardness, plastic deformation, Stress, Continuous Barkhausen, Surface mapping. 


\section{LISTA DE FIGURAS}

Figura 1.1 - Forma do campo magnético gerado por partículas de ferro dispersas numa área afetada por imãs permanentes. (CULLITY, 2009).

Figura 1.2 - Campo magnético de um solenóide. 25

Figura 1.3 - Momentos magnéticos atômicos. a) momento de translação,

b) momento de rotação. (Adaptada da Fig 20.4, Callister 7e). 28

Figura 1.4 - Curvas BxH de três materiais, um diamagnético (linha verde), um paramagnético (linha marrom) e um ferromagnético (linha vermelha). A linha azul é a resposta do B no ar.

Figura 1.5 - Esquema dos dipolos em um material diamagnético.

(Adaptada da Fig 20.5 Callister 7e)

Figura 1.6 - Esquema dos dipolos em um material paramagnético.

(Adaptada da Fig 20.5 Callister 7e) 30

Figura 1.7 - Esquema dos dipolos em um material ferromagnético. (Adaptada da Fig 20.7 Callister 7e) 30

Figura 1.8 - Curva típica de histerese magnética. 31

Figura 1.9 - Alinhamentos spin-spin. 33

Figura 1.10 - Desenho esquemático de domínios Magnéticos.

Figura 1.11 - Direções de magnetização fácil, média e difícil para os cristais de a) Ferro, e b) Níquel (CULLITY, 2009) 34

Figura 1.12 - Estrutura de parede de domino de $180^{\circ}$. (CULLITY, 2009). 35

Figura 1.13 - Comportamento dos domínios magnéticos durante o processo de magnetização.

Figura 1.14 - Movimento das paredes dos domínios. a) reversível. b)irreversível. 36

Figura 1.15 - Rotação dos domínios. a) reversível. b)irreversível. A e B são direções de eixos de fácil magnetização.

Figura 1.16 - Ruído magnético de Barkhausen na curva de histerese.

Figura 2.1 - Experimento feito por Heinrich Barkhausen. 
Figura 2.2 - Ruído Barkhausen e curva de histerese associada. Medição realizada num aço SAE-4140.

Figura 2.3 - Reorientação de domínios produzidas por tensão mecânica.

(KRAUSE T. W, 1996)

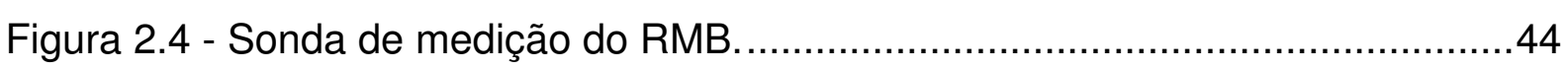

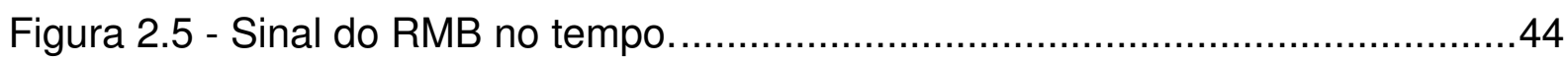

Figura 2.6 - Exemplo do envelope do sinal de RMB medido num aço SAE1070.

Figura 2.7 - Configuração da sonda utilizada na validação do RMBC (E. CROUCH, 2004). .48

Figura 2.8 - Técnicas de medição do Ruído Magentico de Barkhausen. a)

RMBE, b) RMBC. .50

Figura 3.1 - Viga tipo "Iso-flexão". .53

Figura 3.2 - Sentido de corte das amostras de Iso-flexão. 53

Figura 3.3 - Equipamento para ensaios de flexão. .54

Figura 3.4 - Instalação de extensômetros. .55

Figura 3.5 - Programa de aquisição de dados feito no software CATMAN para o registro dos sinais de Extensometria. .56

Figura 3.6 - Simulação por elemento finitos da máxima deflexão aplicada. .56

Figura 3.7 - Fotografias da sonda de RMB utilizada nos ensaios de Flexão. 58

Figura 3.8 - Esquema da cadeia de medida. .58

Figura 3.9 - Medida do campo magnético produzido pela sonda de RMB. .59

Figura 3.10 - Sinal do RMB no tempo (azul) e sinal proporcional ao campo de excitação (vermelho).

Figura 3.11 - Posição e orientações da sonda de RMB no procedimento de medida.

Figura 3.12 - Programa de aquisição de dados feito em LabView para o registro dos sinais de RMB.

Figura 3.13 - Estação experimental nas medidas de tensões de flexão. 61

Figura 3.14 - Comportamento dos valores de deformação medidos na amostra DL

Figura 3.15 - Comportamento dos valores de deformação medidos na amostra DT 
Figura 3.16 - Envelopes do sinal de RMB obtidos com diferentes tensões aplicadas na amostra DL.

Figura 3.17 - Dependência entre os diferentes parâmetros calculados do RMB (Posição pico, Amplitude pico, $\mathrm{RMB}_{\text {rms }}$ e $\mathrm{RMB}_{\text {energy }}$ ) e os valores de tensão aplicada.

Figura 3.18 - Dependencia entre os diferentes parâmetros normalizados do RMB (Posição pico, Amplitude pico, $\mathrm{RMB}_{\mathrm{rms}}$ e RMB $\mathrm{RMergy}_{\text {) }}$ e os valores de tensão aplicada.

Figura 3.19 - Faixas da curva de histerese magnética, em dependência com sua interação com tensões residuais. (U. Hofmann et al., 2005).

Figura 3.20 - Divisão do sinal de RMB em bandas temporais. 68

Figura 3.21 - Comportamento do parâmetro $\mathrm{RMB}_{\text {energy }}$ em relação a tensões de flexão aplicada. Analise de diferentes faixas temporais do sinal. 69

Figura 3.22 - Comportamento do parâmetro $\mathrm{RMB}_{\text {energy }}$ normalizado em relação a tensões de flexão aplicada. Analise de diferentes bandas temporais do sinal.

Figura 3.23 - Divisão do sinal de RMB em bandas de amplitude. .71

Figura 3.24 - Comportamento do parâmetro $\mathrm{RMB}_{\text {energy }}$ em relação a tensões de flexão aplicada. Analise de diferentes bandas temporais do sinal. .72

Figura 3.25 - Comportamento do parâmetro $\mathrm{RMB}_{\text {energy }}$ normalizado em relação a tensões de flexão aplicada. Analise de diferentes bandas de amplitude do sinal.

Figura 3.26 - Variação do parâmetro $\mathrm{RMB}_{\text {energy }}$ em relação a corrente aplicada, para três valores de tensão.

Figura 3.27 - Resposta do parâmetro $\mathrm{RMB}_{\text {energy }}$ em relação a tensão, para diferentes valores de corrente de magnetização aplicada.

Figura 3.28 - Resposta do parâmetro $\mathrm{RMB}_{\text {energy }}$ normalizado em relação a tensão, para diferentes valores de corrente de magnetização aplicada.

Figura 3.29 - Resposta do parâmetro $\mathrm{RMB}_{\text {energy }}$ em relação a tensão, para diferentes freqüências de magnetização aplicada. 
Figura 3.30 - Resposta do parâmetro $\mathrm{RMB}_{\text {energy }}$ normalizado em relação a tensão, para diferentes freqüências de magnetização aplicada.

Figura 3.31 - Microestructuras na chapa de aço SAE-1070, 1500X, a)face

A, b) Face $B$.

Figura 3.32 - Microestructuras na chapa de aço SAE-1070, 3500X, a)face

$A, b)$ Face $B$

Figura 3.33 - Variação do parâmetro $\mathrm{RMB}_{\text {enrgy }}$ em relação a tensões de flexão aplicadas na.....

Figura 3.34 - Variação do parâmetro $\mathrm{RMB}_{\text {energy }}$ em relação a tensões de flexão aplicadas na.

Figura 3.35 - Possível estrutura de domínios magnéticos nas amostras

DL e DT, e o efeito da tensão.

Figura 3.36 - Variação do parâmetro $\mathrm{RMB}_{\text {enrgy }}$ normalizado em relação a tensões de flexão aplicadas nas amostras DT e DL. Medições de RMB na direção longitudinal e transversal a tensão.

Figura 3.37 - Variação do parâmetro $\mathrm{RMB}_{\text {enrgy }}$ em relação a tensões transversais produzidas por flexão, nas amostras DT e DL. Medições de RMB na direção transversal das amostras. 84

Figura 4.1 - Configuração geométrica das amostras Jominy. 88

Figura 4.2 - Posição dos pontos de medida de dureza em cada uma das amostras.

Figura 4.3 - Micrografias da amostra Jominy de aço SAE-4140 obtidas em regiões localizadas a) $11.11 \mathrm{~mm}, 2000 \mathrm{X}$, b) $11.11 \mathrm{~mm}$, $21 \mathrm{X}, \quad \mathrm{c}) 19.05 \mathrm{~mm}, \quad 2000 \mathrm{X}, \quad$ d) $23.81 \mathrm{~mm}, \quad 2000 \mathrm{X}$ and e) $34.92 \mathrm{~mm}, 2000 \mathrm{X}$, da superfície temperada.

Figura 4.4 - Micrografias da amostra Jominy de aço SAE-6150 obtidas em regiões localizadas em, a) $9.52 \mathrm{~mm}, 35 \mathrm{X}$, b) $9.52 \mathrm{~mm}, 2000 \mathrm{X}$, c) $15.87 \mathrm{~mm}, 2000 \mathrm{X}$ d) $22.22 \mathrm{~mm}, 2000 \mathrm{X}$, e) $25.4 \mathrm{~mm}, 2000 \mathrm{X}$ and f) $31.75 \mathrm{~mm}, 3500 \mathrm{X}$, da superfície temperada.

Figura 4.5 - Envelopes do sinal de RMB obtidos em diferentes posições da amostra SAE-4140 utilizando freqüências de excitação de 5, 10 e $20 \mathrm{~Hz}$. 
Figura 4.6 - Envelopes do sinal de RMB obtidos em diferentes posições da amostra SAE-6150 utilizando freqüências de excitação de 5,10 e $20 \mathrm{~Hz}$. 96

Figura 4.7 - Distribuição dos diferentes parâmetros calculados do RMB (Posição pico, Amplitude pico e $\mathrm{RMB}_{\mathrm{rms}}$ ) e Dureza (HRC) no comprimento da amostra Jominy SAE-4140. Medições com freqüências de excitação de 5, 10 e $20 \mathrm{~Hz}$.

Figura 4.8 - Distribuição dos diferentes parâmetros calculados do RMB

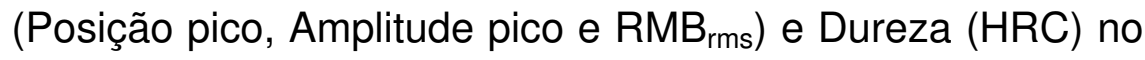
comprimento da amostra Jominy SAE-6150. Medições com freqüências de excitação de 5, 10 e $20 \mathrm{~Hz}$. 98

Figura 4.9 - Dependência de diferentes parâmetros do sinal de RMB (Posição pico, 1/Amplitude pico e $1 / \mathrm{RMB}_{\mathrm{rms}}$ ) em relação as medidas de Dureza(HRC) feitas na amostra SAE-4140. Freqüências de excitação de 5, 10 e $20 \mathrm{~Hz}$. .99

Figura 4.10 - Dependência de diferentes parâmetros do sinal de RMB (Posição pico, 1/Amplitude pico e $1 / \mathrm{RMB}_{\mathrm{rms}}$ ) em relação as medidas de Dureza(HRC) feitas na amostra SAE-6150. Freqüências de excitação de 5, 10 e $20 \mathrm{~Hz}$. 100

Figura 4.11 - Distribuição do parâmetro Posição pico do RMB e Dureza (HRC) no comprimento das amostras Jominy SAE-6150 e SAE-4140. F. ExC $=5 \mathrm{~Hz}$ 101

Figura 5.1 - Sonda de RMBC. a) Esquema de montagem, b ) vistas. Medidas em mm. 105

Figura 5.2 - Bobinas leitoras utilizadas. 106

Figura 5.3 - Estação experimental para a medição do RMBC 107

Figura 5.4 - Esquema do sistema de medição do RMBC. 108

Figura 5.5 - Programa de aquisição de dados feito em LabView para o registro dos sinais de RMBC. 108

Figura 5.6 - Curvas de magnetização $B(H)$ para a)Amostra de aço, e b) Núcleo de ferrite.

Figura 5.7 - Simulação do comportamento do fluxo magnético da sonda de RMBC na amostra. 
Figura 5.8 - Características da distribuição do fluxo magnético numa profundidade de $0.3 \mathrm{~mm}$ na amostra. a) Magnitude $(\mathrm{B} \mid)$ e direção (By/Bx) do fluxo. b) Gradiente espacial da magnitude $(\mathrm{d} \mid \mathrm{B} / \mathrm{dx})$ e direção $(\mathrm{d}(\mathrm{By} / \mathrm{Bx}) / \mathrm{dx})$ do fluxo.

Figura 5.9 - Configuração geométrica da amostra de materiais diferentes. Medidas em mm. 114

Figura 5.10 - Fotografia da amostra de materiais diferentes. 115

Figura 5.11 - Medição do RMBC feito na amostra de materiais deferentes.

a) Sinal no tempo, b) Variação do parâmetro M2-RMBC. 116

Figura 5.12 - Medição do RMBC. a) Espectrograma do sinal, b) Variação do parâmetro M2-RMBC com uma banda de freqüência de análise de $60-70 \mathrm{kHz}$.

Figura 5.13 - Comparação entre medições de RMBE e RMBC em amostra com matérias diferentes.

Figura 5.14 - Amostra com descarbonetação. Medidas em mm.

Figura 5.15 - Medição do RMBC feito na amostra com descarbonetação.

a) Sinal no tempo, b) Variação do parâmetro M2-RMBC.

Figura 5.16 - Medição do RMBC. a) Espectrograma do sinal, b) Variação do parâmetro M2RMBC com uma banda de freqüência de análise de $70-100 \mathrm{kHz}$.

Figura 5.17 - Comparação entre medições de RMBE e RMBC em amostra com descarbonetação.

Figura 5.18 - Geometria das amostras com variação de espessura. 122

Figura 5.19 - Influência do campo aplicado na resposta do RMBC medido na amostra 2. a) Sinal do RMBC no tempo, b) Variação do parâmetro M2-RMBC, c) Espectrograma do sinal. 124

Figura 5.20 Influência da Bobina leitora utilizada na resposta do RMBC medido na amostra 1. a) Sinal no tempo, b) Variação do parâmetro M2RMBC, c) Espectrograma do sinal. 126

Figura 5.21 - Variação do parâmetro M2-RMBC filtrado para cada uma das bobinas utilizadas.

Figura 5.22 - Variação do parâmetro M2-RMBC do sinal medido na amostra 1, com uma banda de freqüência de análise de 1- 
$100 \mathrm{kHz}$. a) Bobina leitora na frente dos ímãs, b) Bobina leitora atrás dos ímãs.

Figura 5.23 - Variação da amplitude máxima do parâmetro M2-RMBC com relação a velocidade da sonda sobre a amostra 1 .

Figura 5.24 - Variação do parâmetro M2-RMBC do sinal medido na amostra 2, com uma banda de freqüência de análise de 1$100 \mathrm{kHz}$. a) Bobina leitora na frente dos ímãs, b) Bobina leitora atrás dos ímãs.

Figura 5.25 - Variação da amplitude máxima do parâmetro M2-RMBC com relação a velocidade da sonda sobre a amostra 2 .

Figura 5.26 - Espectrograma do sinal de RMBC medidos na amostra 1. a) Bobina leitora na frente dos ímãs, b) Bobina leitora atrás dos ímãs. 131

Figura 5.27 - Espectrograma do sinal de RMBC medidos na amostra 2. (a) Bobina leitora na frente dos ímãs, (b) Bobina leitora atrás dos ímãs. 132

Figura 5.28 Variação do parâmetro M2RMBC na amostra 1, com uma banda de freqüência de análise de $60-100 \mathrm{kHz}$. (a) Bobina leitora na frente dos ímãs, (b) Bobina leitora atrás dos ímãs. 133

Figura 5.29 Variação do parametro M2RMBC na amostra 2, com uma banda de freqüência de análise de $60-100 \mathrm{kHz}$. (a) Bobina leitora na frente dos ímãs, (b) Bobina leitora atrás dos ímãs. 134

Figura 5.30 - Posição das deformações plásticas na amostra. Medidas em $\mathrm{mm}$. 136

Figura 5.31 - Influência do campo aplicado na resposta do RMBC. Variação do parâmetro M2-RMBC calculado em uma banda de freqüência de análise $1-100 \mathrm{kHz}$.

Figura 5.32 - Espectrograma do sinal. Influência do campo aplicado. 137

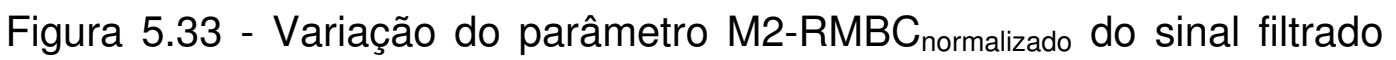
numa banda de freqüência de análise de $30-100 \mathrm{kHz}$ 138

Figura 5.34 - Influência da Bobina leitora na resposta do RMBC medido. Variação do parâmetro M2-RMBC na banda de freqüência de análise $1-100 \mathrm{kHz}$. 139

Figura 5.35 - Espectrograma do sinal. Influência da bobina leitora. 
Figura 5.36 - Variação do parâmetro M2RMBC do sinal filtrado numa banda de freqüência de análise de $60-100 \mathrm{kHz}$. Respostas da bobinas leitoras $\mathrm{B}$ e $\mathrm{C}$

Figura 5.37 - Variação do parâmetro M2-RMBC do sinal medido. Banda de freqüência de análise.

Figura 5.38 - Variação do parâmetro M2-RMBCnormalizado do sinal medido. Banda de freqüência de análise $30-100 \mathrm{kHz}$.

Figura 5.39 - Variação do parâmetro M2-RMBC. Banda de freqüência de análise de $30-100 \mathrm{kHz}$.

Figura 5.40 - Posição das deformações plásticas na amostra 2. Medidas em mm.

Figura 5.41 - Variação do parâmetro M2-RMBC. Banda de freqüência de análise de $30-100 \mathrm{kHz}$.

Figura 5.42 - Montagem da amostra com tensão aplicada. Medidas em $\mathrm{mm}$. 145

Figura 5.43 - Perfil de tensão gerado na amostra. Medidas em mm. 145

Figura 5.44 - Variação do parâmetro M2-RMBC. Resposta da bobina leitora $A$ numa banda de freqüência de análise $1-100 \mathrm{kHz}$. a) Influência do campo aplicado, utilizando $V=23 \mathrm{~mm} / \mathrm{s}$, b) Influência da velocidade de varredura utilizando 1 ímã.

Figura 5.45 - Espectrograma do sinal. Influência do campo aplicado e velocidade de varredura.

Figura 5.46 - Variação do parâmetro M2-RMBC. Resposta da bobina leitora $A$ em uma banda de freqüência de análise 30$100 \mathrm{kHz}$. a) Influência do campo aplicado, utilizando $\mathrm{V}=23 \mathrm{~mm} / \mathrm{s}$, b) Influência da velocidade de varredura, utilizando 1 ímã. 148

Figura 5.47 - Espectogramas e variação do parâmetro M2-RMBC normalizado. $_{\text {. }}$ Resposta das bobinas leitoras A, B e C, em diferentes bandas de freqüência de análise. $V=23 \mathrm{~mm} / \mathrm{s}$. Campo magnético produzido por 1 ímã.

Figura 5.48 - Perfis de tensão gerados por flexão, na zona de medida de RMBC. Linha vermelha, localização do apoio em $X=80 \mathrm{~mm}$. Linha azul, localização do apoio em X=40mm. 
Figura 5.49 - Variação do parâmetro M2-RMBC na deteç̧ão de dois diferentes perfis de tensão gerados por flexão. Banda de freqüência de análise, $30-100 \mathrm{kHz}$. Linha vermelha, localização do apoio em X=80mm. Linha azul, localização do apoio em $\mathrm{X}=40 \mathrm{~mm}$. 


\section{LISTA DE TABELAS}

Tabela 1.1 - Magnitudes magnéticas e suas unidades. (D. C JILES, 1998) 26

Tabela 2.1 - Profundidades aproximadas dos sinais do RMB, em dependência de suas freqüências de emissão.

Tabela 3.1 - Tensões calculadas na superfície das amostras de iso-flexão em função das deformações medidas.

Tabela 3.2 - Correntes de excitação aplicadas ...................................................59

Tabela 4.1 - Composição química das amostras utilizadas (\% em massa). .88

Tabela 5-1 - Campos magnéticos medidos para os diferentes arranjos de ímãs utilizados.

Tabela 5-2 - Composição química dos aços utilizados (\% em massa). Amostra materiais diferentes.

Tabela 5-3 - Composição química das amostras com variação de espessura. 


\section{LISTA DE SÍMBOLOS}

\begin{tabular}{|c|c|}
\hline $\mathrm{H}$ & Campo magnético aplicado \\
\hline $\mathrm{Hc}$ & Campo coercitivo \\
\hline Hmax & $\begin{array}{l}\text { Amplitude de campo necessário para levar o material ao nível de } \\
\text { magnetização máxima. }\end{array}$ \\
\hline B & Indução magnética. \\
\hline $\mathrm{Br}$ & Indução magnética remanente. \\
\hline Bmax & Indução magnética relativo à magnetização máxima. \\
\hline M & Magnetização \\
\hline$\mu$ & Permeabilidade magnética. \\
\hline$\mu_{\mathrm{r}}$ & Permeabilidade relativa. \\
\hline$\mu_{0}$ & Permeabilidade magnética no vácuo. \\
\hline$\chi_{\mathrm{m}}$ & Susceptibilidade magnética. \\
\hline $\mathrm{E}_{\mathrm{T}}$ & Energia total magnética de um material ferromagnético. \\
\hline$E_{e x}$ & Energia de troca. \\
\hline$E_{m}$ & Energia magnetostática \\
\hline $\mathrm{E}_{\mathrm{an}}$ & Energia de anisotropia magnetocristalina \\
\hline$E_{\text {stric }}$ & Energia magnetostrictiva \\
\hline$E_{\text {dis }}$ & Energia de desordem \\
\hline$\delta$ & Profundidade eletromagnética \\
\hline$f$ & Freqüência do sinal \\
\hline$\sigma$ & Condutividade do material \\
\hline $\mathrm{RMB}_{\mathrm{rms}}$ & Valor RMS dos sinais Barkhausen \\
\hline $\mathrm{V}_{\mathrm{i}}$ & Valor da voltagem medida em um determinando instante \\
\hline$V_{m}$ & Valor médio do sinal \\
\hline $\mathrm{n}$ & Número de pontos do sinal \\
\hline $\mathrm{RMB}_{\text {energy }}$ & Valor de energia dos sinais Barkhausen \\
\hline$\sigma_{e}$ & Limite de escoamento do material \\
\hline $\boldsymbol{\varepsilon}$ & Deformação \\
\hline $\mathrm{E}$ & Modulo de elasticidade \\
\hline
\end{tabular}




\section{SUMARIO}

INTRODUÇÃO

PRINCÍPIOS DE MAGNETISMO E TEORIA DE DOMÍNIOS MAGNÉTICOS

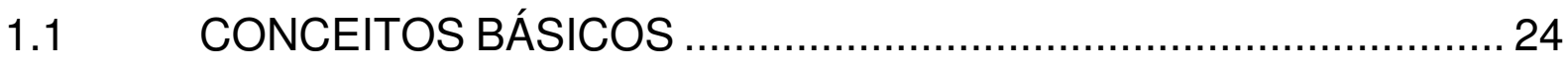

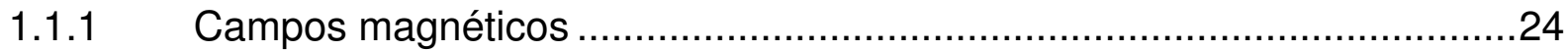

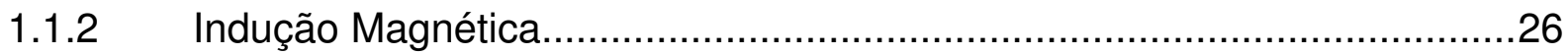

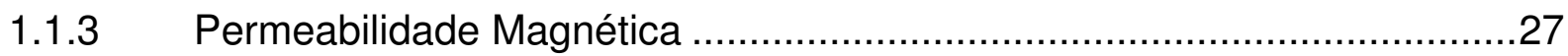

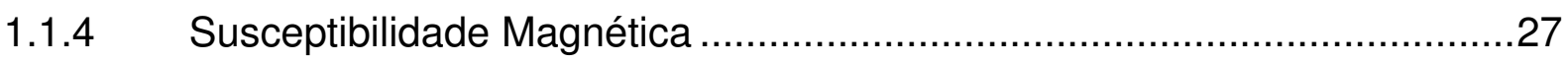

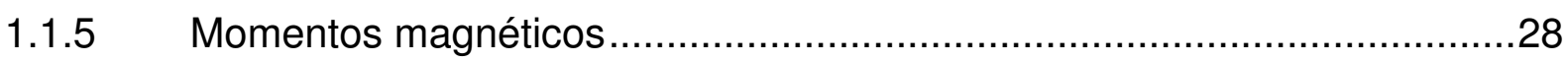

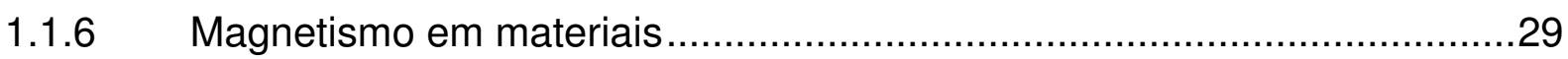

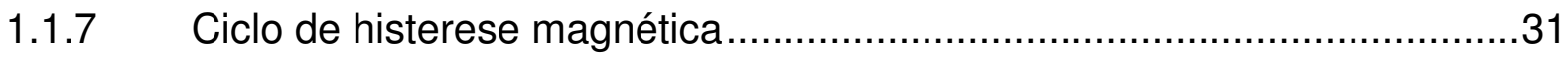

1.2 DOMÍNIOS MAGNÉTICOS EM SISTEMAS FERROMAGNÉTICOS......................................................... 32

1.2.1 Origem dos domínios magnéticos …………….................................

1.2.2 Paredes de domínio e processo de magnetização .....................................35

2 RUÍDO MAGNÉTICO DE BARKHAUSEN............................. 38

2.1 RMB E TENSÕES MECÂNICAS ................................................. 39

2.2 RMB E DEFORMAÇÃO PLÁSTICA ….................................... 41

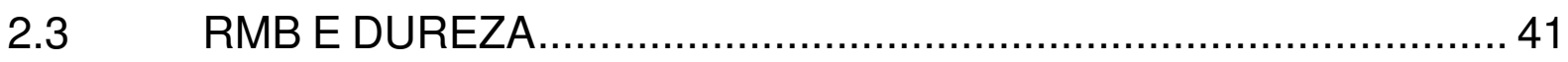

$2.4 \quad$ PROFUNDIDADE DA MEDIDA DO RMB …............................. 42

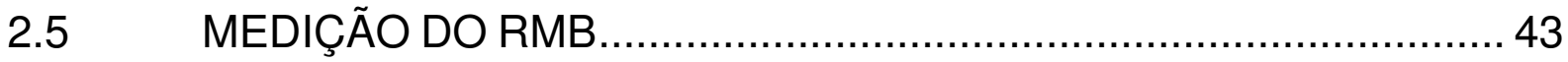

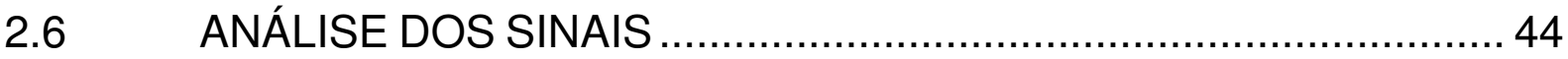

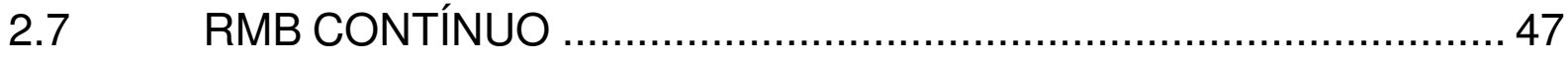

2.8 INTRODUÇÃO AOS ESTUDOS REALIZADOS NO

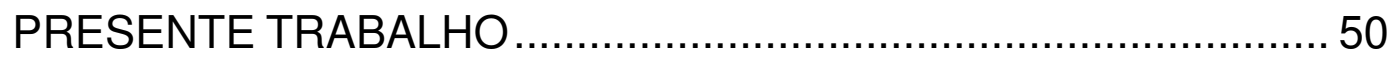

3 MEDIÇÕES DE TENSÕES DE FLEXÃO VIA RMB............... 52

3.1 MATERIAIS E MÉTODOS ........................................................ 52

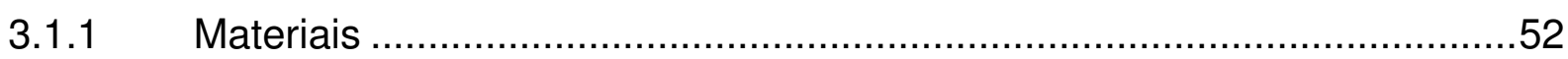




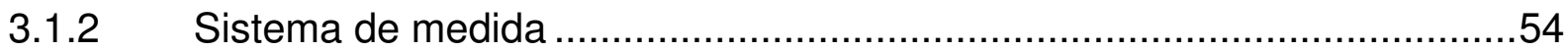

3.1.2.1 Aplicação e controle dos carregamentos ............................................54

3.1.2.2 Medição do Ruído Magnético de Barkhausen (RMB) .............................57

3.2 RESULTADOS E DISCUSSÃO ................................................. 62

3.2.1 Influência de parâmetros de medida e análise do RMB na medição de tensão

3.2.1.1 Correlação entre parâmetros de análise do sinal de RMB e os valores de tensão aplicada .64

3.2.1.2 Análise de diferentes bandas temporais do sinal de RMB.......................67

3.2.1.3 Análise de diferentes faixas de amplitude do sinal de RMB ...................70

3.2.1.4 Influência da amplitude do campo magnético aplicado ...........................74

3.2.1.5 Influência da freqüência de magnetização aplicada ................................77

3.2.2 Influência da direção de laminação .....................................................79

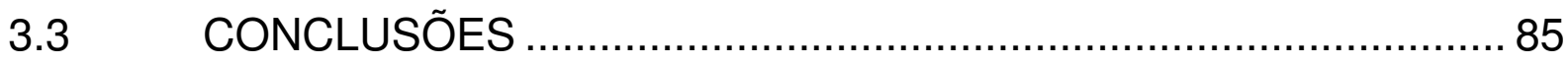

4 UTILIZAÇÃO DO RMB NA AVALIAÇÃO DE DUREZA EM AÇOS ........................................................... 87

4.1 MATERIAIS E MÉTODOS ............................................................ 87

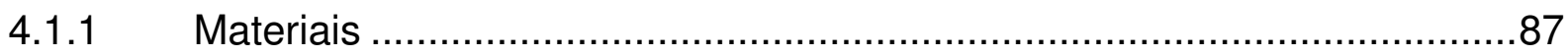

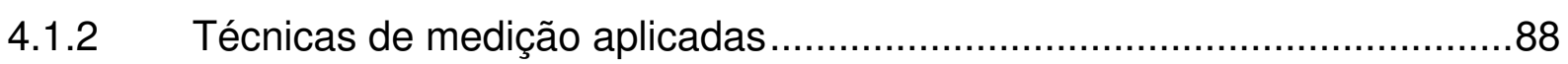

4.1.2.1 Ruído magnético de Barkhausen (RMB) ............................................8

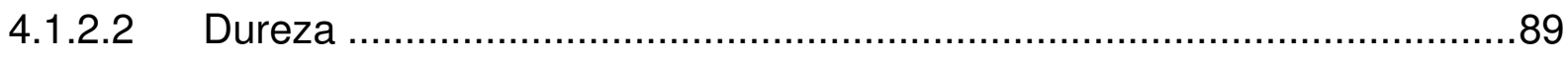

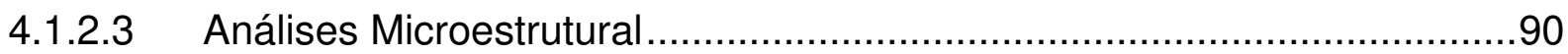

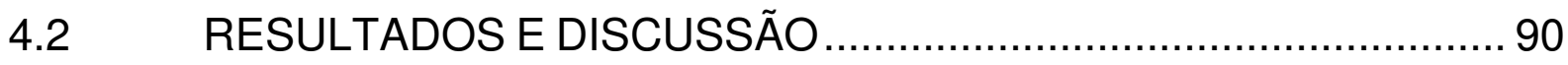

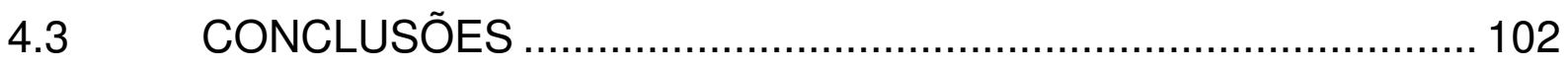

5 BARKHAUSEN CONTÍNUO .............................................. 104

5.1 SISTEMA DE MEDIDA ............................................................ 105

5.2 MÉTODOS DE PROCESSAMENTO DO SINAL DE RMBC .......... 109

5.3 SIMULAÇÃO POR ELEMENTOS FINITOS DO COMPORTAMENTO MAGNÉTICO DA SONDA DE RMBC...........110

$5.4 \quad$ ENSAIOS PRELIMINARES .................................................. 113

5.4.1 Ensaio Preliminar 1: RMBC em amostra com diferentes materiais 
5.4.1.1 Materiais e métodos ................................................................... 114

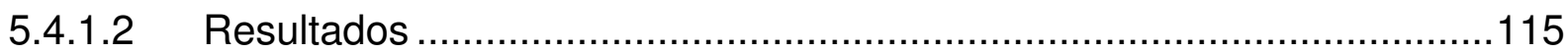

5.4.2 Ensaio preliminar 2: RMBC em amostra com diferentes porcentagens de descarbonetação.............................................118

5.4.2.1 Materiais e métodos.................................................................118

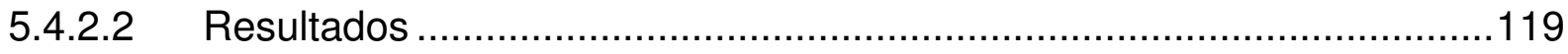

5.5 MEDIÇÕES DE RMBC EM UMA AMOSTRA COM VARIAÇÃO DE ESPESSURA (FRANCO F. A, PADOVESE

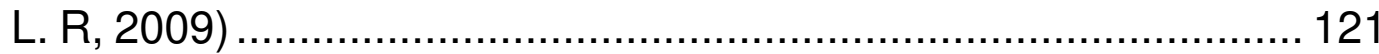

5.5.1 Materiais e métodos...................................................................... 121

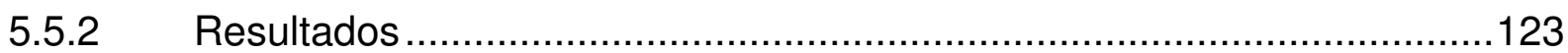

5.5.2.1 Influência do campo aplicado.................................................. 123

5.5.2.2 Influência da bobina leitora ....................................................... 125

5.5.2.3 Influência da velocidade e orientação da sonda .................................128

5.6 MEDIÇÕES DE RMBC EM UMA AMOSTRA COM DEFORMAÇÕES PLÁSTICAS LOCALIZADAS ...................... 135

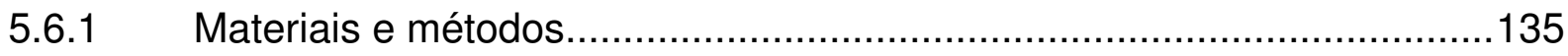

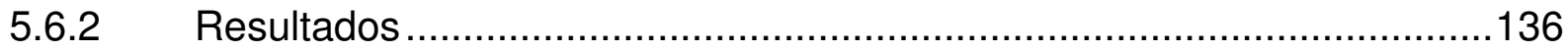

5.6.2.1 Influência do campo aplicado........................................................136

5.6.2.2 Influência da Bobina leitora ..............................................................139

5.6.2.3 Influência da velocidade e orientação da sonda .................................141

5.6.2.4 Resultados adicionais ............................................................... 143

5.7 MEDIÇÕES DE RMBC EM AMOSTRAS COM TENSÃO

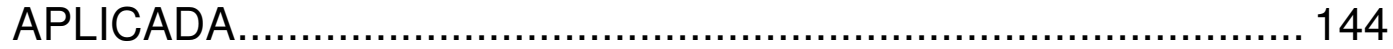

5.7.1 Materiais e métodos.............................................................. 145

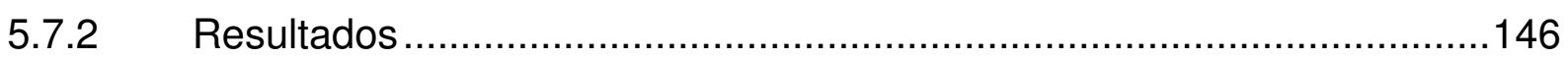

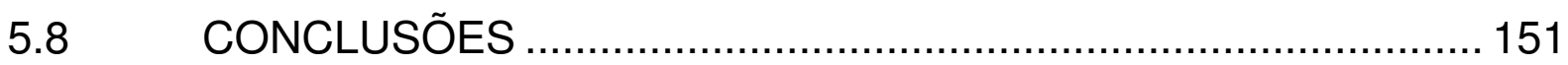

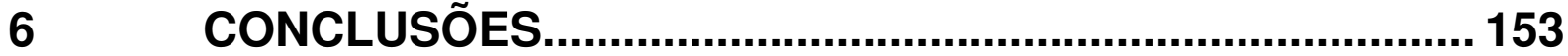

MEDIÇÕES DE TENSÕES DE FLEXÃO VIA RMB .................................. 153

UTILIZAÇÃO DO RMB NA AVALIAÇÃO DE DUREZA EM AÇOS. .............. 154

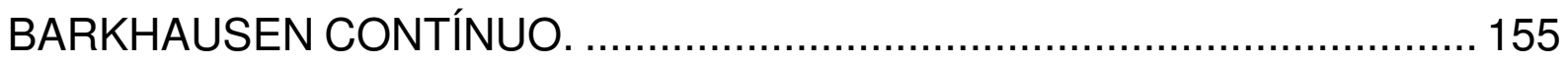

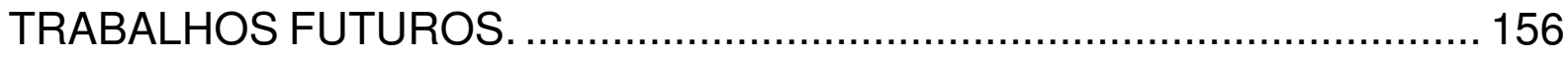




\section{INTRODUÇÃO}

Quando materiais ferromagnéticos são submetidos a campos magnéticos variáveis, a variação da indução ocorre de forma descontínua em decorrência da movimentação das paredes dos domínios magnéticos. Esses saltos discretos da indução produzem pulsos magnéticos conhecidos como Ruído Magnético de Barkhausen (RMB). O RMB é sensível a alterações microestruturais, tensões e deformações plásticas. Como conseqüência pode ser utilizado como Ensaio Não Destrutivo (END), numa grande variedade de aplicações. Neste contexto, o RMB pode ser aplicado no monitoramento de alterações microestruturais decorrentes de processos mecânicos ou térmicos, controle de qualidade de tratamentos superficiais, acompanhamento de processo de envelhecimento, de fadiga, avaliação de textura microestrutural e de alteração de microestrutura em superfícies trabalhadas mecanicamente (usinagem e conformação), etc.

A medição, caracterização e mapeamento de variações microestruturais, deformações plásticas e tensões mecânicas encontram aplicações em vários setores da indústria. Alguns dos métodos existentes, para esses casos, ou são destrutivos ou limitados em sua aplicabilidade. O RMB é uma alternativa tecnológica com grande potencial, sobretudo pelo seu baixo custo, simplicidade de utilização e pelo fato de abrir possibilidades de caracterização de materiais ferromagnéticos que não são possíveis com outras técnicas de END.

Algumas das aplicações industriais em que a técnica de medição do RMB vem sendo utilizada são:

$\checkmark$ Processo e controle de qualidade na produção de engrenagens, válvulas, rolamentos, virabrequim, comando de válvulas, e outras partes importantes de motores e aeronaves.

$\checkmark$ Avaliação de danos por fadiga de contato em engrenagens e rolamentos.

$\checkmark$ Avaliação de tensões residuais em tubulações soldadas e cilindros de laminação

$\checkmark$ Avaliação do efeito "shot peening" em aço. 
$\checkmark$ Medição da inversão de tensões residuais em rodas ferroviárias por efeito térmico.

$\checkmark$ Avaliação de degradação térmica em dutos de Caldeira

$\checkmark$ Inspeção por Ruído Barkhausen para detecção de queima por retifica em peças de aço de alta resistência. Norma SAE ARP 4462.

Existem vários grupos internacionais de pesquisa que estudam o fenômeno do RMB, tanto do ponto de vista do fundamento físico, quanto das aplicações como END. Já na América do Sul, a equipe mais destacada é o grupo do Laboratório de Dinâmica e Instrumentação (LADIN). A equipe do LADIN do Departamento de Engenharia Mecânica (PME) da Escola Politécnica (EPUSP) vem desenvolvendo tecnologia própria em RMB há 9 anos. Esse desenvolvimento compreende tanto o equipamento em si, quanto aplicações tecnológicas.

Os objetivos deste trabalho são inovadores do ponto de vista acadêmico como, sobretudo, industrial. É proposto o desenvolvimento de um método de avaliação não destrutiva de tensões mecânicas, deformações plásticas e dureza em materiais ferromagnéticos através da utilização do Ruído Magnético de Barkhausen. Nesse contexto os seguintes três objetivos gerais são definidos:

1. Estudar a influência dos procedimentos de análise e medida do RMB na medição de tensões de flexão.

$\checkmark$ Analisar as correlações entre diferentes parâmetros de análise do sinal de RMB e os valores de tensão aplicada.

$\checkmark$ Determinar a dependência de diferentes bandas temporais e faixas de amplitude do sinal de RMB.

$\checkmark$ Estudar a influência da amplitude e freqüência do campo de magnetização aplicado.

$\checkmark$ Verificar a influência da direção de laminação.

2. Estudar a utilização do RMB para medição de dureza em aços. 
3. Estudar a possibilidade da utilização do Barkhausen Contínuo como método de mapeamento de falhas, tensões e deformações superficiais em chapas de materiais ferromagnéticos.

$\checkmark$ Desenvolver uma bancada de testes o processo de medição.

$\checkmark$ Desenvolver um sistema de medida.

$\checkmark$ Estudar a possibilidade da utilização do Barkhausen contínuo na avaliação falhas volumétricas, tensões aplicadas e deformações plásticas.

$\checkmark$ Determinar procedimentos adequados de análise dos sinais.

$\checkmark$ Estudar o efeito do campo aplicado e da velocidade da sonda.

$\checkmark$ Avaliar o efeito das características e posicionamento da bobina leitora.

A estrutura do presente texto é apresentada a seguir:

Nos capítulos 1 e 2, são apresentadas, respectivamente, uma revisão bibliográfica e os fundamentos teóricos relacionados ao magnetismo e o RMB.

No capítulo 3, 4 e 5, apresentam-se a metodologia experimental, resultados e discussão, e conclusões relacionadas ao primeiro, segundo e terceiro objetivo geral, respectivamente.

No capitulo 6, são apresentadas as conclusões gerais do trabalho.

No capítulo 7, apresentam-se as referências bibliográficas. 


\section{PRINCÍPIOS DE MAGNETISMO E TEORIA DE DOMÍNIOS MAGNÉTICOS}

O objetivo deste capítulo é introduzir alguns conceitos úteis para a interpretação dos resultados apresentados nesta tese. Ele não deve ser considerado como uma discussão aprofundada sobre o magnetismo, que poderá ser encontrada na literatura clássica a respeito (D. C. JILES, 1994; CHICAZUMI, 1978; CULLITY, 2009; BOZORTH, 1993).

\subsection{CONCEITOS BÁSICOS}

Magnetismo é o fenômeno pelo qual os materiais apresentam uma força atrativa ou repulsiva, ou influem em outros materiais. O ferro, níquel e cobalto, alguns aços e a magnetita (óxido de ferro, $\mathrm{Fe}_{3} \mathrm{O}_{4}$ ) são conhecidos exemplos de materiais que apresentam propriedades magnéticas. Não tão familiar ainda é o fato de que todas as substâncias são influenciadas de uma ou de outra forma pela presença de um campo magnético.

\subsubsection{Campos magnéticos}

A presença de um campo magnético ao redor de uma barra de ímã pode ser visto pela dispersão das pequenas partículas de ferro dispersas sobre um papel colocado sobre o Imã. Ver Figura 1.1 


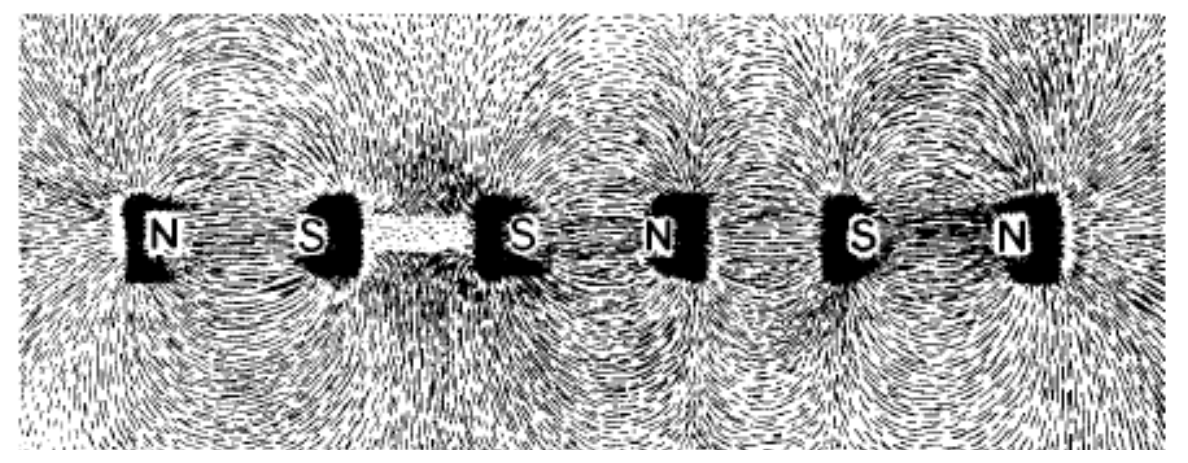

Figura 1.1 - Forma do campo magnético gerado por partículas de ferro dispersas numa área afetada por imãs permanentes. (CULLITY, 2009)

A figura gerada por estas partículas mostra que o imã tem dois pólos magnéticos e as linhas de campo magnético saem de um pólo e entrar no pólo posto. Em geral, o magnetismo tem uma natureza bipolar, há sempre dois pólos magnéticos ou centros de campo magnético separados por uma distância determinada.

Os campos magnéticos são também produzidos por condutores que transmitem corrente. A Figura 1.2 mostra a formação de um campo magnético em torno de uma bobina longa de fio de cobre, chamado de um solenóide, cujo comprimento é maior que seu raio.

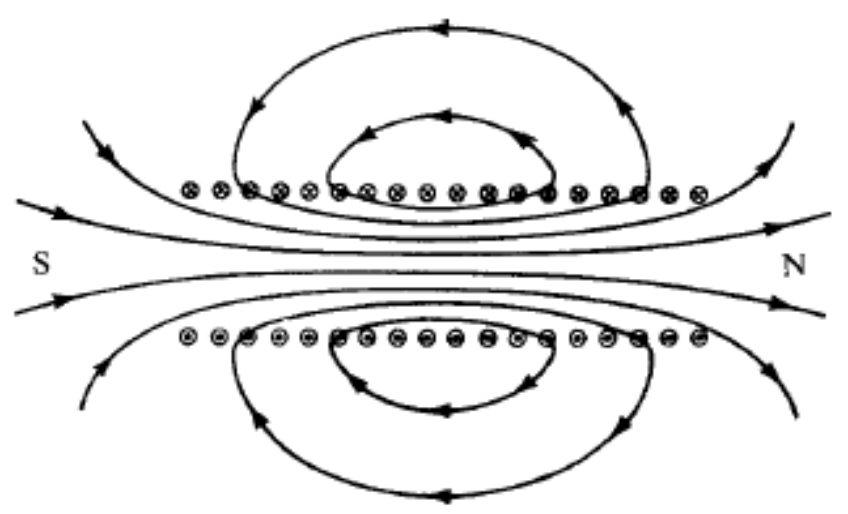

Figura 1.2 - Campo magnético de um solenóide.

Para um solenóide de $\mathbf{n}$ voltas e comprimento $\mathbf{L}$, a intensidade do campo magnético H é:

$H=\frac{n i}{L}[A / m]$ 
Onde:

$\mathrm{n}$ : número de voltas.

i : corrente $[\mathrm{A}]$.

$\mathrm{L}:$ comprimento do enrolamento [m].

\subsubsection{Indução Magnética}

Se colocarmos uma barra de ferro desmagnetizada dentro de um solenóide, observa-se que o campo magnético fora do solenóide aumenta. $O$ aumento desse campo é devido à soma do campo gerado pelo solenóide e do campo magnético da barra que se magnetizou. O novo campo magnético resultante é chamado de indução magnética, densidade de fluxo ou, simplesmente de indução, e è denotado por B.

A indução $\mathbf{B}$, é a soma do campo aplicado $\mathbf{H}$, e o campo externo da magnetização da barra no interior do solenóide. O momento magnético induzido por unidade de volume gerado pela barra é chamado de intensidade da magnetização ou simplesmente magnetização, e é conhecido por M. Em unidades SI:

$B=\mu_{0} H+\mu_{0} M=\mu_{0}(H+M)$

Onde $\mu_{0}=4 \pi 10^{-7}[\mathrm{Tm} / \mathrm{A}]$, permeabilidade magnética no vácuo.

A Tabela 1.1 mostra algumas magnitudes magnéticas e suas unidades.

Tabela 1.1 - Magnitudes magnéticas e suas unidades. (D. C JILES, 1998)

\begin{tabular}{ccc}
\hline Magnitude magnética & Unidades $(\mathrm{SI})$ & Uniadedes (cgs) \\
\hline $\mathrm{B}$, indução magnética & ${\text { Weber } / \text { metro }^{2}\left(\mathrm{~Wb} / \mathrm{m}^{2}\right) \text { ou }}^{\text {Tesla }(\mathrm{T})}$ & Gauss $(\mathrm{G})$ \\
\hline $\mathrm{H}$, campo aplicado & Amperes $/$ metro $(\mathrm{A} / \mathrm{m})$ & Oersted $(\mathrm{Oe})$ \\
\hline $\mathrm{M}$, magnetização & Ampere $/$ metro $(\mathrm{A} / \mathrm{m})$ & \\
& Fatores de conversão: \\
& $1 \mathrm{Oe}=79.58 \mathrm{~A} / \mathrm{m}$ & \\
& $1 \mathrm{~Wb} / \mathrm{m}^{2}=1 \mathrm{~T}=10000 \mathrm{G}$ & \\
\hline
\end{tabular}




\subsubsection{Permeabilidade Magnética}

Quando colocamos um material ferromagnético dentro de um campo magnético, aumenta a intensidade do campo magnético total. Este aumento na magnetização é medido por uma quantidade chamada permeabilidade magnética $\mu$, definido como:

$\mu=\mathrm{B} / \mathrm{H}$

Se o campo magnético é aplicado no ar:

$\mu_{0}=\mathrm{B} / \mathrm{H}$

Às vezes é conveniente descrever o comportamento magnético de um sólido em termos de sua permeabilidade relativa $\left(\mu_{r}\right)$, dada por:

$\mu_{r}=\mu / \mu_{0} \quad ;$ e $B=\mu_{r} \mu_{0} H$

Os materiais magnéticos que são facilmente magnetizados têm alta permeabilidade magnética.

\subsubsection{Susceptibilidade Magnética}

Já que a magnetização de um material magnético é proporcional ao campo aplicado, o fator de proporcionalidade chamada de susceptibilidade magnética $\chi_{m}$, é definido como:

$\chi_{m}=M / H$ 


\subsubsection{Momentos magnéticos ${ }^{1}$}

Os momentos magnéticos são a origem do magnetismo nos materiais. Para a explicação do conceito, adota-se o modelo atômico simplificado, no qual o átomo é simbolizado por um núcleo positivo sendo orbitado por elétrons de carga negativa (Figura 1.3). O momento magnético atômico é gerado pela soma de duas contribuições do momento dos elétrons. Primeiro cada elétron tem um momento magnético intrínseco devido a seu momento angular intrínseco (rotação). E está relacionado com a rotação do elétron em seu eixo (spin do elétron). Segundo, os elétrons podem também ter um momento magnético em conseqüência de seu movimento orbital nos átomos (translação). A órbita do elétron é similar a uma espira de corrente com o sentido oposto no qual o elétron se movimenta. O deslocamento do elétron, portanto produz um campo magnético, perpendicular a sua órbita. Ao se aplicar um campo externo ao sistema, os elétrons recebem um torque (momento) tendendo a alinhar seu campo magnético próprio com o campo externo.

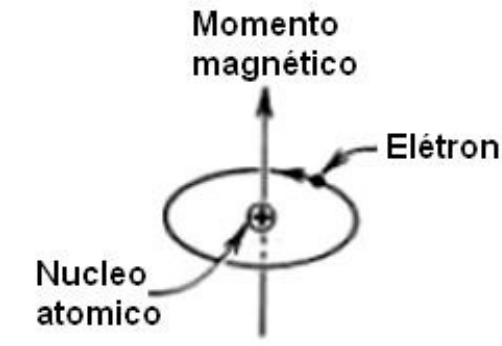

a)

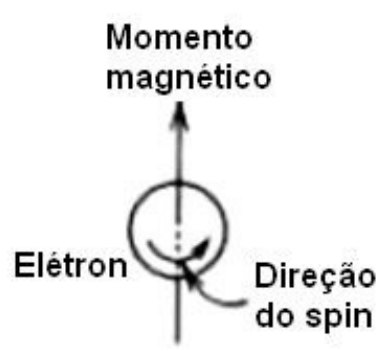

b)

Figura 1.3 - Momentos magnéticos atômicos. a) momento de translação, b) momento de rotação. (Adaptada da Fig 20.4, Callister 7e)

Em cada orbital, cabem dois elétrons, com spins contrários, o seja com direções de magnetização contrárias. Orbitais completos não resultam em campo magnético, pois o campo de um elétron anula o do outro. Átomos com todos os orbitais preenchidos não têm momento magnético: característica dos materiais diamagnéticos. Só átomos com orbitais não completamente preenchidos terão

\footnotetext{
1 Notas de aula, POLI-USP Disciplina PMT 5816 Processamento e desempenho de materiais magnéticos.
} 
momento magnético atômico: os materiais paramagnéticos e ferromagnéticos são assim.

Nos materiais ferromagnéticos, os momentos magnéticos atômicos, tendem a se alinhar numa só direção, formando regiões chamadas de "Domínios magnéticos", tema que é tratado no item 1.2.

\subsubsection{Magnetismo em materiais}

Os diferentes materiais são caracterizados, do ponto de vista magnético, pela sua permeabilidade magnética $(\mu)$, que é a relação entre o campo de indução magnética e o campo magnético dentro do material:

$\mathrm{B}=\mu \mathrm{H} \quad \mu=\mu_{\mathrm{r}} \cdot \mu_{0}=\mu_{0}\left(1+\chi_{\mathrm{m}}\right)$

De acordo com sua permeabilidade, podemos distinguir três tipos de materiais: ferromagnéticos, paramagnéticos e diamagnéticos. Na Figura 1.4 é mostrada a curva $\mathrm{BxH}$ de cada um desses materiais.

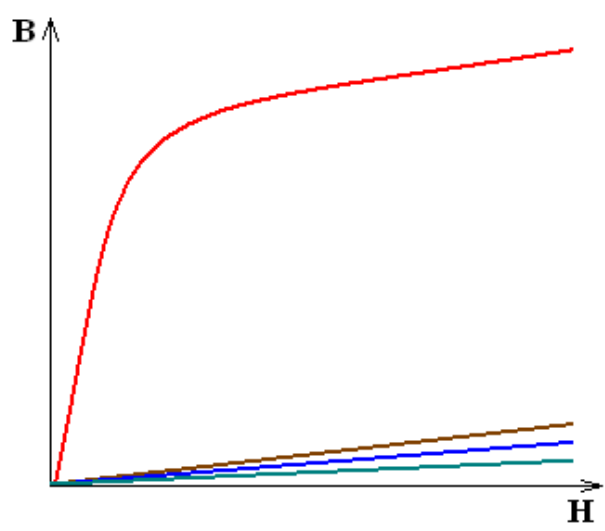

Figura 1.4 - Curvas BxH de três materiais, um diamagnético (linha verde), um paramagnético (linha marrom) e um ferromagnético (linha vermelha). A linha azul é a resposta do B no ar.

Os materiais diamagnéticos se magnetizam debilmente no sentido oposto do campo magnético aplicado. Ver Figura 1.5. Este efeito é devido às correntes elétricas induzidas nos átomos. Estas correntes geram momentos magnéticos opostos ao campo aplicado. A sua suscetibilidade magnética é negativa e pequena. A permeabilidade é então menor que 1. 


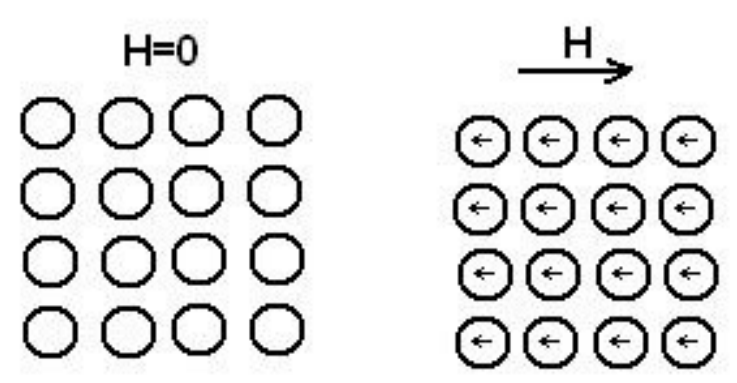

Figura 1.5 - Esquema dos dipolos em um material diamagnético. (Adaptada da Fig 20.5 Callister 7e)

Os materiais paramagnéticos se caracterizam por ter uma distribuição de momentos magnéticos atômicos nula (A soma de todos os momentos magnéticos é zero), que tendem alinhasse no sentido do campo aplicado. A sua suscetibilidade magnética é positiva e pequena, o que gera uma permeabilidade ligeiramente maior que 1. A intensidade da resposta é muito pequena e os efeitos são difíceis de detectar.

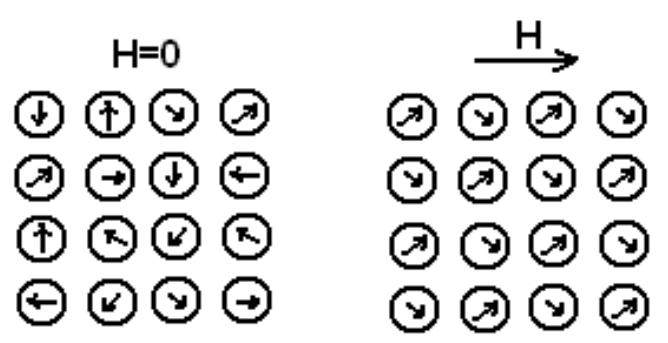

Figura 1.6 - Esquema dos dipolos em um material paramagnético. (Adaptada da Fig 20.5 Callister 7e)

Nos materiais ferromagnéticos os momentos magnéticos individuais de grandes grupos de átomos ou moléculas são mantidos alinhados devido a um acoplamento forte, mesmo na ausência do campo externo. Esses grupos são chamados de domínios magnéticos, e agem como um pequeno ímã permanente. Na ausência de campo aplicado, os domínios têm seus momentos magnéticos distribuídos aleatoriamente.

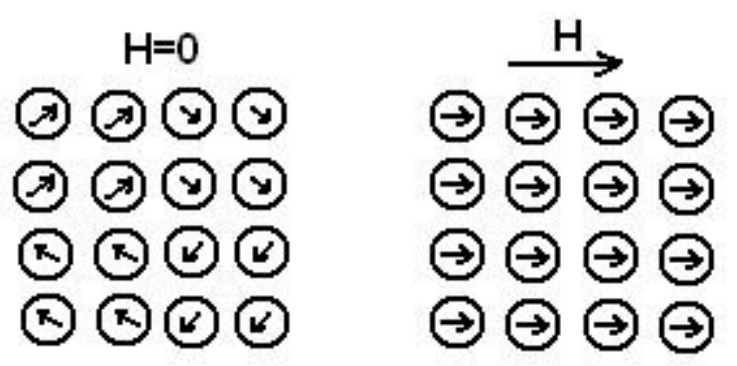

Figura 1.7 - Esquema dos dipolos em um material ferromagnético. (Adaptada da Fig 20.7 Callister 7e) 
Ao aplicar um campo externo, os domínios tendem a se alinhar com o campo. A susceptibilidade magnética é positiva e grande, e a permeabilidade relativa é então muito maior que 1. Além disso, a intensidade da resposta é relativamente alta, e permite que os efeitos sejam detectáveis. É por e essa razão que só este tipo de materiais é considerado nos diferentes estudos do presente trabalho.

\subsubsection{Ciclo de histerese magnética}

O comportamento magnético dos materiais ferromagnéticos apresenta uma grande variedade de configurações, dependendo das diferentes intensidades de energia presentes neles. A evolução dessas configurações, em dependência da aplicação de um campo externo é de grande interesse. Muitos dos parâmetros que descrevem essa evolução podem ser determinados analisando a evolução da indução magnética $(B)$ em função do campo externo $(H)$. Essa função $(B(H))$ é chamado de curva de magnetização, ou ciclo de histerese. Na Figura 1.8 é mostrado um exemplo desta curva.

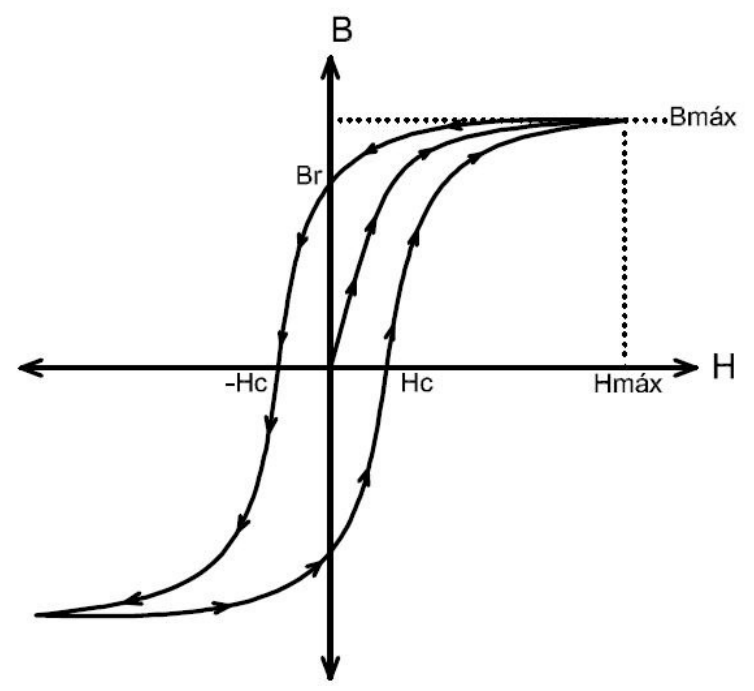

Figura 1.8 - Curva típica de histerese magnética.

Os principais parâmetros que são analisados na curva de histerese são:

$B_{\max }$ : Campo de indução relativo à magnetização máxima $\left(M_{s}\right)$, saturação.

$\mathrm{B}_{\mathrm{r}}$ : Campo de indução remanente. Campo remanente depois da saturação, em $\mathrm{H}=0$. 
$\mathrm{H}_{\mathrm{c}}$ : Campo Coercitivo. Campo necessário para levar a indução de volta à zero após a saturação.

$H_{\max }$ : Amplitude de campo necessário para levar o material a sua saturação magnética $\left(M=M_{s}\right)$.

Partindo do estado desmagnetizado do material $(H=0, B=0)$, o campo de indução segue a curva chamada de "curva inicial". Aumentar $\mathrm{H}$ para $\mathrm{H}_{\max }$ leva o material a o estado de magnetização máxima, ou de saturação magnética $\left(B=B_{\max }\right)$. Depois $B$ diminui para zero (para $\mathrm{H}=-\mathrm{H}_{\mathrm{c}}$ ), e finalmente, vai para o estado de indução oposto quando $\mathrm{H}$ é invertida. A abertura $\left(2 \mathrm{H}_{\mathrm{c}}\right)$ da curva, vem de um comportamento irreversível presente no processo de inversão da magnetização. Esta irreversibilidade é principalmente devida ao movimento interrompido (por tempos muito pequenos) de paredes de domínio.

O valor do campo coercitivo, entre diferentes materiais, pode variar mais de sete ordens de grandeza. É a propriedade mais sensível dos materiais ferromagnéticos. Assim, alguns "permalloys" (ligas NiFe) têm muito baixo campo coercitivo $\left(H_{c}=1 \mathrm{~A} / \mathrm{m}\right)$, enquanto, os ímãs permanentes têm valores na faixa de $10^{6} \mathrm{~A} / \mathrm{m}$. Materiais com baixa coercividade $\left(\mathrm{H}_{\mathrm{c}}<10^{3} \mathrm{~A} / \mathrm{m}\right)$ são chamados matérias macios e aqueles com $\mathrm{Hc}$ alto, materiais duros, já que a magnetização é fácil ou difícil de inverter, respectivamente.

\subsection{DOMÍNIOS MAGNÉTICOS EM SISTEMAS FERROMAGNÉTICOS}

\subsubsection{Origem dos domínios magnéticos}

Interações atômicas obrigam os momentos magnéticos dos átomos a se alinharem em paralelo, como mostra a Figura 1.9. 


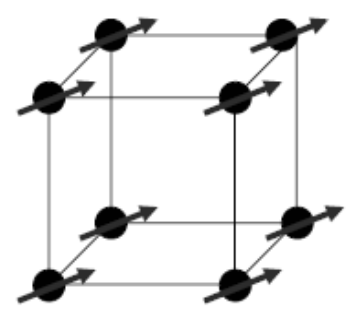

Figura 1.9 - Alinhamentos spin-spin

A direção desses alinhamentos depende do tipo de estrutura do material e se ordena em função da procura de um estado de mínima energia. A energia total de um material ferromagnético pode ser escrita como a soma dos seguintes termos (DURIN, 2004):

$E_{T}=E_{e x}+E_{m}+E_{a n}+E_{\text {stric }}+E_{\text {dis }}$

Onde:

$\mathbf{E}_{\text {ex }}$ é a energia de troca, e favorece configurações de magnetização uniforme e tende a alinhar os momentos magnéticos atômicos. Esta é a contribuição mais importante.

$\mathbf{E}_{\mathbf{m}}$ é a energia magnetostática, e favorece as configurações de magnetização que dão um momento magnético nulo. Esta energia é devida às interações entre os momentos atômicos e o campo externo, e entre os dipolos dos diferentes spins. Nesta parcela considera-se a energia devida ao campo desmagnetizante.

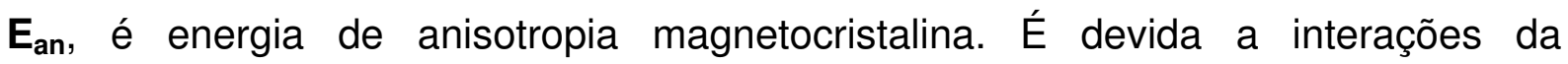
magnetização com a rede cristalina. Na ausência de um campo magnético externo, o material ficará magnetizado em direções chamadas fáceis. Magnetizando o material nessas direções, a energia de anisotropia será mínima.

$\mathbf{E}_{\text {stric }}$ é a energia magnetostrictiva, que indica a deformação na rede cristalina causada pela variação da magnetização. Materiais ferromagnéticos sofrem variação em suas dimensões quando são sujeitos a campos magnéticos externos. $\mathrm{Na}$ saturação magnética (em materiais altamente magnéticos) a deformação pode chagar a $10^{-5} \varepsilon$.

$\mathbf{E}_{\text {dis }}$ é a energia de desordem, que considera os efeitos devidos às não-homogeneidades do material, devido à presença de defeitos como lacunas, discordâncias, impurezas não magnéticas, etc. 
Nos materiais ferromagnéticos existem grandes volumes de átomos nos quais os momentos magnéticos estão alinhados segundo uma direção de magnetização espontânea ou de fácil magnetização. Ditas regiões se conhecem como Domínios Magnéticos. Figura 1.10.

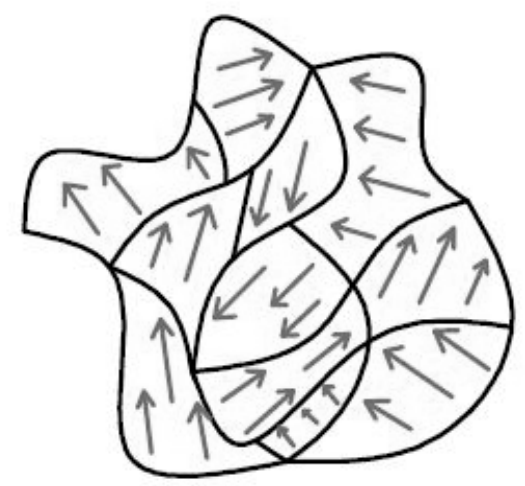

Figura 1.10 - Desenho esquemático de domínios Magnéticos

Em dependência das características da estrutura cristalina, a direção preferencial de magnetização é diferente em diversas regiões do material. Portanto, a direção de alinhamento dos momentos magnéticos varia de domínio para domínio. A Figura 1.11 mostra as direções de fácil magnetização para as estruturas do ferro e níquel.

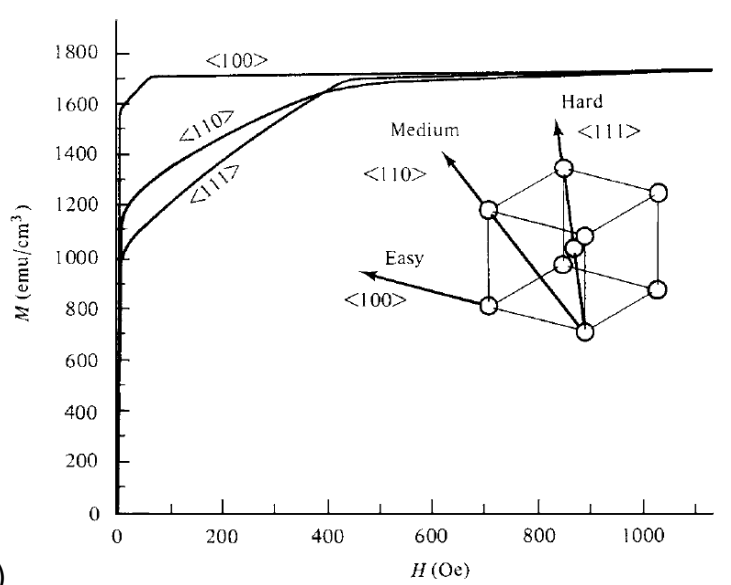

a) Figura 1.11 - Direções de magnetização fácil, média e difícil
(CULLITY, 2009)

b)

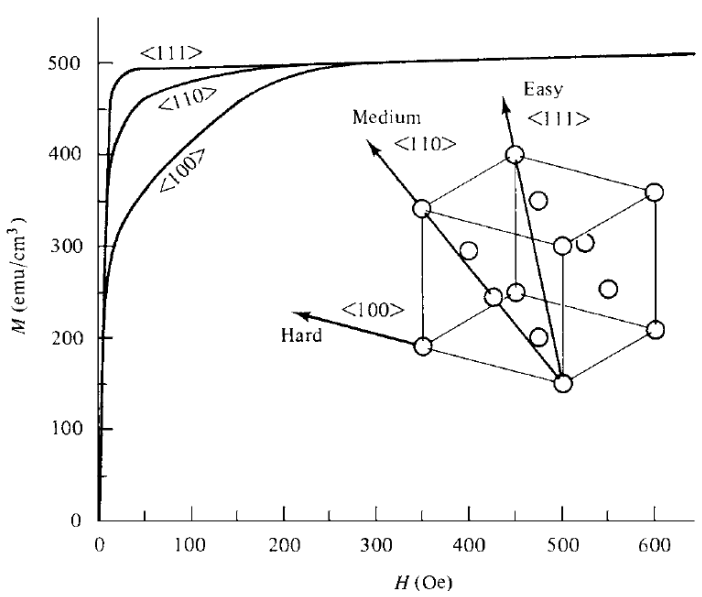

a) Ferro, e b) Níquel

A transição de uma direção de magnetização para outra em domínios adjacentes é contínua, ou seja, a parede de domínio tem uma largura finita e, por tanto, possui 
uma estrutura interna. O deslocamento angular total através de uma parede de domínio é freqüentemente de $180^{\circ}$ ou $90^{\circ}$. A Figura 1.12 mostra como é produzida a mudança de direção dos spins entre dois domínios com direções de magnetização oposta $\left(180^{\circ}\right)$.

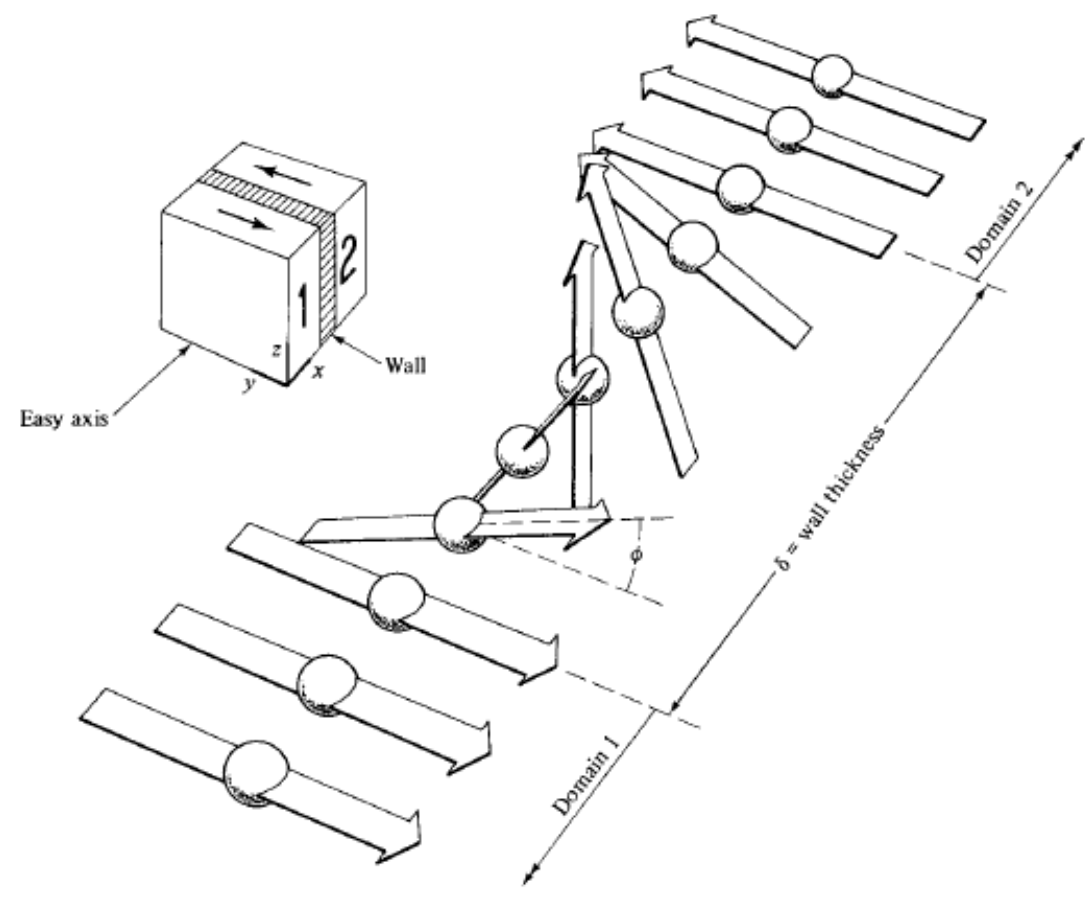

Figura 1.12 - Estrutura de parede de domino de $180^{\circ}$. (CULLITY, 2009)

\subsubsection{Paredes de domínio e processo de magnetização}

Sob a influência de um campo magnético externo alternado, os momentos magnéticos no interior dos domínios sofrem uma rotação continua alinhando-se em uma direção próxima à direção de campo magnético aplicado. Os domínios com orientação na direção do campo tendem a se expandir em todas suas direções, movendo suas paredes e subjugando os domínios vizinhos. A Figura 1.13 mostra esquematicamente este comportamento. 
Aproximação da

saturaçäo negativa
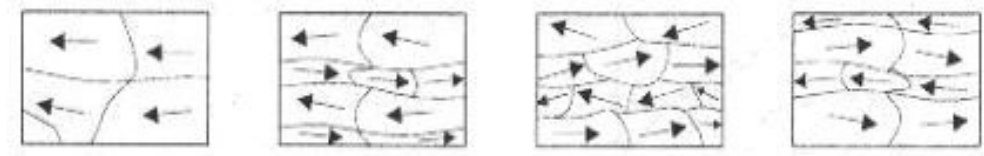

Aproximação da

saturaçäo positiva

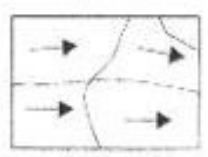

$H=>>$

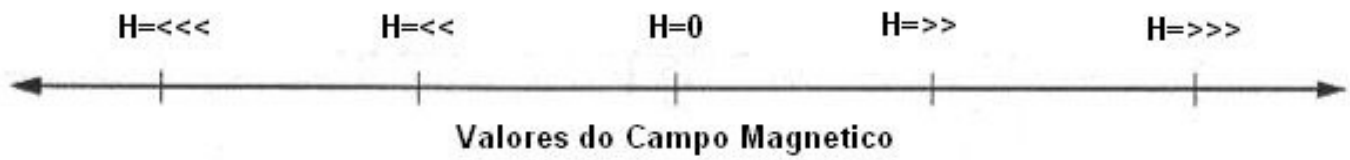

Figura 1.13 - Comportamento dos domínios magnéticos durante o processo de magnetização.

A facilidade com que as paredes dos domínios se movimentam e giram está relacionada com a energia magnetostática total, que varia com o tamanho, forma e a microestrutura do material. A movimentação é afetada pela presença de tensões e defeitos como, vazios, inclusões, partículas de segunda fase, discordâncias, defeitos pontuais e contornos de grão. Os movimentos e rotações das paredes podem ser reversíveis ou irreversíveis (Figura 1.14 e Figura 1.15) dependendo igualmente dessas condições. Os defeitos que atuam como barreiras na movimentação das paredes de domínio, são conhecidas como "pontos de ancoragem".

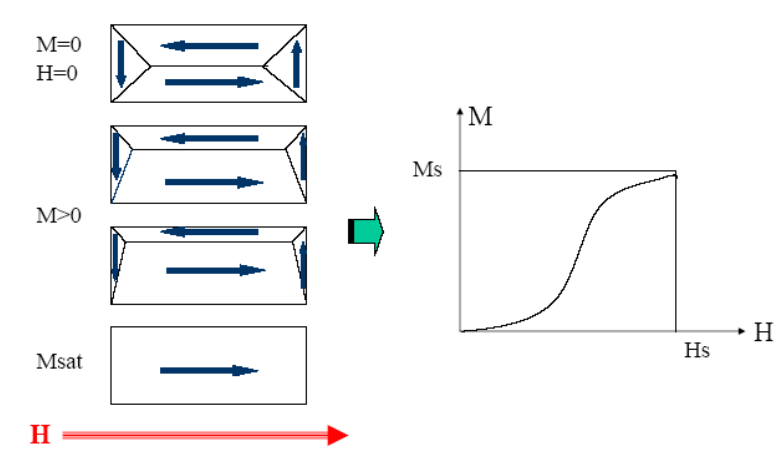

a)

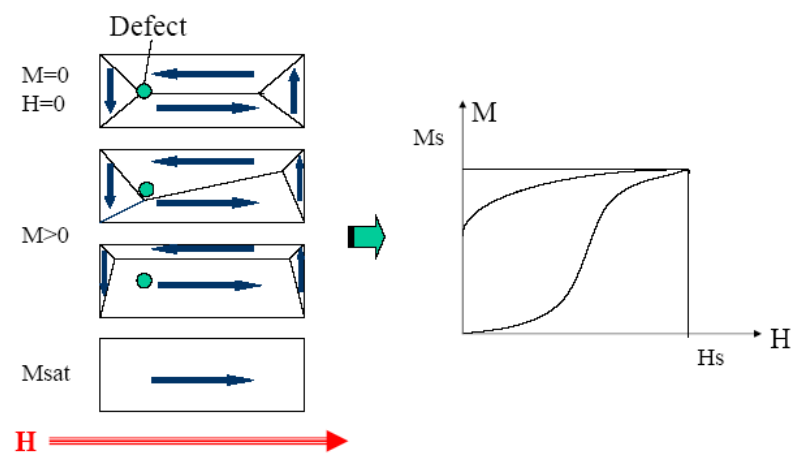

b)

Figura 1.14 - Movimento das paredes dos domínios. a) reversível. b)irreversível. 


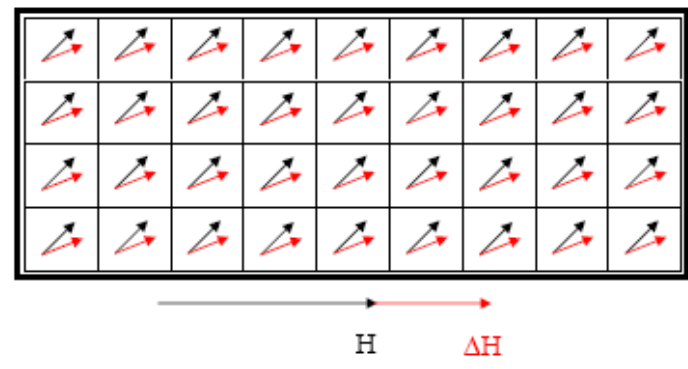

a)

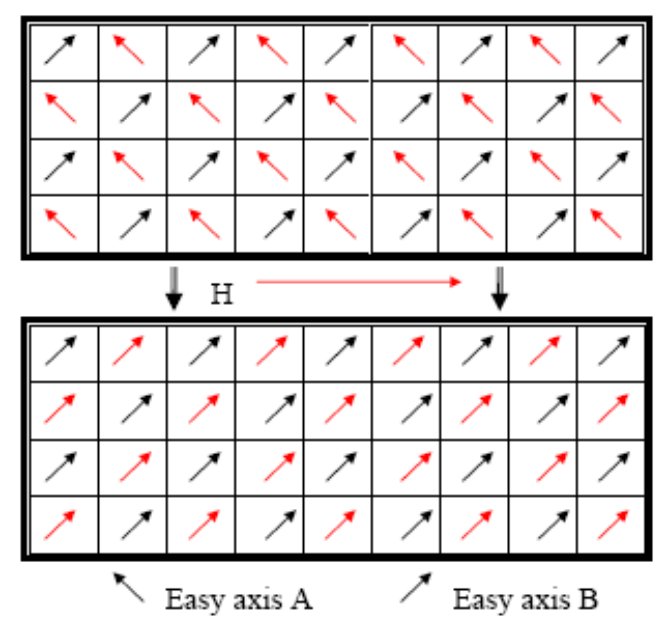

b)

Figura 1.15 - Rotação dos domínios. a) reversível. b)irreversível. A e B são direções de eixos de fácil magnetização.

Com o aumento do campo magnético, a energia potencial da parede que fica ancorada no defeito, cresce, até um valor suficiente para conseguir ultrapassá-lo. Em seguida a parede se movimenta rapidamente até que novamente fica ancorada num novo defeito. Portanto, o processo de magnetização não é continuo, o seja, se compõe de pequenos saltos produzidos pela movimentação das paredes de domínio de defeito em defeito. Ver Figura 1.16. Estes saltos produzem um fenômeno magnético chamado de "Efeito de Barkhausen".

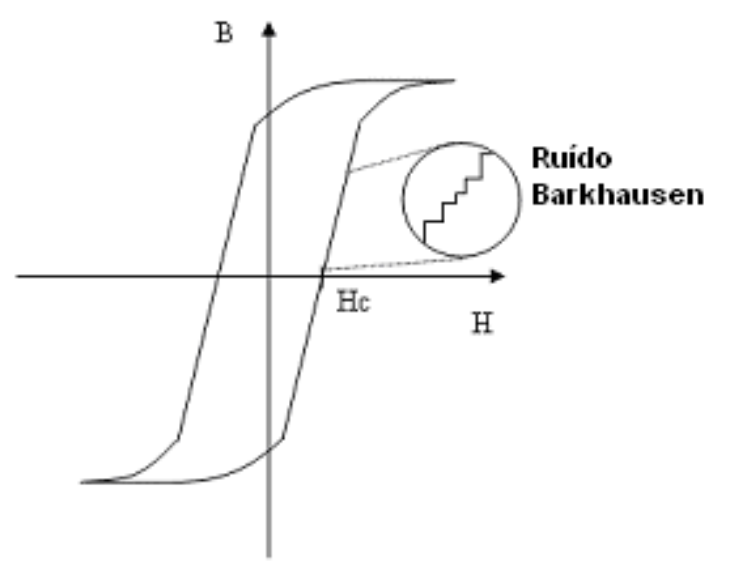

Figura 1.16 - Ruído magnético de Barkhausen na curva de histerese. 


\section{RUÍDO MAGNÉTICO DE BARKHAUSEN}

O Efeito Barkhausen é um fenômeno de mudanças descontínuas na densidade de fluxo B dentro de um material ferromagnético quando submetido a um campo magnético variável. Este foi observado inicialmente pelo professor alemão Heinrich Barkhausen (1919). Ele descobriu que, durante a magnetização de uma barra de ferro, pulsos de tensão elétrica de curta duração são induzidos em uma bobina enrolada em torno da barra. Esses pulsos foram detectados como cliques audíveis em um alto-falante (Figura 2.1). Mesmo quando o campo de magnetização foi mudado lentamente, as descontinuidades persistiram, demonstrando que o fenômeno era um processo intrínsecamente discreto.

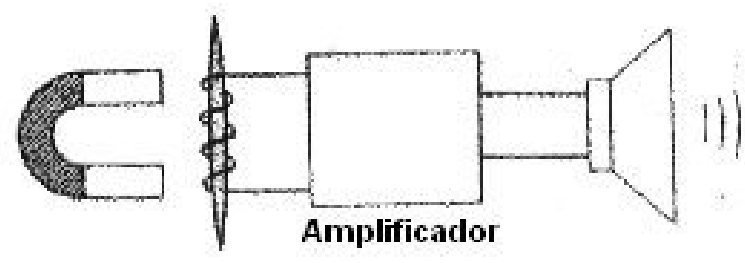

Figura 2.1 - Experimento feito por Heinrich Barkhausen.

A maioria dos eventos Barkhausen é produzida pelo movimento irreversível de paredes de domínio de $180^{\circ}$, e acontecem na região de maior inclinação da curva de magnetização. No avanço do processo de magnetização, outros fatores começam a contribuir, incluindo o movimento de paredes de $90^{\circ}$, rotação de domínios, e aniquilação de paredes. Assim que o processo se aproxima da saturação magnética, o movimento de paredes desaparece. A Figura 2.2 mostra a evolução do Ruído Barkhausen durante um ciclo de histerese. 


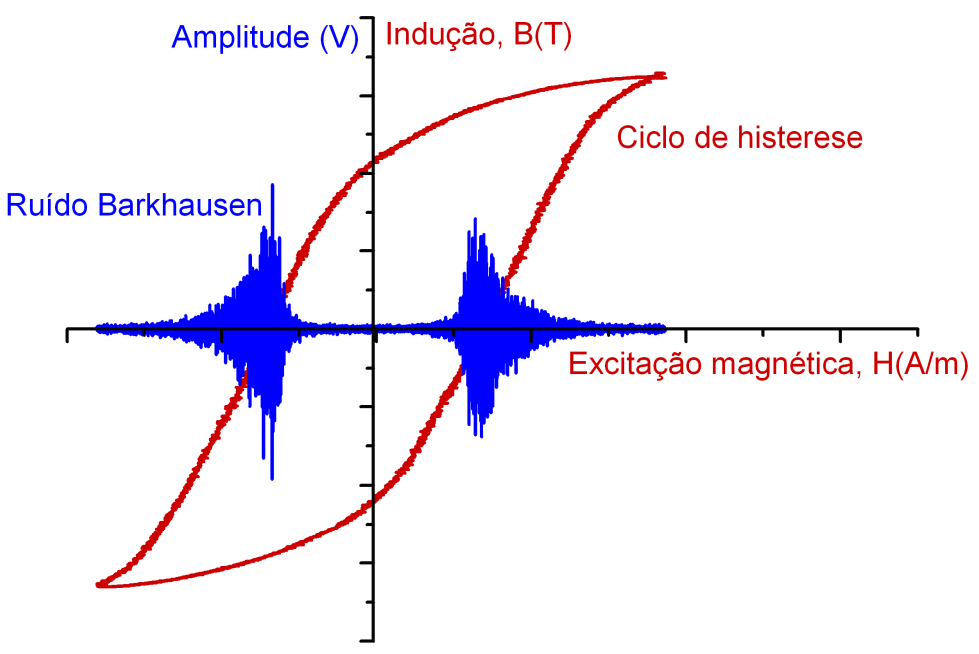

Figura 2.2 - Ruído Barkhausen e curva de histerese associada. Medição realizada num aço SAE4140.

Nos seguintes itens são apresentados resultados relevantes encontrados na literatura, sobre o comportamento do RMB na medição de diferentes efeitos produzidos no material, e relacionados com os temas estudados neste trabalho.

\subsection{RMB E TENSÕES MECÂNICAS}

Diferentes estudos (CAPO-SANCHEZ, 2007b; PEREZ-BENITEZ, 2007; ANGLADARIVERA, 2001; JILES D.C., 1989) têm analisado o efeito da tensão uniaxial mecânica no Ruído Magnético de Barkhausen (RMB), medido em materiais ferromagnéticos. Geralmente mostram que tensões de tração alinham os domínios magnéticos no sentido da tensão, e favorecem o aumento dos sinais do RMB; enquanto que tensões de compressão alinham os domínios magnéticos em direção perpendicular a tensão aplicada, gerando níveis de RMB menores. Este processo é conhecido como efeito magnetoelástico. A Figura 2.3 mostra esquematicamente 0 efeito de tensões de tração na estrutura de domínios. Tensões de tração e compressão produzidas por flexão influem de forma similar sobre o comportamento dos domínios magnéticos e, portanto, sobre o aumento ou diminuição de RMB. 

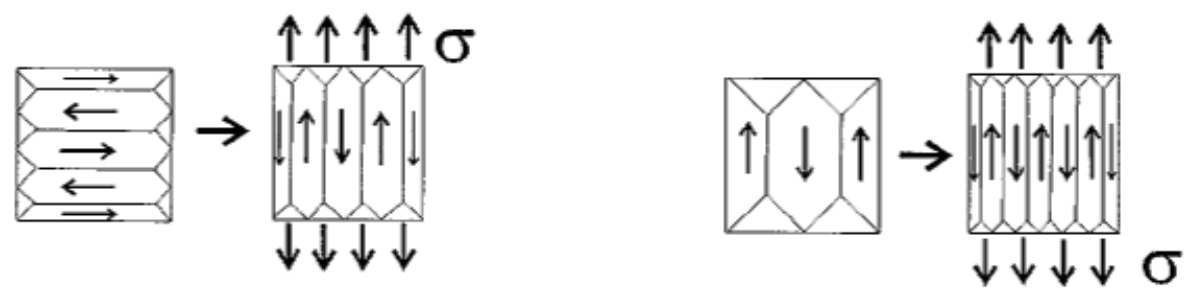

Figura 2.3 - Reorientação de domínios produzidas por tensão mecânica. (KRAUSE T. W, 1996)

Essa tendência geral pode ser invertida em algumas situações. Estudos do efeito da flexão em aços de baixa liga (BLAOW M, 2004), encontraram comportamentos diferentes do RMB. Os picos altos do envelope do RMB aumentaram com a tensão de tração até $\mathrm{o}$ inicio da deformação plástica. Enquanto em compressão $\mathrm{O}$ comportamento foi mais complexo; inicialmente foi observado um decréscimo dos picos altos, e com tensões maiores, os valores de RMB começam a aumentar com a geração de um segundo pico. A explicação da aparição dos picos duplos, foi dada em relação ao favorecimento do movimento das paredes de domínios de $90^{\circ}$ por tensões de compressão. Ainda assim, não é sempre que surgem picos duplos em tensões de compressão. Portanto, a ocorrência ou não desse fenômeno depende da composição e do tratamento térmico do material. Também, em trabalhos mais recentes (M. BLAOW, 2005), foram feitas análises do RMB em materiais com 4 microestruturas diferentes. Nesses resultados, em algumas das amostras, aparecem três picos no envelope do sinal quando são aplicadas tensões de compressão. Nenhuma explicação foi dada para o fato que o perfil multi-pico fosse gerado somente em algumas das microestruturas estudadas. Sustenta-se, que a causa dos outros dois picos no sinal de RMB, pode ser devida à nucleação e aniquilação de domínios.

Em outros estudos (V. MOORTHY, 2004, 2006), é apresentado uma análise da resposta do RMB em duas amostras endurecidas superficialmente, e submetidas a tensões de flexão. Os resultados mostram a evolução de dois picos no envelope do sinal, sendo mais notado o primeiro pico na amostra que foi menos afetada pelo processo de endurecimento. Assim a explicação da diferencia entre os comportamentos dos dois picos em cada uma das amostras, é justificado pela variação das características mecânicas do material que, neste caso, seria a geração de um perfil de dureza. 


\subsection{RMB E DEFORMAÇÃO PLÁSTICA}

Em relação ao efeito da deformação plástica no RMB, a maioria dos trabalhos encontrados (HWANG D.G, 1988; MOORTHY et al, 1999; STEFANITA, C. G. et al, 2000; DHAR A., 2001; CAMPOS M. A et al, 2008) mostram o seguinte comportamento nos resultados: as amplitudes do RMB aumenta conforme aumenta a deformação plástica, atingindo um valor máximo em certo nível de deformação. Depois, ainda aumentando os níveis de deformação, as amplitudes de RMB começam a diminuir e finalmente saturam em valores baixos. O fenômeno é justificado da seguinte forma: apesar do aumento das discordâncias em níveis baixos de deformação, as quais atuam como pontos de ancoragem para 0 movimento de paredes de domínio, estas conseguem ultrapassá-las, produzindo RMB. Mas na medida em que a deformação plástica aumenta, as discordâncias se arranjam em "emaranhados" criando pontos de ancoragem muito fortes que as paredes de domínio não conseguem vencer, e o RMB diminui.

\subsection{RMB E DUREZA}

Vários estudos têm sido publicados utilizando o RMB para caracterizar microestruturas de aços afetadas por diferentes tratamentos térmicos. Amplitude e posição do pico de envelope do RMB em relação ao campo aplicado foram sensíveis às mudanças microestruturais geradas com diferentes tratamentos térmicos em aços SAE1040 e SAE4140 (GUR C. H, 2007). Em outro estudo, amostras de aço SAE5140 foram submetidos a processo de revenido a diferentes temperaturas, entre $200^{\circ} \mathrm{C}$ e $600^{\circ} \mathrm{C}$. Os resultados mostraram que assim que temperatura do tratamento térmico aumenta, o RMB aumenta, devido ao aumento do deslocamento de paredes de domínio produzido pela diminuição da martensita. (DAVUT K, 2007). Caracterização de aços Ferritico-Martensiticos obtidos utilizando tratamentos térmicos, também foram feitas usando RMB. O RMB facilmente diferencia as duas fases, ferrita e martensita (KLEBER X, 2004). Medidas magnéticas foram efetivamente utilizadas para estudar as mudanças microestruturais, em amostras 
temperadas de aço AISI 8620. Boas correlações entre a fração de martensita, e os parâmetros de RMB foram obtidos (KAPLAN M, 2007). Em todos esses estudos, as medições de RMB foram comparadas com medidas de dureza, e foram obtidos altos índices de correlação linear.

\subsection{PROFUNDIDADE DA MEDIDA DO RMB}

As freqüências mais representativas do RMB, vão desde alguns $\mathrm{kHz}(1,2)$ até algumas centenas de $\mathrm{kHz} \quad(100,200)$, embora nenhum estudo afirme que estes sinais tem limite inferior ou superior. Os sinais do RMB, por serem de natureza eletromagnética e em dependência das freqüências em que são geradas, são atenuados em maior ou menor grau pelas correntes parasitas ao passar pelo material. Assim, as faixas de alta freqüência do RMB são atribuídas a seções do material perto da superfície, enquanto as de baixa provêem tanto de pequenas como de maiores profundidades. Desta maneira os campos gerados decaem exponencialmente até a superfície. A profundidade desde a qual os valores dos sinais decaem a uma fração de 1/e (onde e é o numero neperiano) até á superfície esta dada pela seguinte equação (CHIKAZUMI, 1996; JILES D. C, 2000).

$\delta=\frac{1}{\sqrt{\pi^{*} f^{*} \sigma^{*} \mu_{0}{ }^{*} \mu_{r}}}$

Onde:

$\boldsymbol{\delta}=$ Profundidade eletromagnética $(\mathrm{m})$

$f=$ freqüência do sinal

$\boldsymbol{\sigma}=$ Condutividade do material.

$\boldsymbol{\mu}_{0}=$ permeabilidade magnética do vácuo.

$\mu_{r}=$ permeabilidade relativa do material.

Para um aço com $\mu_{r}=50$ até 5000, $\sigma=5^{\star} 10^{6}$ até $10^{*} 10^{6} \Omega^{-1} \mathrm{~m}^{-1}$ e usando $\mu_{o}=4 \pi * 10^{-7} \boldsymbol{H} / \boldsymbol{m}$, na Tabela 2.1 apresentasse a profundidade aproximada de 
emissão dos sinais do RMB a diferentes freqüências (Adaptada de D.C JILES, 2000),

Tabela 2.1 - Profundidades aproximadas dos sinais do RMB, em dependência de suas freqüências de emissão.

\begin{tabular}{cc}
\hline Freqüência de emissão $(\mathrm{kHz})$ & Faixa de profundidade $\delta(\mathrm{mm})$ \\
\hline 0.01 & $0-10.00$ \\
\hline 0.05 & $0-4.50$ \\
\hline 0.1 & $0-3.20$ \\
\hline 0.5 & $0-1.40$ \\
\hline 1 & $0-1.00$ \\
\hline 5 & $0-0.45$ \\
\hline 10 & $0-0.32$ \\
\hline 50 & $0-0.14$ \\
\hline 100 & $0-0.10$ \\
\hline 500 & $0-0.045$ \\
\hline
\end{tabular}

Baseado nesse conceito foi feito uma análise via RMB de perfis de dureza produzidos em amostras de Aço A36, cementado e com processo de têmpera superficial (MOORTHY, 2003). Ali se compararam amplitudes de RMB em diferentes bandas de freqüência com medidas de dureza na profundidade. Nos resultados, foram obtidos coeficientes de correlação linear $R^{2}$ entre 0.85 e 0.99 . Em outros estudos, relacionados com tensões aplicadas e residuais produzidas por flexão no mesmo tipo de aço (MOORTHY, 2004), os resultados amostram que, sinais de RMB produzidos com campos de excitação de baixa freqüência $(0.2 \mathrm{~Hz})$, podem revelar comportamentos da tensão em regiões superficiais e sub-superficiais do material. Neste caso, não foram analisados as bandas de freqüência do sinal, e sim, a evolução dos diferentes picos que aparecem no envelope. Foi relacionado à aparição de um segundo pico com informação proveniente de profundidades maiores no material.

\subsection{MEDIÇÃO DO RMB}

A base de um sistema da medida de RMB é uma sonda que se compõe de um yoke eletromagnético, o qual produz o campo magnético alternado sobre a amostra, e 
uma bobina leitora que serve para detectar a sinal de RMB. A Figura 2.4 mostra um esquema da sonda típica de RMB.

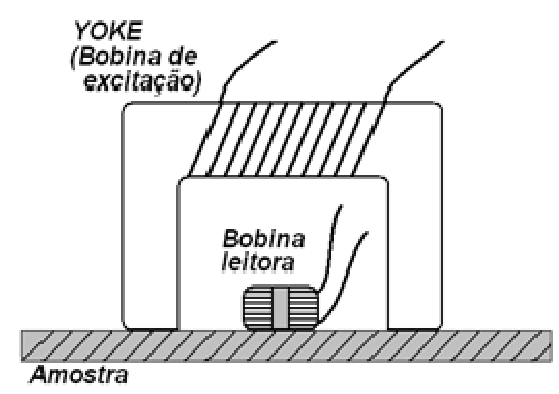

Figura 2.4 - Sonda de medição do RMB.

Assim, a bobina leitora é colocada perto da amostra durante o movimento das paredes do domínio, e então a mudança gerada na magnetização induz pulsos elétricos na bobina. Depois este sinal pode ser processado e analisado. O RMB representado no domínio do tempo é apresentado na Figura 2.5 (linha azul), onde pode ser observada também a corrente de excitação aplicada (Linha vermelha).

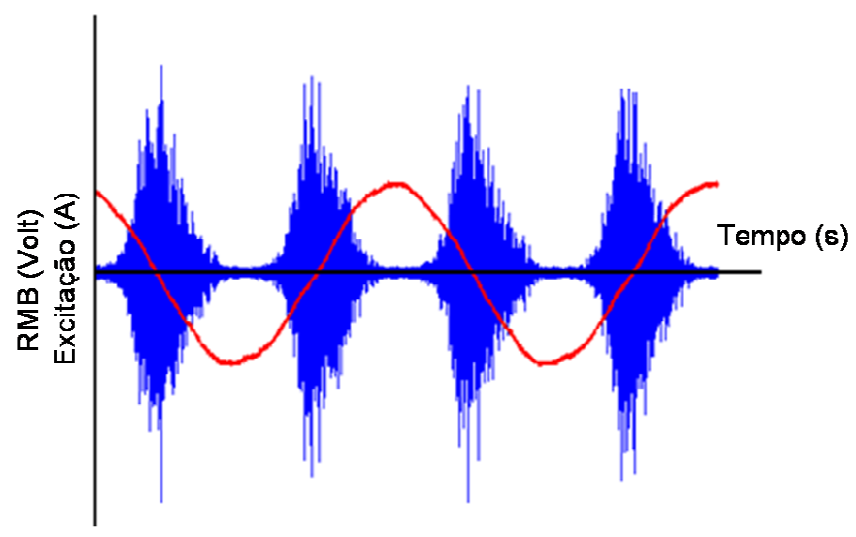

Figura 2.5 - Sinal do RMB no tempo.

\subsection{ANÁLISE DOS SINAIS}

Diferentes métodos de análise de sinais podem ser utilizados para analisar os sinais de RMB. Por ser um sinal aleatório, não estacionário, deve ser tratado por cálculos estatísticos. A seguir são apresentados alguns métodos de processamento de sinais que possibilitam calcular alguns parâmetros utilizados para analisar o RMB 


\section{Valor rms do RMB, $R M B_{r m s}$}

O valor RMS (Root Mean Square) representa a raiz quadrada do valor quadrático médio em volts dos sinais Barkhausen ao longo do tempo e é definido por:

$\mathrm{RMB}_{\mathrm{rms}}=\sqrt{\frac{\sum_{\mathrm{i}}^{\mathrm{n}}\left(\mathrm{V}_{\mathrm{i}}-\mathrm{V}_{\mathrm{m}}\right)^{2}}{\mathrm{n}-1}}$

onde:

$\mathrm{RMB}_{\text {rms }}$ : valor RMS dos sinais Barkhausen em Volts;

$\mathrm{V}_{\mathrm{i}}$ : valor da voltagem medida em um determinando instante;

$V_{m}$ : valor médio do sinal;

$\mathrm{n}$ : número de pontos do sinal.

Como o sinal de RMB é centrado em amplitude, o seja, tem média nula, o valor rms é equivalente ao desvio padrão, e, portanto, representa uma medida do tamanho médio das flutuações ao redor da média.

\section{Energia do $R M B$, $R M B_{\text {energy }}$}

A energia liberada pelo sinal de Barkhausen é definida pela expressão (2-3). $\mathrm{Na}$ formula, a área entre o eixo do tempo e o quadrado do sinal de voltagem é calculada para cada evento e somado sobre todos os eventos medidos.

$\mathrm{RMB}_{\text {energy }}=\sum_{\mathrm{i}=1}^{\mathrm{n}} \mathrm{V}_{\mathrm{i}}^{2} \Delta \mathrm{t}$

onde:

$\mathrm{V}_{\mathrm{i}}$ : valor da voltagem medida em um determinando instante;

$\Delta \mathrm{t}$ : intervalo de tempo entre os pontos do sinal, neste caso o inverso da freqüência de amostragem.

$\mathrm{n}$ : número de pontos do sinal. 
Geralmente é feito uma normalização do valor de $\mathrm{RMB}_{\text {energy }}$ em relação ao número de pontos do sinal. Isto permite comparar parâmetros de sinais gerados com diferentes freqüências de excitação ou diferentes tamanhos de janela.

\section{Envelope do Sinal ${ }^{1}$}

Trata-se da envoltória do sinal temporal. A Figura 2.6 mostra um exemplo do envelope do sinal de RMB.

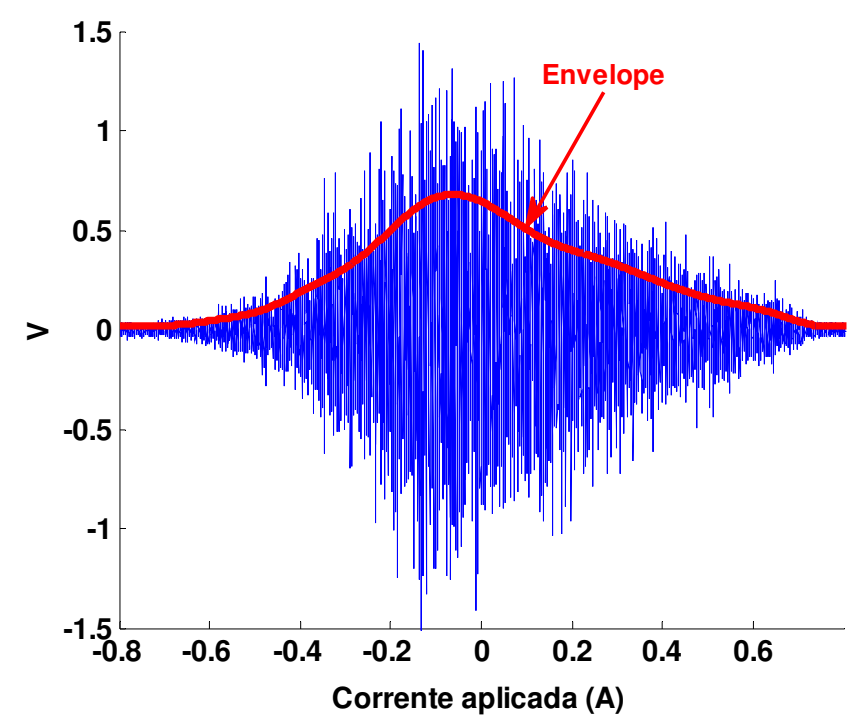

Figura 2.6 - Exemplo do envelope do sinal de RMB medido num aço SAE1070.

A maneira tradicional de se calcular o envelope é através do sinal analítico do sinal. O sinal analítico, é o sinal $s_{+}(t)$ que contém unicamente as freqüências positivas de $\mathrm{s}(\mathrm{t})$. Assim, o sinal $\mathrm{s}_{+}(\mathrm{t})$ associado ao sinal $\mathrm{s}(\mathrm{t})$, cuja Transformada de Fourier é expressa por $\mathrm{S}(\mathrm{v})$ é definido como:

$\mathrm{s}_{+}(\mathrm{t})=\left|\operatorname{TFI}\left(\mathrm{Z}_{\mathrm{s}}(\mathrm{v})\right)\right|$

Onde:

$Z_{s}(v)=\left\{\begin{array}{c}2 S(v) \text { para } v \geq 0 \\ 0 \text { para } v<0\end{array}\right.$

\footnotetext{
${ }^{1}$ Notas de aula, POLI-USP Disciplina PME5224 Processamento de Sinais aplicados à Engenharia Mecânica.
} 
Após calcular o envelope é necessário utilizar um filtro passa baixa (utilizando uma certa taxa de decimação), para eliminar as freqüências altas do envelope e, assim, recuperar um envelope mais liso.

Do gráfico do envelope são calculados principalmente dois parâmetros:

Amplitude pico: relativo ao valor máximo do envelope, e Posição pico: localização do valor máximo em relação à corrente, ou campo aplicado.

\section{Análise do sinal de RMB no domínio da freqüência. Espectro do sinal}

Indica como a potência do sinal aleatório está distribuída no domínio da freqüência. É definida pela transformada de Fourier, da função de autocorrelação do sinal:

$$
S(f)=\int_{-\tau_{0}}^{\tau_{0}} R(\tau) e^{-j \pi f \tau} d \tau
$$

Onde $R(\tau)$ é a função de autocorrelação. Com esta metodologia consegue-se determinar a participação de diferentes bandas de freqüência do sinal no valor total do $\mathrm{RMB}_{\mathrm{rms}}$.

\subsection{RMB CONTÍNUO}

A maioria das aplicações do efeito de Ruído magnético de Barkhausen utiliza um campo magnético externo variável no tempo que excita os domínios magnéticos do material, dando como resultado a produção do RMB. Nesse procedimento, a sonda de RMB deve permanecer estática sobre a mostra enquanto os sinais são adquiridos. Portanto é considerado como uma Medição de Ruído Magnético de Barkhausen Estático ou tradicional (RMBE). 
Por outro lado, na técnica de medição do "Barkhausen contínuo" (RMBC) a sonda é movimentada a velocidade constante sobre a amostra, e o Ruído de Barkhausen é monitorado de forma contínua.

No ano 2004, numa Conferência Internacional de Gasodutos, realizada em Alberta, Canadá, foi apresentado o primeiro e único trabalho (não publicado em revista cientifica), que até agora estudou a utilização desta técnica de medição do RMB (ALFRED E. CROUCH, 2004). Esta nova metodologia foi utilizada, na inspeção de defeitos mecânicos em tubulações, e deu inicio ao desenvolvimento do Método do Barkhausen Contínuo.

Nesse trabalho citado foi apresentado o seguinte conceito: Imãs permanentes geram na suas vizinhanças zonas de transição magnética. Quando são movimentados sobre materiais ferromagnéticos, fazem com que aquelas zonas que se aproximam do imã experimentem fluxos magnéticos que mudam de direção e amplitude. Estas mudanças do fluxo no material geram o movimento das paredes de domínios magnéticos, e conseqüentemente, sinais contínuos de Ruído de Barkhausen.

Um esquema da sonda que foi utilizada, no trabalho de Crouch, é mostrado na Figura 2.7.

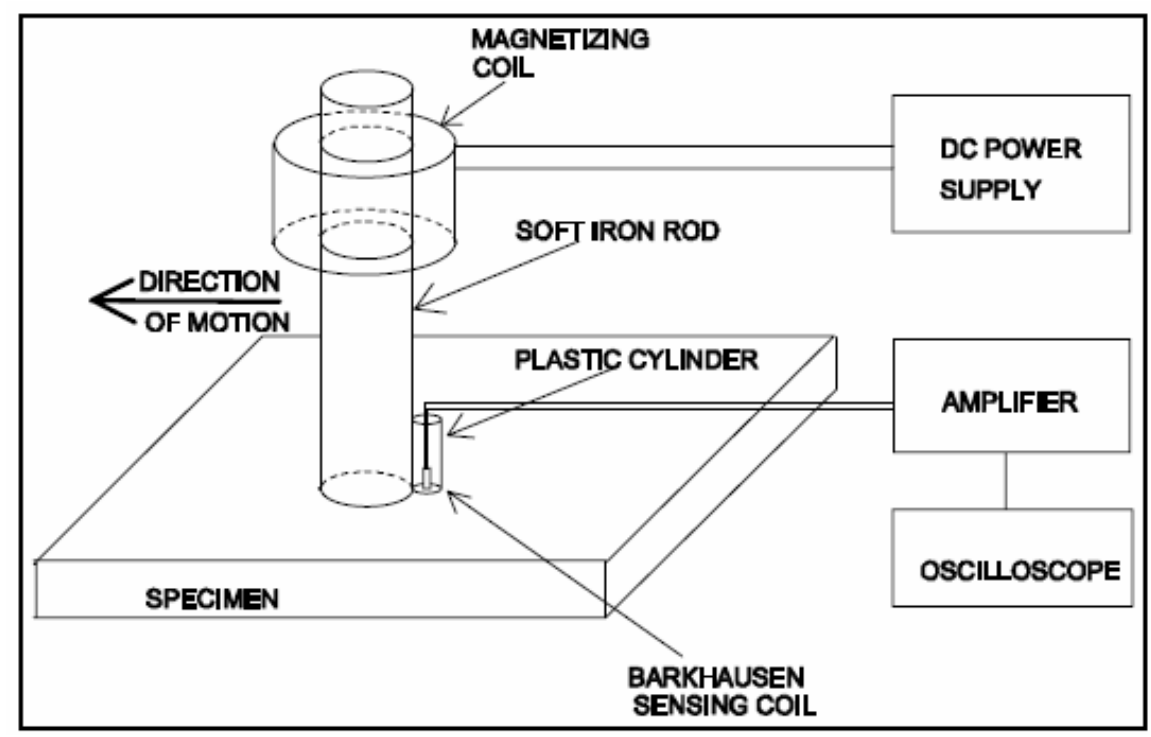

Figura 2.7 - Configuração da sonda utilizada na validação do RMBC (E. CROUCH, 2004). 
Com essa montagem foram avaliados diferentes aspectos que poderiam influir nas medições, no caso da aplicação desenvolvida. Assim se estudaram a influência de variáveis como: Distribuição do campo magnético gerado pela sonda, distância entre a sonda de medida e a superfície do material, velocidade relativa entre a sonda e a amostra, e a magnitude do campo aplicado. Baseados em esses estudos foram feitas as seguintes conclusões importantes:

- A bobina leitora do RMBC deve se posicionar em regiões muito próximas do imã indutor. Nestas regiões as bobinas têm maior sensibilidade, e são gerados os maiores gradientes de campo magnético. O posicionamento da bobina foi determinado por simulações de elementos finitos, da distribuição do fluxo magnético gerado, nas vizinhanças do eletro-imã;

- A velocidade da sonda tem baixa influência na amplitude do sinal de RMB. Nos ensaios realizados, variações na velocidade de $150 \%$ produzirem uma variação da amplitude do sinal de $45 \%$;

- A magnitude do campo usado é diretamente proporcional às amplitudes dos sinais do RMBC. Enquanto maior é o campo, maiores são os sinais do RMBC;

- O afastamento da sonda da superfície da amostra diminui em forma exponencial as amplitudes dos sinais de RMB. A maior distância utilizada foi de 6,35mm;

- Os sinais do RMBC diminuem em forma linear em relação ao ângulo formado entre, o eixo vertical da sonda, e a perpendicular do plano da amostra. Assim, para um ângulo máximo de $90^{\circ}$ o sinal tem uma diminuição de $40 \%$.

Sem dúvida, com a utilização desta nova técnica de mapeamento contínuo de superfícies podem-se obter informações adicionais do estado do material, que não são fornecidas atualmente pelas técnicas comumente usadas. 


\subsection{INTRODUÇÃO AOS ESTUdOS REALIZADOS NO PRESENTE TRABALHO}

Como mostrado até aqui, existem duas técnica de medição do RMB, o RMBE e o RMBC (Figura 2.8).

Em todos os trabalhos conhecidos da literatura utilizam sempre o RMBE. Apesar dos diferentes aspectos e aplicações que têm sido estudados, ainda se encontram lacunas importantes na compreensão do comportamento do RMB e seus procedimentos de medida.

Por outro lado o RMBC é uma técnica bastante nova, sendo encontrada uma única publicação (ALFRED E. CROUCH, 2004). Por tanto, muitas questões ainda precisam ser resolvidas. O desenvolvimento desta técnica pode gerar um impacto importante na solução de diferentes problemas, presentes atualmente na área industrial.
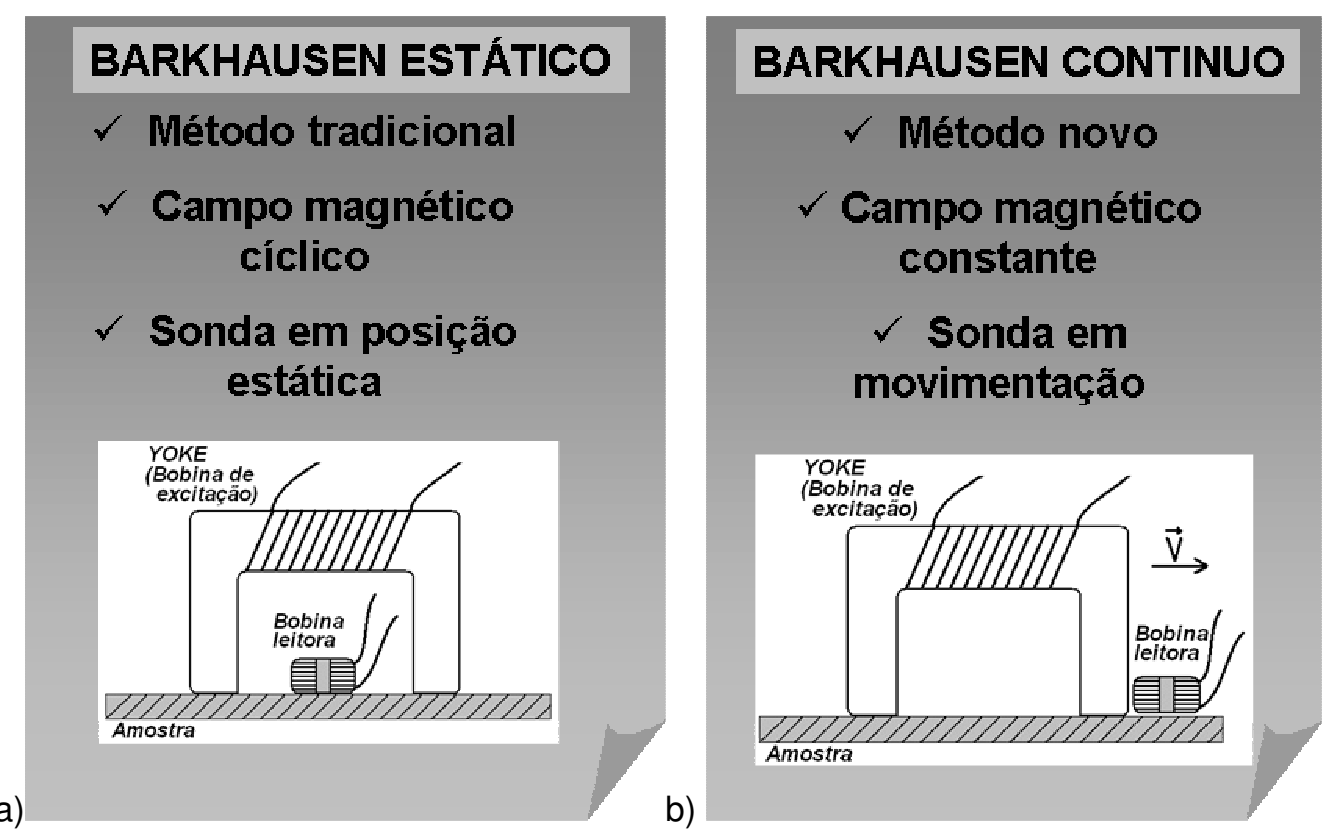

Figura 2.8 - Técnicas de medição do Ruído Magentico de Barkhausen. a) RMBE, b) RMBC. 
No presente trabalho foram realizados estudos das duas técnicas de medição do RMB. Nos capítulos seguintes, são apresentados resultados de diferentes assuntos, que ainda não têm sido estudados na literatura pesquisada.

Aplicando o RMBE, são apresentados dois estudos:

- Em um primeiro estudo, no Capitulo 3, é analisada a influência de, parâmetros de medição, parâmetros de análise dos sinais, e anisotropia das amostras, no monitoramento de tensões produzidas por flexão.

- E em um segundo estudo, no Capitulo 4, é apresentada a aplicação do RMB na avaliação de graus de dureza em aços. É estudado o comportamento de diferentes parâmetros de análise dos sinais, alem da influência da freqüência de magnetização, na caracterização de perfis microestructurais gerados em amostras Jominy.

Em relação ao RMBC, no Capítulo 5 são apresentados resultados inovadores no desenvolvimento dessa nova técnica de varredura de superfícies. É mostrada sua aplicação na detecção de diferentes falhas. São analisados, principalmente, casos de detecção de perda de material, deformação plástica, e tensão aplicada. Diferentes aspectos que influem na utilização da técnica são estudados: projeto da sonda, análise dos sinais, e amplitude de campo e velocidades de varredura aplicada. 


\section{MEDIÇÕES DE TENSÕES DE FLEXÃO VIA RMB}

Neste capítulo é apresentada a utilização da técnica de medição do Ruído Magnético de Barkhausen, na medição de tensões produzidas por flexão. É apresentada uma descrição das amostras, equipamentos de geração de cargas de flexão e medição do RMB, e controle das diferentes variáveis de medida. Diferentes estudos foram realizados, e são mostrados resultados referentes aos seguintes aspectos:

- Influência de parâmetros de medida e análise do RMB na medição de tensão.

$\checkmark$ Correspondência entre diferentes parâmetros de análise do sinal de RMB e os valores de tensão aplicada.

$\checkmark$ Análise de diferentes faixas temporais e de amplitude do sinal, em relação à tensão.

$\checkmark$ Influência da amplitude e freqüência do campo magnético aplicado na medição de tensão.

- Influência da direção de laminação na medição de tensões de flexão.

\subsection{MATERIAIS E MÉTODOS}

\subsubsection{Materiais}

Para a fabricação das amostras, foi utilizada uma chapa de aço SAE-1070 laminada e recozida, com $3 \mathrm{~mm}$ de espessura e limite de escoamento, $\sigma_{e}=500 \mathrm{MPa}$. No projeto da amostra foram considerados diferentes aspectos que minimizassem os erros no processo de medida, e facilitassem o controle dos diferentes efeitos a serem estudados, como: controle dos carregamentos aplicados, repetibilidade de ensaio e posicionamento da sonda de RMB. Para isso se decidiu utilizar amostras tipo "viga iso-flexão". Uma viga tipo iso-flexão apresenta o mesmo valor (teórico) de 
tensão em qualquer ponto da superfície. A Figura 3.1 mostra a configuração da amostra projetada.

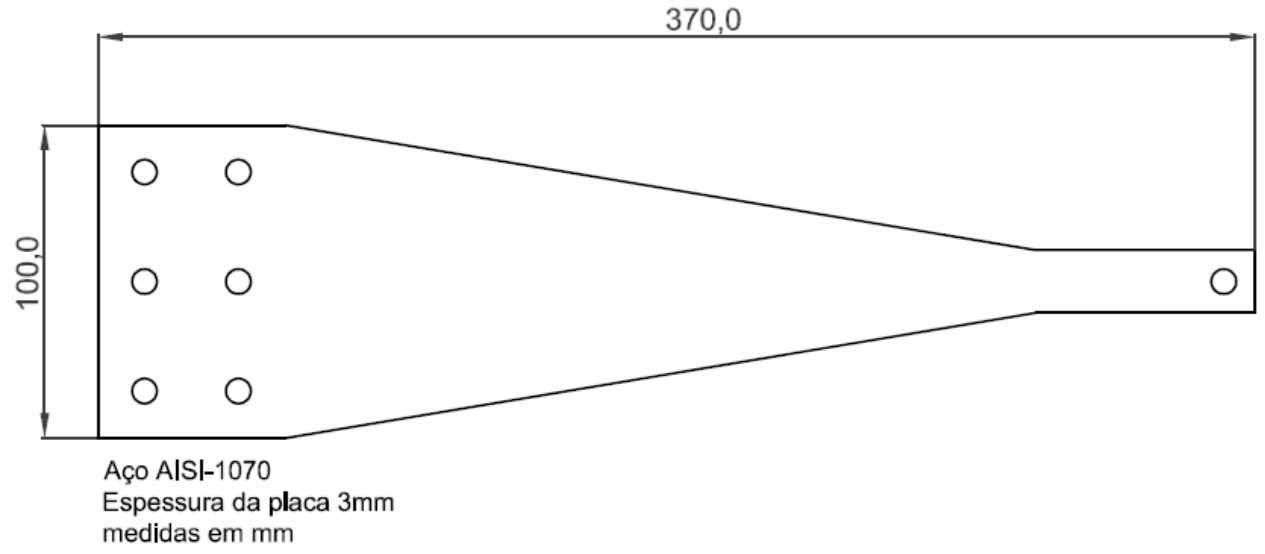

Figura 3.1 - Viga tipo "Iso-flexão".

Foram cortadas duas amostras como indicado na Figura 3.2, uma na direção longitudinal de laminação (Amostra DL) e outra na direção transversal (Amostra DT) da chapa de aço SAE-1070.

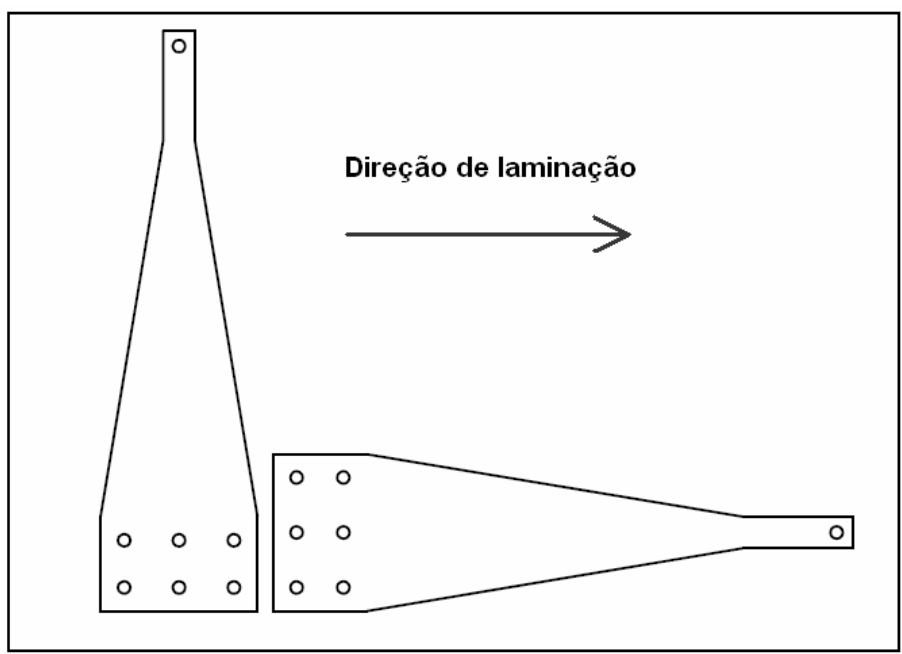

Figura 3.2 - Sentido de corte das amostras de Iso-flexão. 


\subsubsection{Sistema de medida}

\subsubsection{Aplicação e controle dos carregamentos}

Para produzir as tensões de flexão nas amostras especificadas, foi projetado o equipamento mostrado na fotografia da Figura 3.3. O equipamento permite gerar de modo controlado deflexões na extremidade livre da viga e, portanto, tensões de tração e compressão na superfície superior e inferior da mesma.

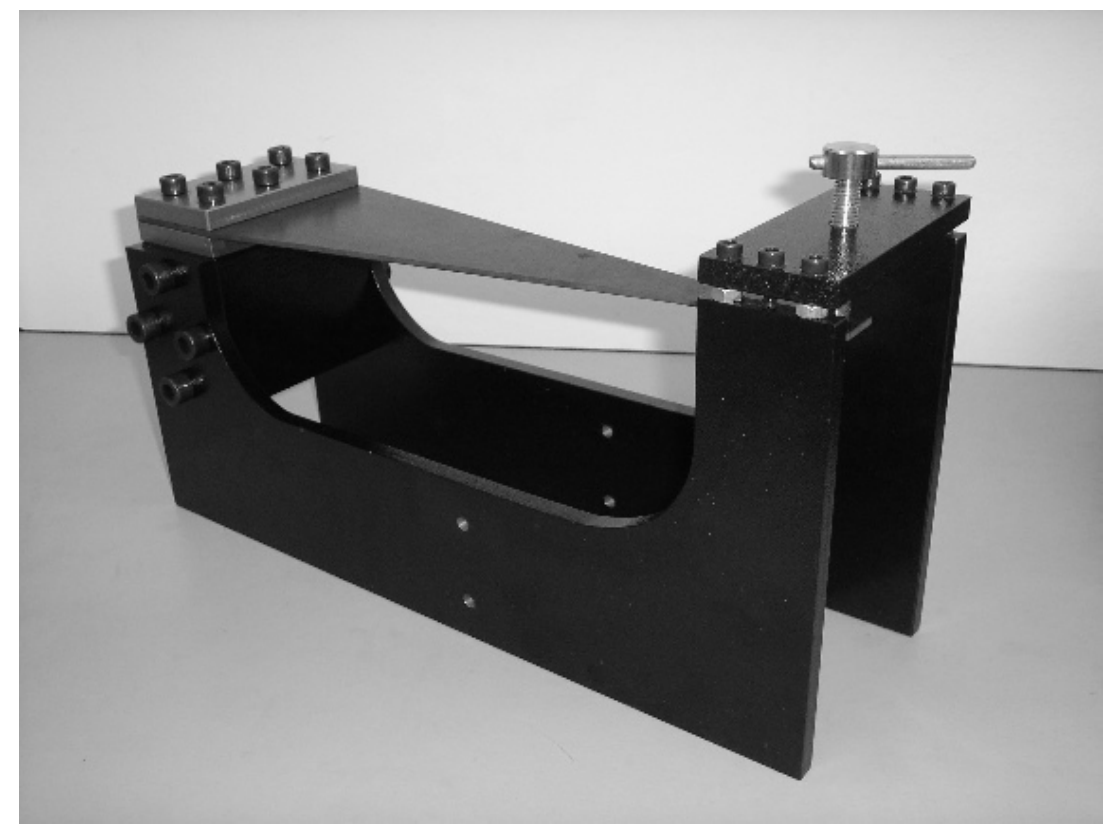

Figura 3.3 - Equipamento para ensaios de flexão.

As tensões produzidas foram medidas utilizando 0 método clássico de extensometría resistiva. Extensômetros bidirecionais (roseta $90^{\circ}$ ) foram instalados na superfície de cada uma das amostras (DL e DT). A Figura 3.4 mostra uma fotografia da montagem e posicionamento destes dispositivos. 


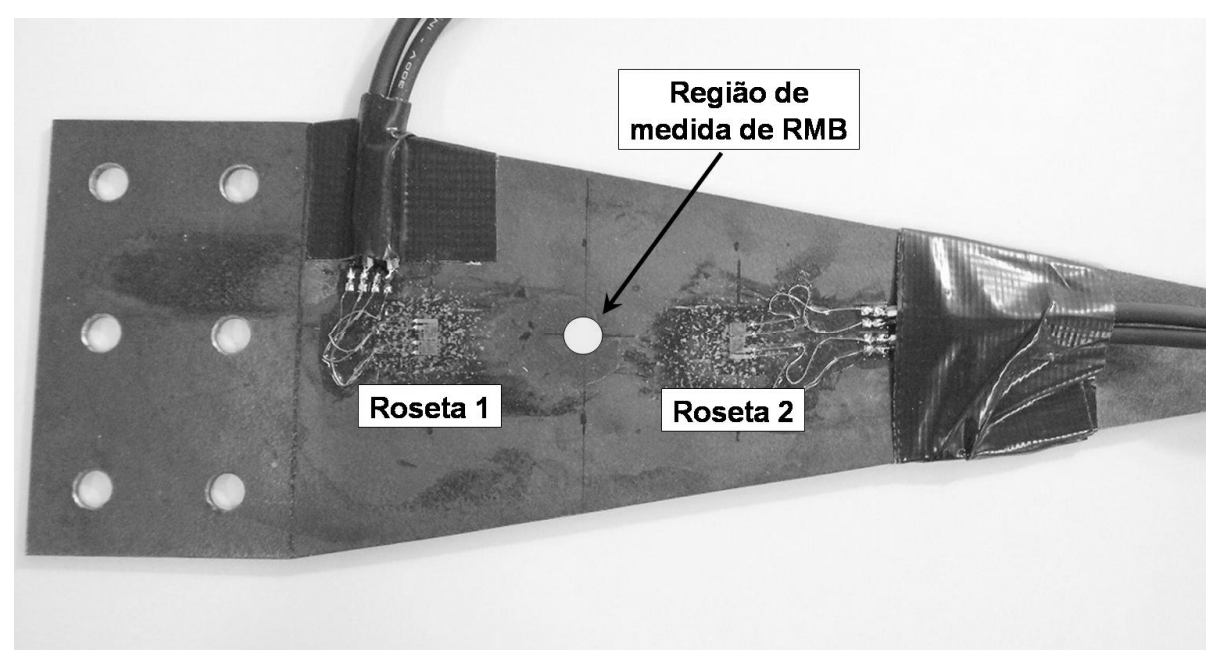

Figura 3.4 - Instalação de extensômetros.

Com a roseta $90^{\circ}$ foi possível medir a deformação longitudinal e transversal da superfície. As rosetas foram instaladas em dois pontos diferentes da superfície das amostras com o objetivo de verificar a distribuição homogênea de tensão prevista pelos cálculos teóricos. Utilizaram-se extensômetros do tipo PA-06-125TG-350L (EXCEL sensor, Brasil), com resistência de $350 \Omega$ e Constante (gage factor) de 2.12.

$\mathrm{Na}$ aquisição das medidas de deformação utilizou-se o condicionador de sinal Spider8-30 (HBM, Brasil), que através de conexão USB transmite as medidas de tensão já calibradas e digitalizadas para o computador. A conexão dos extensômetros no Spider8-30 foi feita em $1 / 4$ de ponte de wheatstone e com ligação por três fios.

Para visualizar os dados adquiridos e controlar os parâmetros de medida do sistema, foi desenvolvida uma aplicação no software CATMAN (Software que acompanha o Spider8-30). A Figura 3.5 mostra uma janela da aplicação feita no CATMAN. 


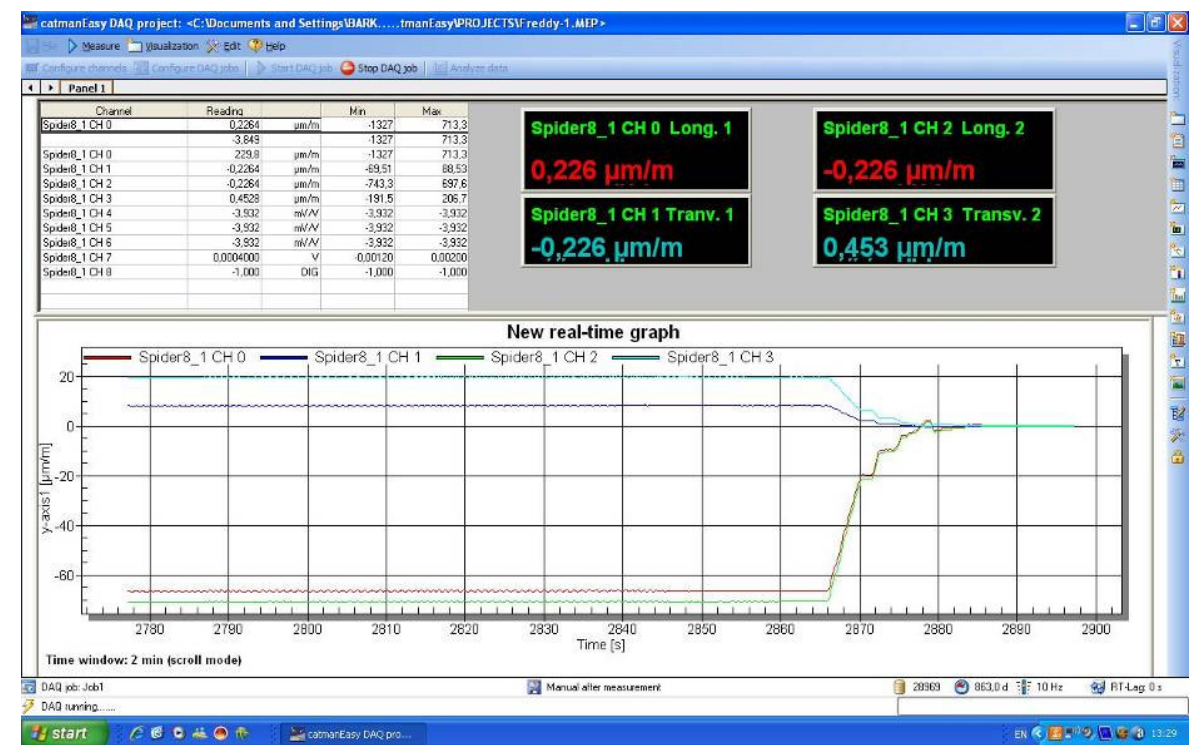

Figura 3.5 - Programa de aquisição de dados feito no software CATMAN para o registro dos sinais de Extensometria.

A correspondência entre deformações produzidas na superfície das amostras e os valores de tensão, carga e deflexão no extremo da viga, segundo cálculos teóricos são indicados na Tabela 3.1. Uma simulação por elementos finitos confirmou estes resultados. A Figura 3.6 amostra uma simulação feita no programa ANSYS. A máxima tensão aplicada foi de $\pm 133.3 \mathrm{MPa}$ correspondente a uma deflexão de $\pm 20 \mathrm{~mm}$, mantendo assim o material na região elástica do gráfico tensão vs deformação.

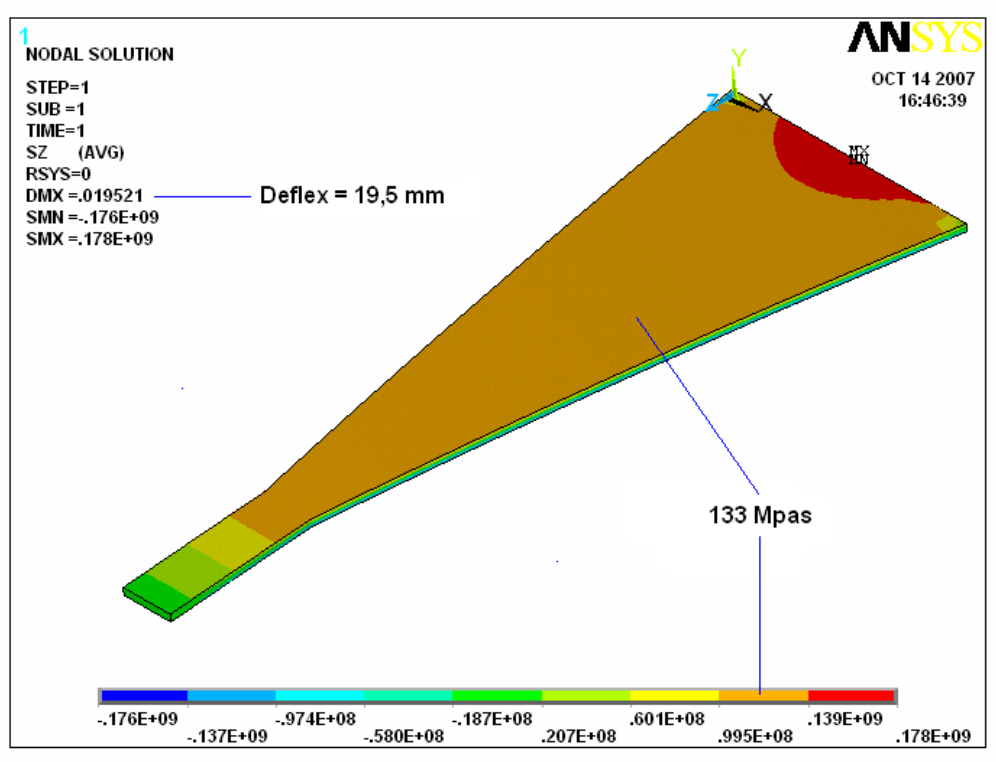

Figura 3.6 - Simulação por elemento finitos da máxima deflexão aplicada. 
Tabela 3.1 - Tensões calculadas na superfície das amostras de iso-flexão em função das deformações medidas.

\begin{tabular}{ccc}
\hline $\begin{array}{c}\text { Tensão } \\
(\mathbf{M P a})\end{array}$ & $\begin{array}{c}\text { Deflexão no extremo } \\
(\mathbf{m m})\end{array}$ & $\begin{array}{c}\text { Deformação } \\
(\mathbf{u} \varepsilon)\end{array}$ \\
\hline-133.33 & 20.00 & -666.67 \\
\hline-120.00 & 18.00 & -600.00 \\
\hline-106.67 & 16.00 & -533.33 \\
\hline-93.33 & 14.00 & -466.67 \\
\hline-80.00 & 12.00 & -400.00 \\
\hline-66.67 & 10.00 & -333.33 \\
\hline-53.33 & 8.00 & -266.67 \\
\hline-40.00 & 6.00 & -200.00 \\
\hline-26.67 & 4.00 & -133.33 \\
\hline-13.33 & 2.00 & -66.67 \\
\hline 0.00 & 0.00 & 0.00 \\
\hline 13.33 & -2.00 & 66.67 \\
\hline 26.67 & -4.00 & 133.33 \\
\hline 40.00 & -6.00 & 200.00 \\
\hline 53.33 & -8.00 & 266.67 \\
\hline 66.67 & -10.00 & 333.33 \\
\hline 80.00 & -12.00 & 400.00 \\
\hline 93.33 & -14.00 & 466.67 \\
\hline 106.67 & -16.00 & 533.33 \\
\hline 120.00 & -18.00 & 600.00 \\
\hline 133.33 & -20.00 & 666.67 \\
\hline
\end{tabular}

\subsubsection{Medição do Ruído Magnético de Barkhausen (RMB)}

Para a medição de RMB foi utilizado o equipamento "Barktech" desenvolvido totalmente no Laboratório de Dinâmica e Instrumentação (LADIN) da Universidade de São Paulo (Figura 3.13). O equipamento é responsável tanto pela geração e controle da corrente de excitação, como pela aquisição e filtragem dos sinais de voltagem gerados pelo sensor de RMB. Assim, o "Barktech" permite gerar, utilizando uma fonte bipolar, correntes de excitação em forma senoidal ou triangular com freqüências de 0,4 a $100 \mathrm{~Hz}$, e amplitudes de 0 a $4 \mathrm{~A}$. Os sinais de RMB podem ser adquiridos em diferentes faixas de freqüência e amplificados com diferentes valores de ganhos. Todas estas funções são controladas desde o computador.

A sonda de RMB tem a função de aplicar o campo magnético de excitação aos materiais e detectar o Ruído magnético de Barkhausen gerados nos mesmos. Para 
o estudo de tensões de flexão via RMB foi projetada e construída a sonda mostrada na fotografia da Figura 3.7.
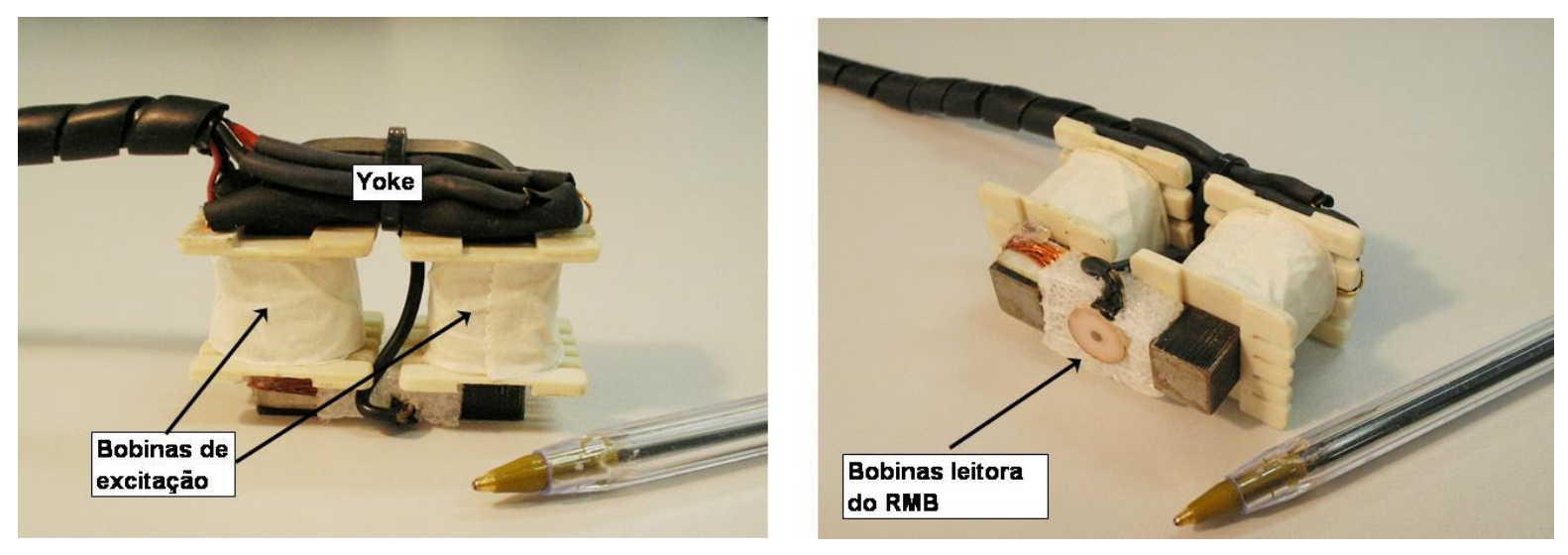

Figura 3.7 - Fotografias da sonda de RMB utilizada nos ensaios de Flexão.

Um núcleo de Fe-Si em forma de "U" (Yoke), no qual foi enrolado bobinas de fios de de cobre, tem a função de gerar indução magnética no circuito magnético formado pelo Yoke e amostra. Entre os pólos do Yoke está colocado o sensor de RMB, uma bobina (1000 voltas de arame AWG44) leitora de alta sensibilidade. Assim quando no material é induzido o campo magnético variável, os pulsos magnéticos produzidos pela movimentação discreta das paredes de domínio geram pulsos de voltagem na bobina leitora posicionada na superfície. A Figura 3.8 mostra o esquema da cadeia de medida utilizado para gerar e detectar o RMB.

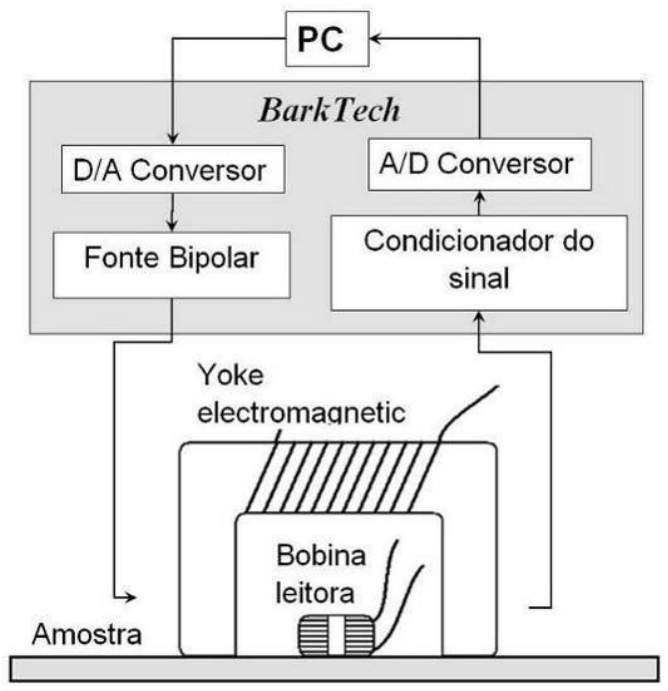

Figura 3.8 - Esquema da cadeia de medida. 
Os sinais de RMB foram adquiridos com diferentes parâmetros de medida:

- Freqüências de excitação: $0.7 \mathrm{~Hz}, 2 \mathrm{~Hz}, 6 \mathrm{~Hz}, 10 \mathrm{~Hz}, 15 \mathrm{~Hz}, 30 \mathrm{~Hz}$ e $60 \mathrm{~Hz}$.

- Correntes de excitação: A Tabela 3.2 indica os valores de corrente aplicada e os valores correspondentes de campo medido. O campo foi medido com ajuda de um gaussímetro, colocando o sensor Hall entre a face de um pólo do Yoke e a amostra. Ver fotografias mostradas na Figura 3.9

Tabela 3.2 - Correntes de excitação aplicadas

\begin{tabular}{cc}
\hline Corrente (A) & Campo (A/m) \\
\hline 0,57 & 38208 \\
\hline 0,80 & 51740 \\
\hline 1,22 & 90744 \\
\hline 1,90 & 144872 \\
\hline 2,57 & 168752 \\
\hline 3,32 & 197408 \\
\hline 4,25 & 226064 \\
\hline
\end{tabular}
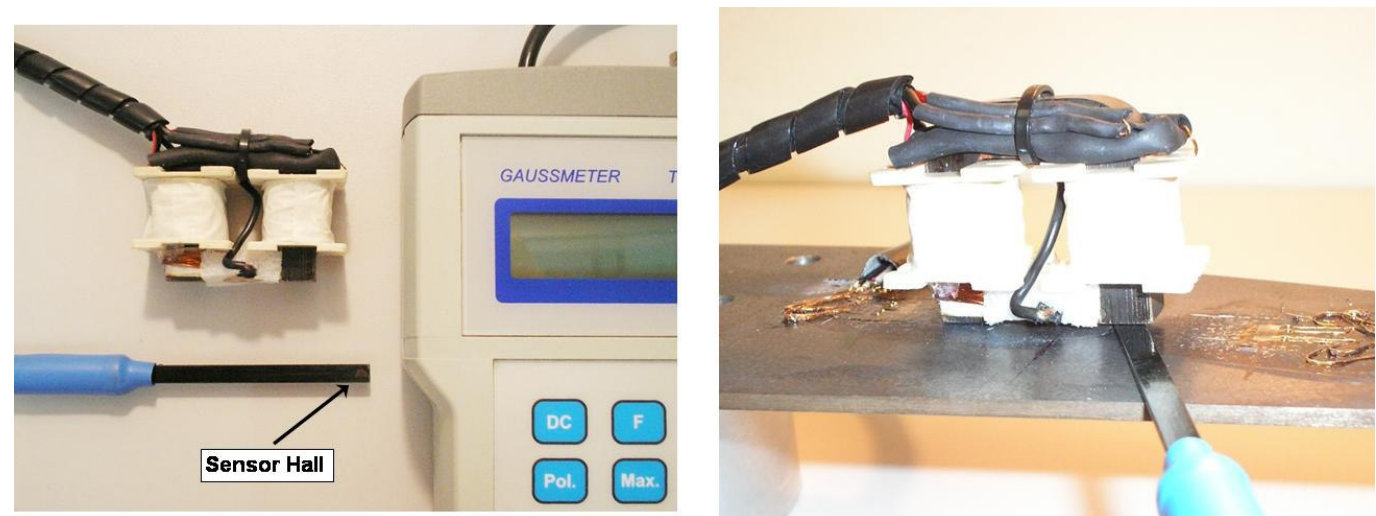

Figura 3.9 - Medida do campo magnético produzido pela sonda de RMB.

- Aquisição do sinal: Cada medida é composta por sinais de RMB gerados em dois ciclos completos de magnetização (Figura 3.10). A taxa de amostragem foi mantida em $200 \mathrm{kHz}$. E foram gravadas 10 repetições de cada condição de medida. 


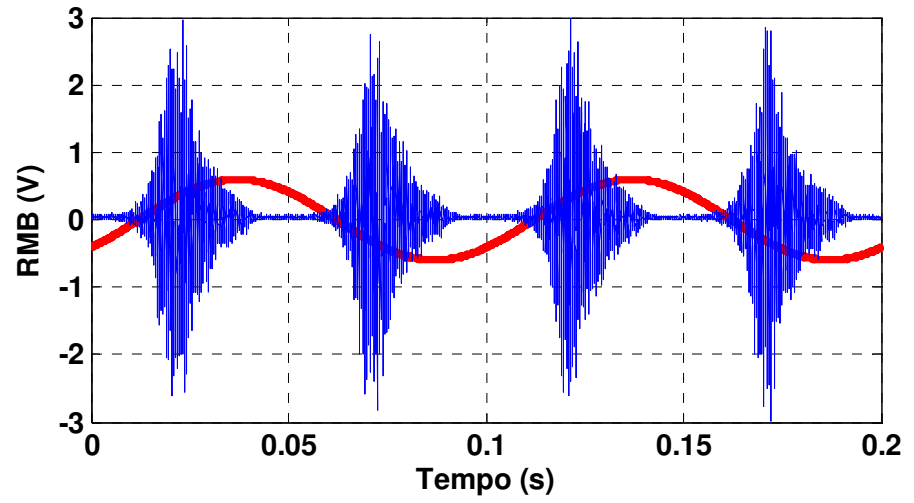

Figura 3.10 - Sinal do RMB no tempo (azul) e sinal proporcional ao campo de excitação (vermelho).

- Orientações da sonda: A sonda foi orientada em duas direções diferentes em relação à direção da tensão aplicada. A orientação da sonda controla a direção do campo magnético. Assim, foram feitas medidas de RMB magnetizando a amostra em direção longitudinal e transversal á tensão aplicada. A Figura 3.11 indica a posição e orientações usadas da sonda, no procedimento de medida do RMB.
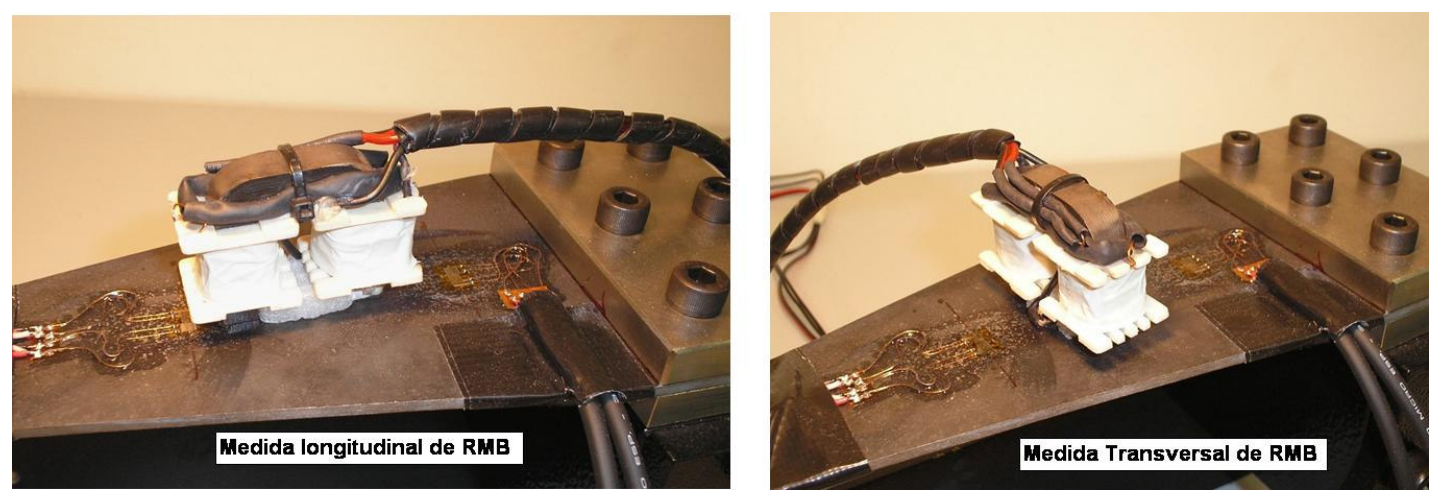

Figura 3.11 - Posição e orientações da sonda de RMB no procedimento de medida.

Foram calculados diferentes parâmetros dos sinais medidos: Posição Pico e Amplitude Pico do envelope do sinal, $R M_{\text {rms }}$ e $R M B_{\text {energy. }} A$ visualização e gravação dos sinais obtidos foram feitas com uma aplicação desenvolvida no programa Labview 8.0. Na Figura 3.12 mostra-se a tela do painel de visualização e controle do programa. A Figura 3.13 mostra uma fotografia da estação experimental com todos os equipamentos utilizados. 


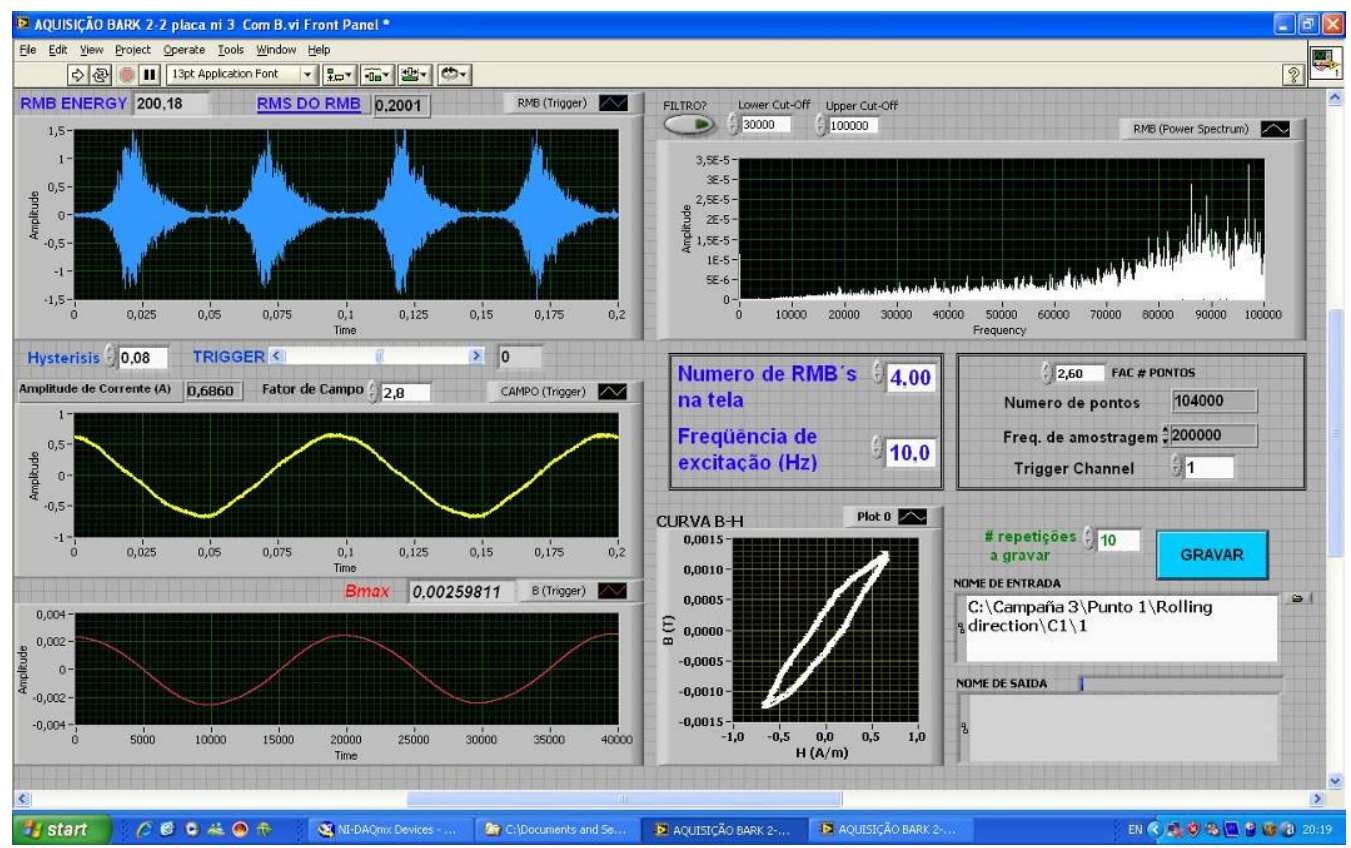

Figura 3.12 - Programa de aquisição de dados feito em LabView para o registro dos sinais de RMB.

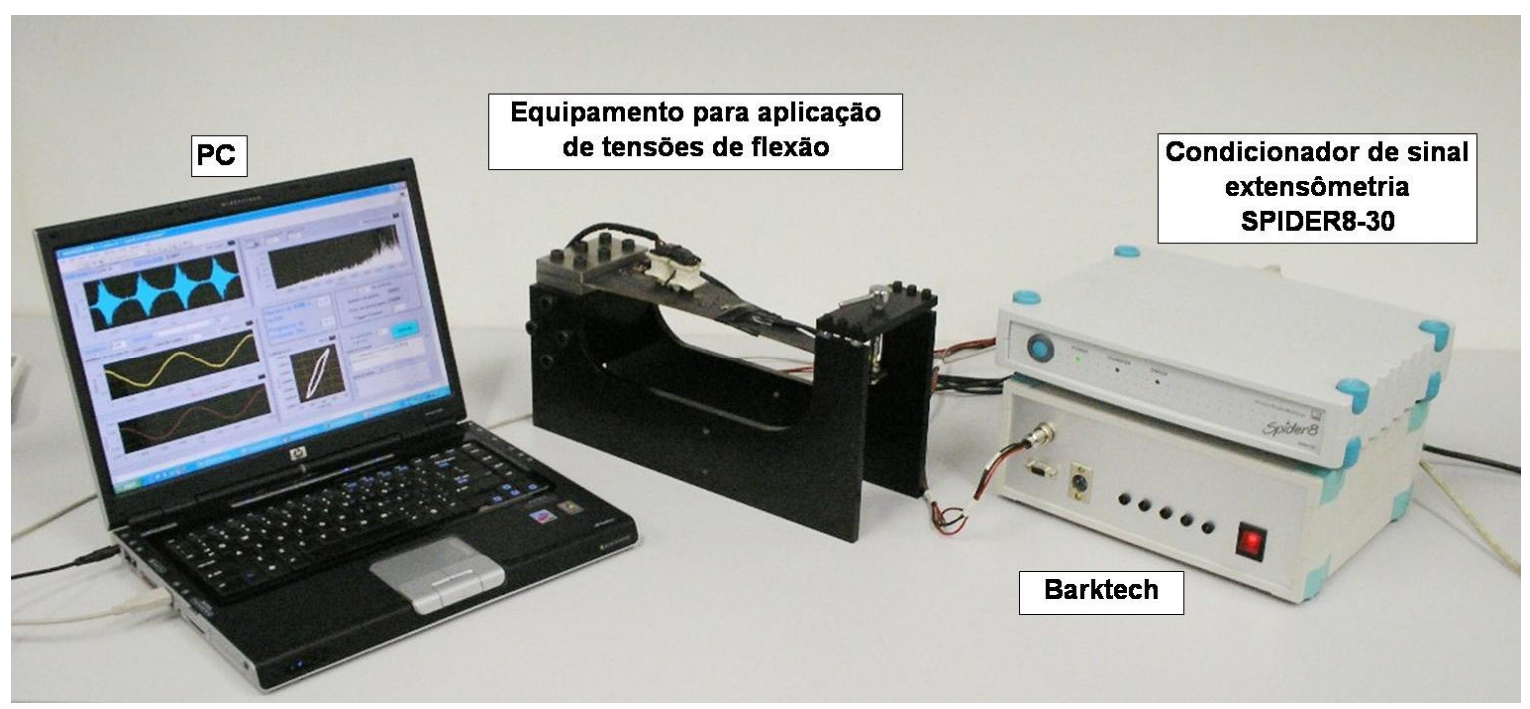

Figura 3.13 - Estação experimental nas medidas de tensões de flexão. 


\subsection{RESULTADOS E DISCUSSÃO}

Como exposto no item 3.1.2.1, duas rosetas bidirecionais para medição de deformação foram instaladas em cada uma das amostras (DL e DT). Os resultados das deformações, obtidas por cada uma das rosetas, na amostra DL e na amostra DT são indicados na Figura 3.14 e Figura 3.15, respectivamente.

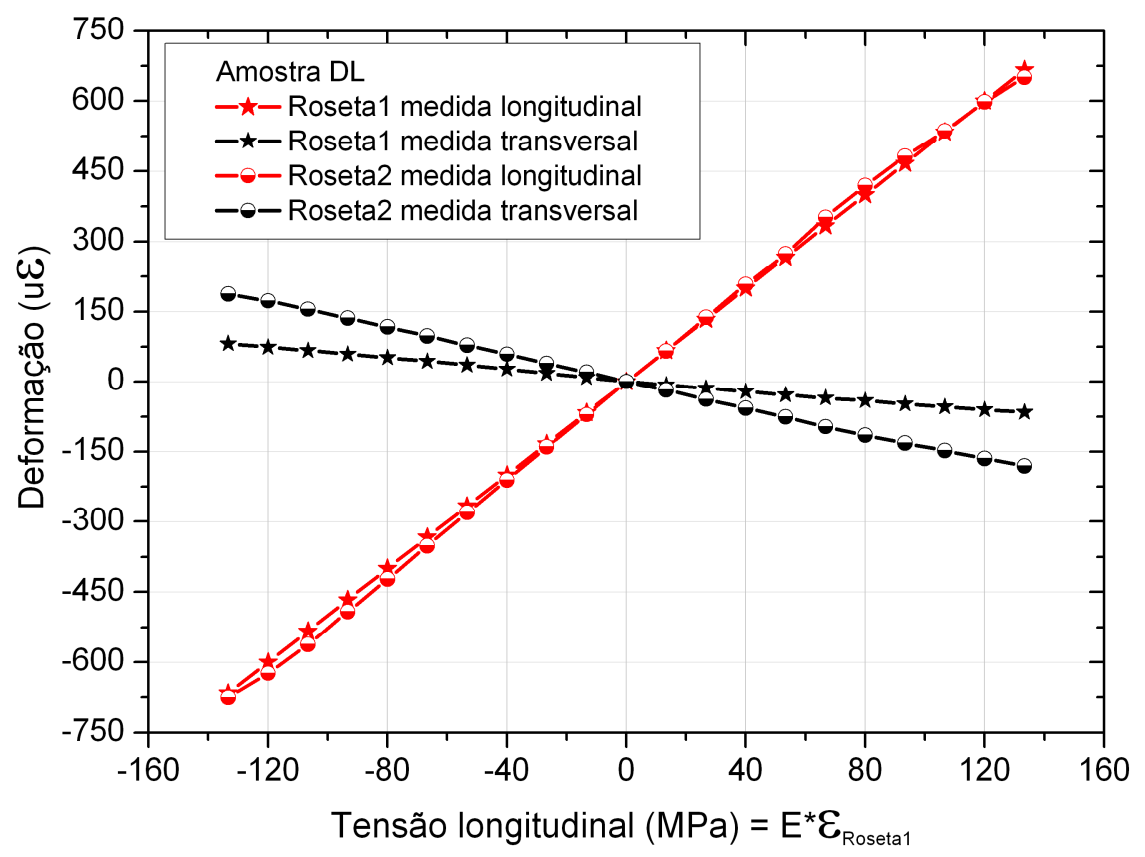

Figura 3.14 - Comportamento dos valores de deformação medidos na amostra DL pelas Rosetas 1 e 2.

É observado, nos dois casos, que as leituras de deformação longitudinal dadas pelos extensômetros colados em diferentes regiões da superfície das vigas de isoflexão, apresentam valores bastante similares, fato que confirma a distribuição homogênea de tensão longitudinal que é produzida na superfície das amostras. Por outro lado as leituras de deformação transversal apresentaram diferenças. Para todos os carregamentos aplicados, a leitura da Roseta 1 sempre foi menor da leitura da Roseta 2. Foi mostrado na Figura 3.4, que a Roseta 1 foi instalada numa região perto do engaste da viga, e a Roseta 2 numa posição mais afastada. Acredita-se que as diferenças entre as leituras é devida ao efeito do engaste. $O$ atrito gerado no engaste diminui 0 efeito das tensões longitudinais sobre as deformações 
transversais. O efeito é maior em zonas do material localizadas perto dele. Portanto, as zonas do material perto do engaste (Roseta 1), são menos deformadas transversalmente que as zonas afastadas (Roseta 2).

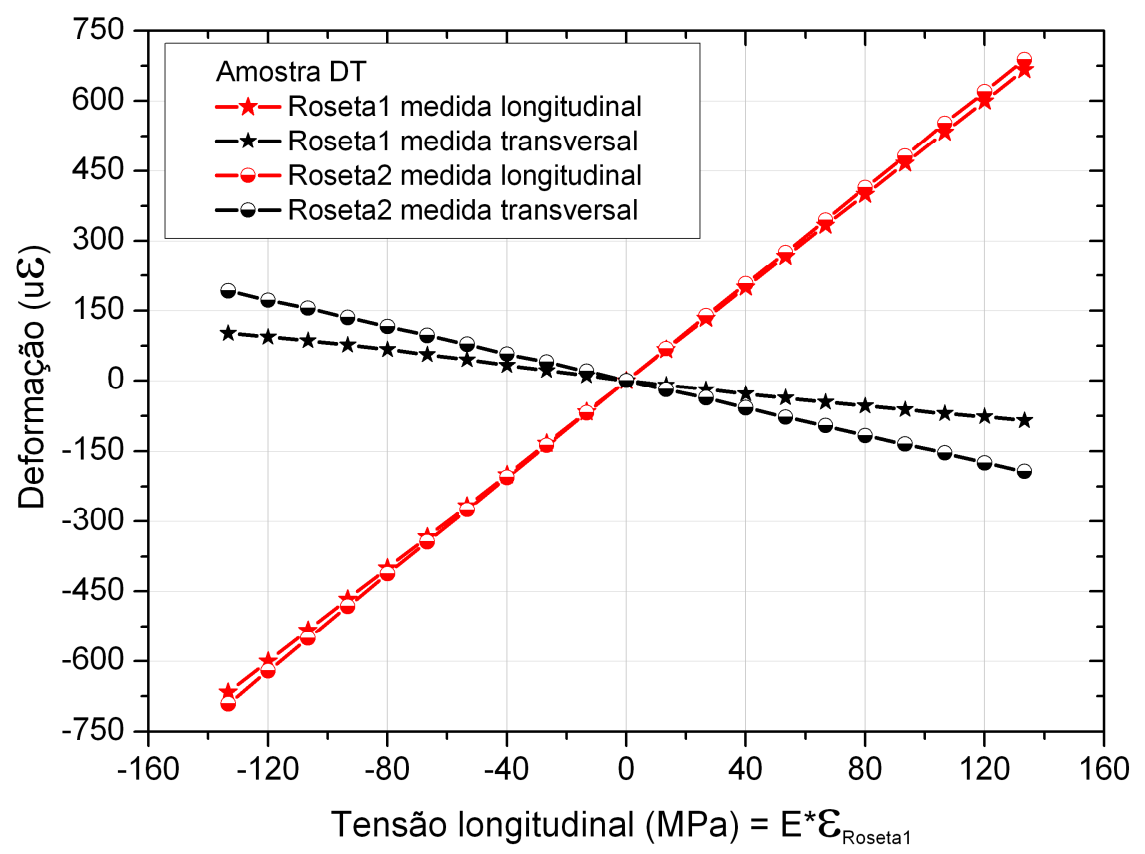

Figura 3.15 - Comportamento dos valores de deformação medidos na amostra DT pelas Rosetas 1 e 2.

Dada a similitude apresentada pelas leituras de deformação longitudinal produzidas pelas duas Rosetas, os dados de tensão longitudinal utilizados em cada um dos estudos realizados, são calculados a partir das leituras de deformação longitudinal dadas pela Roseta 1. Já no caso das tensões transversais, foi utilizado para o cálculo, o valor médio entre as leituras da Roseta 1 e a Roseta 2. Isto, implica na hipótese, que na posição média das duas rosetas (posição das medidas do RMB), a deformação transversal tem um valor médio.

Nos seguintes itens são apresentados e discutidos em forma individual, cada um dos aspectos analisados no estudo da aplicação da técnica do RMB na medição de tensões de flexão. 


\subsubsection{Influência de parâmetros de medida e análise do RMB na medição de tensão}

\subsubsection{Correlação entre parâmetros de análise do sinal de RMB e os valores de tensão aplicada}

Os resultados mostrados neste item são correspondentes à medições feitas na Amostra DL. As medidas do RMB foram feitas na direção longitudinal à tensão aplicada, e utilizando uma corrente senoidal de magnetização com $0.8 \mathrm{~A}$ de amplitude e freqüência de $10 \mathrm{~Hz}$. As tensões aplicadas são indicadas na Tabela 3.1.

Envelopes do sinal de RMB correspondentes a 10 diferentes tensões aplicadas são mostrados na Figura 3.16. Alguns valores de tensão foram omitidos para simplificar a figura. É observado como a altura do pico (Amplitude pico) aumenta enquanto a tensão aplicada passa de valores de compressão para valores de tração. A posição do pico (Posição pico) também tem alterações. Assim que as tensões de compressão aumentam, a posição do pico se movimenta para valores maiores de correntes aplicadas. No entanto com tensões de tração não são observadas mudanças importantes na posição do pico.

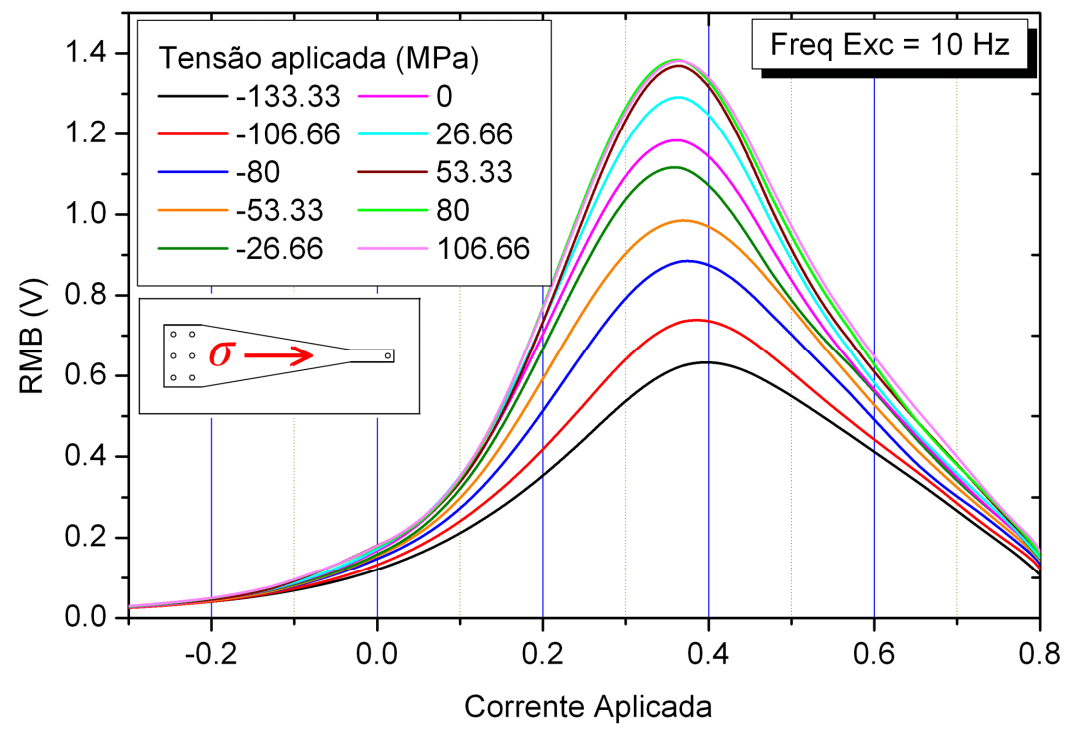

Figura 3.16 - Envelopes do sinal de RMB obtidos com diferentes tensões aplicadas na amostra DL. 
Tensões de compressão induzem alinhamento dos domínios magnético na direção transversal à tensão aplicada. Portanto, o processo de magnetização se dificulta e o valor de Hc aumenta (Posição pico aumenta). A posição do pico de envelope do RMB está diretamente relacionada à posição do campo coercitivo, Hc (Kinser ER , 2005).

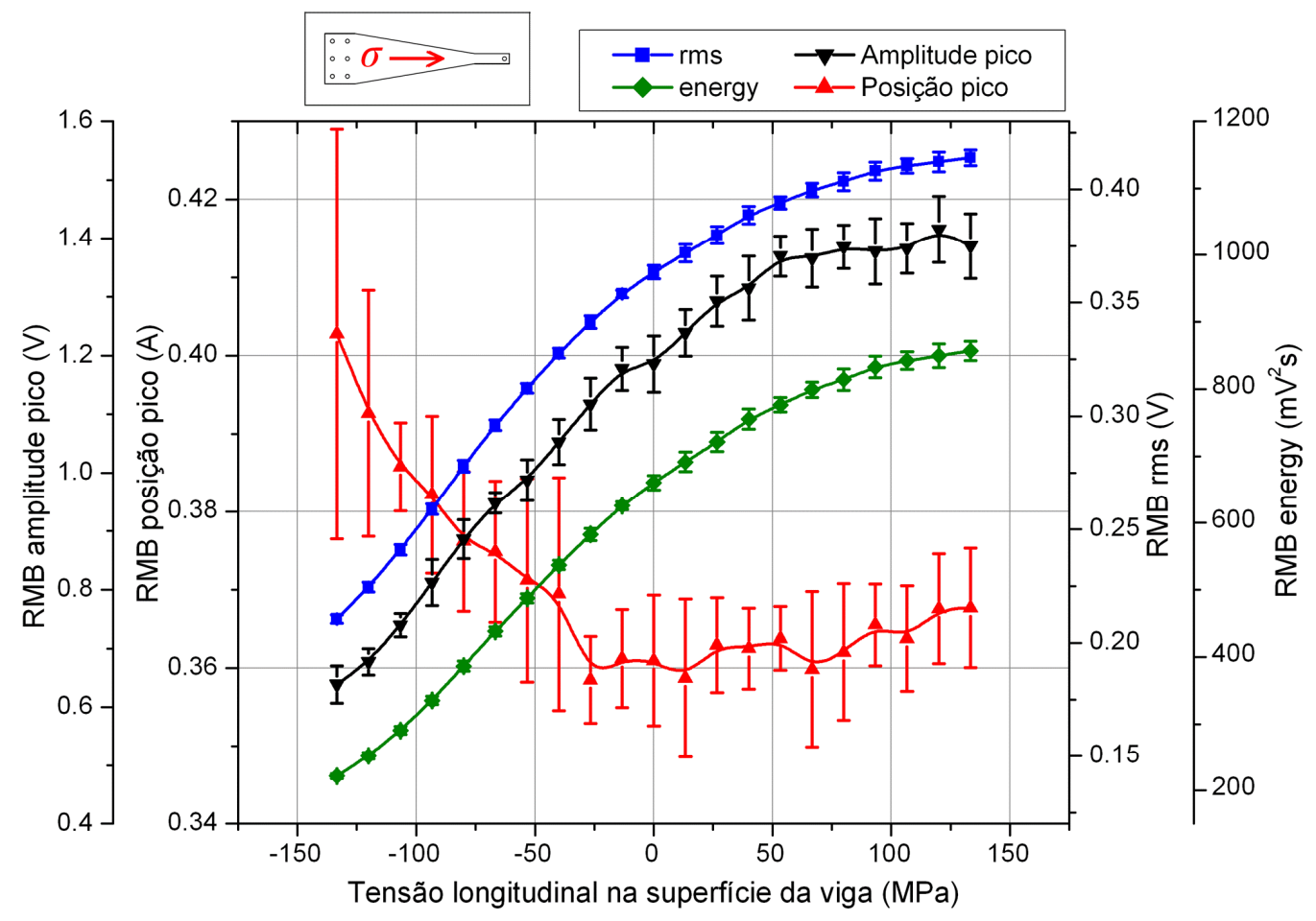

Figura 3.17 - Dependência entre os diferentes parâmetros calculados do RMB (Posição pico, Amplitude pico, $\mathrm{RMB}_{\text {rms }}$ e $\mathrm{RMB}_{\text {energy }}$ ) e os valores de tensão aplicada.

A Figura 3.17 mostra a dependência entre os parâmetros Posição pico, Amplitude pico, $\mathrm{RMB}_{\text {rms }}$ e $\mathrm{RMB}_{\text {energy }} \mathrm{e}$ os valores de tensão aplicada. Em relação ao comportamento estatístico, é observado como os parâmetros calculados a partir dos gráficos de envelope, Posição pico e Amplitude pico, apresentam maiores desvios

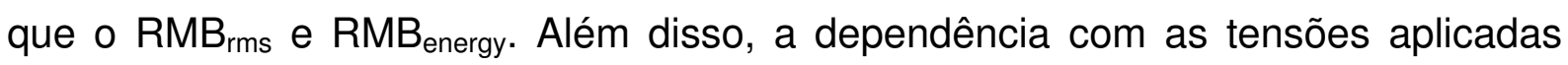
também é menor. Por outro lado, o comportamento dos parâmetros $\mathrm{RMB}_{\mathrm{rms}} \mathrm{e}$ $\mathrm{RMB}_{\text {energy }}$ apresentaram baixos desvios em cada condição de medida, e uma evolução homogênea dos valores médios em relação às tensões produzidas.

Assim que os valores de tensão passam de compressão para tração, a quantidade de domínios magnéticos alinhados na direção longitudinal da amostra aumenta. 
Tensões de tração alinham os domínios magnéticos no sentido da tensão, enquanto que tensões de compressão os alinham na direção perpendicular (J. CAPO, 2007; J.P. BENITEZ, 2007; J. A. RIVERA, 2001; D.C. JILES, 1989). Por tanto a quantidade de paredes de domínio de $180^{\circ}$, e conseqüentemente sua interação com defeitos microestruturais também é aumentada. Desta forma o sinal de RMB registrado pela bobina leitora é aumentado, bem seja pela quantidade de pulsos magnéticos produzidos, ou pela superposição deles no processo de medida. Estas condições fazem que os parâmetros, Amplitude pico, $\mathrm{RMB}_{\text {rms }}$ e $\mathrm{RMB}_{\text {energy }}$ aumentem com a tensão aplicada.

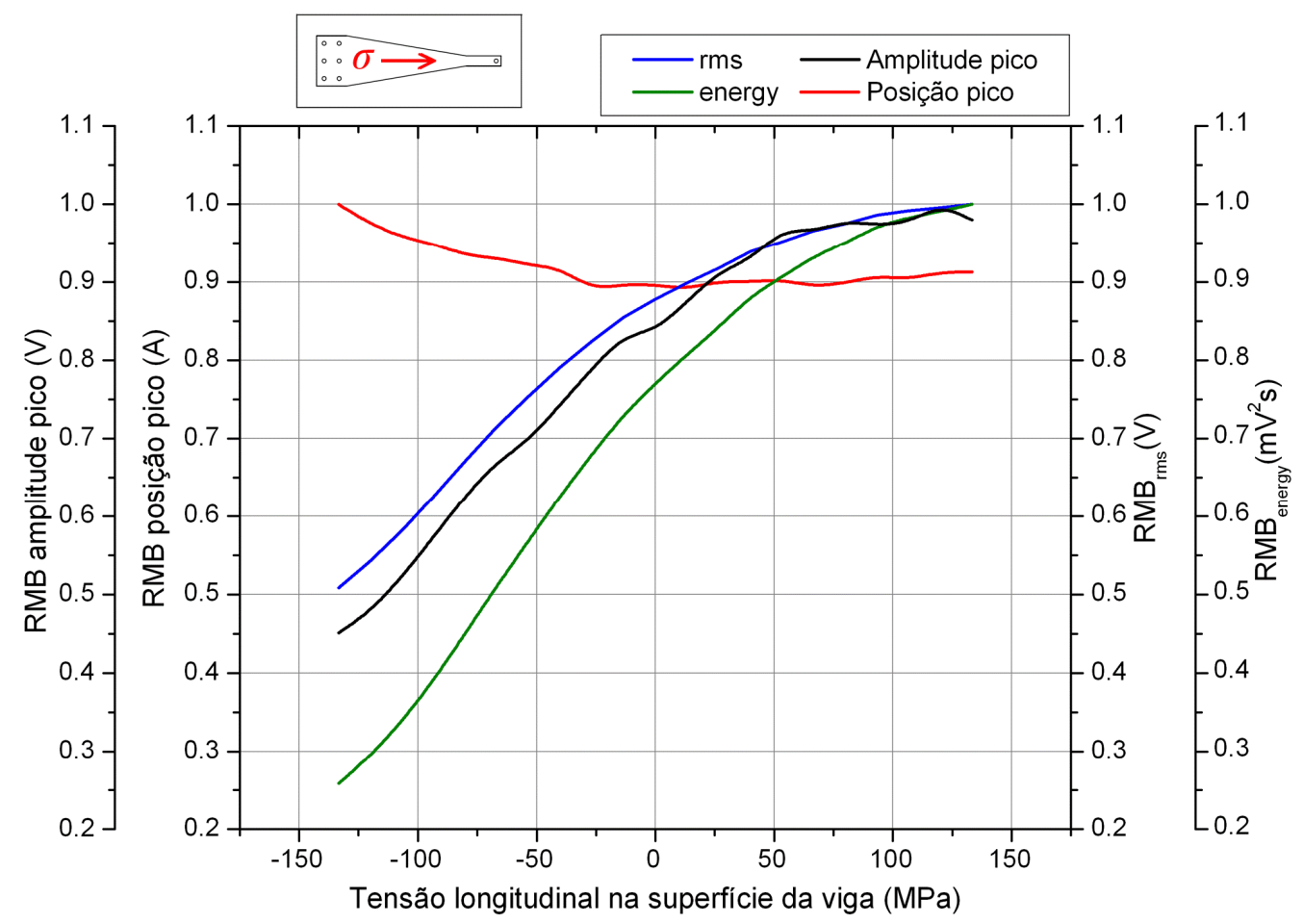

Figura 3.18 - Dependencia entre os diferentes parâmetros normalizados do RMB (Posição pico, Amplitude pico, $\mathrm{RMB}_{\text {rms }}$ e $\mathrm{RMB}_{\text {energy }}$ ) e os valores de tensão aplicada.

Para comparar a sensibilidade na medição de tensão de cada um dos parâmetros calculados, foi feita uma normalização de cada um deles em relação a seus valores máximos. A Figura 3.18 mostra de forma conjunta o comportamento dos 4 parâmetros normalizados. É observado que o parâmetro $\mathrm{RMB}_{\text {energy }}$ apresenta a melhor resposta, maior sensibilidade e correlação com os valores de tensão aplicada. A maior parte da literatura encontrada utiliza este parâmetro na análise dos 
resultados. No entanto, o parâmetro $\mathrm{RMB}_{\mathrm{rms}}$ apresenta resultados relativamente bons. Por outro lado os parâmetros calculados a partir dos gráficos de envelope (Amplitude pico e Posição pico) tiverem menor sensibilidade e, sobretudo menor linearidade dos valores em relação às tensões aplicadas.

\subsubsection{Análise de diferentes bandas temporais do sinal de RMB}

Não foram encontrados estudos relacionando a análise de diferentes bandas temporais do sinal de RMB e sua dependência com a tensão mecânica aplicada. No entanto, na medição de tensões residuais, a sensibilidade do RMB gerado em três zonas (RP, BW1 e BW2) da curva de Histerese magnética do material, foi diferente. Ver Figura 3.19

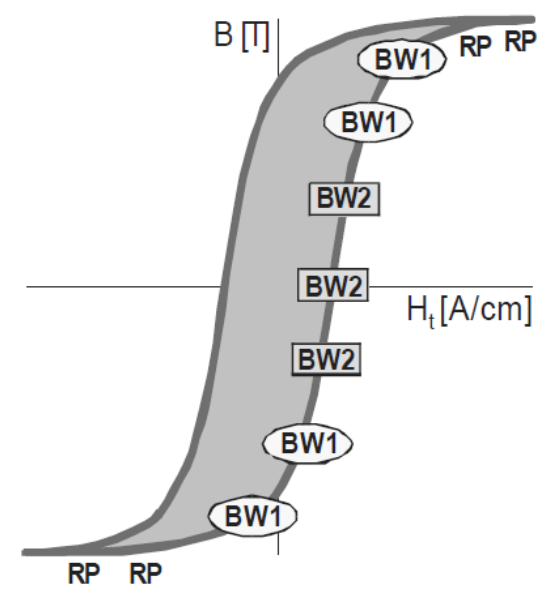

Figura 3.19 - Faixas da curva de histerese magnética, em dependência com sua interação com tensões residuais. (U. Hofmann et al., 2005).

As zonas de rotação de domínios (RP) e movimento de paredes de domínio de $90^{\circ}$ (BW1) são afetadas por Macro e Micro tensões residuais, enquanto que a zona de movimentação de paredes de $90^{\circ}$ e $180^{\circ}$ (BW2) resulta ser mais sensível a Microtesões (U. Hofmann et al., 2005).

No presente trabalho, análises do sinal de RMB foram realizadas com objetivo de verificar a sensibilidade de diferentes bandas temporais do sinal, na medição de tensão. Resultados dessa análises são apresentados a seguir. 
As medidas do RMB foram feitas na direção longitudinal à tensão aplicada na Amostra DL, e utilizando uma corrente senoidal de magnetização com 0.8A de amplitude e $10 \mathrm{~Hz}$. As tensões aplicadas são indicadas na Tabela 3.1.

No domínio do tempo, o sinal de RMB foi dividido em três partes, e agrupado em diferentes bandas, como mostrado na Figura 3.20. Esta divisão foi feita com o objetivo de separar em forma aproximada o movimento de paredes de $90^{\circ}$ (Primeira e Terceira parte do sinal) do movimento simultâneo de paredes de $90^{\circ}$ e $180^{\circ}$ que acontece na zona central dos sinais de RMB (Segunda parte do sinal). O parâmetro $\mathrm{RMB}_{\text {energy }}$ foi calculado em forma independente para cada uma das mencionadas bandas.

b)

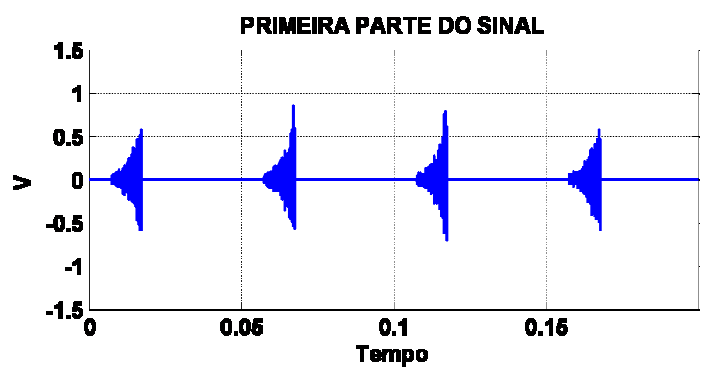

d)

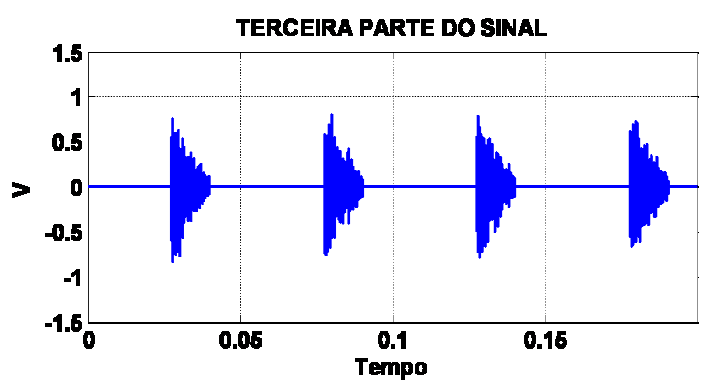

c)

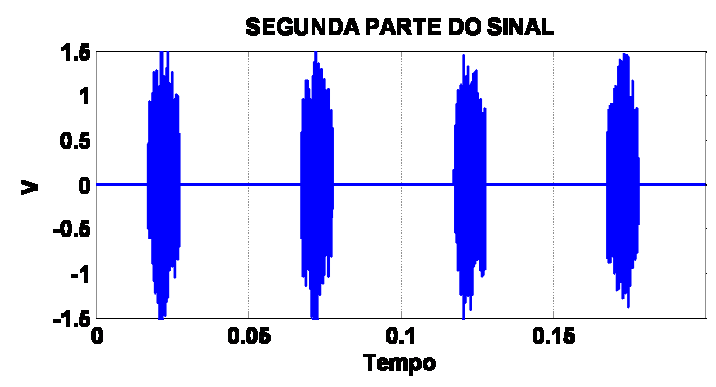

e)

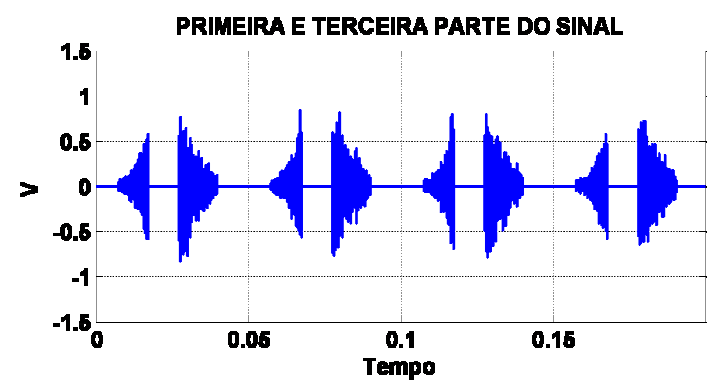

Figura 3.20 - Divisão do sinal de RMB em bandas temporais. 
A evolução do parâmetro $\mathrm{RMB}_{\text {energy }}$ de cada uma das bandas temporais do sinal é mostrada na Figura 3.21. Observa-se como as respostas da Primeira e Terceira partes do sinal, ou as duas em conjunto, não mostram melhores resultados em relação aos do sinal completo. No entanto, a resposta da Segunda parte apresenta um comportamento relativamente melhor. A dispersão dos dados, amplitude e sensibilidade são similares aos mostrados na análise do Sinal completo.

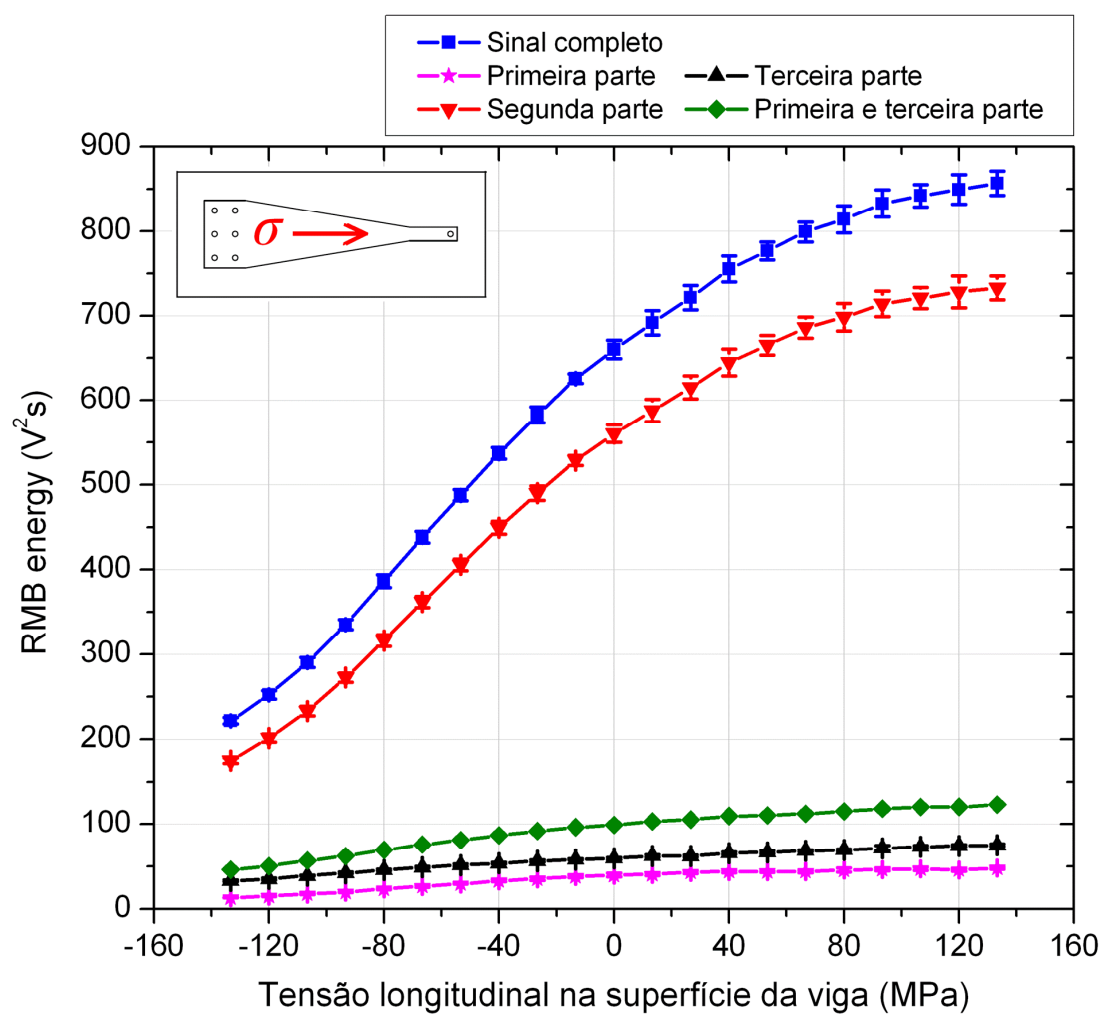

Figura 3.21 - Comportamento do parâmetro $\mathrm{RMB}_{\text {energy }}$ em relação a tensões de flexão aplicada. Analise de diferentes faixas temporais do sinal.

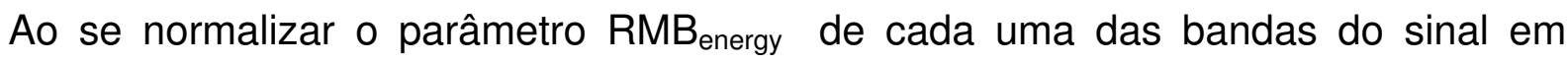
relação a seus valores máximos, se obtêm o gráfico mostrado na Figura 3.22. Nessa figura se observa com maior facilidade como a resposta do Sinal completo e Segunda parte é semelhante. É de ressaltar como o comportamento da Segunda parte do sinal (linha laranja), mostra uma sensibilidade à tensão levemente superior. Coeficientes de correlação $\mathrm{R}^{2}$ polinomial (grau 2) foram calculados para essas duas configurações. Com o Sinal completo foi obtido um coeficiente $R^{2}=0.9969$, e com a Segunda parte do sinal, $R^{2}=0.9963$. Comprova-se assim como a tensão aplicada tem um efeito importante no movimento de paredes de $180^{\circ}$. Ainda assim, as outras 
duas partes do sinal (em conjunto, linha verde), geradas principalmente pelo movimento de paredes de $90^{\circ}$, mostraram também, ter boa sensibilidade à tensão aplicada.

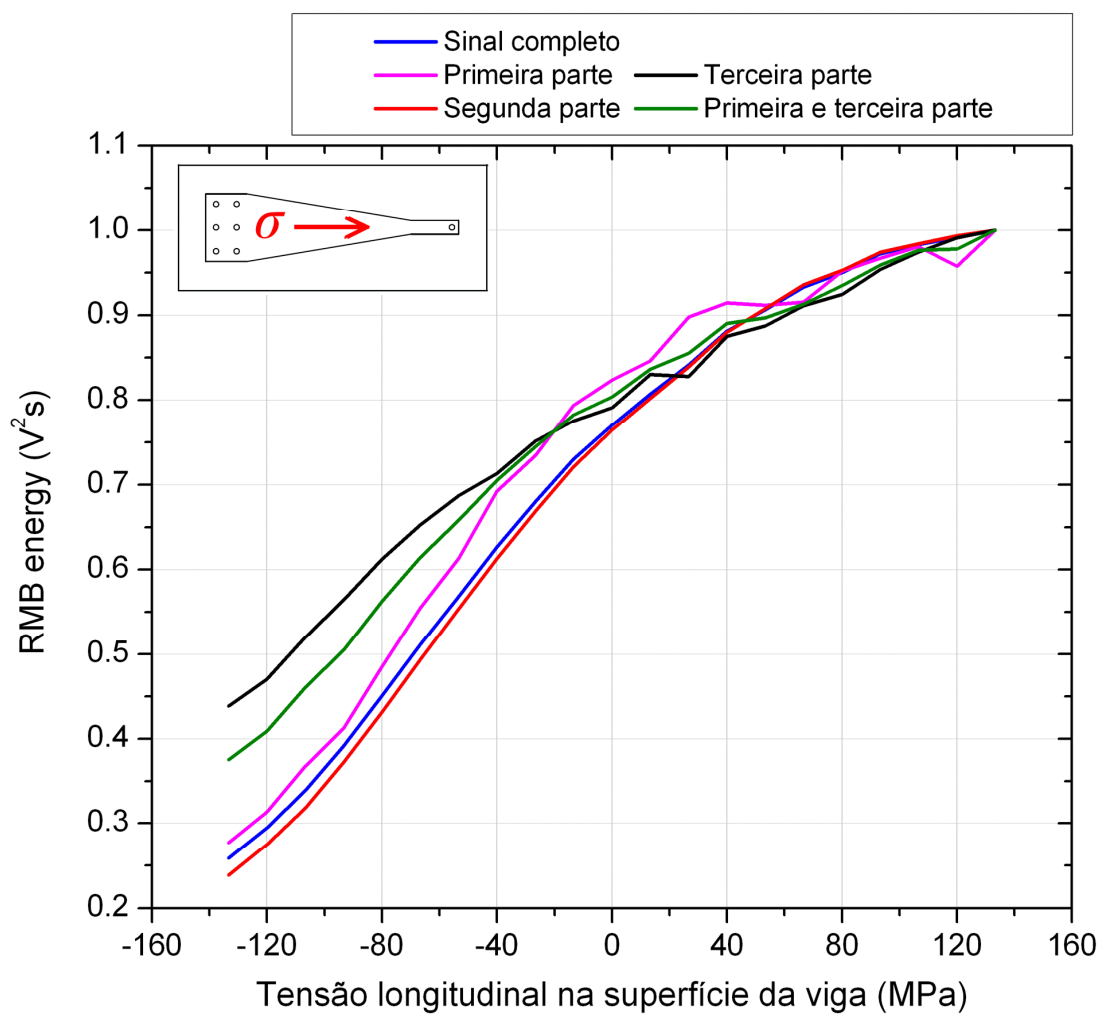

Figura 3.22 - Comportamento do parâmetro $\mathrm{RMB}_{\text {energy }}$ normalizado em relação a tensões de flexão aplicada. Analise de diferentes bandas temporais do sinal.

\subsubsection{Análise de diferentes faixas de amplitude do sinal de RMB}

Análises do comportamento de diferentes faixas de amplitude do sinal de RMB foram feitos com o objetivo de determinar o efeito da tensão na direção do eixo de fácil magnetização em aço ASTM-36 (J. CAPÓ -SÁNCHEZ, 2007). Os sinais de RMB foram divididos em três categorias, dividindo a amplitude do sinal em partes iguais: Pulsos altos, médios e baixos. Nos resultados foi verificado que, tanto os pulsos altos como os pulsos baixos, não tinham informação importante da anisotropia. Já, os Pulsos médios mostraram uma alta sensibilidade na identificação do eixo de fácil magnetização. 
É analisada nesta secção a sensibilidade de diferentes faixas de amplitude do sinal de RMB na medição de tensão mecânica. As medidas de RMB foram feitas na amostra DL. Na sonda de medida de RMB foi aplicado uma corrente de excitação senoidal com, amplitude de $0.8 \mathrm{~A}$ e freqüência de $10 \mathrm{~Hz}$.

Os sinais foram divididos segundo a amplitude (voltagem, V) dos pulsos em 5 faixas diferentes, ver Figura 3.23:

- Sinal completa (SC):

$$
|\mathrm{Vmin}|<|\mathrm{V}|<|\mathrm{Vmax}| \text {. }
$$

- Pulsos altos (PA):

$|0.66 \mathrm{Vmax}|<|\mathrm{V}|<|\mathrm{Vmax}|$.

- Pulsos médios (PM):

$|0.33 \mathrm{Vmax}|<|\mathrm{V}|<|0.66 \mathrm{Vmax}|$.

- Pulsos baixos (PB):

$|\mathrm{Vmin}|<|\mathrm{V}|<|0.33 \mathrm{Vmax}|$.

- Pulsos médios e baixos (PMB): $|\mathrm{Vmin}|<|\mathrm{V}|<|0.66 \mathrm{Vmax}|$.

b)

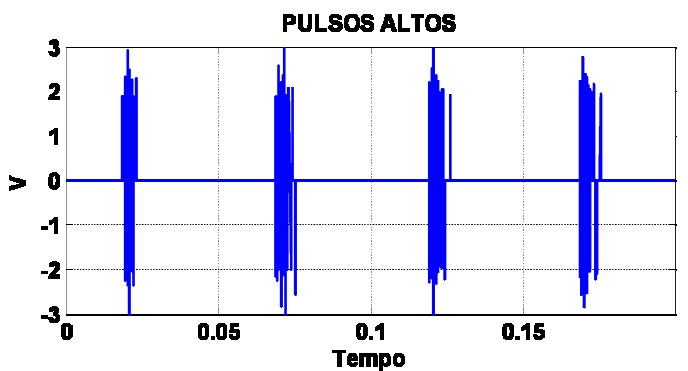

d)

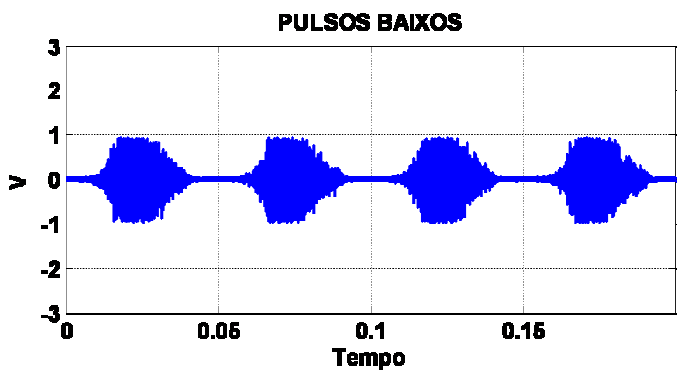

c)

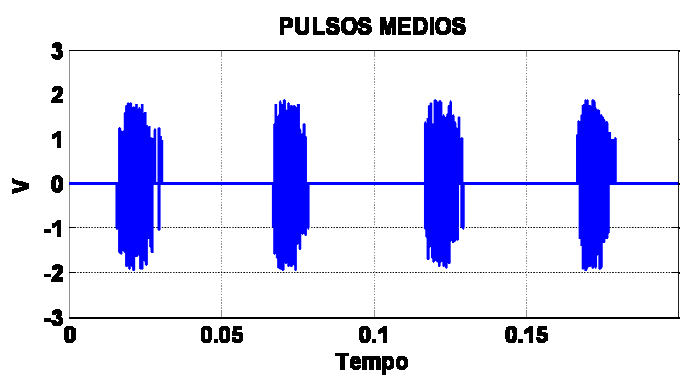

e)

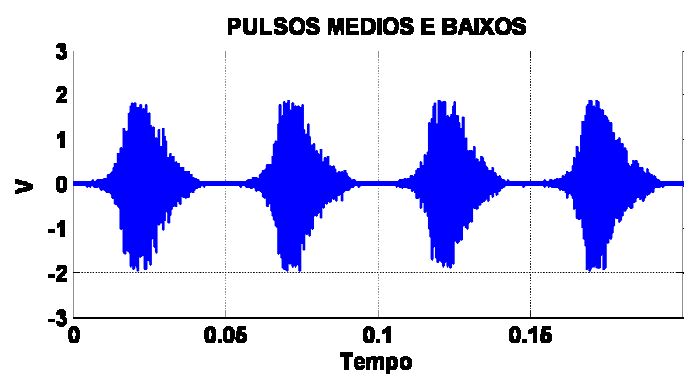

Figura 3.23 - Divisão do sinal de RMB em bandas de amplitude. 
A Figura 3.24 mostra a evolução do parâmetro $\mathrm{RMB}_{\text {energy }}$ de cada uma das faixas de amplitude do sinal, em relação a tensão aplicada. Todas as faixas analisadas apresentaram sensibilidade na medição de tensão. O perfil que tem o melhor comportamento é o mostrado pela análise da faixa do SC (linha azul). Apresentando maior continuidade na evolução dos valores médios, e menor relação dispersão/amplitude do parâmetro calculado, em comparação às outras faixas.

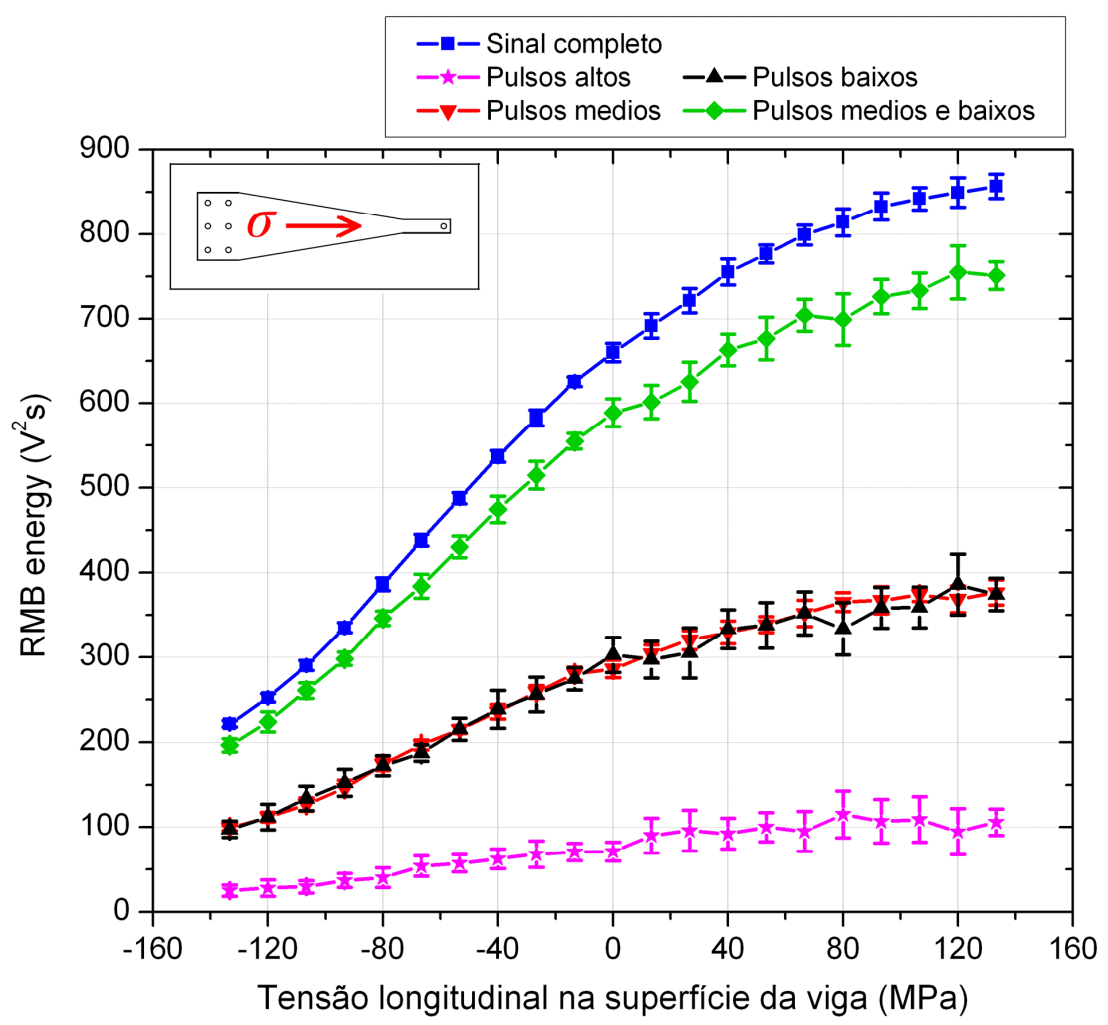

Figura 3.24 - Comportamento do parâmetro $\mathrm{RMB}_{\text {energy }}$ em relação a tensões de flexão aplicada. Analise de diferentes bandas temporais do sinal.

A Figura 3.25 mostra o comportamento do parâmetro $\mathrm{RMB}_{\text {energy }}$ normalizado, de cada uma das faixas de amplitude analisadas. O nível de sensibilidade é similar nas faixas de SC, PM e PMB. Já a sensibilidade e continuidade mostrada pelas faixas de PA e PB é significativamente menor. Pulsos altos de voltagem gerados na bobina leitora são produzidos principalmente pela movimentação em cadeia de pequenos grupos de paredes de domínio magnético, chamadas de avalanches. Essas avalanches são principalmente produzidas quando a variação de fluxo magnético 
induzido no material passa por seu valor mais alto, perto da região do Hc na curva B-H. A reorientação de domínios acontece em forma coletiva, e o processo de movimentação de paredes é relativamente instável. Nestas condições, a dinâmica da movimentação de paredes de domínios magnéticos, e por defeito o RMB, resulta ser menos sensível as características do material. Isso explica porque a análise da faixa de PA apresentou baixa correlação na medição de tensão.

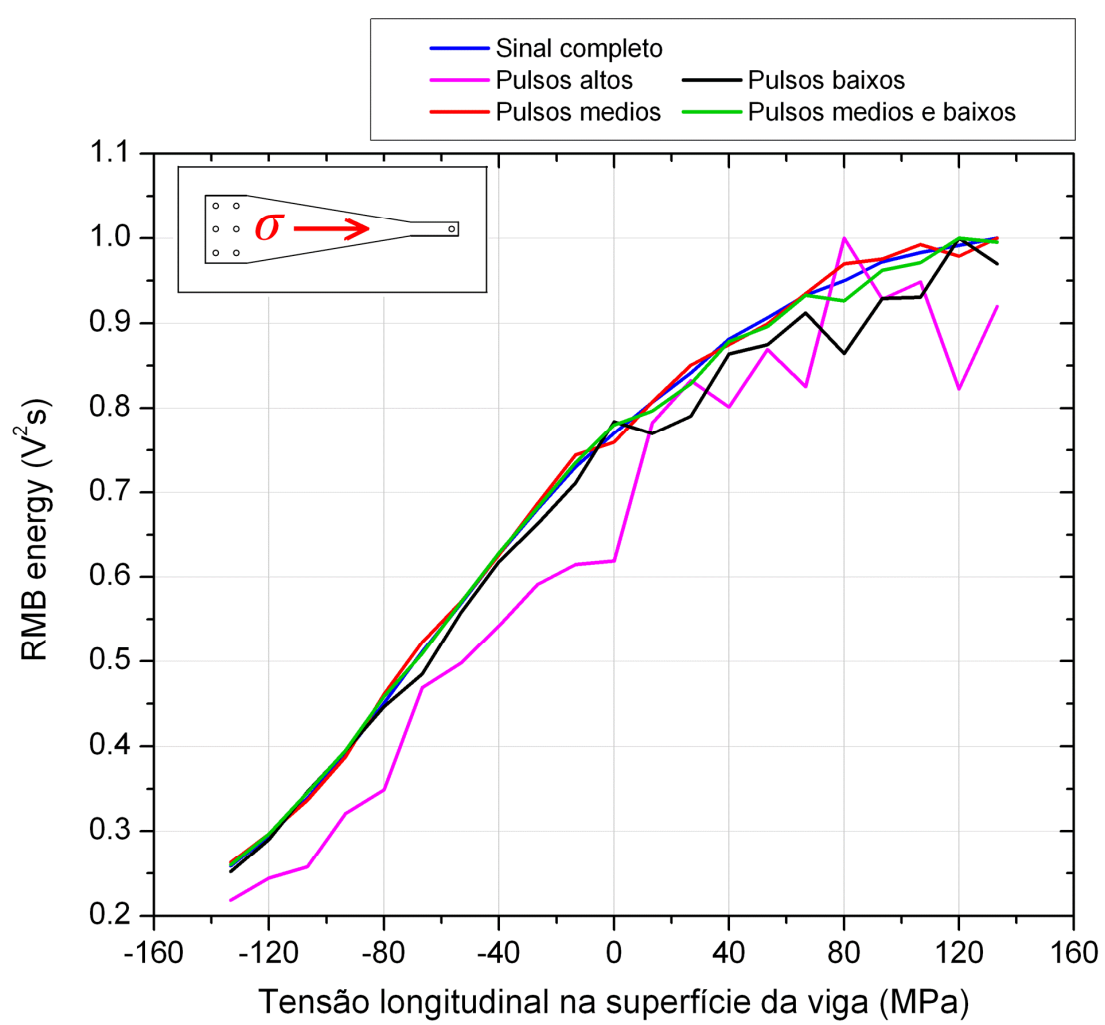

Figura 3.25 - Comportamento do parâmetro $\mathrm{RMB}_{\text {energy }}$ normalizado em relação a tensões de flexão aplicada. Analise de diferentes bandas de amplitude do sinal.

A resposta dada pela faixa de PMB (linha verde), que não leva em conta os pulsos altos do sinal (pulsos instáveis gerados principalmente por avalanches), não foi superior a resposta de SC (linha azul). O comportamento da faixa de PMB apresentou instabilidades na resposta, sobretudo na faixa positiva das tensões aplicadas. Aparentemente, os problemas apresentados no comportamento de cada uma das faixas analisadas (PA, PM, PB e PMB) em relação às medidas de tensão, são auto-corrigidos quando analisado o sinal completo. Não foi possível encontrar uma explicação para este fenômeno. A utilização de outros tipos de análise do sinal poderia acrescentar alguma informação. 


\subsubsection{Influência da amplitude do campo magnético aplicado}

Medições de RMB foram feitas na direção longitudinal da amostra DL. O campo de magnetização foi aplicado em forma senoidal, com 6 diferentes amplitudes de corrente, e uma freqüência de $10 \mathrm{~Hz}$. A Tabela 3.2 (repetida abaixo) mostra as correntes aplicadas, e os correspondentes valores de campo de magnetização medidos.

Tabela 3.2 repetida- Correntes de excitação aplicadas

\begin{tabular}{cc}
\hline Corrente (A) & Campo (A/m) \\
\hline 0,57 & 38208 \\
\hline 1,22 & 90744 \\
\hline 1,90 & 144872 \\
\hline 2,57 & 168752 \\
\hline 3,32 & 197408 \\
\hline 4,25 & 226064 \\
\hline
\end{tabular}

A Figura 3.26 mostra a variação do parâmetro $\mathrm{RMB}_{\text {energy }}$ em relação a corrente aplicada, quando geradas na superfície da amostra tensões de -133,33, 0 e 133,33MPa. É observado que para cada uma das tensões aplicadas, o parâmetro $\mathrm{RMB}_{\text {energy }}$ aumenta até certos valores de corrente, e depois diminui. Aumentar a corrente de excitação, mantendo a freqüência constante, resulta num aumento na variação do fluxo magnético induzido no material. Essa condição aumenta a taxa de movimento de paredes de domínio, a quantidade de pulsos gerada é maior e,

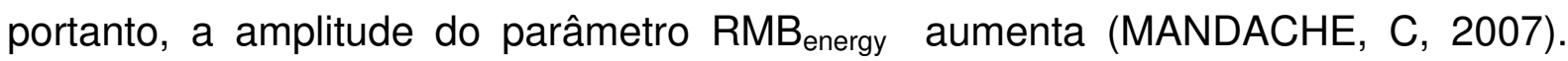
Ainda assim o aumento de pulsos de RMB lidos pela bobina leitora saturou para diferentes valores de corrente em dependência da tensão aplicada. 1,9A para uma tensão de 133,33MPa, 2,57A para 0MPa, e 3,32A para -133,33MPa. Acredita-se que os valores de corrente onde são alcançados os valores máximos do $\mathrm{RMB}_{\text {energy }}$ ficam próximos dos que produzem a saturação do material. O material em estado de compressão é magneticamente duro, e precisa da aplicação de campos relativamente altos para atingir a saturação. O contrário acontece com o material submetido a tensões de tração. Aumentar o nível de corrente acima daquele que 
produz a saturação magnética do material, faz que aumente o efeito de superposição de pulsos de RMB no sistema de medida, o que pode produzir uma redução da sensibilidade da técnica.

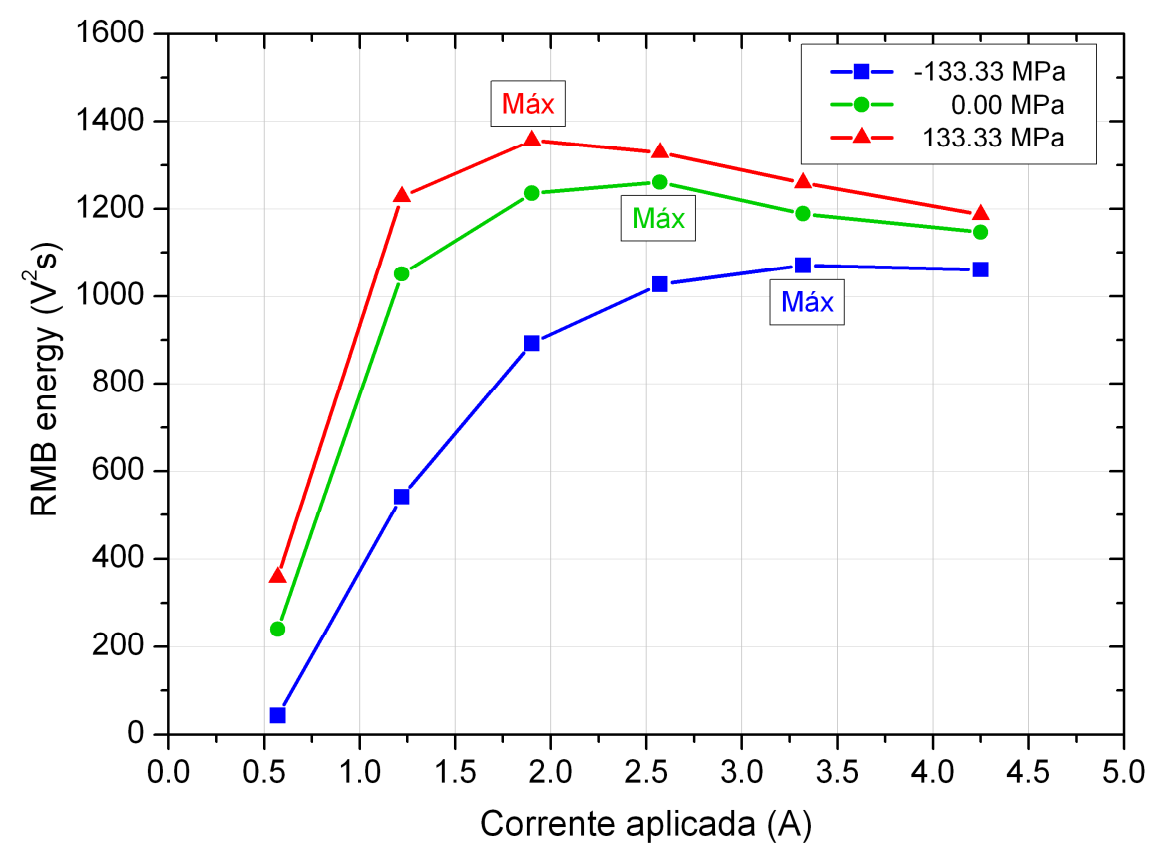

Figura 3.26 - Variação do parâmetro $\mathrm{RMB}_{\text {energy }}$ em relação a corrente aplicada, para três valores de tensão.

A resposta do parâmetro $\mathrm{RMB}_{\text {energy }}$ e $\mathrm{RMB}_{\text {energy }}$ normalizado, para diferentes valores de corrente aplicada é mostrada na Figura 3.27 e Figura 3.28 respectivamente. Observa-se na Figura 3.27, que na medida em que aumenta a corrente de excitação, os desvios das medidas aumentam, e a correlação dos valores médios com a tensão aplicada, diminui. Comportamento que confirma o dito no parágrafo anterior. $\mathrm{O}$ aumento da corrente incrementa a dinâmica das paredes de domínio, o RMB gerado em cada ciclo de magnetização acontece em um intervalo de tempo menor, e conseqüentemente o comportamento do sinal medido é mais aleatório. 


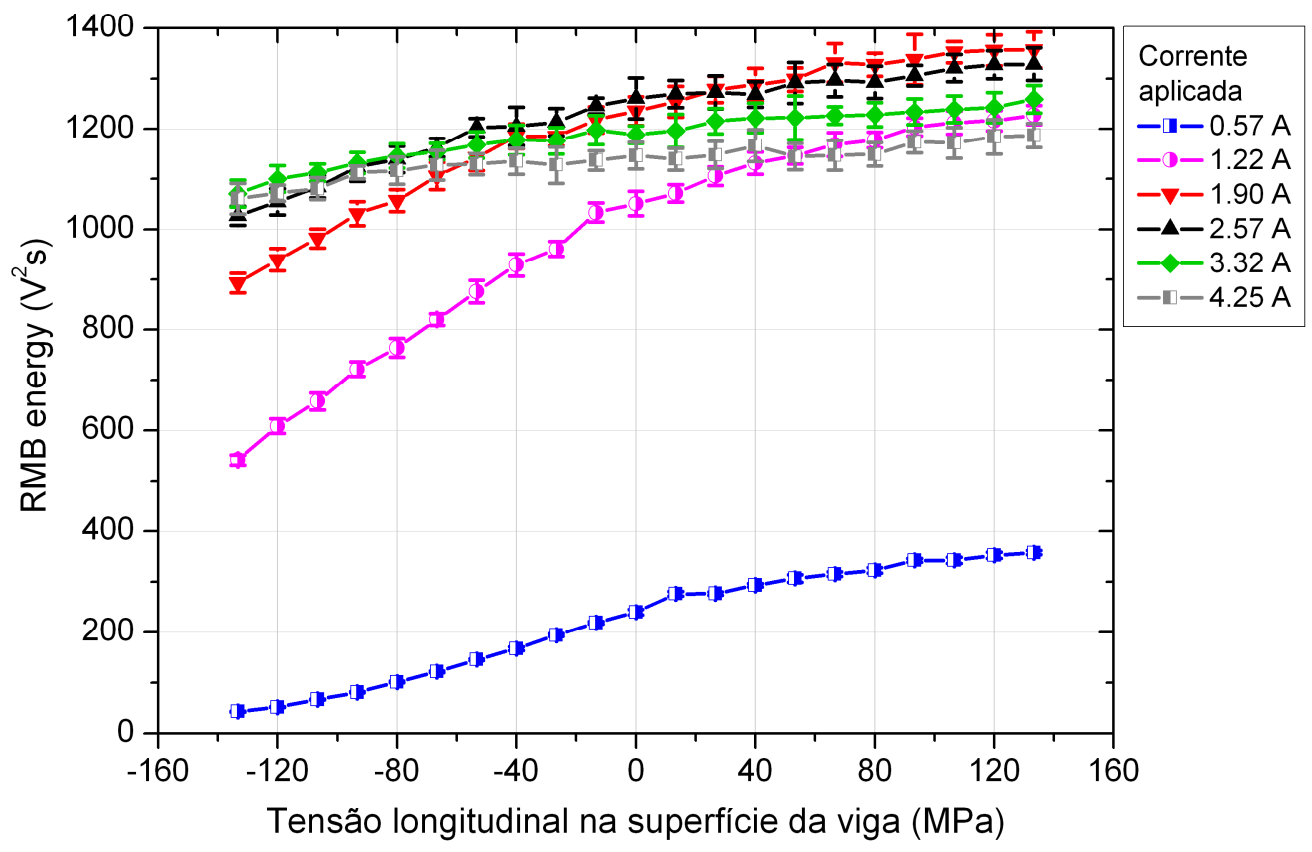

Figura 3.27 - Resposta do parâmetro $\mathrm{RMB}_{\text {energy }}$ em relação a tensão, para diferentes valores de corrente de magnetização aplicada.

Na Figura 3.28 claramente é observado como o nível de sensibilidade do sinal de RMB na medição de tensão, diminui com o aumento da corrente de excitação. A melhor condição de medida, para o caso estudado, foi obtida aplicando a corrente mais baixa. Com baixos níveis de campo aplicado, a movimentação de paredes de domínio é mais ordenada, e sua interação com as alterações microestruturais do material é maior. Além disso, nessa condição, as alterações na permeabilidade magnética produzidas pelas tensões aplicadas, geram maiores mudanças no comportamento do RMB. Esta combinação de efeitos aumenta a sensibilidade do RMB na medição de tensão.

É importante ressaltar, que a determinação da amplitude do campo magnético que maximiza a resposta do RMB na medição de tensão, deve ser determinada de forma específica para cada aplicação, e dependerá das características magnéticas do material. 


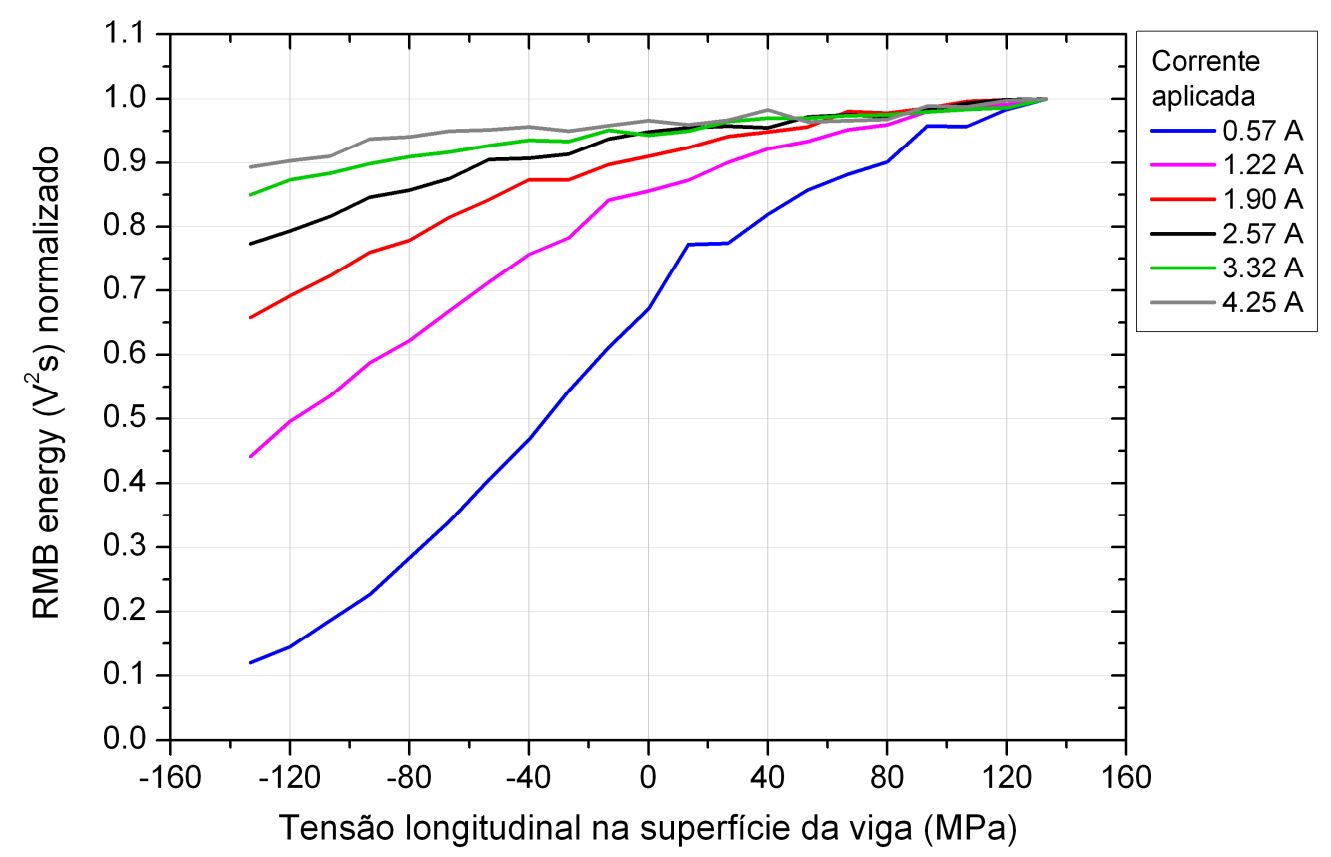

Figura 3.28 - Resposta do parâmetro $\mathrm{RMB}_{\text {energy }}$ normalizado em relação a tensão, para diferentes valores de corrente de magnetização aplicada.

\subsubsection{Influência da freqüência de magnetização aplicada}

Analogamente aos itens anteriores, as medidas de RMB foram feitas na amostra DL aplicando o campo na direção de tensão. $O$ campo de magnetização foi aplicado com uma corrente de amplitude fixa $(0,8 \mathrm{~A})$, e 6 freqüências diferentes: 0,7, 2, 6, 15, 30 e 60 HZ. Os níveis de tensão são indicados na Tabela 3.1.

Na Figura 3.29 é mostrado o comportamento do parâmetro $\mathrm{RMB}_{\text {energy }}$ na medição de tensão, para as 6 freqüências de magnetização utilizadas. Nessa figura os seguintes aspectos podem ser observados:

- Aumento da amplitude do sinal com o aumento da freqüência de magnetização. Com o aumento da freqüência de magnetização o número de saltos das paredes de domínio por unidade de tempo aumenta (HALLER TR, 1970; HIGUCHI T, 1974). Portanto a amplitude do sinal e conseqüentemente do parâmetro $\mathrm{RMB}_{\text {energy }}$ aumenta. 
- O desvio padrão do parâmetro $\mathrm{RMB}_{\text {energy }}$ sobe com o aumento da freqüência de magnetização. Com maiores variações de fluxo magnético no material, as avalanchas de movimento de paredes são cada vez mais freqüentes, e a superposição de pulsos no sistema de medida é aumentada. Como conseqüência, os sinais de RMB começam a serem mais instáveis, o que é refletido na dispersão dos dados. Ainda assim, em todos os casos, 0 parâmetro $\mathrm{RMB}_{\text {enrgy }}$ acompanhou de forma aceitável os valores de tensão produzidos na amostra.

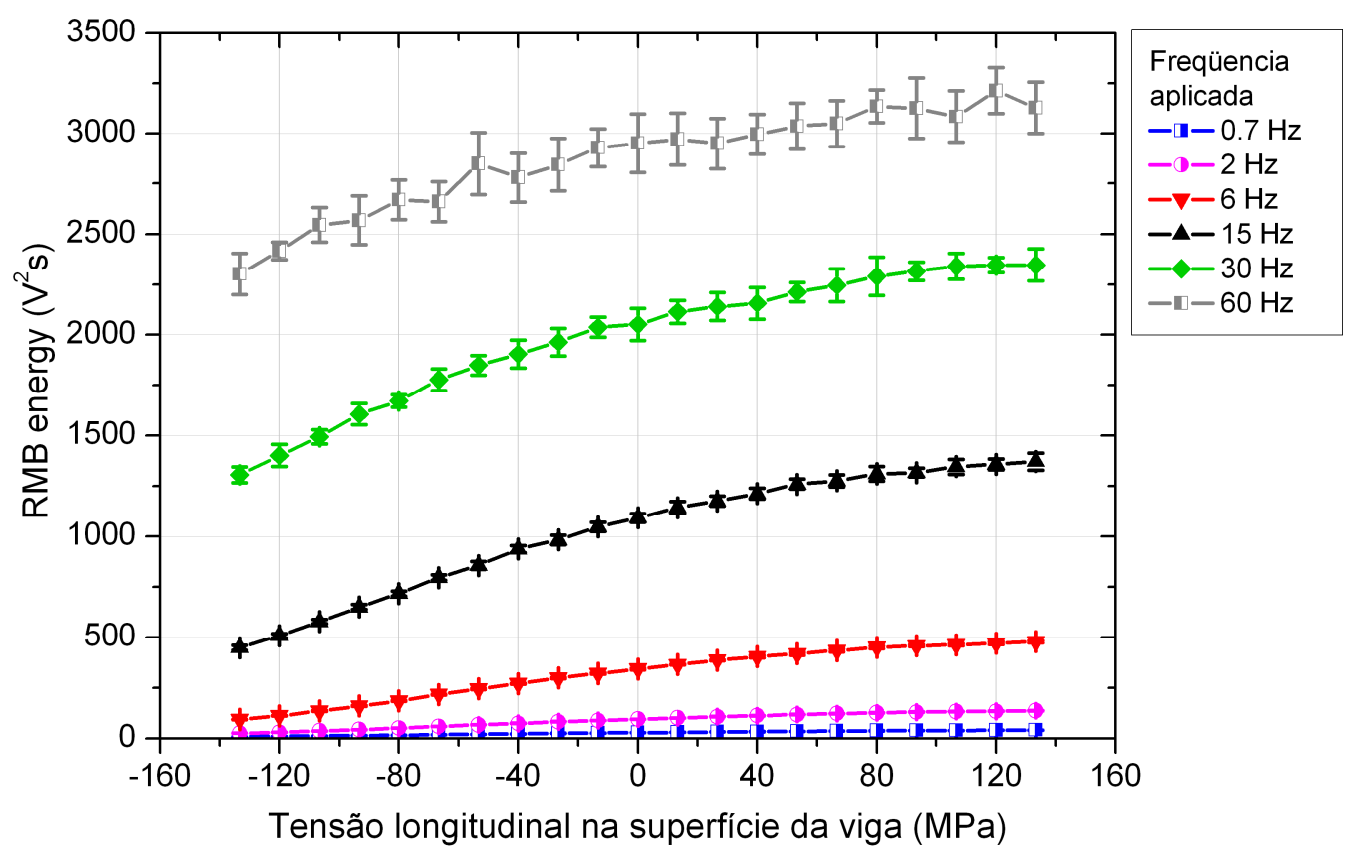

Figura 3.29 - Resposta do parâmetro $\mathrm{RMB}_{\text {energy }}$ em relação a tensão, para diferentes freqüências de magnetização aplicada.

A Figura 3.30 mostra os resultados da Figura 3.29 de forma normalizada. É observado nessa figura que a sensibilidade do sinal de RMB é máxima, quando aplicadas freqüências de excitação baixas. Especificamente no caso estudado, freqüências de até $6 \mathrm{~Hz}$ apresentaram os mesmos níveis de sensibilidade. Como foi explicado anteriormente, a aplicação de altas freqüências diminuem a interação das paredes de domínio com o estado microestrural do material, os pulsos são gerados em forma de clusters (superposição de pulsos), avalanchas são mais freqüentes e a aleatoriedade do sinal aumenta. Como conseqüência a correspondência entre o $\mathrm{RMB}$ e os valores de tensão diminuem. 


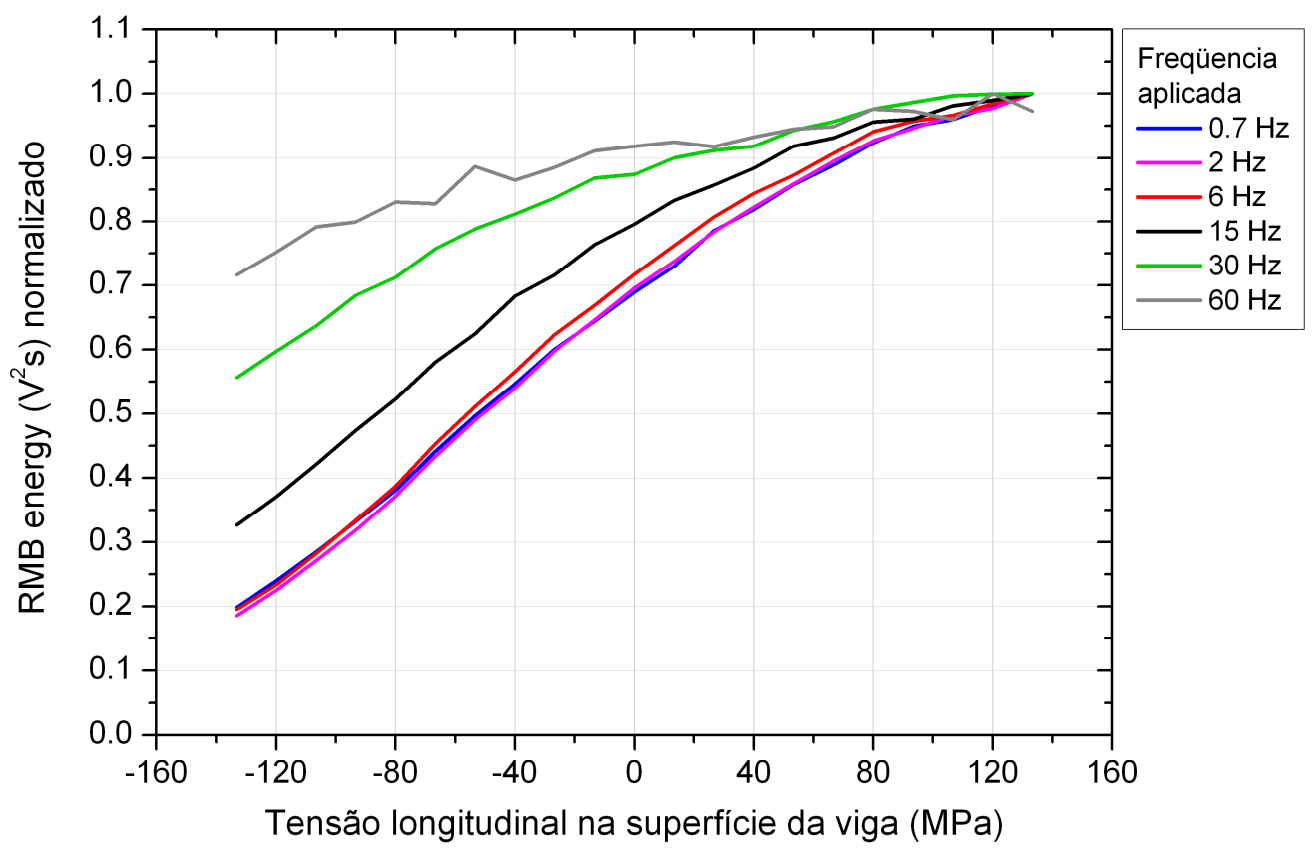

Figura 3.30 - Resposta do parâmetro $\mathrm{RMB}_{\text {energy }}$ normalizado em relação a tensão, para diferentes freqüências de magnetização aplicada.

\subsubsection{Influência da direção de laminação}

Utilizado uma análise microestructural foi verificada a direção de laminação da chapa de aço SAE-1070 utilizada, e da qual foram cortadas as amostras DL e DT. A Figura 3.31 e Figura 3.32 mostram micrografias feitas em faces transversais da chapa, com aumentos de 1500X e 3500X, respectivamente.

Na Figura 3.31 e Figura 3.32 é observado que a microestrutura do aço é formada por colônias de perlita e pequenas ilhas de ferrita cor escura. Nas micrografias obtidas na Face A, se observa alguns precipitados alinhados no sentido longitudinal de laminação, e que acompanham os contornos de algumas colônias de perlita. Alinhamento que foi direcionado pelos antigos contornos de grãos alongados que recristalizaram durante a laminação. Por outro lado, na Face $B$, não foi identificado nenhum alinhamento nos precipitados, ficando distribuídos em forma aleatória, e sem orientação preferencial. 


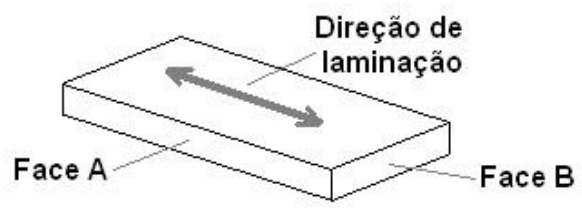

a)
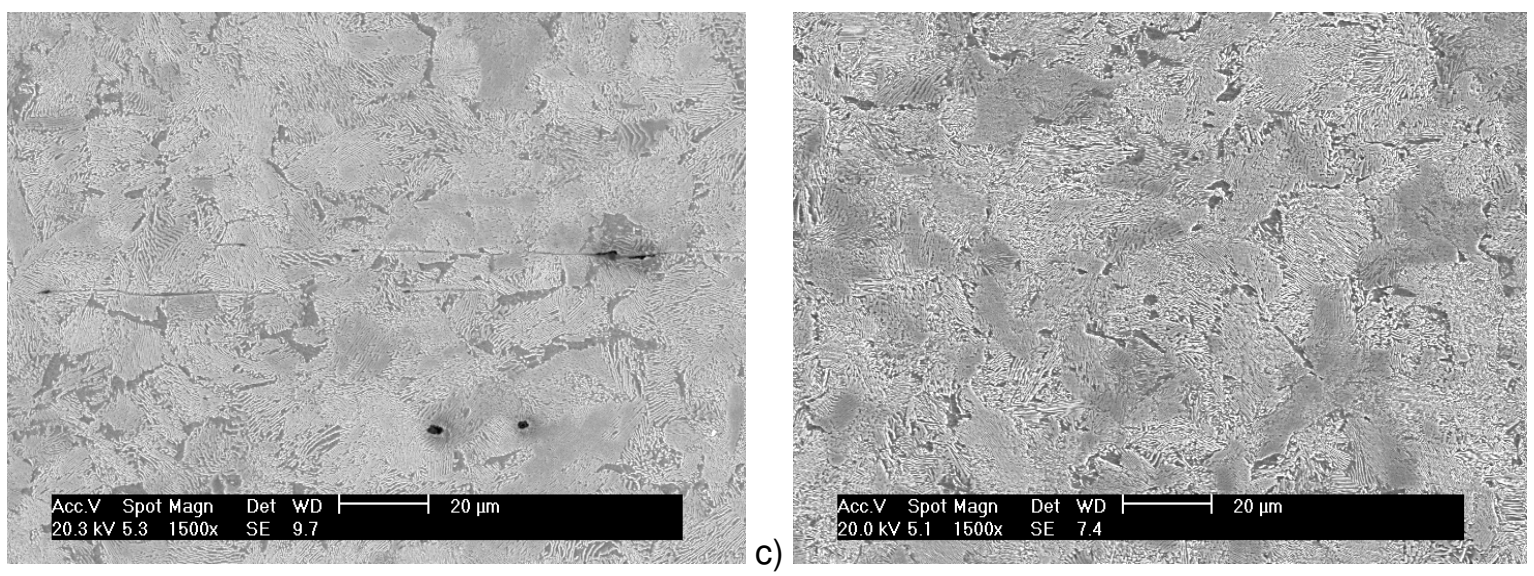

Figura 3.31 - Microestructuras na chapa de aço SAE-1070, 1500X, a)face A, b) Face B.

a)

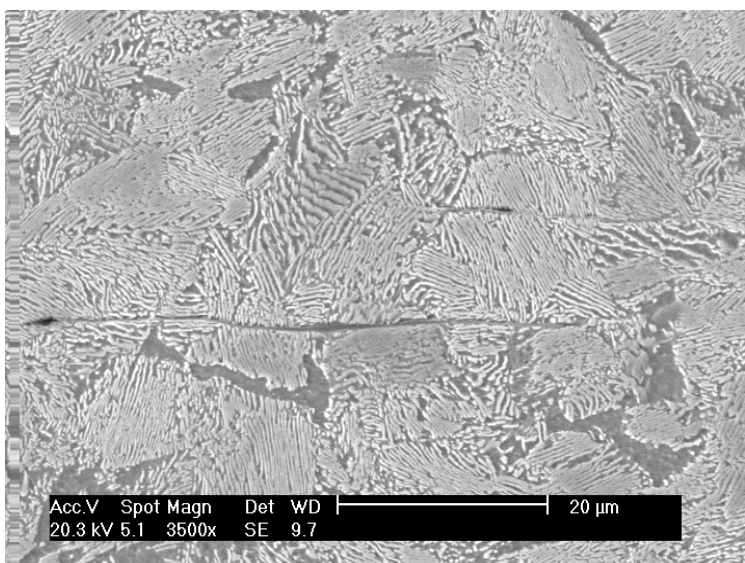

Figura 3.32 - Microestructuras na chapa de aço SAE-1070, 3500X, a)face A, b) Face B

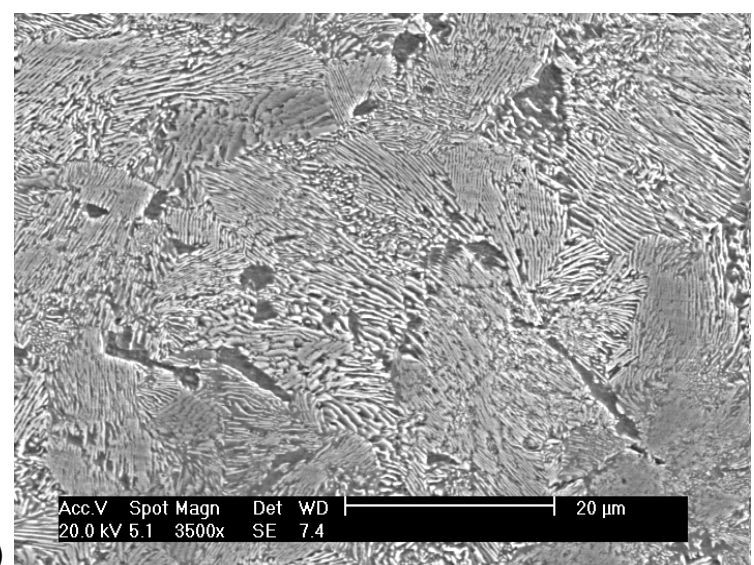

b) 
A Figura 3.33 e Figura 3.34 mostram os resultados das medidas de $R M B \|$ e $R M B \perp$ na medição de tensão, para a amostra DL e DT respectivamente. Os seguintes aspectos são observados:

- Nas duas amostras, a amplitude do parâmetro $\mathrm{RMB}_{\text {energy }}$ calculado das medidas de RMB\|, aumenta com a tensão aplicada, enquanto o $\mathrm{RMB}_{\text {energy }}$ das medidas de $\mathrm{RMB} \perp$ diminuem. $O$ efeito das tensões aplicadas no material é principalmente refletido na dinâmica do movimento de paredes de domínio de $180^{\circ}$. Tensões elásticas de tração alinham paredes de domínio de $180^{\circ}$ na direção da tensão em decorrência de uma diminuição de paredes de $180^{\circ}$ alinhadas na direção transversal. Por outro lado tensões elásticas de compressão alinham as paredes de $180^{\circ}$ na direção transversal e as diminuem na direção longitudinal da tensão (CAPO-SANCHEZ, 2007a; BENITEZ-BENITEZ, 2007; ANGLADA-RIVERA, 2001; JILES D.C, 1989) . Portanto, assim que as tensões passam de valores negativos para positivos, a quantidade de paredes de domínio de $180^{\circ}$ alinhadas na direção longitudinal aumentam (RMB $\|$ aumenta), em quanto as alinhadas na direção transversal diminuem $(\mathrm{RMB} \perp$ diminui).

- Na amostra DL, a distribuição das medidas de RMB\| encontra-se num nível maior em relação às medidas de $\mathrm{RMB} \perp$. Caso contrario acontece na amostra DT. Em chapas laminadas, e devido ao processo de fabricação (tensões residuais e microestruturas geradas), encontra-se um número maior de domínios magnéticos alinhados na direção de laminação (eixo de fácil magnetização). Portanto as anisotropias mecânica e magnética coincidem em sua direção. Desta forma a quantidade de paredes de domínio de $180^{\circ}$ alinhados inicialmente na direção longitudinal da amostra é maior, na amostra $\mathrm{DL}$ (medidas de $\mathrm{RMB} \|$ são maiores em relação ao $\mathrm{RMB} \perp$ ) do que na amostra TD (medidas de RMB\| são menores em relação ao $R M B \perp$ ). 


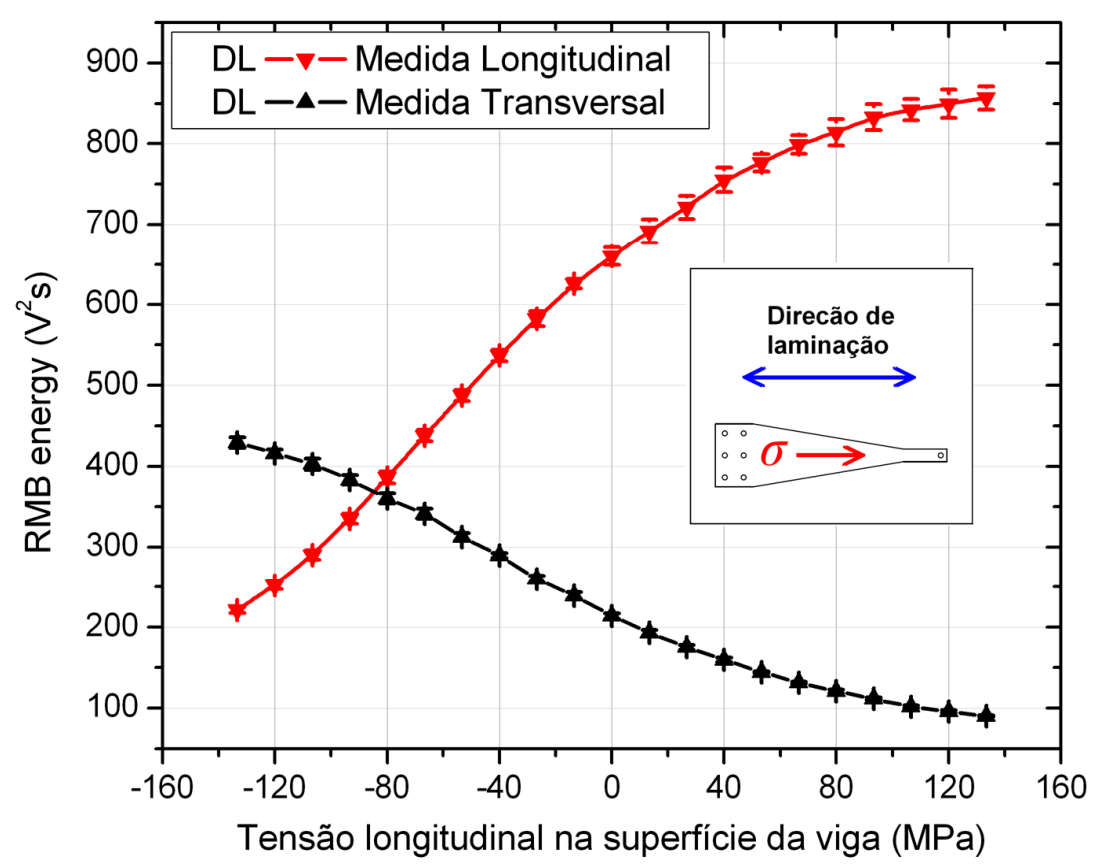

Figura 3.33 - Variação do parâmetro $\mathrm{RMB}_{\text {enrgy }}$ em relação a tensões de flexão aplicadas na amostra DL. Medições de RMB na direção longitudinal e transversal a tensão.

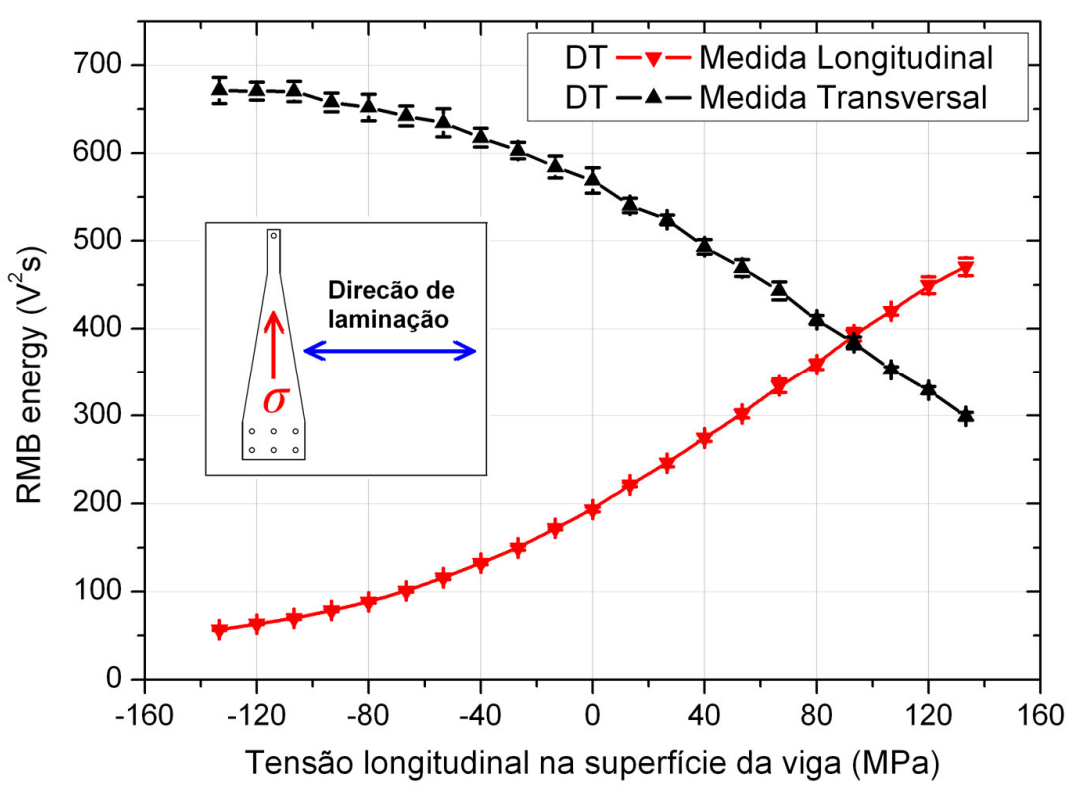

Figura 3.34 - Variação do parâmetro $\mathrm{RMB}_{\text {energy }}$ em relação a tensões de flexão aplicadas na amostra DT. Medições de RMB na direção longitudinal e transversal a tensão.

A Figura 3.36 mostra o comportamento do parâmetro $\mathrm{RMB}_{\text {energy }}$ normalizado mostrado na Figura 3.33 e Figura 3.34. O nível de sensibilidade de cada uma das 
condições de medida é facilmente conferível nessa Figura 3.36. Ao comparar o nível de sensibilidade das medidas de RMB \| (linhas vermelhas) das duas amostras (DL e DT), se observa que são mais sensíveis as medidas feitas na amostra DT que as medidas feitas na amostra DL. Comportamento inverso apresentam as medidas de $\mathrm{RMB} \perp$.

Uma aproximação do efeito das tensões aplicadas na estrutura de domínios é representada esquematicamente na Figura 3.35 para as duas amostras (DL e DT). A amostra DT (como foi dito anteriormente) apresenta maior quantidade de domínios de $180^{\circ}$ alinhados na sua direção transversal. Portanto, tensões de tração conseguem fazer girar uma grande quantidade de paredes de domínio de $180^{\circ}$ na

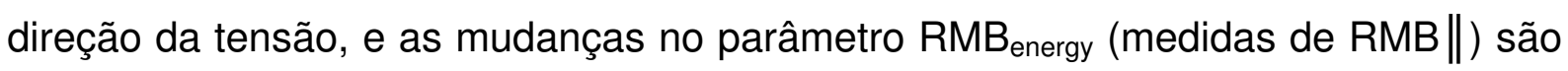
altas. Por outro lado na amostra DL, os domínios magnéticos apresentam uma orientação preferencial inicial, em sentido longitudinal da amostra, e as tensões aplicadas favorecem o alinhar mais domínios nessa direção, mas as mudanças são pequenas (sensibilidade menor das medidas de RMB\|). Efeitos similares acontecem nas medidas de $\mathrm{RMB} \perp$ nas duas amostras.

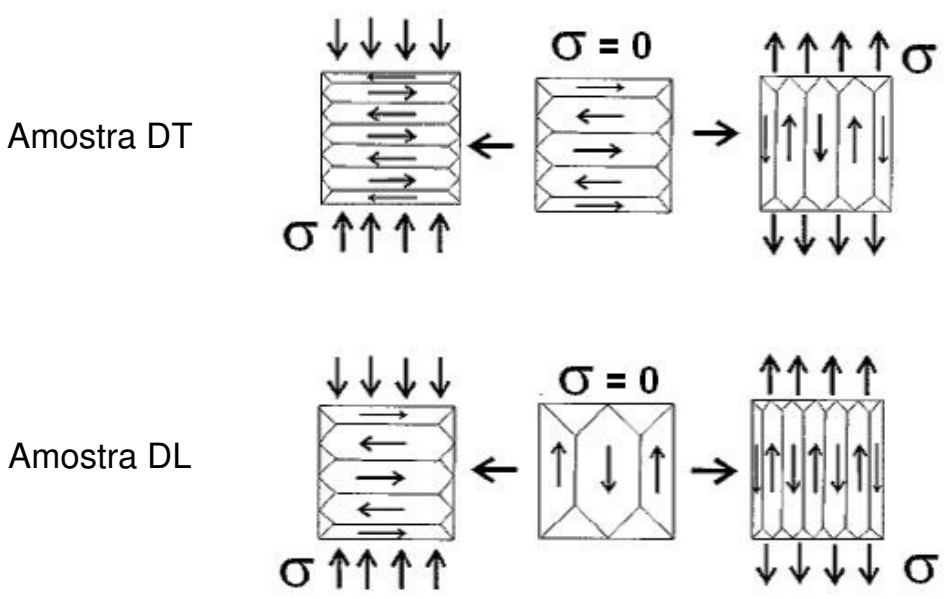

Figura 3.35 - Possível estrutura de domínios magnéticos nas amostras DL e DT, e o efeito da tensão. 


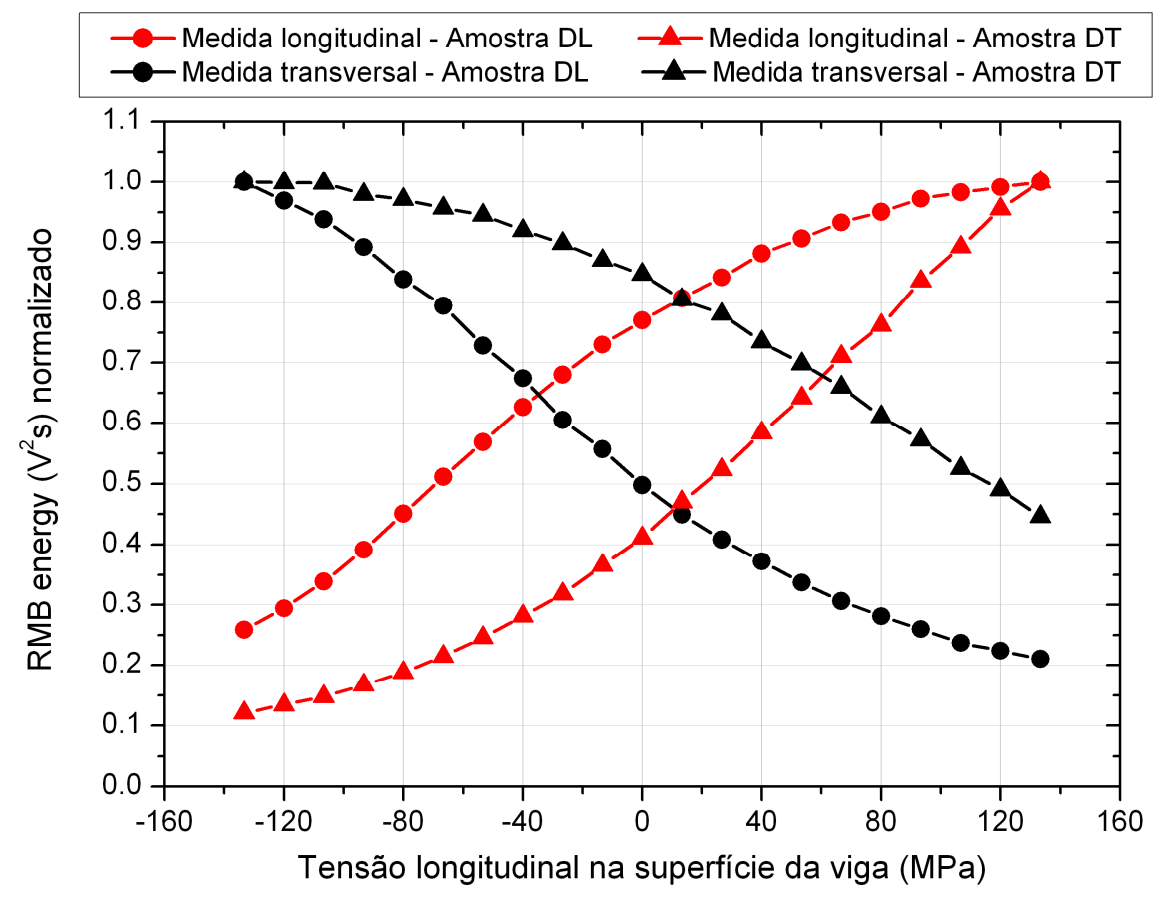

Figura 3.36 - Variação do parâmetro $\mathrm{RMB}_{\text {enrgy }}$ normalizado em relação a tensões de flexão aplicadas nas amostras DT e DL. Medições de RMB na direção longitudinal e transversal a tensão.

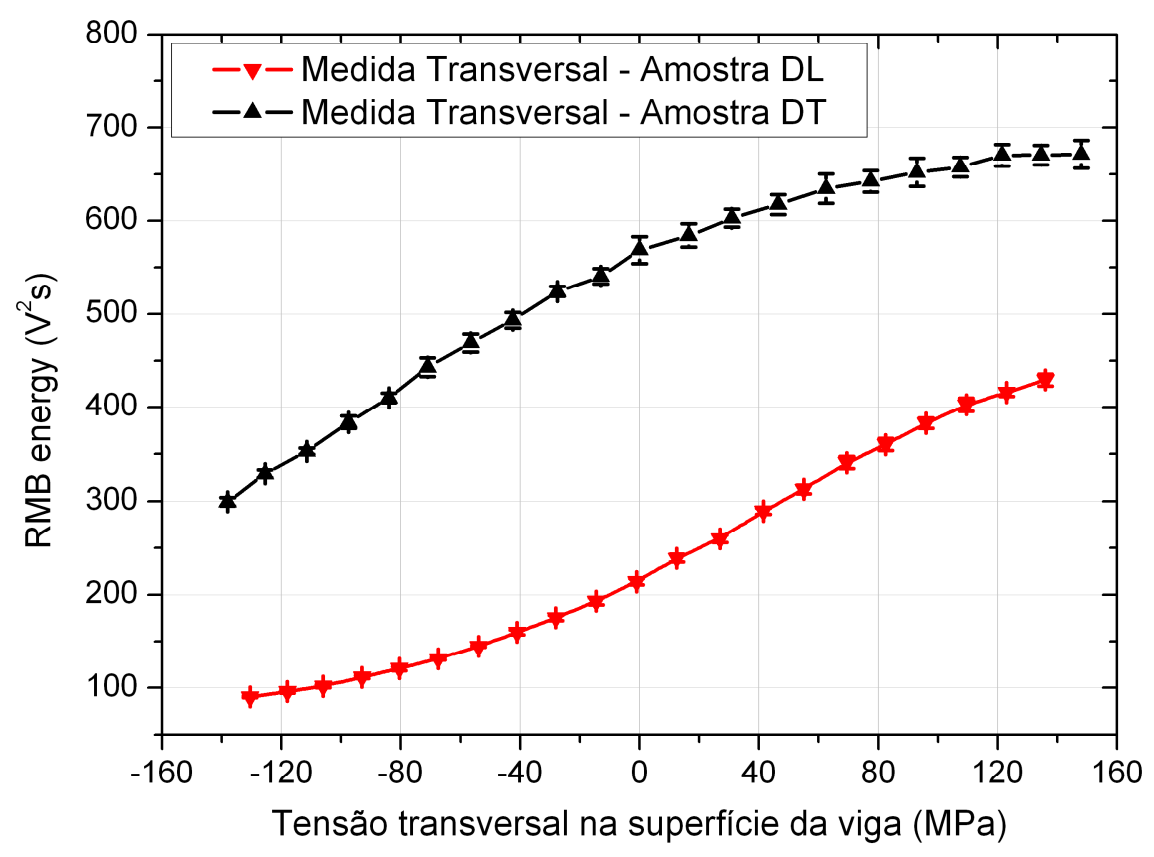

Figura 3.37 - Variação do parâmetro RMB $\mathrm{R}_{\text {nrgy }}$ em relação a tensões transversais produzidas por flexão, nas amostras DT e DL. Medições de RMB na direção transversal das amostras. 
Correlação entre as medições de $\mathrm{RMB}^{\perp}$ nas duas amostras, e os valores de tensão transversal medido, são mostradas na Figura 3.37. É observado como a variação do parâmetro $\mathrm{RMB}_{\text {energy }}$ das medidas de $\mathrm{RMB} \perp$ nas duas amostras acompanha de forma apropriada as amplitudes das tensões transversais produzidas.

A interação entre tensões aplicadas, e a dinâmica das paredes de domínio (principalmente de $180^{\circ}$ ) é sempre a mesma, e independe do ângulo em que seja aplicada a tensão em relação à direção de laminação.

\subsection{CONCLUSÕES}

- A correspondência entre diferentes parâmetros de análise do sinal de RMB e os valores de tensão aplicada, foi analisada. Assim que os valores de tensão passam de compressão para tração, a quantidade de domínios magnéticos alinhados na direção longitudinal da amostra aumenta. Portanto, os parâmetros, Amplitude pico, $\mathrm{RMB}_{\mathrm{rms}}$ e $\mathrm{RMB}_{\text {energy }}$ aumentam, enquanto a "Posição pico" diminui. Os parâmetros calculados a partir dos gráficos de envelope, Posição pico e Amplitude pico, apresentaram maiores desvios e menores correlações na medição de tensão, que os parâmetros $R B_{\text {rms }}$ e $\mathrm{RMB}_{\text {energy. }}$ Na medição de tensões elásticas via RMB, o parâmetro que mostra o melhor comportamento é o $\mathrm{RMB}_{\text {energy. }}$

- A resposta de diferentes faixas temporais e de amplitude do sinal de RMB, na medição de tensão, também foi examinada. Nenhum dos casos analisados apresentou vantagens em relação à análise do sinal completo.

- Diferentes amplitudes de correntes e freqüências de excitação foram aplicadas na sonda de RMB. Encontrou-se que a resposta do sinal de RMB melhora, quando utilizados valores baixos nesses parâmetros de medida.

- A influência da direção de laminação das amostras na medição de tensão via RMB, também foi avaliada. Nas duas amostras estudadas (Uma cortada na 
direção longitudinal de laminação e outra cortada na direção transversal), a amplitude do parâmetro $\mathrm{RMB}_{\text {energy }}$ calculado a partir medidas de RMB longitudinais $(\mathrm{RMB} \|)$, aumenta com a tensão aplicada, enquanto o $\mathrm{RMB}_{\text {energy }}$ de medições de $\mathrm{RMB}$ transversais $\left(\mathrm{RMB}^{\perp}\right)$, diminui. Para o material estudo (SAE-1070) o comportamento sempre é o mesmo, e independe do ângulo em que seja aplicada a tensão em relação à direção de laminação. 


\section{UTILIZAÇÃO DO RMB NA AVALIAÇÃO DE DUREZA EM AÇOS}

Diferentes estudos têm correlacionado resultados de medições de dureza com medições de RMB. Geralmente são obtidas boas correlações lineares (ver item 2.3). Porém, as diferentes microestruturas estudadas são geradas em amostras diferentes, o que gera certa homogeneidade no material de cada corpo de prova. Não se tem conhecimento da existência de algum tipo de Ensaio Não Destrutivo (END), que consiga avaliar gradientes microestuturais gerados numa única peça. Com o objetivo de contribuir no desenvolvimento de END para avaliação de dureza dos aços, neste capítulo é apresentada a avaliação do perfil microestrutural produzidos em amostras tipo Jominy em aço SAE 4140 e SAE 6150. Parâmetros calculados dos sinais de RMB são correlacionados com análises microestruturais (metalografias) e medidas de dureza (HRC).

\subsection{MATERIAIS E MÉTODOS}

\subsubsection{Materiais}

Os materiais usados para realização dos ensaios foram o SAE-4140 e o SAE-6150. A sua composição química é apresentada na Tabela 4.1. De cada um dos materiais foram preparadas amostras cilíndricas (25 mm diâmetro, e 101,6 mm de comprimento) para ensaio Jominy de temperabilidade, segundo norma ASTM225 (ASTM, 1999), ver Figura 4.1. Os estudos realizados foram feitos na região longitudinal central das amostras. Considera-se que a variação microestrutural produzida no comprimento de uma amostra Jominy é mais homogênea nas regiões centrais da peça do que na superfície, já que na região central o índice de resfriamento apresenta menos variações. Portanto, depois de realizado o tratamento térmico segundo as especificações da norma ASTM225, as amostras foram cortadas em duas metades longitudinalmente. Os cortes foram feitos numa máquina de corte 
de disco abrasivo, em velocidade baixa e alto nível de refrigeração. Isto com objetivo de não acrescentar modificações importantes na microestrutura gerada pelo tratamento térmico realizado.
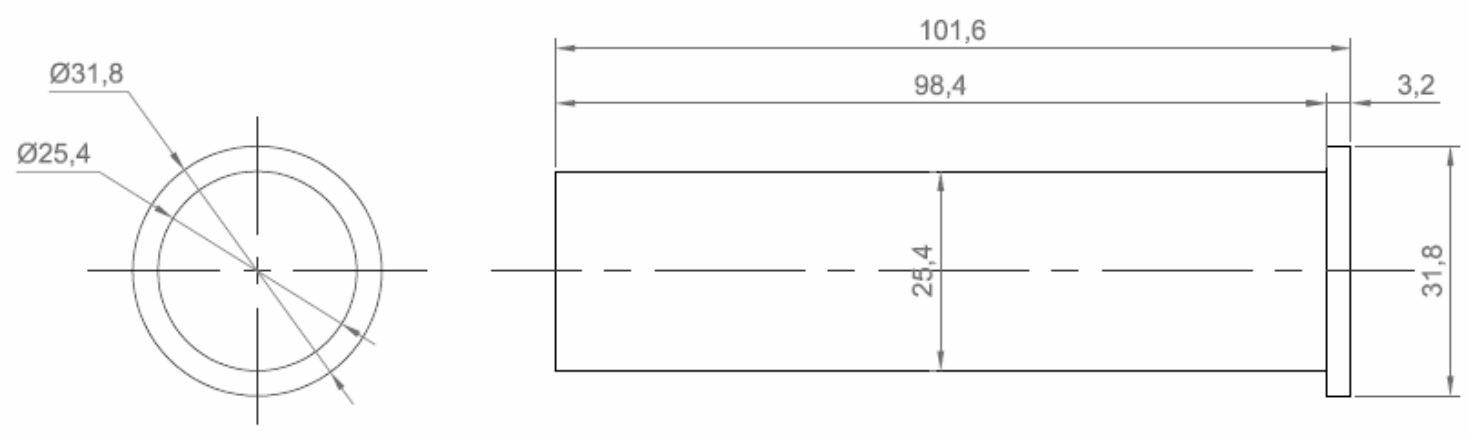

Figura 4.1 - Configuração geométrica das amostras Jominy.

Tabela 4.1 - Composição química das amostras utilizadas (\% em massa).

\begin{tabular}{ccccccccccccc}
\hline Steel & $\mathbf{C}$ & $\mathbf{M n}$ & $\mathbf{S i}$ & $\mathbf{P}$ & $\mathbf{S}$ & $\mathbf{C r}$ & $\mathbf{N i}$ & $\mathbf{M o}$ & $\mathbf{V}$ & $\mathbf{A l}$ & $\mathbf{C u}$ & $\mathbf{N}$ \\
\hline $\begin{array}{l}\text { SAE- } \\
4140\end{array}$ & 0.390 & 0.870 & 0.240 & 0.021 & 0.026 & 0.980 & 0.020 & 0.170 & - & 0.035 & 0.010 & 0.005 \\
\hline $\begin{array}{l}\text { SAE- } \\
6150\end{array}$ & 0.520 & 0.820 & 0.190 & 0.010 & 0.007 & 0.930 & 0.120 & 0.020 & 0.169 & - & - & - \\
\hline
\end{tabular}

\subsubsection{Técnicas de medição aplicadas}

\subsubsection{Ruído magnético de Barkhausen (RMB)}

Utilizando o equipamento "Barktech" foi aplicada na sonda de RMB uma corrente alternada senoidal com uma amplitude de 1,2 A e freqüências de 5,10 e $20 \mathrm{~Hz}$. As medidas de RMB foram feitas aplicando o campo magnético na direção transversal ao eixo das amostras. O sinal de saída do sensor foi amplificado e filtrado numa banda de amostragem de $1-200 \mathrm{kHz}$. 
Medidas de RMB foram feitas na região central da face plana das amostras, em pontos localizados a cada $1,58 \mathrm{~mm}(1 / 16 \mathrm{in})$ da superfície temperada. $O$ posicionamento da sonda foi controlado com uma mesa de movimentação XYZ (ver item 5.1). Cada medida é composta por os sinais de RMB gerados em dois ciclos completos de magnetização. Diferentes parâmetros dos sinais medidos foram

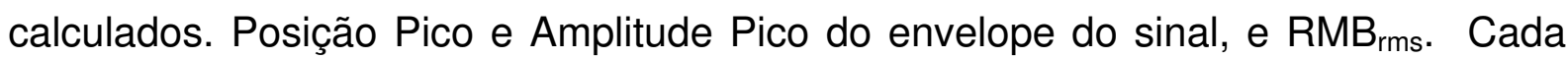
condição de medida foi repetida 10 vezes. A visualização e gravação dos sinais obtidos foram feitas com uma aplicação desenvolvida no programa Labview 8.0 (Figura 3.12).

\subsubsection{Dureza}

Foram feitas medições de dureza Rocwell C (HRC) usando o equipamento Otto Wolpert-Werke. Todas as medidas foram feitas aplicando uma carga de 150kgf. De maneira análoga que com as medições de RMB, foram feitas medidas de dureza a cada $1.58 \mathrm{~mm}$ da superfície temperada. Para cada nível de dureza (a cada $1.58 \mathrm{~mm}$ ) foram medidos três pontos separados um do outro $2.5 \mathrm{~mm}$. A Figura 4.2 ilustra esquematicamente a posição das endentações produzidas.

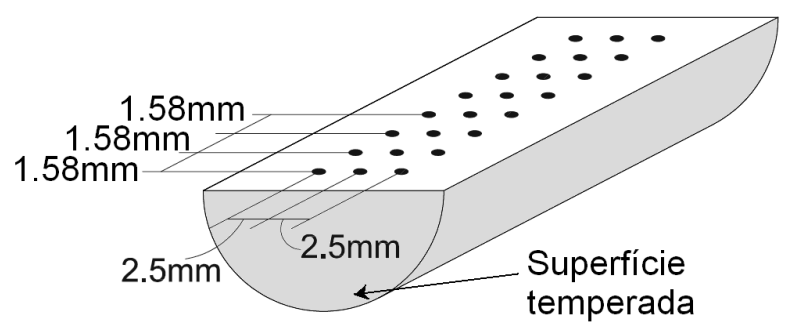

Figura 4.2 - Posição dos pontos de medida de dureza em cada uma das amostras. 


\subsubsection{Análises Microestrutural}

As análises microestruturais foram feitas em regiões na direção axial das faces planas geradas nas amostras, e localizadas a diferentes distâncias em relação à superfície temperada. Para metalografia, as amostras foram lixadas e polidas totalmente (Figura 4.2) até 1 micrômetro de pasta de diamante. O reagente utilizado para revelar a microestrutura foi Nital 3\%. As imagens foram obtidas com microscópio eletrônico de varredura (MEV) marca Philips LX30.

\subsection{RESULTADOS E DISCUSSÃO}

Fotografias dos resultados das análises microestructurais são amostradas na Figura 4.3 e Figura 4.4 .

A microestrutura no aço SAE-4140, a uma distância de $11,11 \mathrm{~mm}$ da superfície atingida pelo jato de água, está formada por áreas escuras de martensita (Figura 4.3 a) e áreas mais claras de bainita inferior (Bi) e bainita superior (Bs), predominando em maior porcentagem a bainita inferior. A Martensita (M) e o agregado eutetóide estão orientados no sentido axial do corpo de prova (Figura 4.3 b). Para uma distância de 19,05mm apresenta-se menor quantidade de martensita com aumento da quantidade de bainita (Figura 4.3 c); devido à menor taxa de resfriamento a transformação entra numa área de maior campo bainitico. Na medida em que a distância aumenta para 23,81mm a microestrutura é formada em sua maioria por bainita inferior e superior. A bainita superior caracteriza-se por ser grosseira comparada com a inferior (Figura 4.3 d). Para distâncias de 34,92mm (Figura 4.3 e) ainda se observa algumas transformações de martensita com presença de bainita e maior quantidade de estruturas grosseiras como bainita superior. 


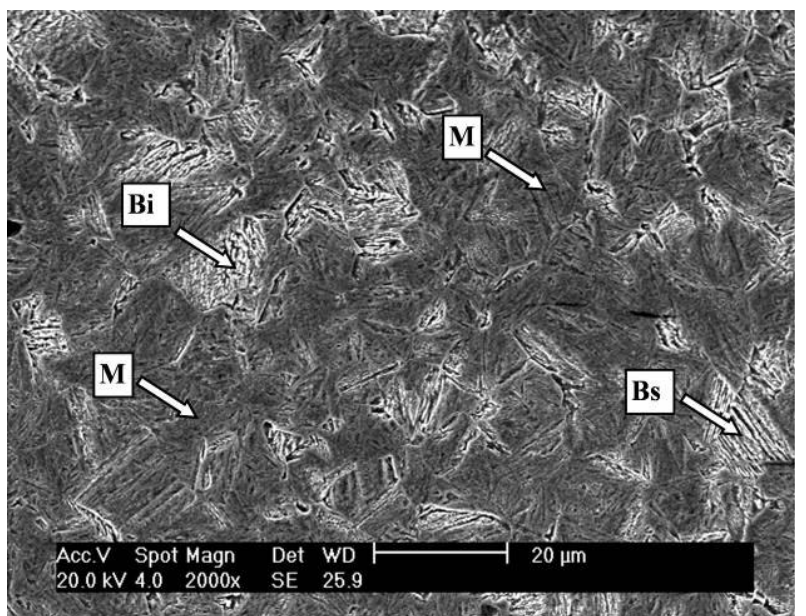

a)

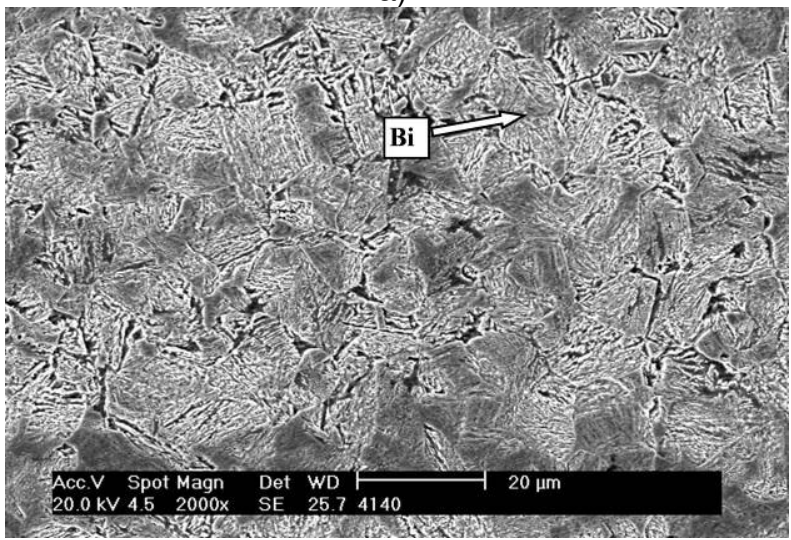

c)

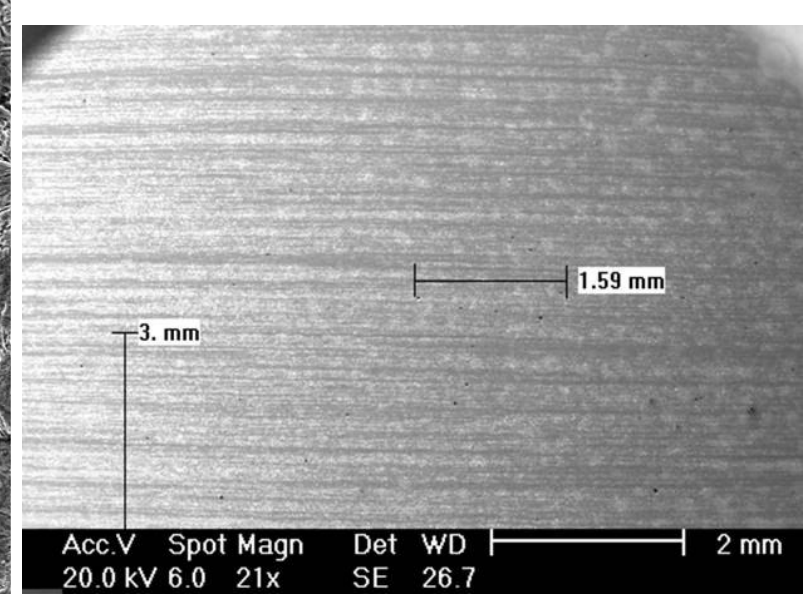

b)

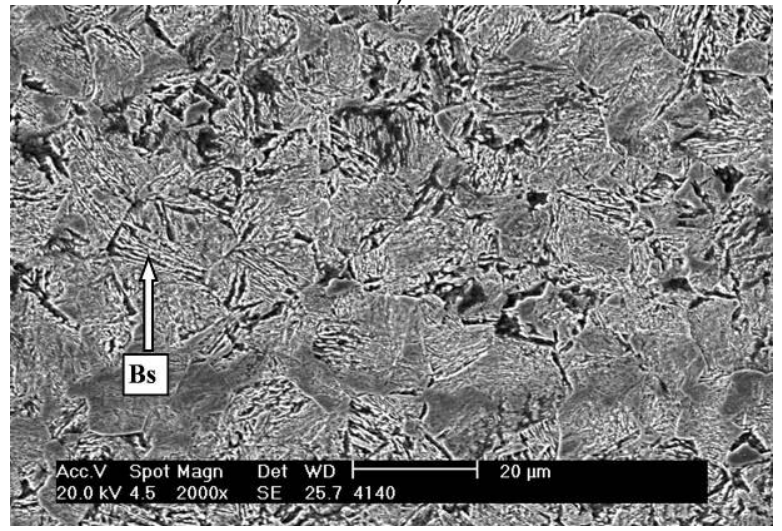

d)

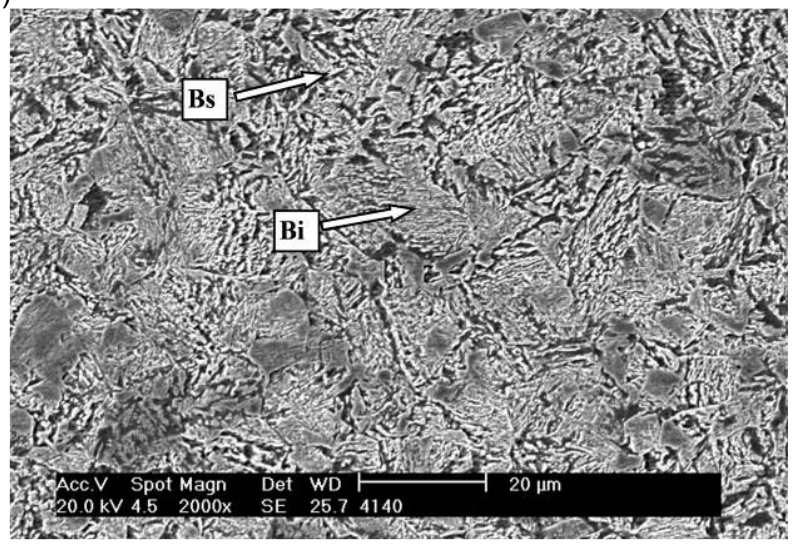

e)

Figura 4.3 - Micrografias da amostra Jominy de aço SAE-4140 obtidas em regiões localizadas a) $11.11 \mathrm{~mm}, 2000 \mathrm{X}$, b) $11.11 \mathrm{~mm}, 21 \mathrm{X}, \mathrm{c}) 19.05 \mathrm{~mm}, 2000 \mathrm{X}$, d) $23.81 \mathrm{~mm}, 2000 \mathrm{X}$ and e)34.92mm, 2000X, da superfície temperada. 


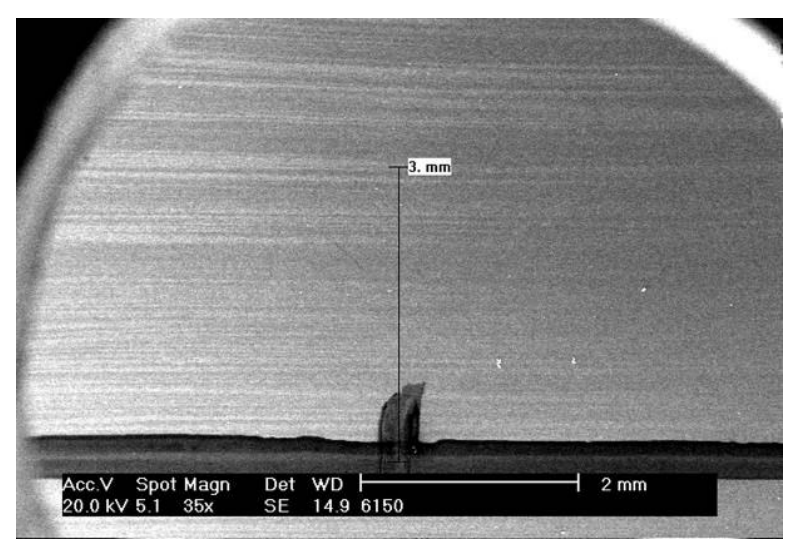

a)

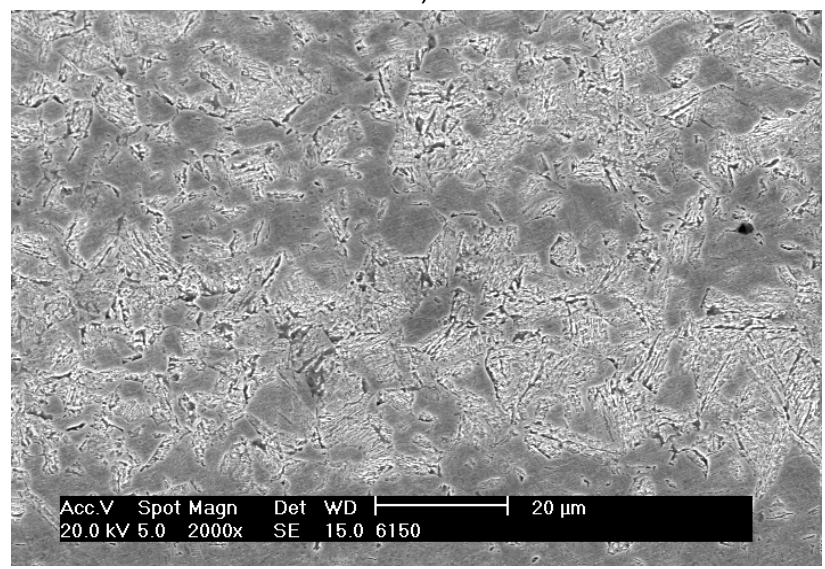

c)

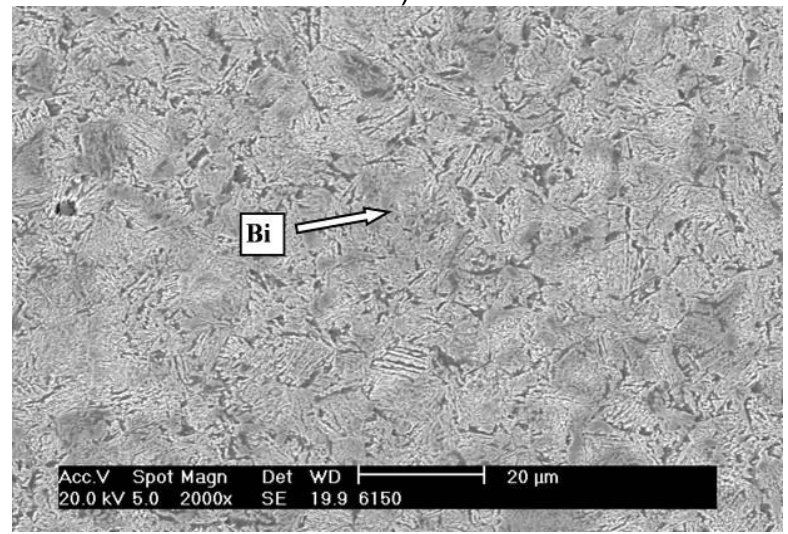

e)

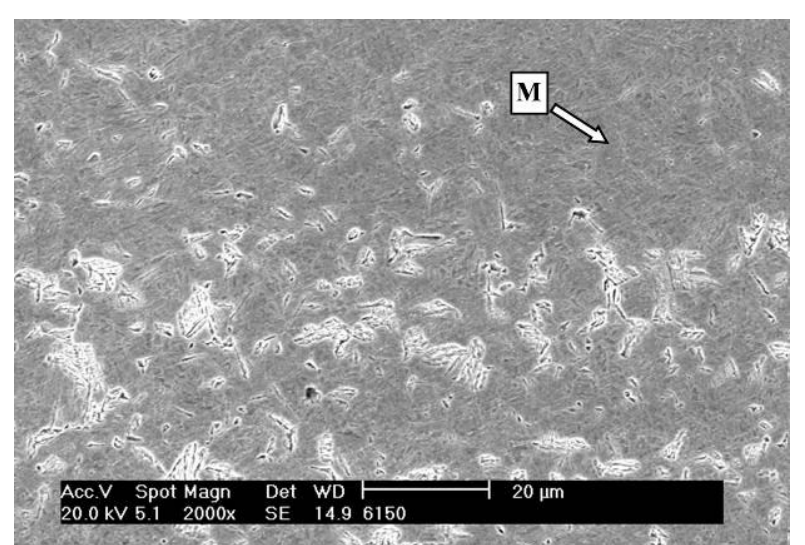

b)

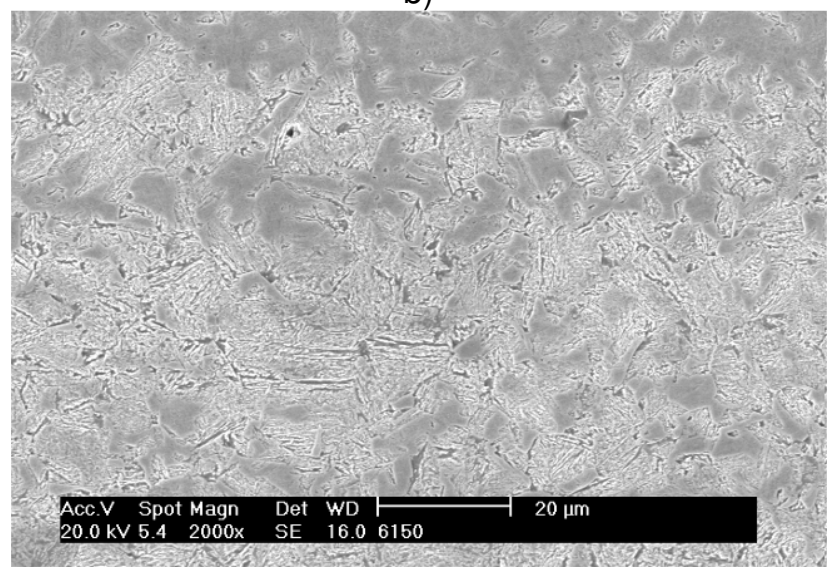

d)

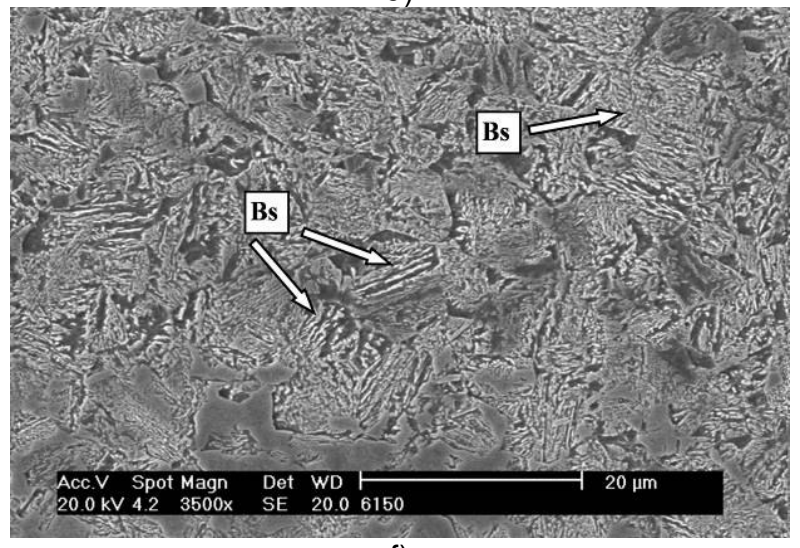

f)

Figura 4.4 - Micrografias da amostra Jominy de aço SAE-6150 obtidas em regiões localizadas em, a) $9.52 \mathrm{~mm}, 35 \mathrm{X}$, b) $9.52 \mathrm{~mm}, 2000 \mathrm{X}$, c) $15.87 \mathrm{~mm}, 2000 \mathrm{X}$ d)22.22mm, 2000X, e)25.4mm, 2000X and f) $31.75 \mathrm{~mm}, 3500 \mathrm{X}$, da superfície temperada.

As variações microestruturais geradas na amostra de aço SAE-6150 apresentaram resultados similares. Para uma distância de 9,52mm a partir da superfície atingida pelo jato, observa-se para baixos aumentos, linhas brancas de bainita inferior numa matriz de martensita (Figura 4.4 b) alinhadas na direção do resfriamento (Figura 4.4 a). Na medida em que aumenta a distância para 15,87mm e 22,22mm (Figura 4.4 c 
e Figura 4.4 d), o menor resfriamento permite obter maior quantidade de bainita e menor presença de martensita. Já para $25,4 \mathrm{~mm}$ de distância, a microestrutura é formada em sua grande maioria por bainita inferior (Figura 4.4 e) a qual predomina na microestrutura. Maiores aumentos numa distancia de $31,75 \mathrm{~mm}$ (Figura $4.4 \mathrm{f}$ ) observa se a bainita inferior e surgimento de grupos de bainita superior.

As análises microestruturais nos dois materiais mostraram um comportamento similar. As regiões do material com altas taxas de resfriamento presentes em distâncias próximas da superfície temperada têm maior concentração de defeitos na rede cristalina. A M é uma estrutura cristalina com alta quantidade de defeitos como resultado das altas taxas de resfriamento. Características que geram um material com elevada dureza. À medida que a distância aumenta, a taxa de resfriamento é menor, a porcentagem da martensita e bainita inferior diminuem, e a porcentagem de bainita superior aumenta. A densidade de defeitos diminui, devido ao maior tempo que tem a estrutura para se reorganizar. A reorganização estrutural reduz a quantidade de defeitos, como: defeito ponto (vacâncias, átomos impuros), defeitos lineares (borda e discordâncias de hélice) e interface ou defeitos de contorno. Esta redução ajuda a reduzir a tensão residual no material, e são gerados menores níveis de dureza.

$\mathrm{Na}$ Figura 4.5 e Figura 4.6 são amostrados os envelopes dos sinais de RMB medidos em diferentes posições nas amostras SAE 4140 e SAE 6150 respectivamente. As medições correspondentes aos primeiros 9,52mm da superfície temperada (6 primeiros pontos de medida) em cada uma das amostras foram descartadas, para evitar efeitos de borda na excitação magnética.

São observados na Figura 4.5 e Figura 4.6 os seguintes aspectos:

- A amplitude do envelope das medidas de RMB é baixa em distâncias próximas da superfície temperada, e aumenta gradualmente na medida em que ditas distâncias aumentam. Essa variação é causada pela distribuição de densidade de defeitos apresentada na microestrutura das amostras. O RMB é altamente sensível à densidade de defeitos da rede cristalina do material (Jiles DC , 2000). Nas regiões próximas da superfície temperada foi encontrada uma microestrutura martensítica com alta densidade de defeitos, os quais atuam como pontos de ancoragem no movimento das paredes de 
domínio. Essas condições geram baixas amplitudes de RMB. A microestrutura dos materiais foi mudando gradualmente com o aumento da distância da superfície temperada. A microestrutura encontrada nessas regiões (bainita superior e baixos níveis de martensita) apresenta uma densidade relativamente baixa de defeitos que geraram altos níveis de RMB. Esse comportamento é apresentado nos dois materiais ensaiados e com as três freqüências de excitação utilizadas.

- Na medida em que as medições de RMB foram feitas em regiões do material localizadas a maiores distâncias da superfície temperada, a posição do pico do envelope do sinal, em relação à corrente aplicada, foi se deslocando de valores altos para valores baixos. Todos os casos estudados apresentaram o mesmo comportamento. Microestrutura martensitica, como a produzida próxima da superfície temperada gera fases magneticamente duras com emissões de RMB localizadas em campos altos, enquanto microestruturas como á bainita superior produz emissões localizados em campos baixos (KINSER ER et al, 2005).

- Aumentos da freqüência de excitação geram deslocamento das posições dos picos do envelope para valores menores de correntes aplicadas. A posição do pico de envelope do MBN é diretamente relacionada à posição do campo coercitivo, Hc (Kinser ER , 2005). Aumentos na freqüência de excitação, acima de 50Hz. (SZCZYGLOWSKI J , 2001; ARAGONESES P et al, 1998) produzem incrementos nas correntes parasitas, que são responsáveis pela geração de campos magnéticos de reação ao campo externo, e conseqüentemente geram aumentos do Hc. No entanto para valores de freqüências de excitação baixas (como o caso em estudo), o efeito das correntes parasitas é mínimo, e a dinâmica do movimento de paredes de domínio ganha maior importância no deslocamento do Hc. Aumentos da freqüência de excitação fazem que o movimento de paredes de domínio seja produzido em saltos maiores e as avalanchas sejam mais freqüentes. Por tanto o processo de magnetização é menos sensível aos defeitos do material, e o valor de Hc diminui. 


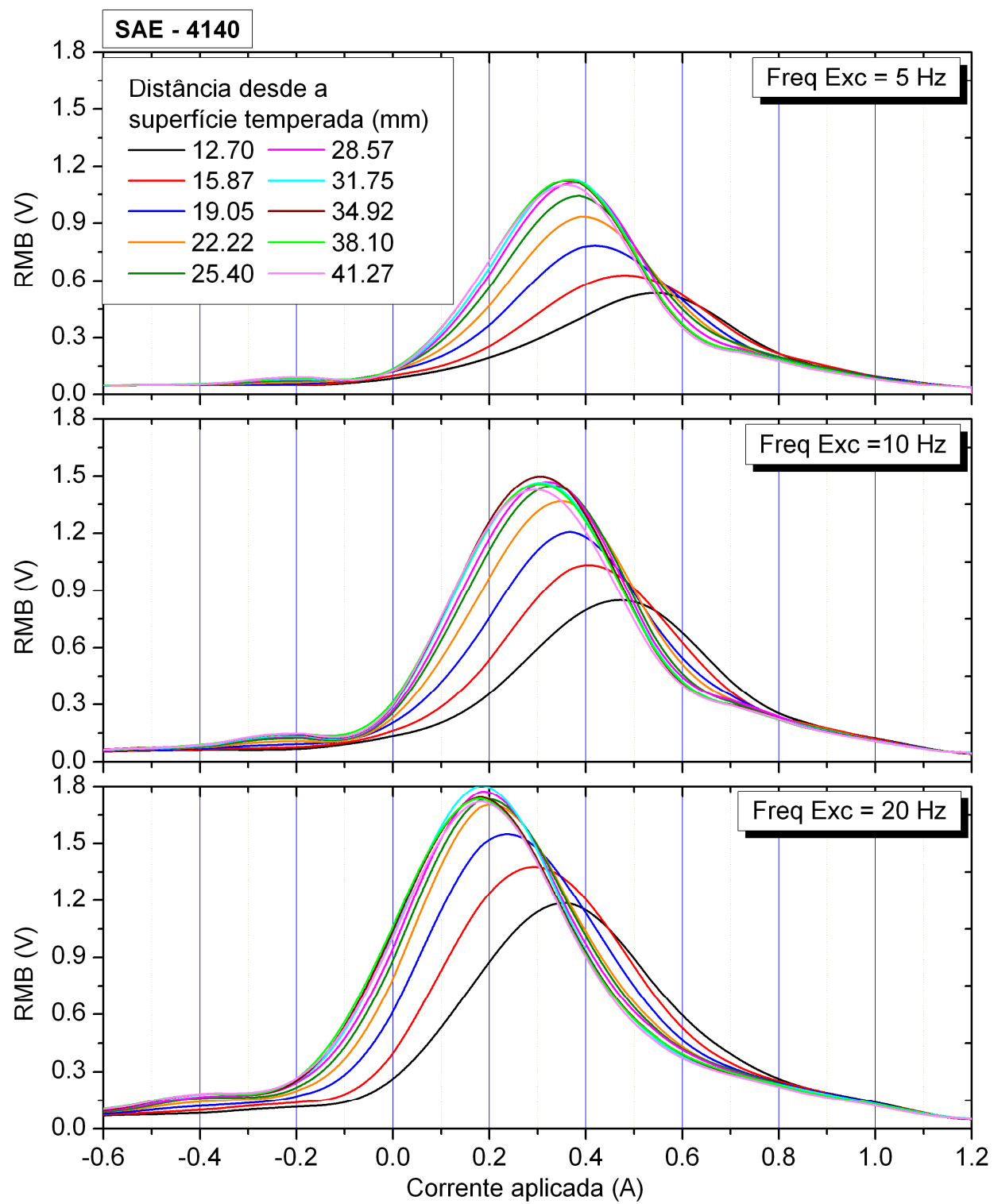

Figura 4.5 - Envelopes do sinal de RMB obtidos em diferentes posições da amostra SAE-4140 utilizando freqüências de excitação de 5,10 e $20 \mathrm{~Hz}$. 


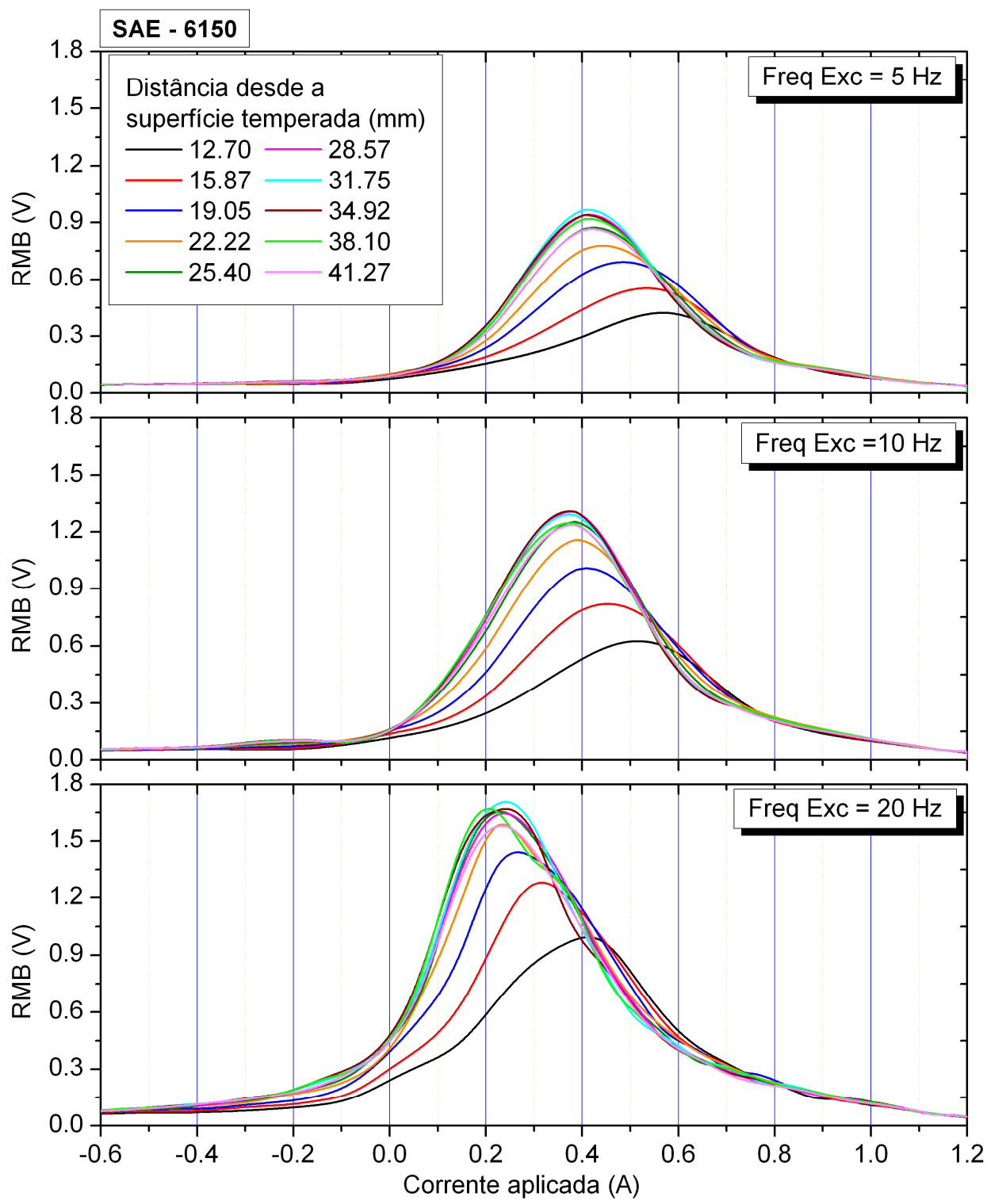

Figura 4.6 - Envelopes do sinal de RMB obtidos em diferentes posições da amostra SAE-6150 utilizando freqüências de excitação de 5,10 e $20 \mathrm{~Hz}$.

A distribuição dos parâmetros Posição pico, Amplitude pico, e $R B_{\text {rms }}$ do $R M B$, e medições de dureza (HRC) ao longo do comprimento das amostras Jominy SAE4140 e SAE-6150 são amostrados na Figura 4.7 e Figura 4.8 respectivamente com freqüências de excitação de 5, 10 e $20 \mathrm{~Hz}$.

As distribuições de amplitude das medidas de dureza HRC realizadas nos dois materiais confirmam as análises metalográficas realizadas. Os resultados obtidos nas amostras Jominy SAE-4140 e SAE-6150 indicam alta dureza, 52 HRC e 55 HRC, na região martensítica próxima da superfície temperada, e baixa dureza, 34 
HRC e 38 HRC em regiões afastadas da superfície temperada (bainita superior), respectivamente.

Assim que os pontos de medida vão se afastando da superfície temperada os valores medidos de dureza HRC e o parâmetro Posição pico do RMB diminuem, enquanto os parâmetros Amplitude pico e $\mathrm{RMB}_{\text {rms }}$ do RMB aumentam. Todos os gráficos mostram uma variação no perfil que acompanha a variação microestrutural gerada pelo tratamento térmico. Este aspecto é observado na amostra SAE-4140 assim com na amostra SAE-6150.

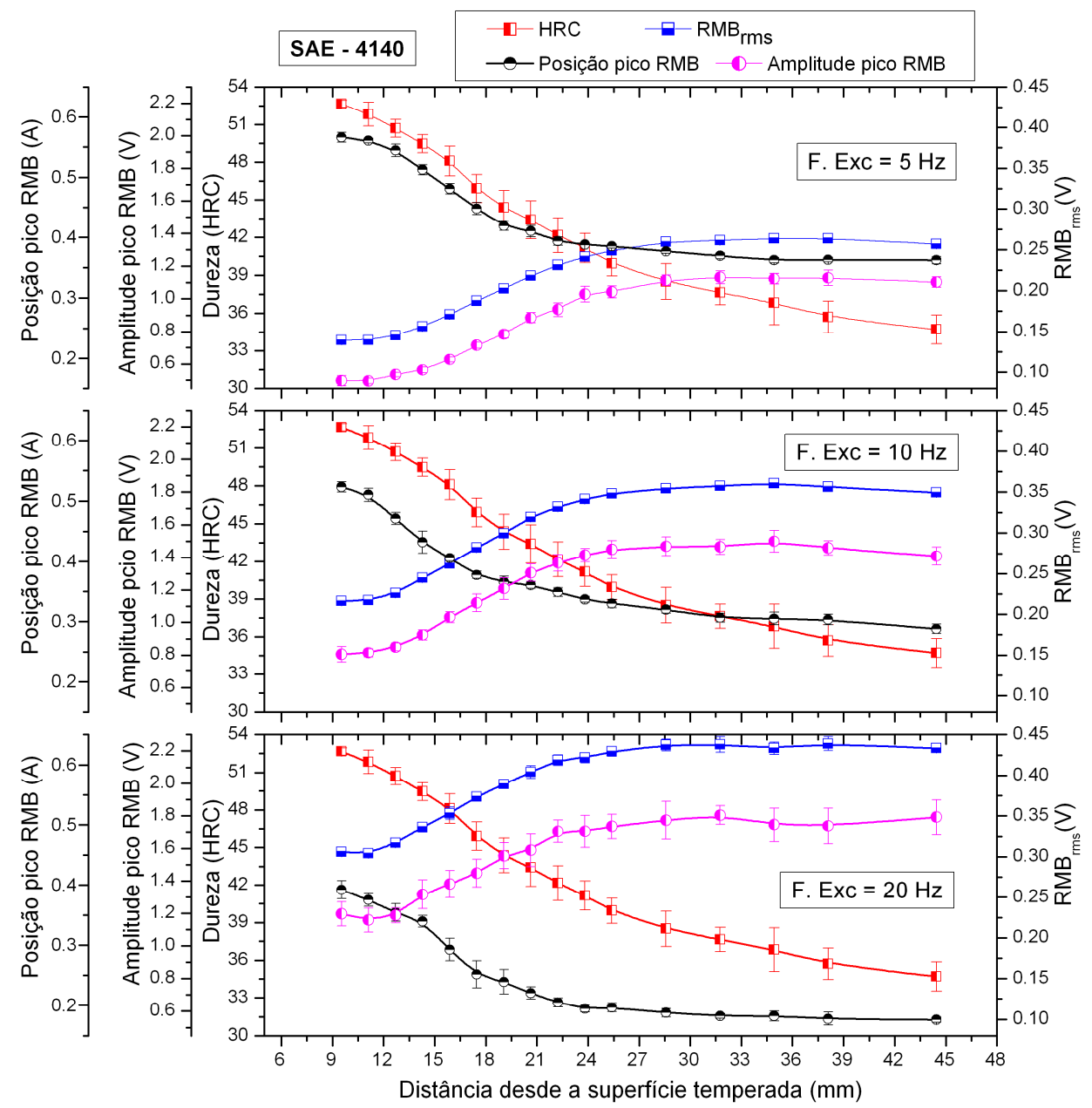

Figura 4.7 - Distribuição dos diferentes parâmetros calculados do RMB (Posição pico, Amplitude pico e $\mathrm{RMB}_{\mathrm{rms}}$ ) e Dureza (HRC) no comprimento da amostra Jominy SAE-4140. Medições com freqüências de excitação de 5, 10 e $20 \mathrm{~Hz}$. 
Como foi discutido nas análises metalográficas, as amostras dos dois materiais ensaiados apresentam uma variação continua da densidade de defeitos cristalinos. A alta densidade de defeitos presente em regiões próximas da superfície temperada, atuam como pontos de ancoragem das paredes de domínio, e dificultam seu movimento. Essas condições geram baixas emissões de RMB, e então, os parâmetros Amplitude pico e $\mathrm{RMB}_{\mathrm{rms}}$ do RMB apresentam amplitudes baixas. Além disso, a inversão da magnetização exige um forte campo, deslocamentos das paredes de domínio são curtas, e é difícil criar novos domínios, portanto, a posição do pico do RMB esta situado em um campo magnético relativamente elevado (GUR $\mathrm{CH}$; CAM I, 2007).

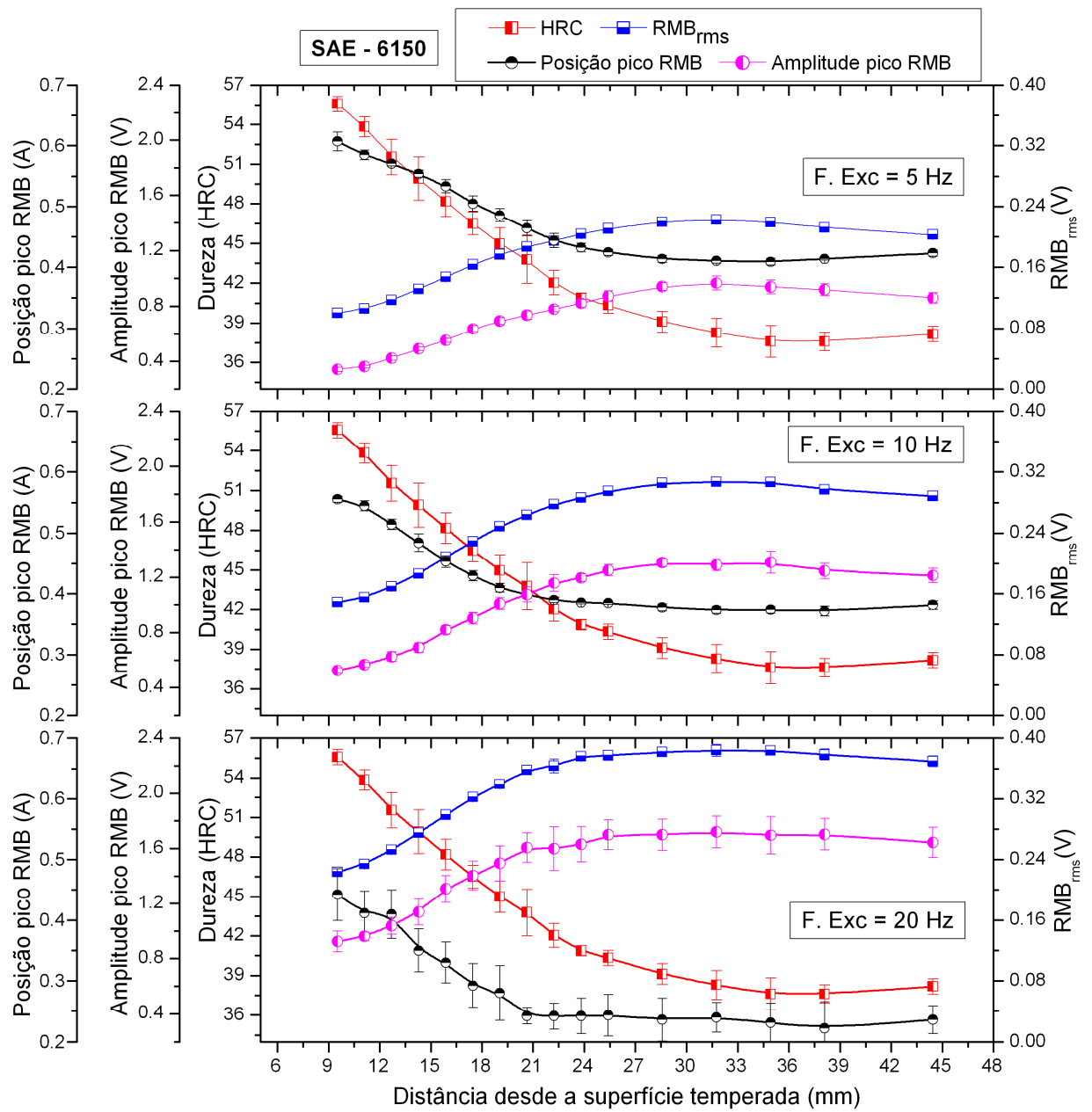

Figura 4.8 - Distribuição dos diferentes parâmetros calculados do RMB (Posição pico, Amplitude pico e $R_{M B} B_{r m s}$ ) e Dureza (HRC) no comprimento da amostra Jominy SAE-6150. Medições com freqüências de excitação de 5, 10 e $20 \mathrm{~Hz}$. 
Com a diminuição das taxas de resfriamento a maiores distâncias da superfície temperada, a microestrutura gradualmente muda diminuindo a densidade de defeitos e quantidade de martensita, enquanto a quantidade de bainita superior aumenta. Já em posições afastadas da superfície temperada, $44,45 \mathrm{~mm}$, a densidade de defeitos cristalinos presente na microestrutura, diminui. Portanto, a movimentação de paredes de domino é produzida com maior facilidade. As emissões de RMB aumentam (amplitudes dos parâmetros Amplitude pico e $\mathrm{RMB}_{\mathrm{rms}}$ aumentam) e amplitude de campo necessário para reverter a magnetização diminui (Posição pico do RMB diminui).

A correlação entre diferentes parâmetros de RMB (Posição pico, 1/Amplitude pico e 1/ $\mathrm{RMB}_{\text {rms }}$ ) e as medições de dureza nas amostras SAE-4140 e SAE-6150 são mostrados na Figura 4.9 e Figura 4.10 respectivamente.

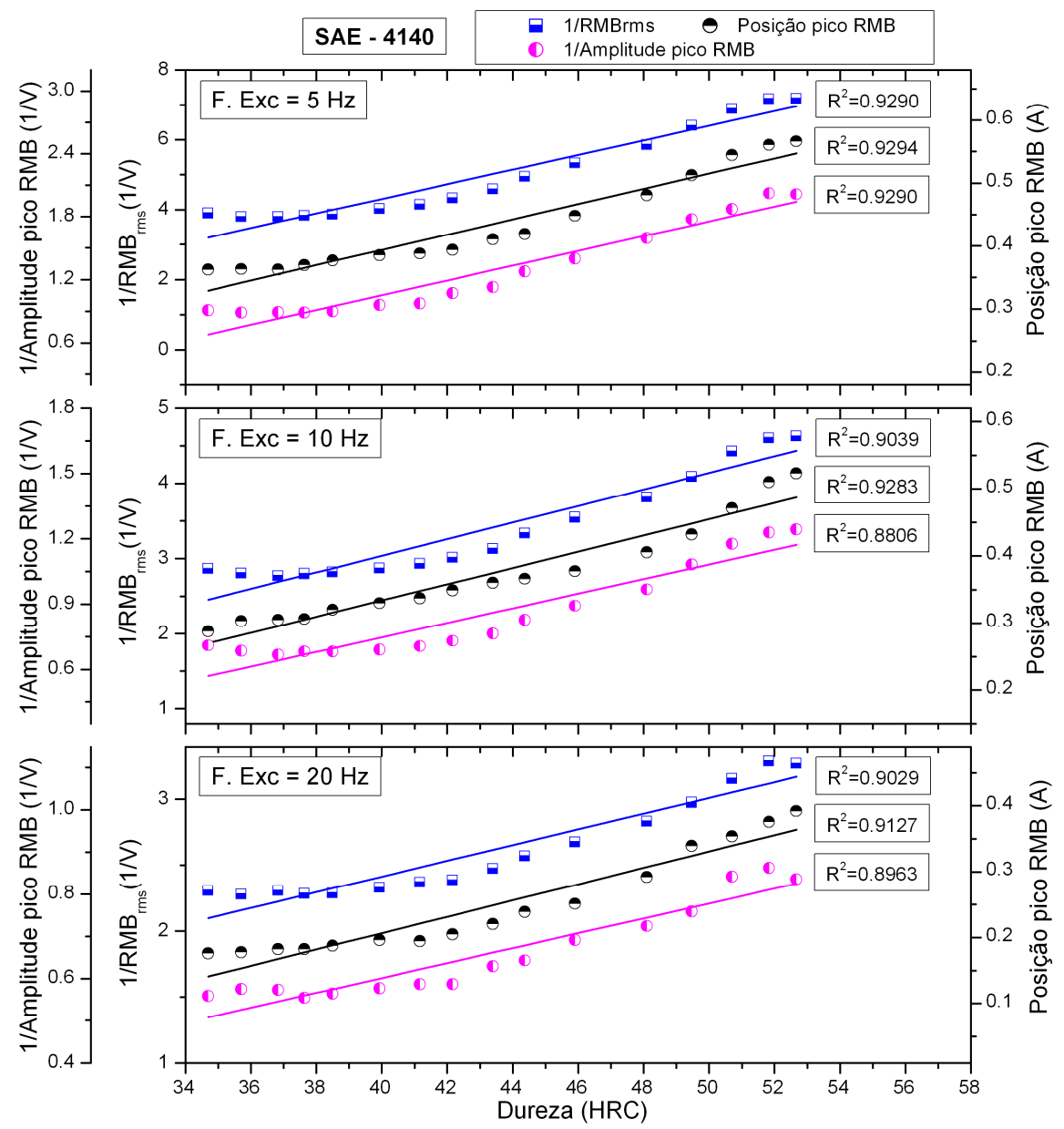

Figura 4.9 - Dependência de diferentes parâmetros do sinal de RMB (Posição pico, 1/Amplitude pico e $1 / R_{M B}$ rms $)$ em relação as medidas de Dureza(HRC) feitas na amostra SAE-4140. Freqüências de excitação de 5, 10 e $20 \mathrm{~Hz}$. 
Os gráficos mostram boas correlações lineares entre todos os parâmetros calculados do RMB e as medidas de dureza (HRC). O parâmetro do RMB que apresentou a melhor correlação em relação às medidas de dureza foi a Posição pico. O aumento da freqüência de excitação causou uma leve diminuição dos índices de correlação linear $\mathrm{R}^{2}$ de todos os parâmetros calculados.

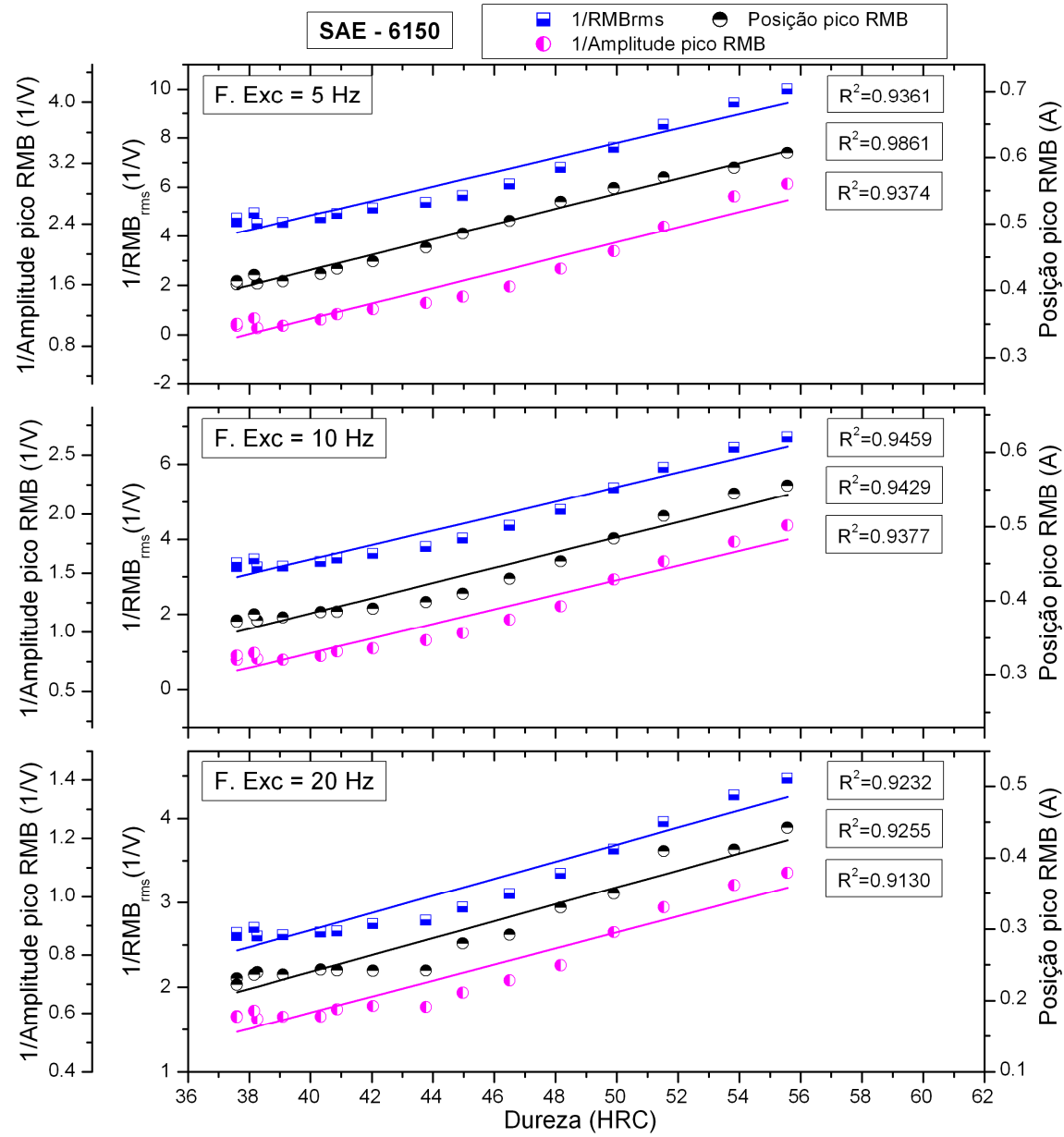

Figura 4.10 - Dependência de diferentes parâmetros do sinal de RMB (Posição pico, 1/Amplitude pico e 1/RMB ${ }_{\text {rms }}$ ) em relação as medidas de Dureza(HRC) feitas na amostra SAE-6150. Freqüências de excitação de 5,10 e $20 \mathrm{~Hz}$.

A quantidade de paredes de domínio participantes no processo de magnetização, assim como seu espaçamento é dependente da freqüência de excitação. Com o aumento da freqüência de excitação o numero de paredes de domínio e saltos por unidade de tempo aumentam (HALLER TR, KRAMER JJ, 1970; HIGUCHI T, 1974). 
Isto favorece o aumento da influencia do solapamento ou superposição de pulsos. O solapamento é entendido como o processo de agrupação, no sistema de media de RMB, de clusters de pulsos que provêm de regiões diferentes do material (HWANG DG; KIM HC, 1988). Portanto a quantidade de pulsos registrados diminui e o $\mathrm{RMB}_{\mathrm{rms}}$ aumenta com o aumento da freqüência de excitação (MITRA A; JILES DC, 1997; PALA J; BYDZOVSKY J, 2008; STUPAKOV O; PAL'A J, 2009). Assim, a diminuição da correlação dos diferentes parâmetros calculados do RMB e as medidas de dureza com o aumento da freqüência de excitação, pode ser atribuída à diminuição da quantidade de pulsos registrados. O solapamento de pulsos agrava a sensibilidade das medições de RMB.

Como observado na Figura 4.9 e Figura 4.10, o parâmetro Posição Pico do RMB apresentou a melhor correspondência com as medidas de Dureza (HRC), e utilizando F. Exc=5Hz. A Figura 4.11 mostra a maneira de comparação, o comportamento desses parâmetros no comprimento das duas amostras.

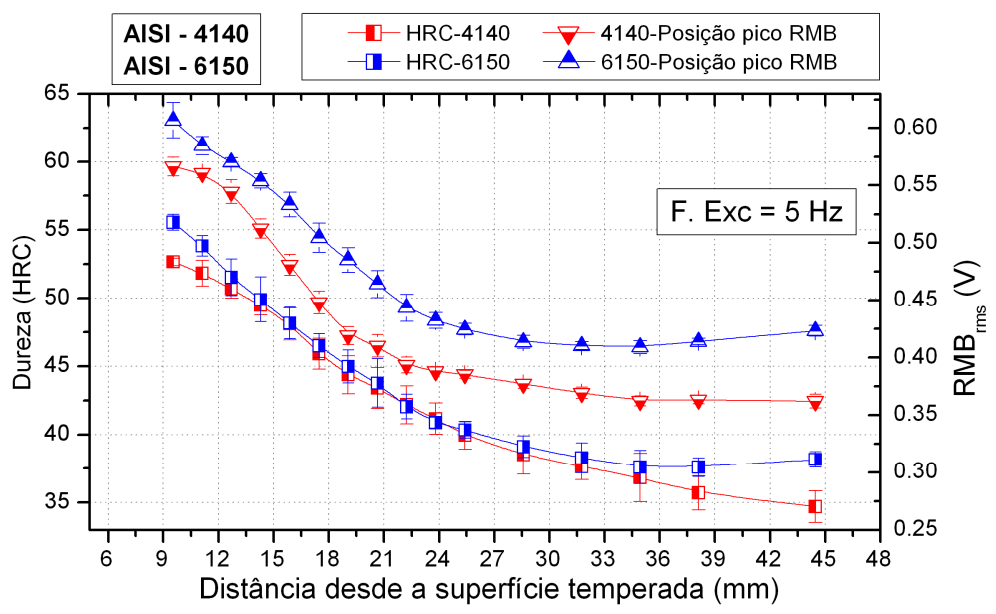

Figura 4.11 - Distribuição do parâmetro Posição pico do RMB e Dureza (HRC) no comprimento das amostras Jominy SAE-6150 e SAE-4140. F. ExC=5 Hz.

É observado na Figura 4.11 que o RMB apresenta comportamento similar, para as duas amostras, com a variação de dureza.

Ao se comparar com a variação de dureza HRC, observa-se um comportamento um pouco diferente para cada uma das amostras. 
Por exemplo, para as distâncias de 15,87 e 22,22mm, enquanto as medições de dureza apresentam amplitudes muito similares nos dois materiais, os valores correspondentes do parâmetro Posição Pico do RMB apresentam diferencias relativamente altas. Por outro lado, e para distâncias de 9,52 e $44,45 \mathrm{~mm}$, as diferencias entre medidas de Dureza e RMB entre os dois materiais é proporcional.

Essa diferença de comportamento pode ser devido a outros fatores presentes na microestrutura das amostras. No presente estudo, somente foram utilizados uma amostra para cada material. Um estudo com várias amostras poderia fornecer maiores informações sobre as razões desse comportamento.

\subsection{CONCLUSÕES}

Medições do RMB foram realizadas para caracterizar gradientes de microestruturas geradas em amostras de SAE-4140 e SAE-6150. Os gradientes microestuturais foram gerados com tratamentos térmicos de ensaio Jominy. Microestruturas e valores de dureza foram determinados em diferentes regiões das amostras por ensaios convencionais destrutivos. Diferentes parâmetros do RMB foram calculados e comparados com as medidas de dureza e análises microestruturais. As seguintes conclusões foram feitas:

- As análises metalograficas das amostras dos dois materiais ensaiados apresentaram uma variação contínua de densidade de defeitos cristalinos (principalmente discordâncias) ao longo da superfície submetida a diferentes taxas de resfriamento. Na medida em que aumenta a taxa de resfriamento, a microestrutura muda de martensita a bainita inferior e finalmente a bainita superior.

- Pequenas agulhas de martensita, além da alta densidade de defeitos cristalinos presente em regiões próximas da superfície temperada geram baixas emissões de RMB, e os parâmetros calculados, Amplitude pico e $\mathrm{RMB}_{\text {rms }}$ apresentam 
amplitudes baixas. Por outro lado a posição da amplitude máxima do envelope do RMB, parâmetro "Posição pico", esteve localizado em correntes de excitação relativamente altos.

- Em posições afastadas da superfície temperada, a microestrutura apresenta níveis relativamente baixos de densidade de defeitos e martensita. Predomina a bainita superior. As emissões de RMB aumentam (amplitudes dos parâmetros Amplitude pico e $\mathrm{RMB}_{\mathrm{rms}}$ do RMB aumentam) e amplitude de campo necessário para reverter a magnetização diminui (Posição pico do RMB diminui).

- Os parâmetros calculados dos sinais de RMB acompanharam o gradiente microestrutural gerado. Foram encontrados bons coeficientes de correlação lineares entre os diferentes parâmetros calculados do RMB e as medidas de dureza.

- Um aumento da freqüência de excitação (de $5 \mathrm{~Hz}$ para $20 \mathrm{~Hz}$ ) gera uma leve diminuição nos coeficientes de correlação linear entre os diferentes parâmetros calculados do RMB e às amplitudes de dureza. 


\section{BARKHAUSEN CONTÍNUO}

Os métodos baseados no RMB têm um diferencial importante em relação aos métodos clássicos, já que são sensíveis à variação microestruturais, tensões mecânicas e deformações plásticas.

O Barkhausen Contínuo é uma nova metodologia de medição, que estende essa características à inspeção de superfícies.

Como foi exposto na revisão bibliográfica (item 2.7), foi encontrado só um trabalho técnico em relação à utilização da técnica de medição do Ruído Magnético de Barkhausen Contínuo (RMBC) (ALFRED E. CROUCH, 2004). O trabalho foi apresentado numa conferência internacional relacionada com Gasodutos. Nele foram detectados diferentes danos mecânicos e térmicos por mapeamento linear em tubulações. Não existem artigos publicados em revistas cientificas relacionado com o tema.

Neste capítulo são apresentados resultados inovadores da aplicação da técnica de medição do RMBC, na detecção de diferentes falhas em materiais ferromagnéticos. No desenvolvimento da técnica, diferentes aspectos foram estudados:

- Projeto de sonda de medida, e estudo de seu comportamento magnético utilizando o método de elementos finitos.

- Análise de métodos apropriados de processamento de sinais.

- Efeito do campo aplicado e velocidade da sonda, na capacidade de detecção de falhas.

- Efeito das características e posicionamento da bobina leitora.

São apresentados resultados experimentais para os seguintes casos:

- Identificação de materiais diferentes.

- Detecção de materiais com e sem descarbonetação.

- Detecção de falhas volumétricas.

- Mapeamento de deformações plásticas.

- Mapeamento de tensões aplicadas. 


\subsection{SISTEMA DE MEDIDA}

A sonda de medição do RMBC é composta por uma bobina leitora com núcleo de ferrita, e um arranjo de ímãs permanentes que geram um campo magnético constante. $\mathrm{O}$ arranjo varia de 1 a 4 ímãs colocados um acima do outro, o qual permite variar a magnitude do campo aplicado. Cada um dos ímãs tem uma configuração geométria em forma de paralelepípedo com dimensões de 10x16x4mm. Um gaussímetro foi utilizado para medir os campos magnéticos produzidos por cada um desses arranjos de ímãs. Desta forma medições feitas no ar, e sobre a superfície dos pólos determinaram os valores mostrados na Tabela 5-1.

Tabela 5-1 - Campos magnéticos medidos para os diferentes arranjos de ímãs utilizados.

\begin{tabular}{cc}
\hline Tipo de arranjo & Campo medido \\
\hline 1 ímã & 2600 Gauss $=0,26 \mathrm{~T}$ \\
\hline 2 ímã & 3650 Gauss $=0,36 \mathrm{~T}$ \\
\hline 3 ímã & 4100 Gauss $=0,41 \mathrm{~T}$ \\
\hline 4 ímã & 4500 Gauss $=0,45 \mathrm{~T}$ \\
\hline
\end{tabular}
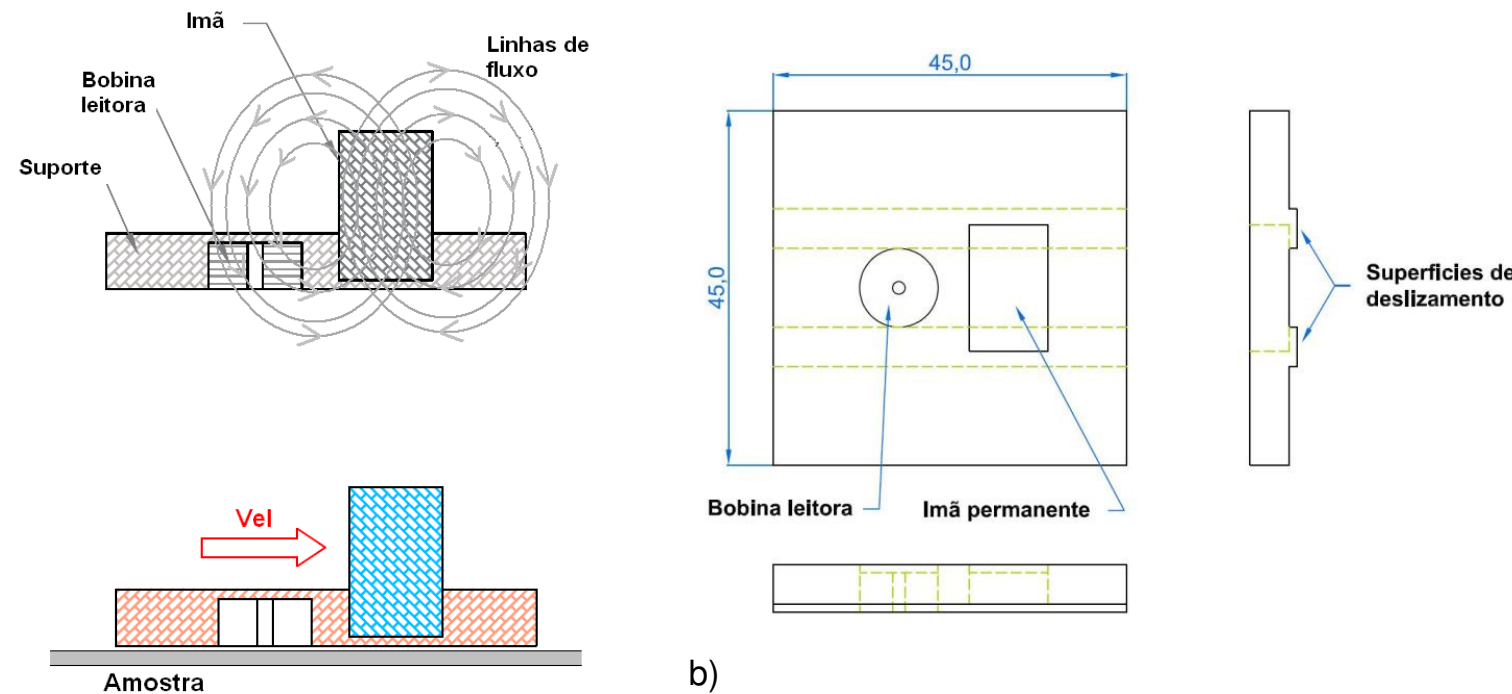

a)

b)

Figura 5.1 - Sonda de RMBC. a) Esquema de montagem, b ) vistas. Medidas em mm.

A Figura 5.1 mostra um esquema da sonda de RMBC utilizada nos experimentos. $\mathrm{Na}$ Figura $5.1 \mathrm{~b}$ se observam três vistas do dispositivo projetado. Foi usinada 
manualmente uma placa de teflon na qual se posicionaram a bobina leitora e o ímã permanente. A área inferior da sonda que faz contato com a amostra foi reduzida a duas pistas de $5 \mathrm{~mm}$ de largura, que tocam a superfície a ser inspecionada.

A sonda de RMBC é usada em duas orientações com relação ao movimento; uma colocando a bobina leitora na frente dos ímãs, e outra colocando-la atrás. Foram usadas diferentes bobinas leitoras. Na Figura 5.2 é mostrada a geometria de algumas delas.

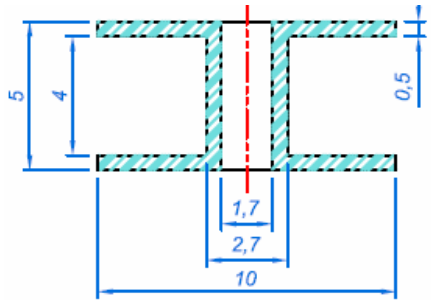

a) Bobina A. 1250 voltas Núcleo ferrite cilíndrico

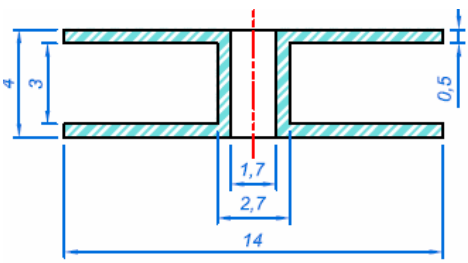

b) Bobina B. 2000 voltas Núcleo ferrite cilíndrico

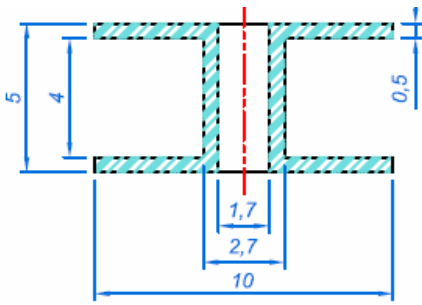

c) Bobina C. 2500 votas Núcleo ferrite cilíndrico

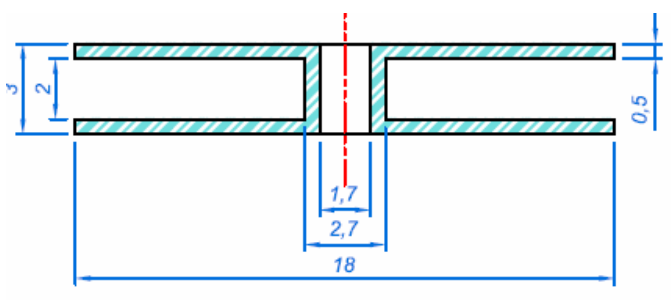

d) Bobina E. 4000 voltas Núcleo ferrite cilíndrico

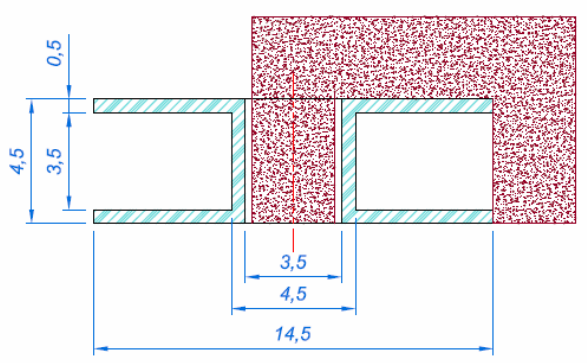

e) Bobina E. 4000 voltas Núcleo ferrite em U

Figura 5.2 - Bobinas leitoras utilizadas.

Para realizar análises estatísticas, em cada condição de medida são realizadas várias repetições. Durante o processo de medição, a sonda sempre se manteve estática, e a amostra se movimentou com diferentes velocidades no sentido horizontal. Para o controle desses movimentos foi projetada uma mesa de movimentação XYZ. A Figura 5.3 mostra a estação experimental utilizada. $O$ equipamento é composto de uma estrutura de aço sobre a qual estão posicionadas duas placas horizontais que realizam movimentos horizontais em direções 
perpendiculares $(\mathrm{X} \mathrm{e} \mathrm{Y})$ entre si, mais uma placa vertical que fornece o movimento na direção Z. As placas deslizam sobre guias tipo eixo-bucha e estão fixas cada uma a um sistema de parafusos de esferas. Estes fusos por sua vez estão conectados por transmissões polia-correia a motores passo. Três "drivers" de controle de motores de passo conectados às portas de comunicação RS232 do computador controlam cada um dos movimentos $\mathrm{X}, \mathrm{Y}$ e/ou $\mathrm{Z}$ da mesa porta amostra.

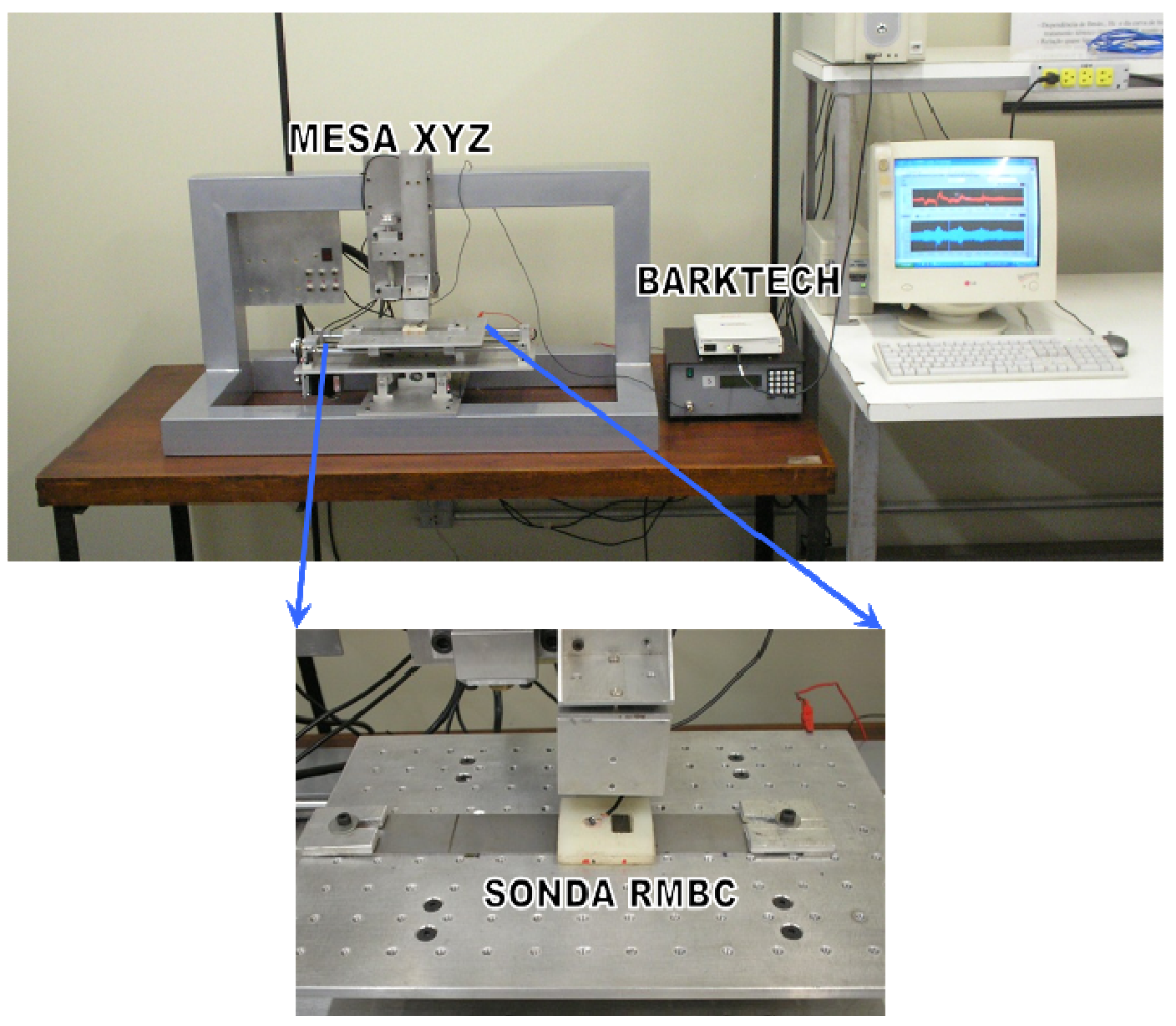

Figura 5.3 - Estação experimental para a medição do RMBC.

Para a aquisição dos sinais de RMBC foi utilizado o equipamento "BarkTech". Na aquisição foi usado um filtro passa banda de 1 a $200 \mathrm{kHz}$. Um diagrama esquemático do sistema de medida de RMBC é mostrado na Figura 5.4. 


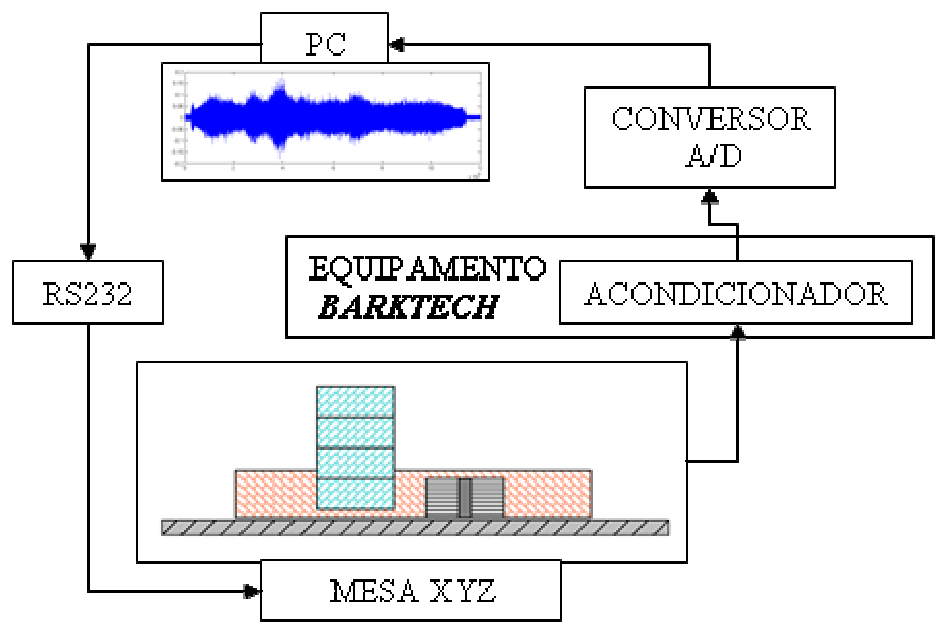

Figura 5.4 - Esquema do sistema de medição do RMBC.

A visualização e gravação dos sinais obtidos foram feitas com uma aplicação desenvolvida no programa Labview 8.0. Na Figura 5.5 mostra-se uma imagem da tela do programa, onde se podem observar os sinais de RMBC, com filtragem (azul) e sem filtragem (vermelho). Para a sincronização entre o posicionamento da sonda de RMBC e o início da gravação de dados foi instalado um sensor óptico na mesa $X Y Z$. Assim, a aplicação feita em LabView registra um pulso do sensor óptico que aciona o registro e gravação do sinal.

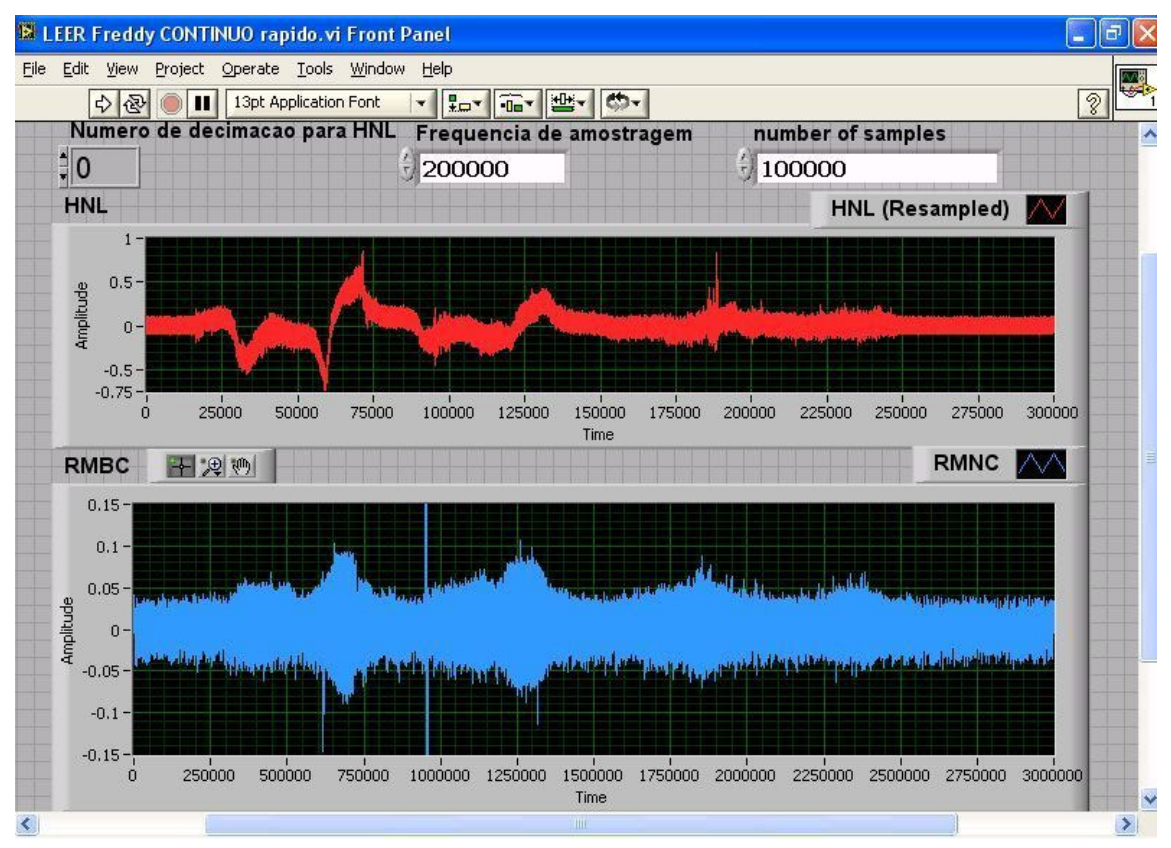

Figura 5.5 - Programa de aquisição de dados feito em LabView para o registro dos sinais de RMBC. 


\subsection{MÉTODOS DE PROCESSAMENTO DO SINAL DE RMBC}

$\mathrm{Na}$ análise dos sinais de RMBC foram usados dois métodos de processamento de sinais. O primeiro é um método de suavização do sinal, chamado neste trabalho, como M2-RMBC. É uma média móvel que substitui cada valor de dados com o momento de segunda ordem estatístico calculado a partir dos valores vizinhos, e é matematicamente expressa por:

$M 2-R M B C[i]=\frac{1}{2 M+1} \sum_{j=-M}^{M} s^{2}[i+j]$

onde $2 \mathrm{M}$ é o tamanho da janela temporal deslizante e $\mathrm{s}[\mathrm{i}]$ é o sinal do RMBC. Esta técnica de alisamento pode ser pensada como um filtro passa-baixa. Quanto maior $M$, mais estreita a resposta de freqüência do filtro. A escolha deste parâmetro depende do tipo de sinal e é determinada empiricamente.

O segundo é uma representação tempo-freqüência (TFR), chamado Spectograma, com base em uma forma quadrática (QTFR (t, f)) (PADOVESE, L. R, 2009; COHEN $L$, 1994). A TFR linear com base na transformada de Fourier pode ser alcançada pelo pré-janelamento temporal do sinal em torno de cada instante de tempo do sinal e (com uma largura temporal previamente definida) o cálculo da sua transformada de Fourier. Esta transformação é conhecida como "Short-Time Fourier Transform" e referidos como STFT $(t, f)$, onde t é a variável tempo e f a variável freqüência. Uma forma quadrática, relacionada com o "Short-Time Fourier Transform", pode ser obtida calculando o quadrado desta transformação. Esse cálculo é conhecido como espectrograma e mede a densidade de energia espectral do sinal no domínio tempofreqüência. $O$ espectrograma de um sinal $x$ (t) é referido como SPECT ( $t$, f) e é calculado como: 
$\operatorname{SPEC}(t, f)=|\operatorname{STFT}(t, f)|^{2}=\left|\int_{-\infty}^{\infty} x(\tau) h^{*}(\tau-t) e^{-j 2 \pi f \tau} d \tau\right|^{2}$

onde $h(t)$ é uma janela de ponderação deslizante e o sobrescrito * denota conjugado. O tamanho de $h(t)$ está relacionado com a freqüência e resolução temporal. Quanto maior for, maior é a resolução de freqüência e menor a resolução temporal. Portanto, a escolha de seu tamanho depende das características do sinal e é determinada empiricamente.

\subsection{SIMULAÇÃO POR ELEMENTOS FINITOS DO COMPORTAMENTO MAGNÉTICO DA SONDA DE RMBC}

A posição relativa entre a bobina leitora e o ímã permanente durante o movimento é um fator importante para otimizar a sensibilidade da técnica. Uma vez que a geração de MBN está relacionada com a intensidade do gradiente de campo magnético, esse posicionamento deve ser feito de forma a maximizar o campo magnético na região de leitura. Esse fator foi analisado por simulação numérica da distribuição de campo magnético, utilizando o Método dos Elementos Finitos (FEM). Além disso, essa questão também foi comprovada experimentalmente.

A Figura 5.7 mostra alguns resultados da simulação numérica. As simulações foram feitas com o Software de análise de Elementos Finitos ANSYS. Curvas não lineares $\mathrm{B}(\mathrm{H})$ da amostra de aço e do núcleo de ferrite da bobina (medido no laboratório), foram tidos em conta nas simulações (Figura 5.6). A resistividade elétrica foi fixada em $0.010 h m$ * $\mathrm{m}$ para o núcleo de ferrite, e $1.68 \mathrm{e}-7$ ohm * $\mathrm{m}$ para a amostra de aço. Foi usado o modo de análise não-linear na solução numérica. 


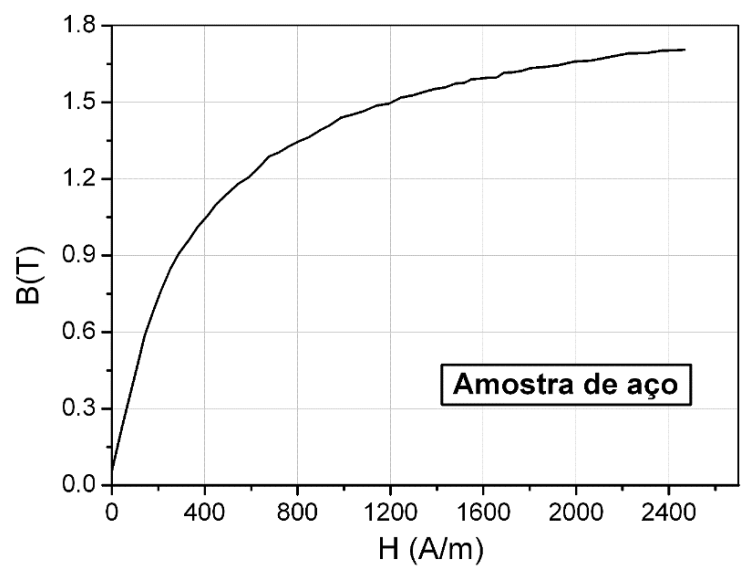

a)

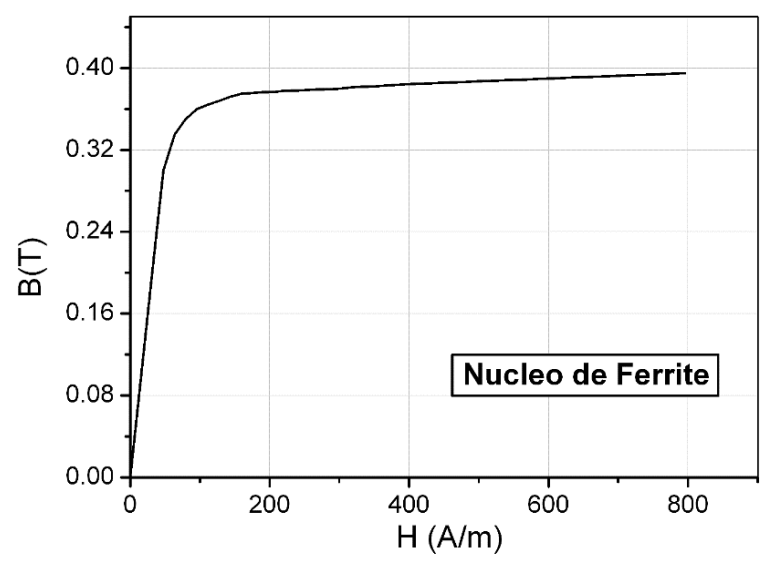

b)

Figura 5.6 - Curvas de magnetização $B(H)$ para a)Amostra de aço, e b) Núcleo de ferrite.

a)
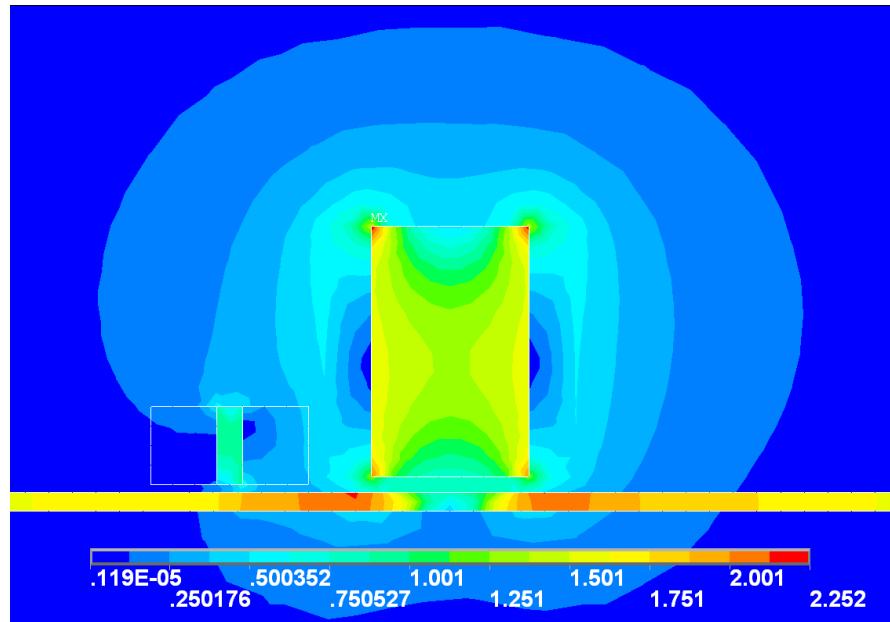

SONDA RMBC

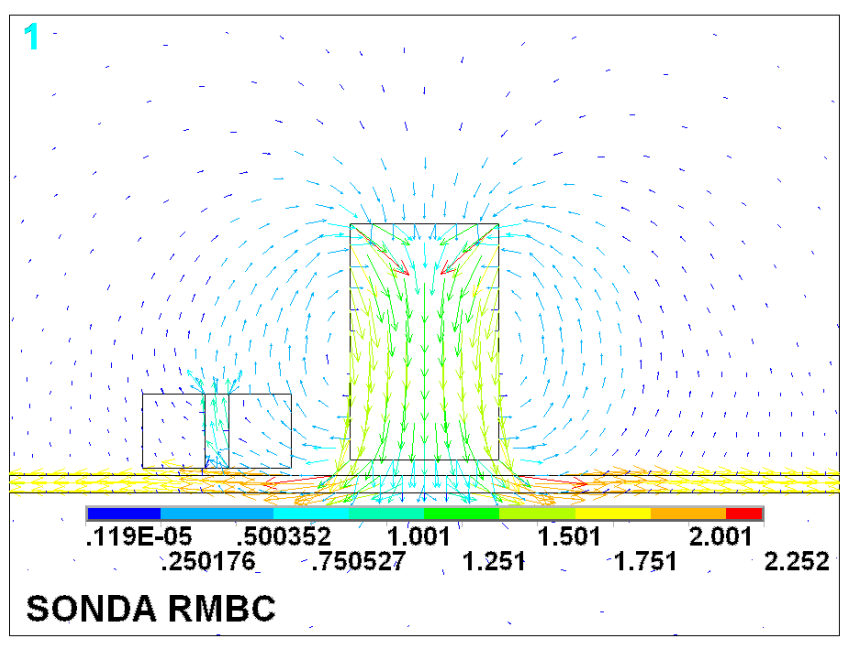

Figura 5.7 - Simulação do comportamento do fluxo magnético da sonda de RMBC na amostra.

a) Distribuição de densidade de fluxo magnético $(T)$, b) Vetores de fluxo magnético, 
A Figura 5.7a mostra a distribuição de densidade de fluxo magnético em torno da sonda. Observa-se como ao utilizar um núcleo de ferrite de alta permeabilidade magnética na bobina leitora, consegue-se gerar uma concentração do fluxo, na vizinhança do núcleo de ferrite. Isto produz mudanças bruscas no comportamento do fluxo magnético na zona de material justo embaixo da posição da bobina leitora. A Figura 5.7b mostra a distribuição de vetores de fluxo e confirma o dito acima.

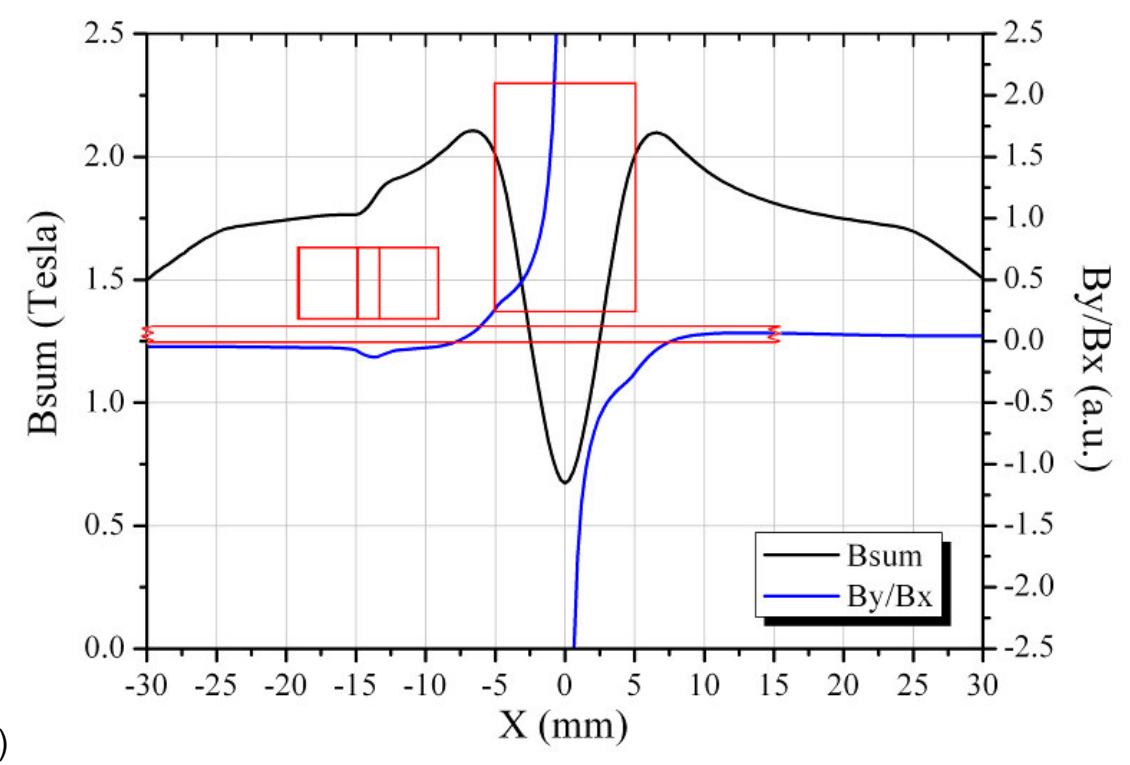

a)

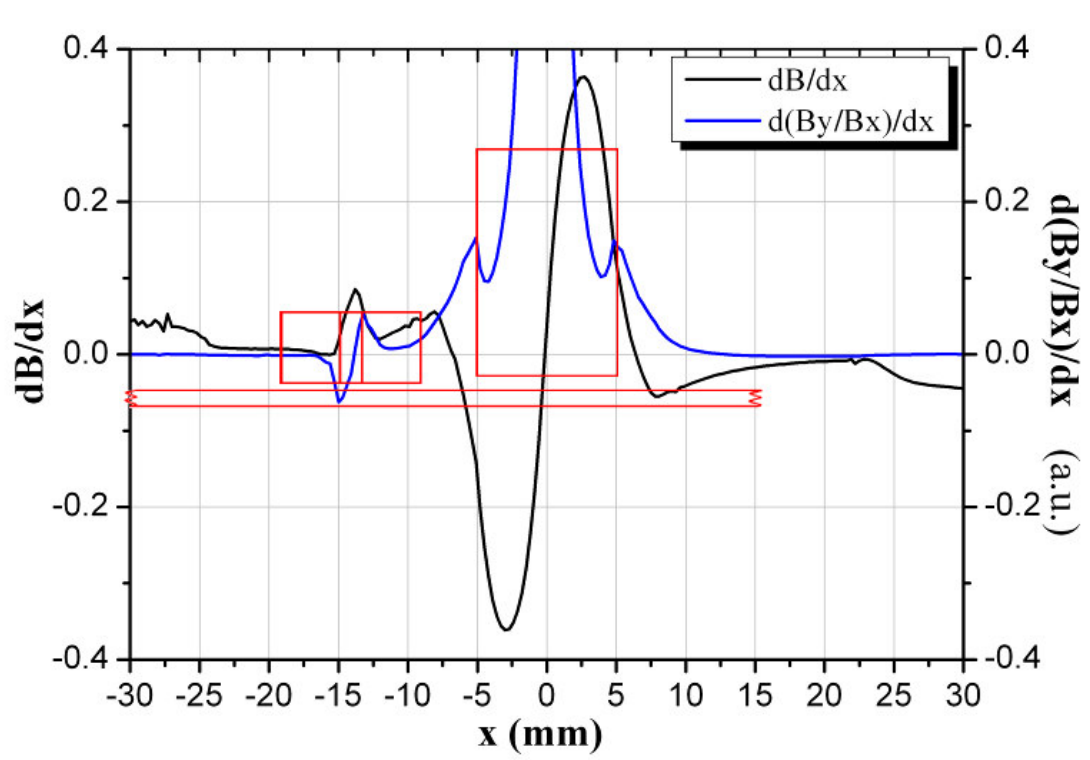

b)

Figura 5.8 - Características da distribuição do fluxo magnético numa profundidade de $0.3 \mathrm{~mm}$ na amostra. a) Magnitude ( $|\vec{B}|$ ) e direção (By/Bx) do fluxo. b) Gradiente espacial da magnitude $(\mathrm{d} \mid \overrightarrow{\mathrm{B}} / \mathrm{dx})$ e direção $(\mathrm{d}(\mathrm{By} / \mathrm{Bx}) / \mathrm{dx})$ do fluxo. 
A Figura 5.8a e Figura 5.8b mostram algumas distribuições calculadas das características do fluxo magnético numa profundidade de $0.3 \mathrm{~mm}$ na amostra.

A Figura 5.8a mostra a distribuição da magnitude ( $\mathrm{B}$, linha preta) e direção (By/Bx), enquanto a Figura 5.8b ilustra a distribuição do gradiente espacial da magnitude $(\mathrm{d} \mid \mathrm{B} / \mathrm{dx}$, linha preta ) e direção $(\mathrm{d}(\mathrm{By} / \mathrm{Bx}) / \mathrm{dx})$. Observa-se nessas figuras, com mais detalhe, as mudanças relativamente grandes que são produzidas tanto na amplitude com na direção do fluxo magnético, justo embaixo da zona central da bobina leitora. Este efeito tem particular importância, na medida que favorece a produção e medição do RMB, já que são as mudanças de amplitude e direção do campo magnético aplicado, os responsáveis da movimentação de paredes de domínio.

\subsection{ENSAIOS PRELIMINARES}

Como as lacunas conceituais da aplicação da técnica são grandes, devido ao ineditismo e complexidade, foi realizada uma primeira fase de ensaios preliminares. O objetivo foi avaliar propostas de procedimentos de medida, configurações de sonda, métodos de análises de sinais, e demais fatores que pudessem determinar a viabilidade da aplicação da nova técnica na detecção de danos do material.

Baseados na experiência adquirida em medições clássicas de RMB (medições estáticas, RMBE) foram projetadas amostras com variações microestruturais facilmente detectáveis. Assim neste item são apresentados os parâmetros de medida e resultados preliminares de medições de RMBC em 2 amostras diferentes, do tipo chapa: uma primeira, composta por 6 materiais diferentes, e uma segunda, onde o material apresenta diferentes porcentagens de descarbonetação.

Após da apresentação desses resultados preliminares, são apresentados nos item 5.5 ao 5.7, estudos mais aprofundados aplicando a técnica em três casos específicos, e envolvendo a análise da influência de parâmetros tais como: amplitude de campo magnético aplicado, velocidade e orientação da sonda do RMBC. 


\subsubsection{Ensaio Preliminar 1: RMBC em amostra com diferentes materiais}

\subsubsection{Materiais e métodos}

Para a fabricação da amostra foram utilizados 6 materiais diferentes. A composição química de cada um deles é amostrado na Tabela 5-2.

Tabela 5-2 - Composição química dos aços utilizados (\% em massa). Amostra materiais diferentes.

\begin{tabular}{|c|c|c|c|c|c|c|c|c|c|c|c|c|}
\hline No. & Material & C & $\overline{\mathrm{Si}}$ & $\bar{S}$ & $M n$ & $\bar{P}$ & $\mathrm{Cr}$ & $\mathrm{Ni}$ & $\overline{A l}$ & Mo & $\bar{V}$ & $\overline{\mathrm{Ti}}$ \\
\hline$\overline{1}$ & UNSS-43000 & 0,05 & 0,33 & & 0,19 & & 16,1 & 0,18 & & & & \\
\hline 2 & AISI-1070 & 0,67 & 0,22 & 0,003 & 0,69 & 0,018 & & & 0,043 & & & \\
\hline 3 & $\mathrm{X} 80$ & 0,07 & 0,19 & 0,003 & 1,83 & 0,019 & 0,19 & 0,16 & 0,024 & 0,25 & & 0,104 \\
\hline 4 & DP & 0,11 & 0,30 & 0,014 & 1,11 & 0,017 & & & 0,038 & & & \\
\hline 5 & ASI-D2 & 1,59 & 0,29 & 0,006 & 0,34 & 0,02 & 11,2 & & & 0,56 & 0,94 & \\
\hline 6 & ASI-H13 & 0,39 & 1,06 & 0,001 & 0,36 & 0,02 & 5,12 & & & 1,00 & 0,96 & \\
\hline
\end{tabular}

Foram cortados pedaços retangulares de cada um desses aços. Depois, colocados um junto a outro na ordem mostrada na tabela 8, foram encapsulados em resina para formar um único corpo rígido. A Figura 5.9 indica a geometria da amostra obtida e a ordem em que foi colocado cada um dos materiais listados na Tabela 5-2. Uma fotografia é apresentada na Figura 5.10.

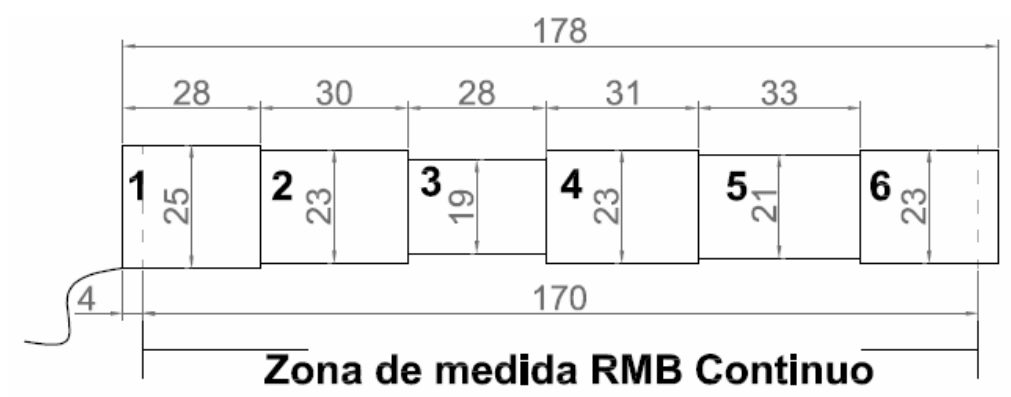

Figura 5.9 - Configuração geométrica da amostra de materiais diferentes. Medidas em mm. 


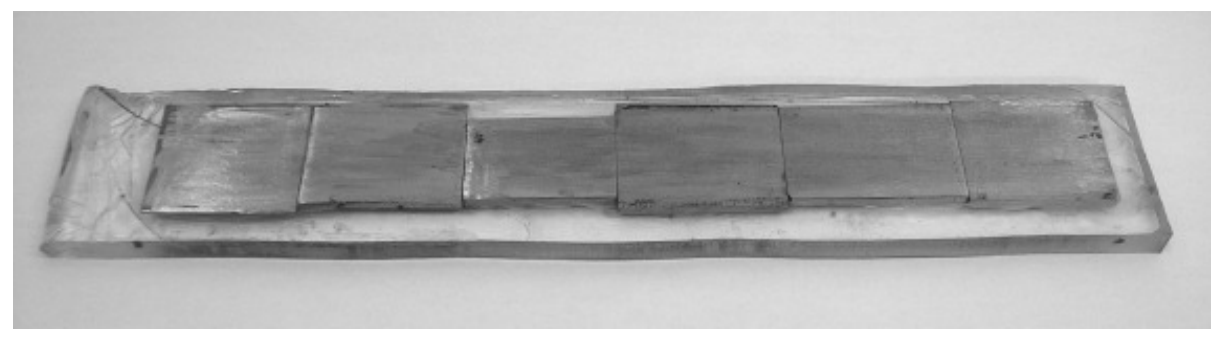

Figura 5.10 - Fotografia da amostra de materiais diferentes.

Na medição do RMBC foi utilizada uma sonda em uma configuração de 1 Ímã e a bobina leitora $C$ (ver Figura 5.2). O movimento foi feito sempre com a bobina atrás do ímã. O comprimento do mapeamento foi de $170 \mathrm{~mm}$ e a velocidade da sonda de $16.23 \mathrm{~mm} / \mathrm{s}$. A Figura 5.9 mostra a localização da zona de medida do RMBC.

Alem das medidas de RMBC, e com o objetivo de ter a maior quantidade de informação ao fazer a análise dos sinais, também foram feitas medições de RMBE. Foi utilizada uma sonda de RMB com Yoke de ferrite, bobina de excitação 80 espiras e bobina leitora de 4000 espiras. Ditas medidas foram feitas aplicando uma corrente de excitação alternada a uma freqüência de $10 \mathrm{~Hz}$ e amplitude $1.8 \mathrm{~A}$. Foram feitas três repetições de medida em pontos diferentes em cada um dos materiais.

\subsubsection{Resultados}

A Figura 5.11a mostra a variação da amplitude do sinal medido de RMBC no tempo e a Figura 5.11b a variação do parâmetro M2-RMBC (ver secção 5.2) calculado na banda completa de análise (1-100kHz).

$\mathrm{Na}$ Figura 5.11a se consegue identificar algumas variações na amplitude do sinal, e com um pouco de dificuldade, correlacionar-las com as variações de material ao longo da amostra. Igualmente o gráfico do parâmetro M2-RMBC do sinal original, Figura 5.11b não acrescenta melhoras nos resultados. Nela se observa a presença de alguns picos correspondentes a transição entre os diferentes materiais da amostra, que pode estar mais relacionados à efeitos de borda na magnetização, na 
passagem pelas transições dos pedaços de material. A alta amplitude mostrada pelo pico presente após dos $160 \mathrm{~mm}$ na Figura 5.11 , é conseqüência do aumento na densidade de fluxo gerado na região quando a sonda de RMBC sai do amostra. Aumento de fluxo por efeito de borda.

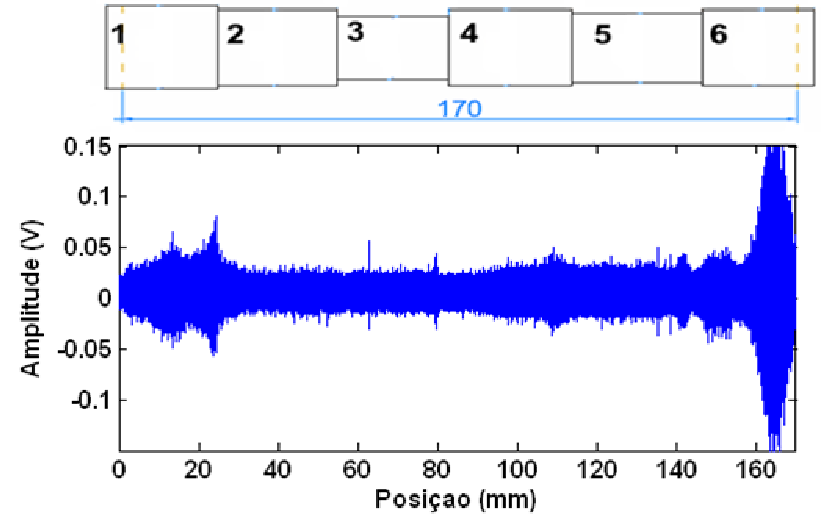

a)
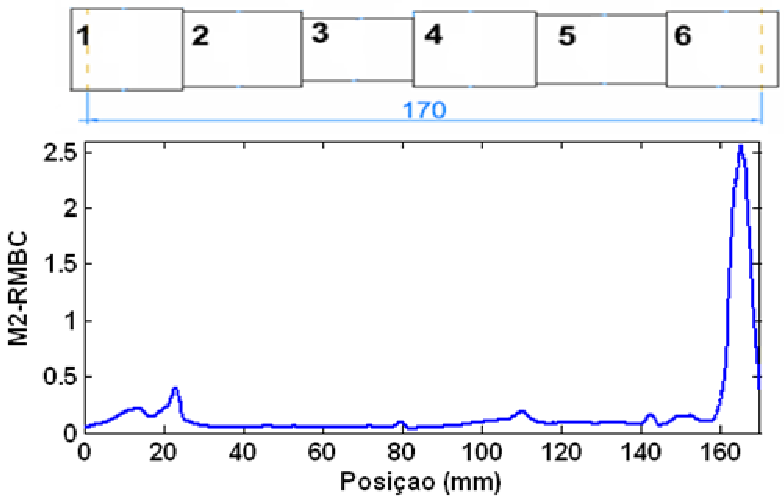

b)

Figura 5.11 - Medição do RMBC feito na amostra de materiais deferentes. a) Sinal no tempo, b) Variação do parâmetro M2-RMBC.
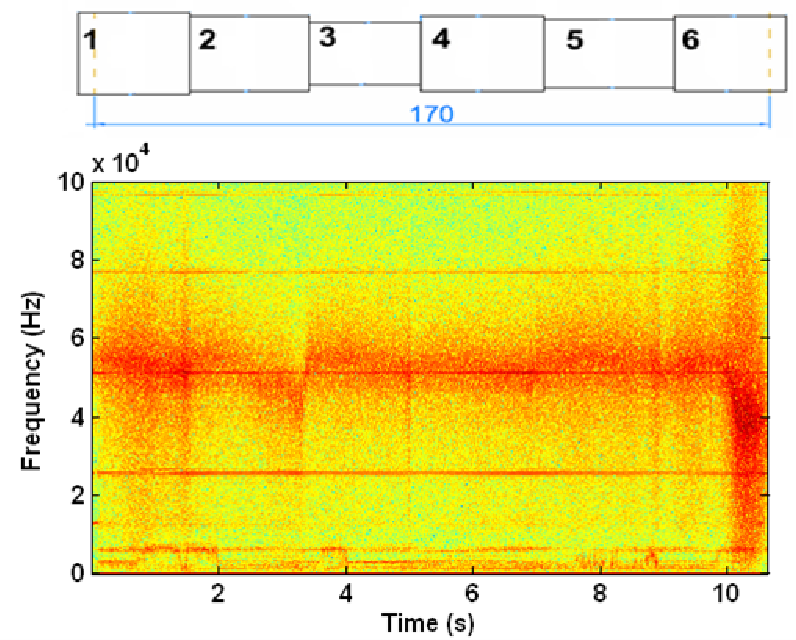

a)
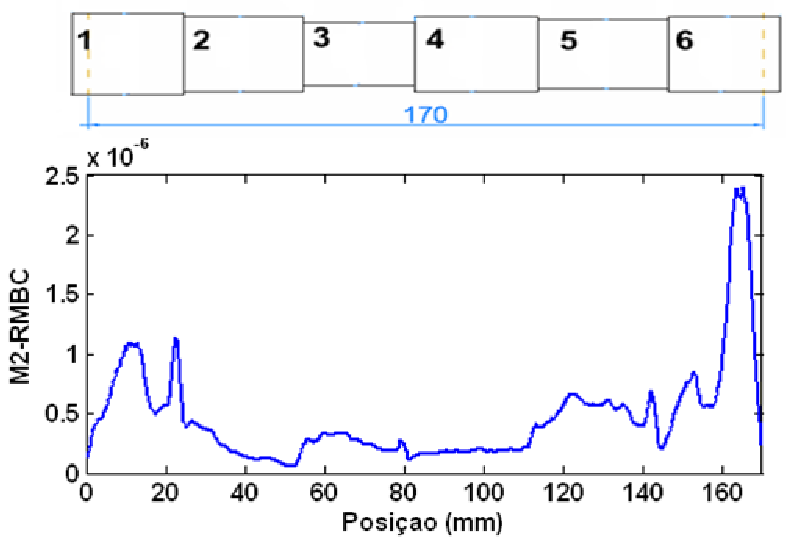

b)

Figura 5.12 - Medição do RMBC. a) Espectrograma do sinal, b) Variação do parâmetro M2-RMBC com uma banda de freqüência de análise de $60-70 \mathrm{kHz}$.

A Figura 5.12a mostra o Espectrograma do sinal de RMBC . As bandas estreitas presentes em 24 e $77 \mathrm{kHz}$ são ruídos eletromagnéticos, não relacionados com o fenômeno magnético. As características elétricas das bobinas leitoras são influenciadas pelo tipo de arame, quantidade de voltas e arranjo do enrolamento 
(bobina alta o baixa) utilizado na fabricação. Em dependência dessas características (resistência, indutância e capacitância) a bobina leitora apresenta ressonância na resposta, em determinadas freqüências de campo medido (TUMANSKI, S, 2007; CAPO-SANCHEZ, J.; PADOVESE, L, 2009). No caso da bobina leitora utilizada (Bobina C), apresenta ressonância em $50 \mathrm{kHz}$, e o sinal de RMB fica distribuído principalmente ao redor desse valor. Nesta figura é possível identificar claramente flutuações do sinal no tempo que correspondem com as posições dos diferentes materiais da amostra. Percebe-se também, como algumas bandas de freqüência são mais sensíveis na identificação dos materiais. Se o sinal de RMBC é filtrado em uma banda de freqüência de $60-70 \mathrm{kHz}$, e o parâmetro M2-RMBC é calculado para este sinal filtrado, obtemos o gráfico mostrado na Figura $5.12 b$. Nessa figura se percebe como a sensibilidade da técnica melhora.
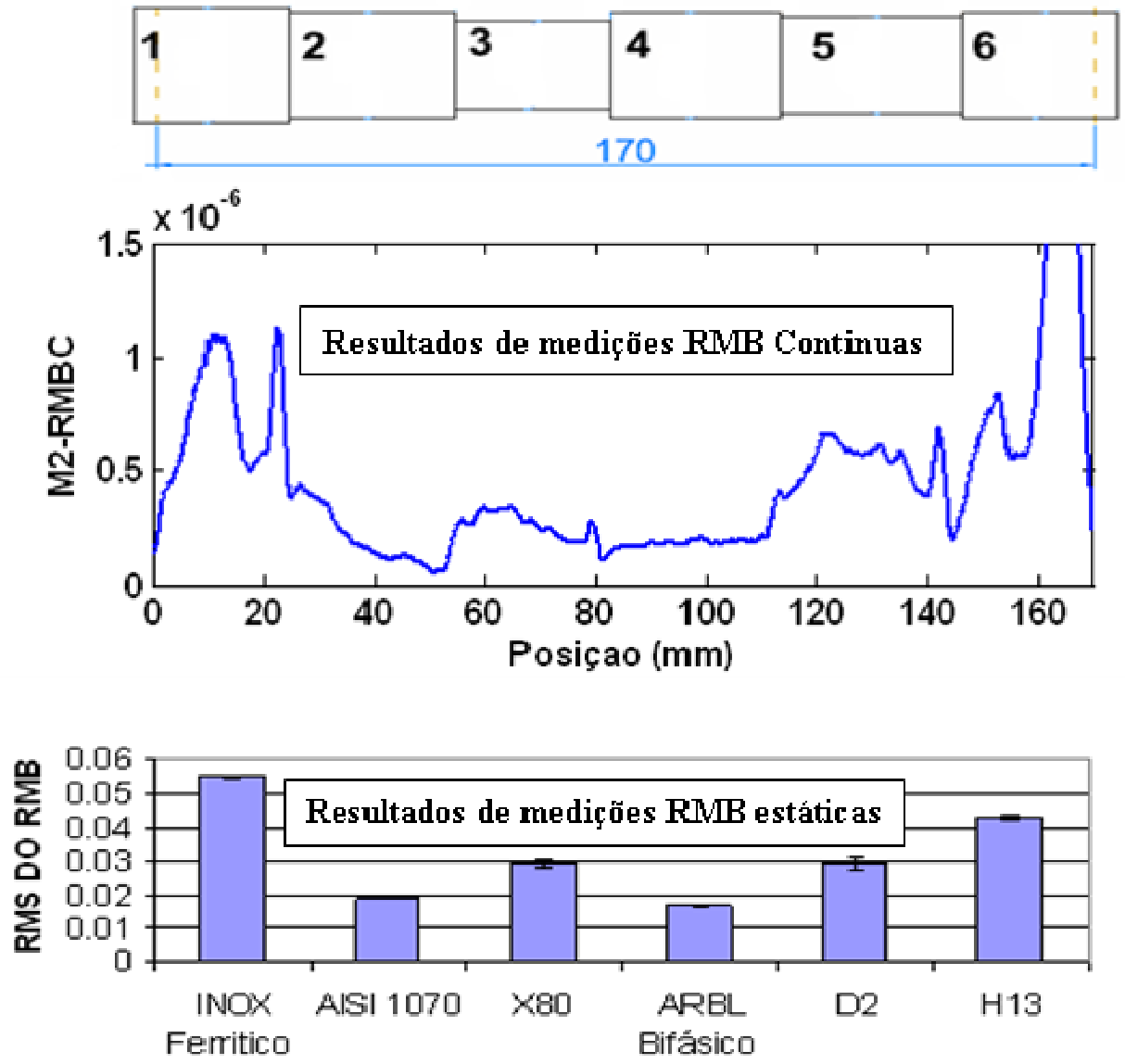

Figura 5.13 - Comparação entre medições de RMBE e RMBC em amostra com matérias diferentes. 
A Figura 5.13 compara os resultados da Figura 5.12b com medições de RMBE realizados na mesma amostra. Observa-se como a variação de amplitude do sinal de RMB entre os materiais é relativamente similar nas duas técnicas utilizadas. Estes primeiros resultados evidenciam a potencialidade do método de medição do RMBC.

\subsubsection{Ensaio preliminar 2: RMBC em amostra com diferentes porcentagens de descarbonetação}

\subsubsection{Materiais e métodos}

Foi utilizado aço AISI -1006 no projeto da amostra. Chapas com $0,6 \mathrm{~mm}$ de espessura. $\mathrm{O}$ material foi submetido a diferentes porcentagens de descarbonetação realizadas através de tratamentos térmicos em fornos de atmosfera controlada. Ao final, foram obtidas cinco chapas com diferentes teores de carbono: 0,061\%C (material virgem), $0,047 \% \mathrm{C}\left(10 \mathrm{~min}, 760^{\circ} \mathrm{C}\right.$, sem umidade, $\left.90 \% \mathrm{~N}_{2}, 10 \% \mathrm{H}_{2}\right), 0,019 \% \mathrm{C}$ (20min, $760{ }^{\circ} \mathrm{C}$, sem umidade, $\left.90 \% \mathrm{~N}_{2}, 10 \% \mathrm{H}_{2}\right), 0,0074 \% \mathrm{C}\left(60 \mathrm{~min}, 760{ }^{\circ} \mathrm{C}\right.$, sem umidade, $\left.\quad 90 \% \mathrm{~N}_{2}, 10 \% \mathrm{H}_{2}\right)$ e $0,0029 \% \mathrm{C} \quad\left(60 \mathrm{~min}, \quad 760^{\circ} \mathrm{C}\right.$, sem umidade, $\left.85 \% \mathrm{~N}_{2}, 15 \% \mathrm{H}_{2}\right)$. Cada chapa foi cortada em tamanhos iguais $(30 \times 30 \mathrm{~mm})$, colocadas uma junto à outra, e depois encapsuladas em resina para assim formar uma amostra só. A Figura 5.14 ilustra a configuração geométrica e uma fotografia da amostra projetada.

O comprimento do mapeamento linear feito sobre a amostra com descarbonetação foi de $190 \mathrm{~mm}$. Como no caso anterior, foi usada a bobina leitora $C$ acompanhada de 1 Ímã. O movimento foi feito com a bobina atrás do ímã. A velocidade da sonda foi de $16,23 \mathrm{~mm} / \mathrm{s}$. Para cada caso de descarbonetação também foram feitas medições utilizando RMBE com os mesmos parâmetros de medida que no caso anterior. 


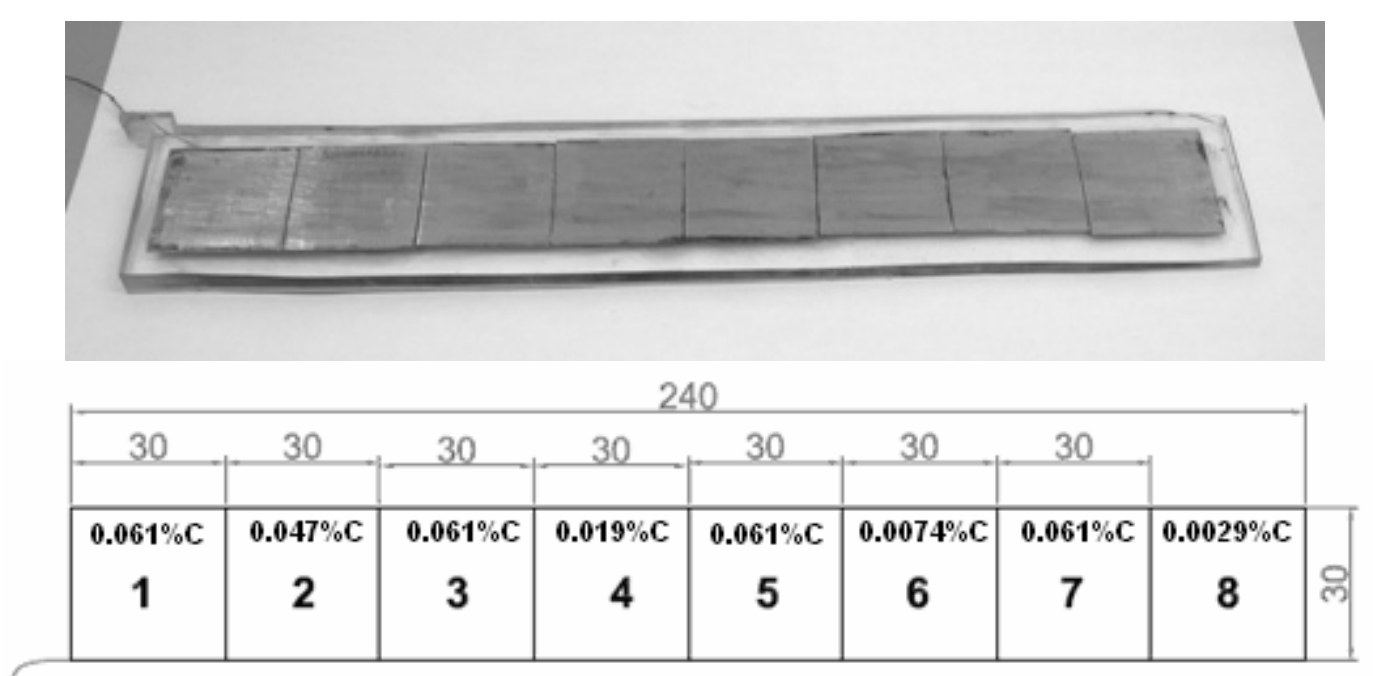

Figura 5.14 - Amostra com descarbonetação. Medidas em mm.

\subsubsection{Resultados}

A Figura 5.15a mostra a variação da amplitude do sinal de RMBC no tempo e a Figura 5.15b a variação do parâmetro M2-RMBC. Observa-se na Figura 5.15a que só com o sinal no tempo, e sem nenhum tipo de análise ou processamento é possível determinar variações de amplitude que identificam algumas regiões da amostra. Entretanto, o gráfico da variação do parâmetro M2-RMBC, calculado tomando o sinal em toda a banda de freqüência de análise $(0-100 \mathrm{Khz})$ mostra uma leve melhoria na identificação e classificação das diferentes zonas da amostra.

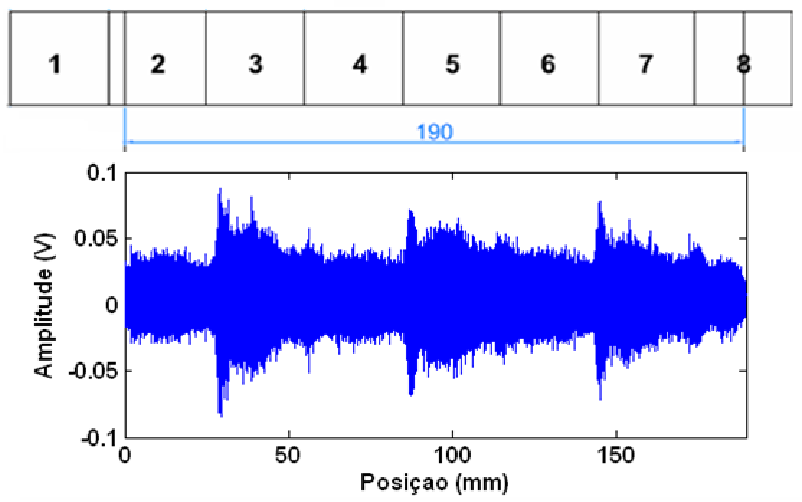

a)
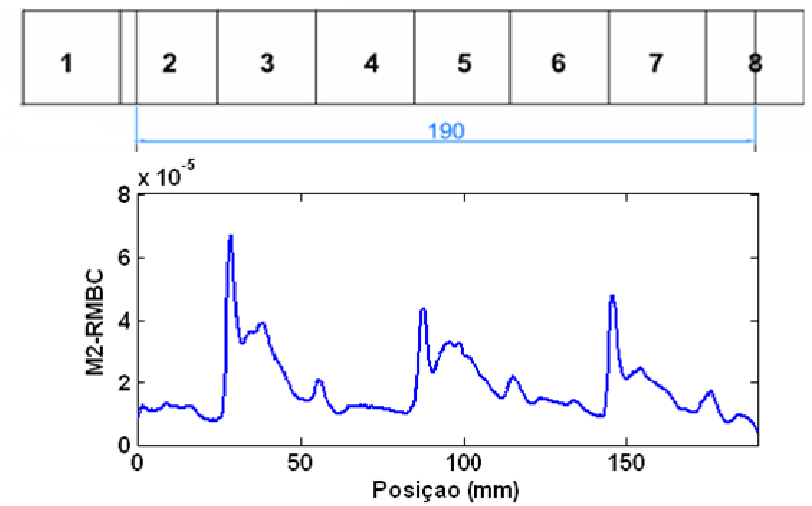

b)

Figura 5.15 - Medição do RMBC feito na amostra com descarbonetação. a) Sinal no tempo, b) Variação do parâmetro M2-RMBC. 
Na Figura 5.16a é mostrado o Espectrograma do sinal de RMBC. Nesta figura é identificada claramente uma divisão do sinal em diferentes faixas temporais. Cada uma destas faixas verticais está visualmente diferenciada em toda a banda de freqüência de análise do sinal, e suas posições correspondem exatamente com a distribuição das chapas (2 a 8) na amostra. A distribuição de amplitudes de ditas faixas é diferente abaixo dos $50 \mathrm{kHz}$ do que acima. Abaixo dos $50 \mathrm{kHz}$ cada uma das faixas apresenta um comportamento similar. Entretanto acima dos $50 \mathrm{kHz}$, as diferenças são mais importantes. Observam-se como as chapas que não foram submetidas ao processo de descarbonetação (chapas 3, 5 e 7) apresentam maiores emissões de RMB de alta freqüência do que as chapas descarbonetadas. A Figura 5.16b mostra a distribuição do parâmetro M2-RMBC com uma banda de freqüência de análise de $70-100 \mathrm{kHz}$. Nessa Figura se consegue identificar de uma maneira mais clara cada um dos casos de descarbonetação.

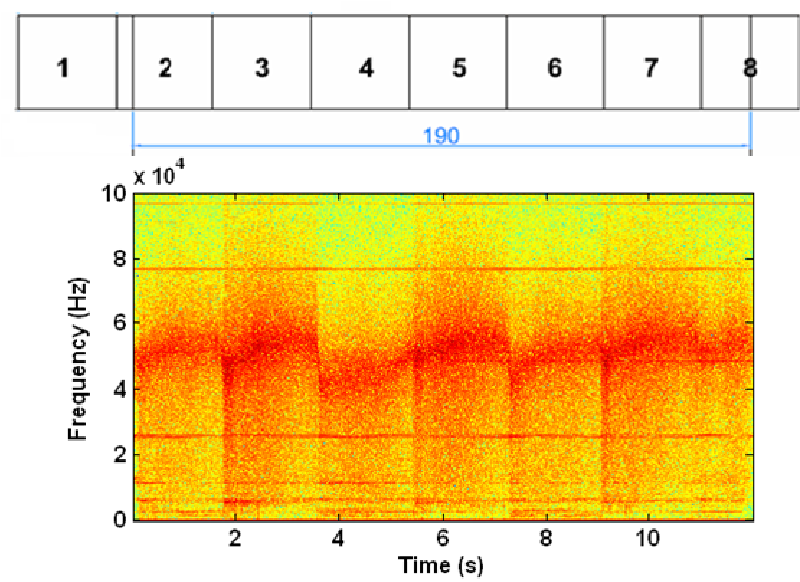

a)

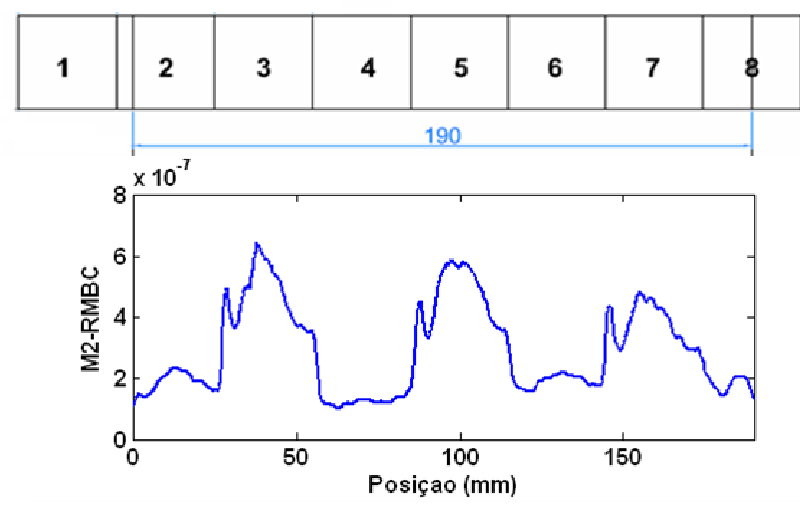

b)

Figura 5.16 - Medição do RMBC. a) Espectrograma do sinal, b) Variação do parâmetro M2RMBC com uma banda de freqüência de análise de $70-100 \mathrm{kHz}$.

A Figura 5.17 mostra conjuntamente os resultados das medidas de RMBE e RMBC. Como no caso da amostra com materiais diferentes, aqui também se observa como os resultados de RMBC são bastante aproximados aos resultados das medidas de RMBE. Estes resultados são importantes, e abre a possibilidade de aplicar esta nova técnica de mapeamento, na avaliação de peças degradadas termicamente. 


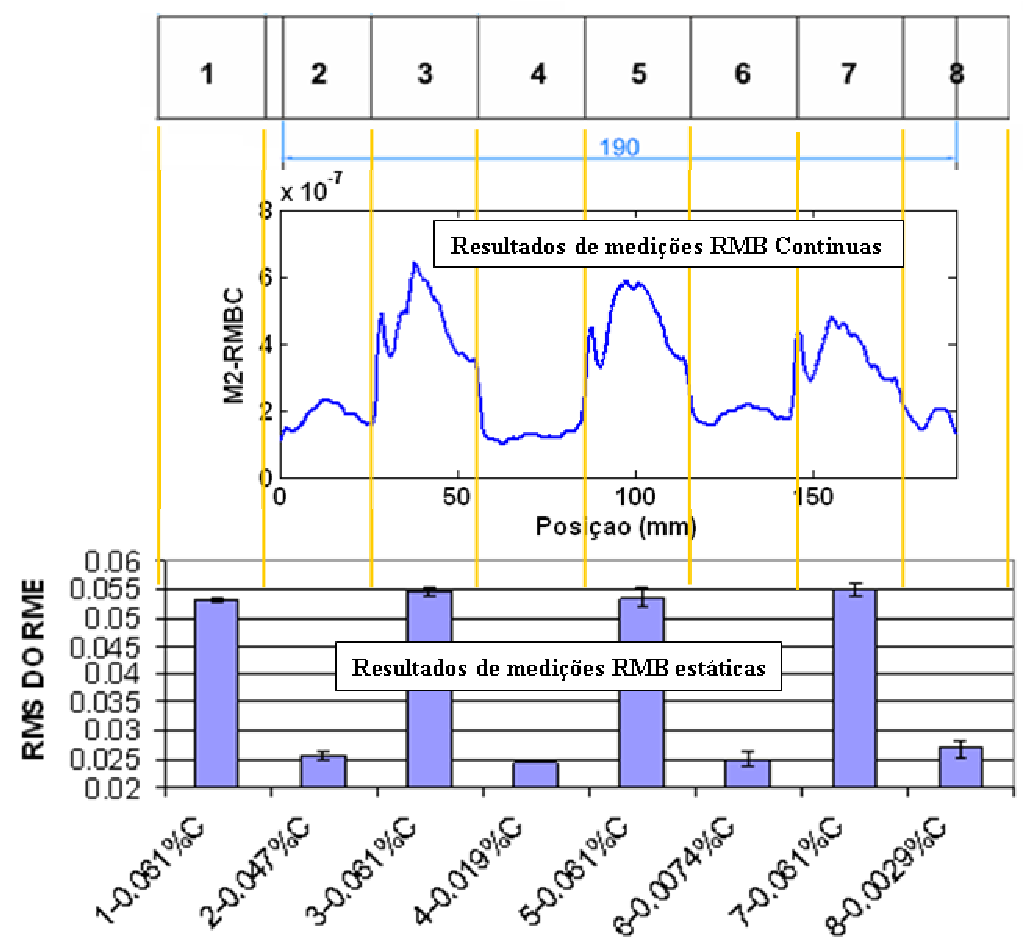

Figura 5.17 - Comparação entre medições de RMBE e RMBC em amostra com descarbonetação.

\subsection{MEDIÇÕES DE RMBC EM UMA AMOSTRA COM VARIAÇÃO DE ESPESSURA (FRANCO F. A, PADOVESE L. R, 2009)}

\subsubsection{Materiais e métodos}

O material estudado foi o aço AISI-1070, do qual a sua composição química está dada na Tabela 5-3. De uma chapa de 1,2mm de espessura, foram cortadas amostras retangulares de $40 \times 250 \mathrm{~mm}$. Nas amostras foram usinadas em uma da suas faces, ranhuras com diferentes larguras e profundidades. A Figura 5.18 ilustra esquematicamente a geometria das amostras estudadas. $O$ comprimento maior das amostras coincide com direção de laminação da chapa. 


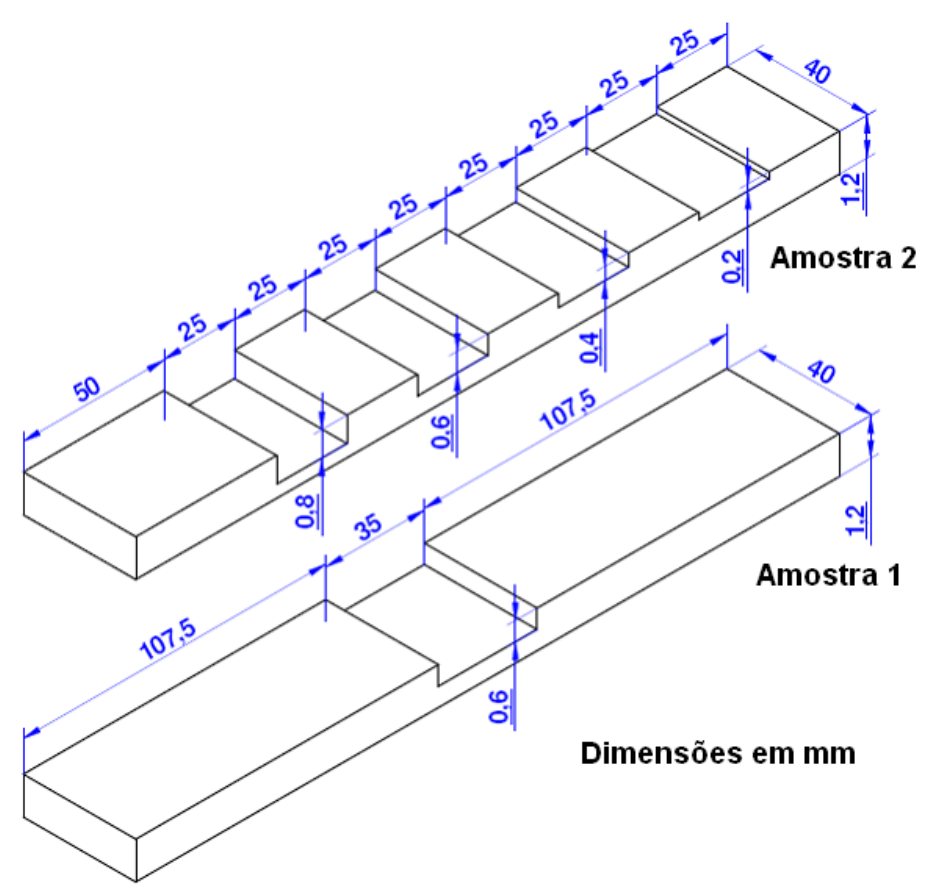

Figura 5.18 - Geometria das amostras com variação de espessura.

$\mathrm{Na}$ sonda de medição de RMBC foram usadas 4 bobinas leitoras diferentes. Bobina A, C, D e E. (Figura 5.2). Em relação aos campos magnéticos aplicados, se utilizaram arranjos de 1, 2, 3, e 4 ímãs.

Tabela 5-3 - Composição química das amostras com variação de espessura..

\begin{tabular}{cccccccc}
\hline \multicolumn{7}{c}{ \% em massa do elemento } \\
\hline $\mathrm{C}$ & $\mathrm{Si}$ & $\mathrm{S}$ & $\mathrm{Mn}$ & $\mathrm{P}$ & $\mathrm{Cr}$ & $\mathrm{Ni}$ & $\mathrm{Al}$ \\
\hline 0,67 & 0,22 & 0,003 & 0,69 & 0,018 & --- & -- & 0,043 \\
\hline
\end{tabular}

Em cada uma das amostras preparadas foram feitas medições na face lisa da chapa e com 4 velocidades diferentes. Usaram-se duas orientações da sonda com relação ao movimento; uma colocando a bobina leitora na frente dos ímãs, e outra colocando-la atrás. A sonda sempre esteve em contato com a amostra. Para cada condição de medida, foram feitas 6 repetições. Os comprimentos e localização das medidas de RMBC são indicados em cada um dos resultados. 


\subsubsection{Resultados}

\subsubsection{Influência do campo aplicado}

Na Figura 5.19 são apresentados resultados de medições feitas na amostra 2, com velocidade da sonda de $16.5 \mathrm{~mm} / \mathrm{s}$, e utilizando a bobina leitora C posicionada na frente dos ímãs. Usaram-se campos produzidos por 1, 2, 3 e 4 ímãs. 0 comprimento de medida é de $185 \mathrm{~mm}$.

Observa-se na Figura 5.19a, e no caso em que é utilizado um arranjo de 4 ímãs, a produção de alterações visíveis do sinal de RMBC no tempo. Ditas variações ficam cada vez menos perceptíveis enquanto o numero de ímãs utilizado passa de 4 para 1.

Na Figura 5.19b, que mostra a variação do parâmetro M2-RMBC, se observa um comportamento similar. São gerados regiões de alta emissão de RMB nas secções da chapa com menor espessura, produzidas principalmente pelo aumento da densidade do fluxo. Igualmente, ditas emissões diminuem com a redução do campo magnético aplicado (número de ímãs utilizados). Nos gráficos dos espectrogramas, Figura 5.19c, também se apresenta melhores resultados quando são utilizados 4 ímãs. Conseguem-se identificar nesse caso, algumas bandas do sinal no tempo que correspondem às posições das ranhuras produzidas na amostra.

Conclui-se segundo o observado, e especificamente para o caso de detecção de variações de espessura, que ao utilizar altos campos de excitação, se consegue obter uma melhora importante nos resultados em relação à utilização de campos baixos. Campos altos produzem maior densidade de linhas do fluxo e atingem maiores profundidades no material. Essas condições de fluxo magnético são mais sensíveis as mudanças na espessura das amostras e, portanto as emissões de RMB que são altamente dependentes dos parâmetros do fluxo magnético fornecem melhor informação sobre as descontinuidades da amostra. Experimentos análogos foram realizados utilizando as demais bobinas leitoras e os resultados foram similares. 

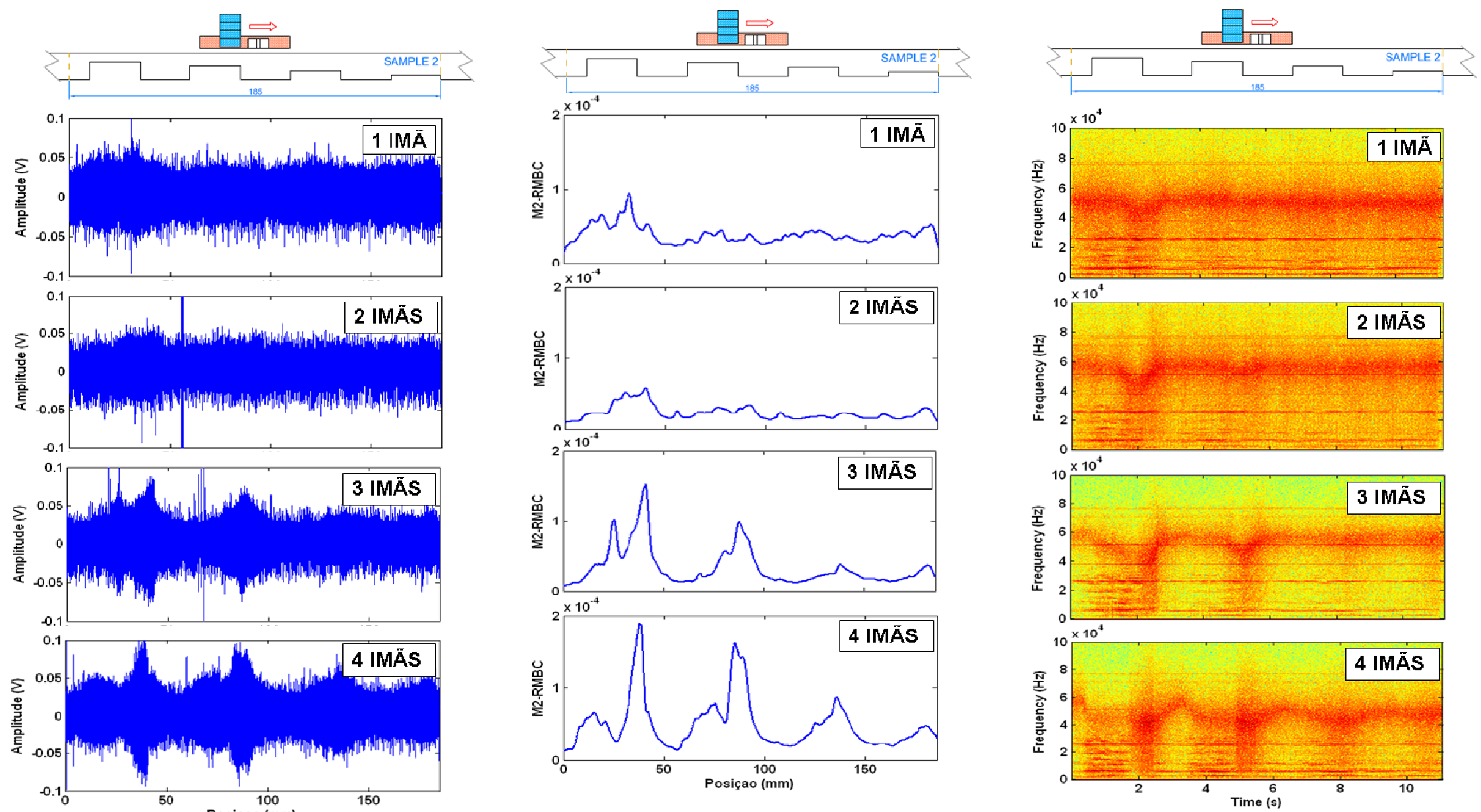

b)

c)

Figura 5.19 - Influência do campo aplicado na resposta do RMBC medido na amostra 2. a) Sinal do RMBC no tempo, b) Variação do parâmetro M2-RMBC, c) Espectrograma do sinal. 


\subsubsection{Influência da bobina leitora}

Apresentam-se resultados de medições feitas na amostra 1, com uma velocidade da sonda de $23 \mathrm{~mm} / \mathrm{s}$, e utilizando o campo produzido por um arranjo de 4 ímãs. Foi comparado o desempenho das bobinas leitoras A, C, D e E (ver características na Figura 5.2). Em todas as medições, as bobinas sempre permaneceram atrás dos ímãs. O comprimento de medida foi de $160 \mathrm{~mm}$. A Figura 5.20 mostra os resultados de RMBC lidos por cada uma das bobinas.

Na Figura 5.20a, variação da amplitude do sinal no tempo e Figura 5.20b, variação do parâmetro M2-RMBC é observado como, a amplitude da resposta do RMBC varia proporcionalmente ao número de voltas de fio dado em cada uma das bobinas leitoras, o qual é um comportamento esperado. Ao aumentar o número de voltas na bobina leitora se conseguem maiores graus de amplificação do sinal de RMB.

Por outro lado, se percebe como o perfil gerado pelo parâmetro M2-RMBC, na banda de análise completa (1-100 kHz), é aparentemente similar em cada um dos casos. Porém, se observarmos os gráficos dos espectrogramas obtidos, encontramos algumas diferenças importantes. O sinal de RMBC fica concentrado ao redor de bandas de freqüência diferentes, dependendo da bobina leitora utilizada. Como foi explicado no item 5.4.1.2, as bobinas leitoras, em dependência de suas características elétricas, amplificam o sinal de RMB em determinadas bandas de freqüência. Assim, quanto maior número de voltas, menor é o valor da freqüência de amplificação ou ressonância. Além disso, e segundo os resultados obtidos nos ensaios preliminares, se podem conseguir melhoras nos resultados calculando o parâmetro M2-RMBC para determinadas bandas de freqüência. Os gráficos dos espectrogramas mostram como certas bandas são mais sensíveis que outras na avaliação do dano estudado. Neste caso a determinação dessas bandas deve ser realizada em forma independente para cada uma das bobinas utilizadas. 

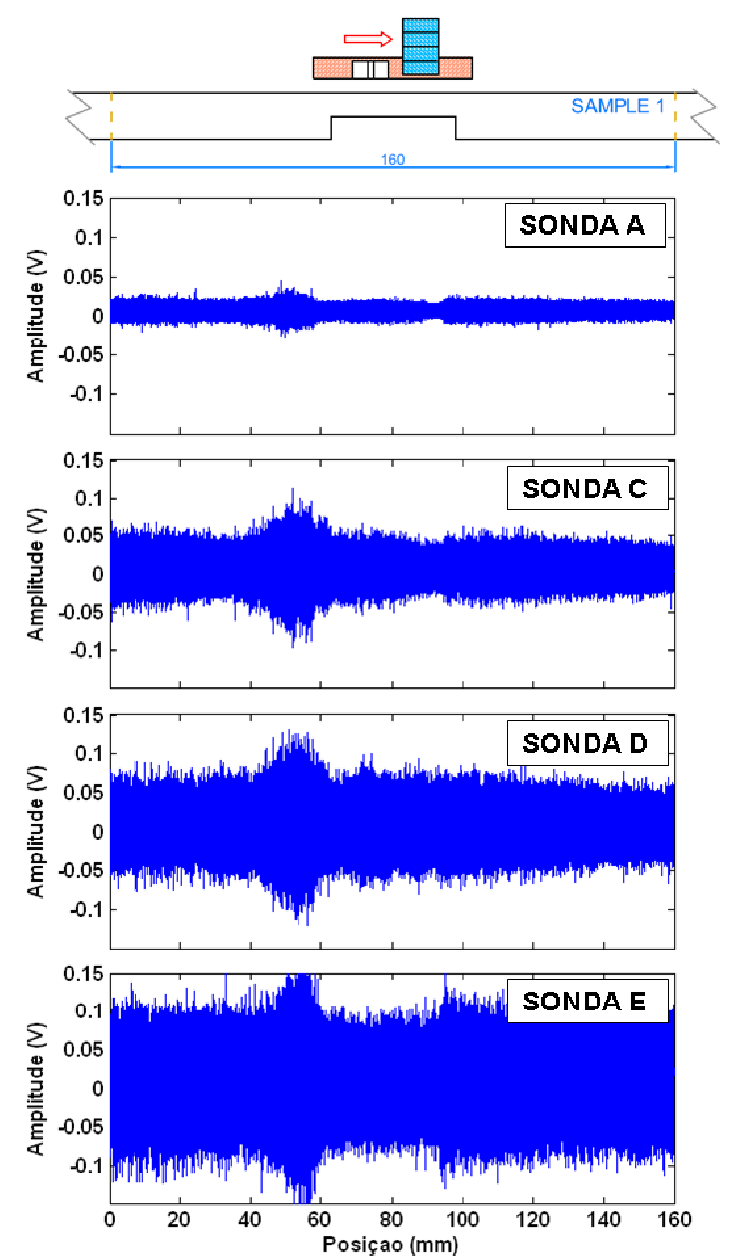

a)
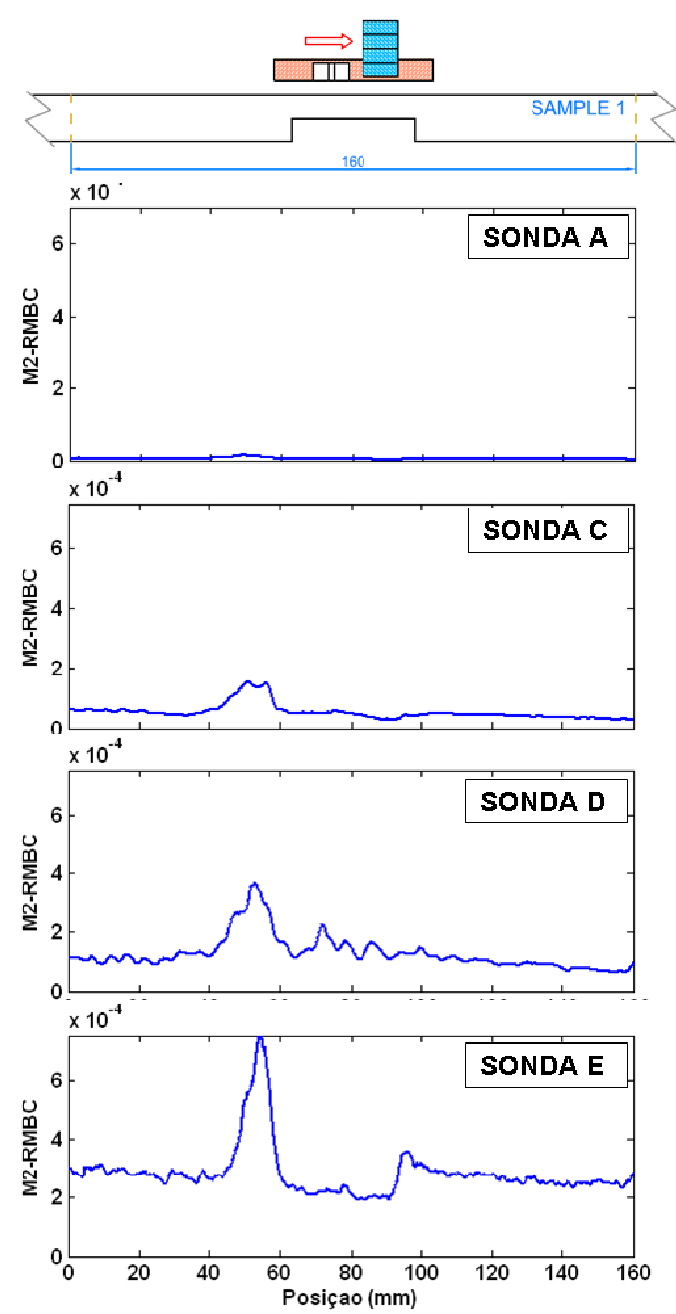

b)
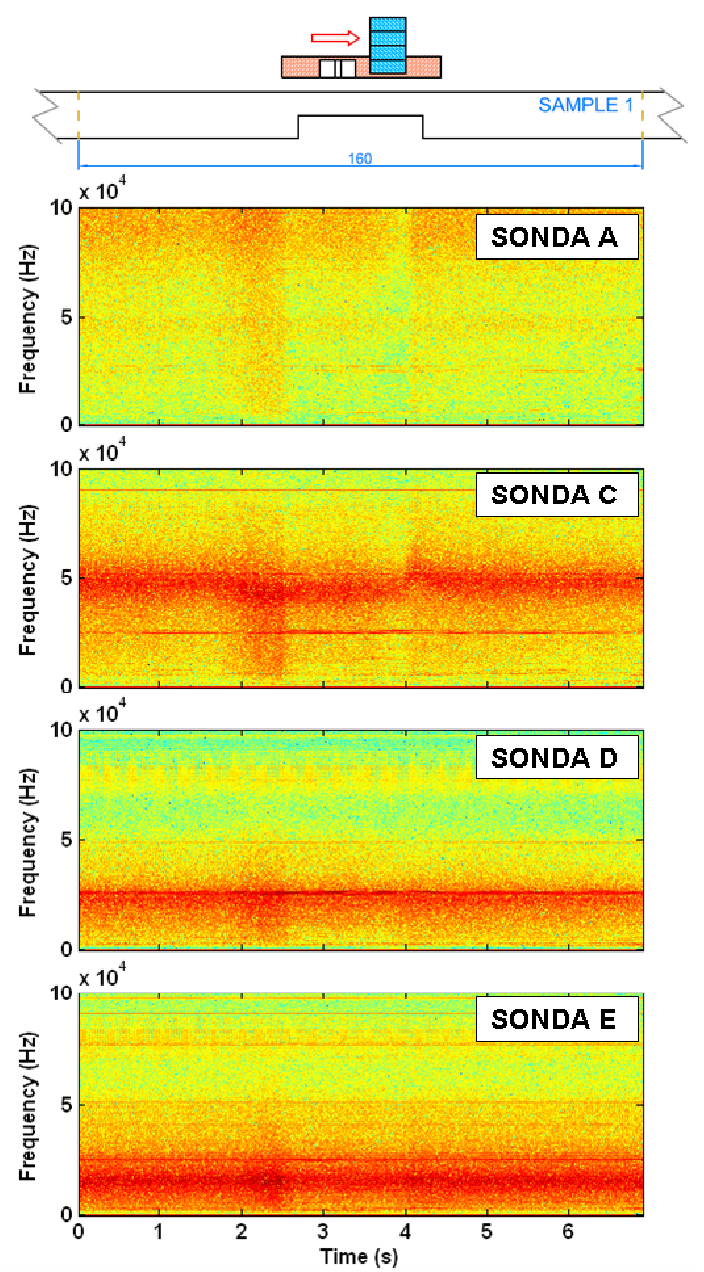

c)

Figura 5.20 Influência da Bobina leitora utilizada na resposta do RMBC medido na amostra 1. a) Sinal no tempo, b) Variação do parâmetro M2RMBC, c) Espectrograma do sinal. 
Para cada uma dos sinais obtidos foi calculado o parâmetro M2-RMBC em diferentes bandas de freqüência. Os melhores resultados para cada uma das bobinas utilizadas é mostrado na Figura 5.21. Em cada um dos gráficos é indicada a banda de freqüência de análise usada.

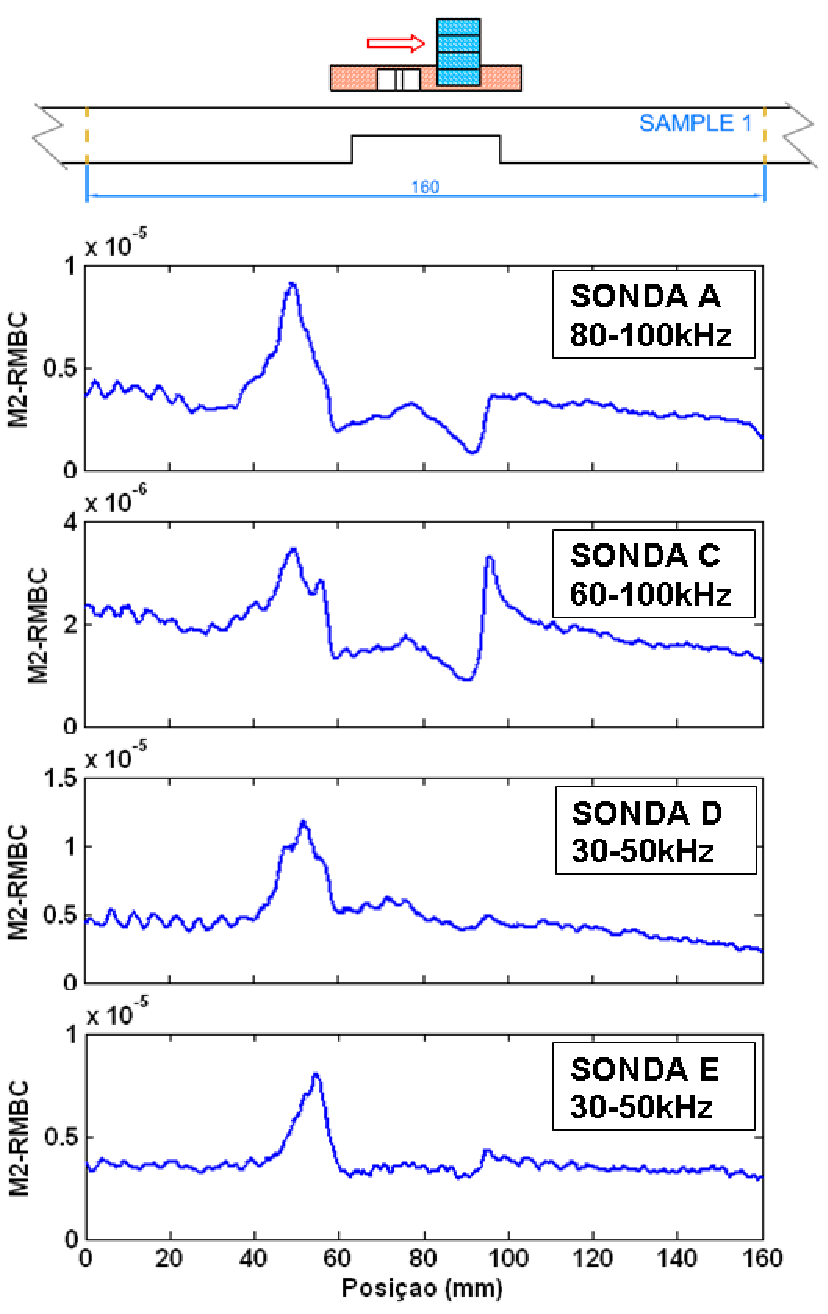

Figura 5.21 - Variação do parâmetro M2-RMBC filtrado para cada uma das bobinas utilizadas.

Observa-se na Figura 5.21 como a resposta das bobinas A e C sofreram uma notável melhoria na identificação da falha produzida. Conclui-se que a utilização do método de RMBC no mapeamento deste tipo de falhas (perda de espessura de chapas), apresenta bons resultados quando os sinais são analisados em bandas de alta freqüência. 


\subsubsection{Influência da velocidade e orientação da sonda}

A seguir são apresentados resultados de medições feitas nas duas amostras (ver Figura 5.18). Foram utilizadas 4 velocidades diferentes na sonda de RMBC 9, 13, 23 e $33 \mathrm{~mm} / \mathrm{s}$. A bobina leitora $C$ foi usada em duas orientações: movimento com a bobina atrás, e na frente dos ímãs. O campo aplicado foi o produzido pelo arranjo de 4 ímãs.

A variação do parâmetro $M 2-R M B C$ dos sinais medidos nas amostras 1 e 2 são ilustradas na Figura 5.22 e Figura 5.24 respectivamente. Em cada uma das figuras é mostrado o valor médio de 6 sinais e seu desvio padrão. Observa-se como o desvio padrão de todas as medidas realizadas é relativamente pequeno, o qual é um indicador da boa reprodutibilidade que apresenta o processo de medição.

Altos transientes são produzidos no início e no final da ranhura, dependendo da posição relativa da bobina e ímã. Na Figura 5.22 é observado como no aumento da velocidade da sonda, é produzido um aumento do valor máximo do sinal captado pela bobina leitora (posição $105 \mathrm{~mm}$ na Figura 5.22a e 55mm na Figura 5.22b ). $\mathrm{Na}$ Figura 5.23 é mostrada a variação da amplitude máxima do parâmetro M2-RMBC em relação a aumento da velocidade da sonda, na amostra 1.

Ao analisar a Figura 5.22 é possível observar que o alto transiente na voltagem do sinal de RMBC é medido quando o ímã encontra-se passando sobre a ranhura (quando há também uma transição de alta densidade de fluxo magnético) e a bobina leitora esta sobre a parte da amostra de maior espessura. 


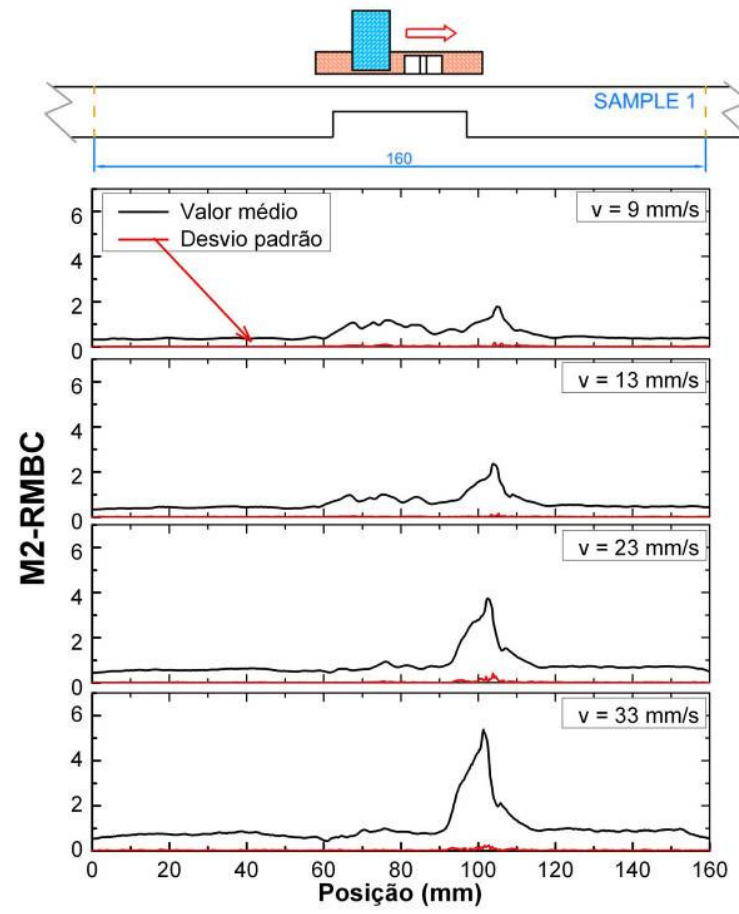

a)

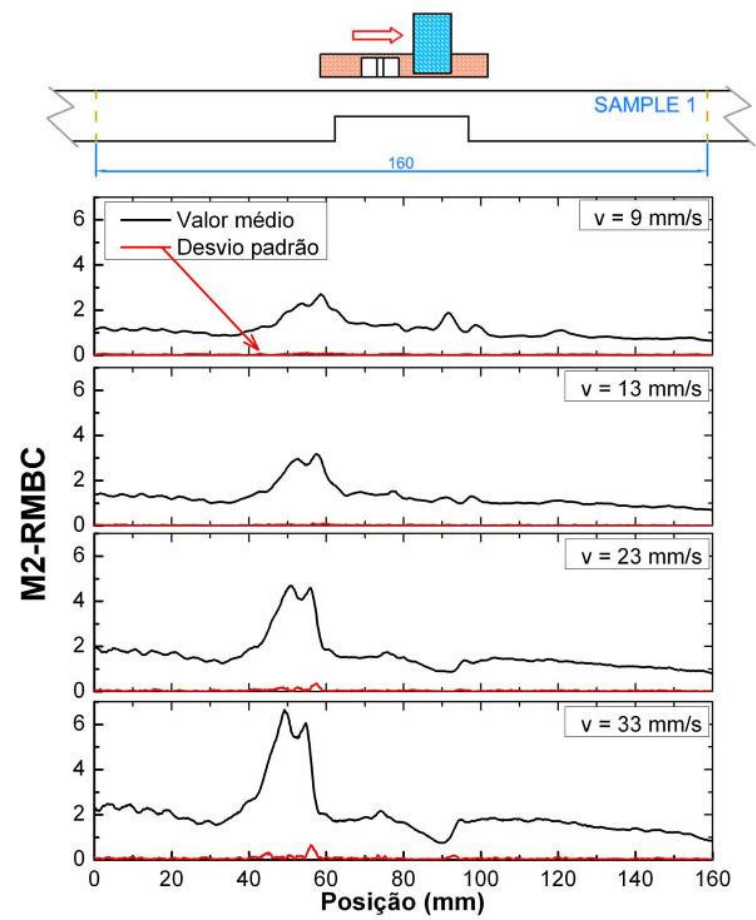

b)

Figura 5.22 - Variação do parâmetro M2-RMBC do sinal medido na amostra 1, com uma banda de freqüência de análise de 1-100 kHz. a) Bobina leitora na frente dos ímãs, b) Bobina leitora atrás dos ímãs.

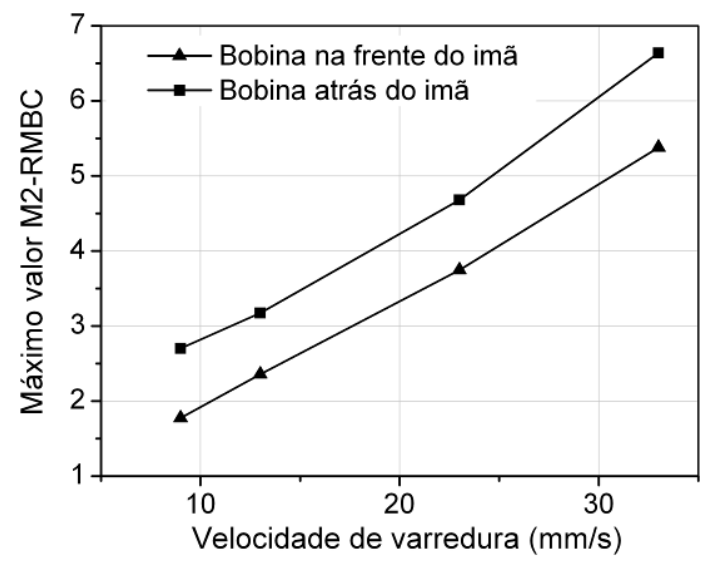

Figura 5.23 - Variação da amplitude máxima do parâmetro M2-RMBC com relação a velocidade da sonda sobre a amostra 1.

Na Figura 5.24 é observado um comportamento similar a resposta mostrada pela amostra 1: altos picos são vistos nas vizinhanças das bordas das ranhuras. Neste caso, porém, uma vez que há ranhuras com profundidades diferentes, pode-se observar que, para cada velocidade da sonda, as amplitudes dos picos do parâmetro $\mathrm{M} 2-\mathrm{RMBC}$ diminuem à medida que diminui a profundidade. Portanto, é possível não 
apenas detectar ranhuras no interior do material, mas também ter uma idéia da sua profundidade.

A Figura 5.25 expõe para a amostra 2 como (de maneira similar ao caso da amostra 1) o aumento da amplitude do pico máximo do parâmetro M2-RMBC é diretamente proporcional ao aumento da velocidade da sonda.

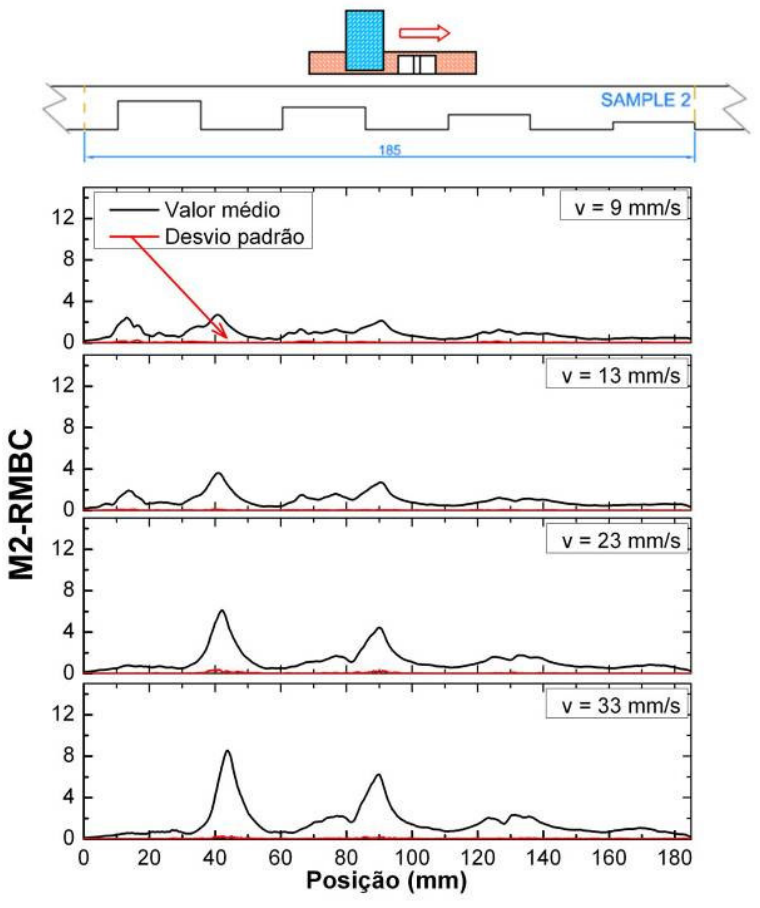

a)

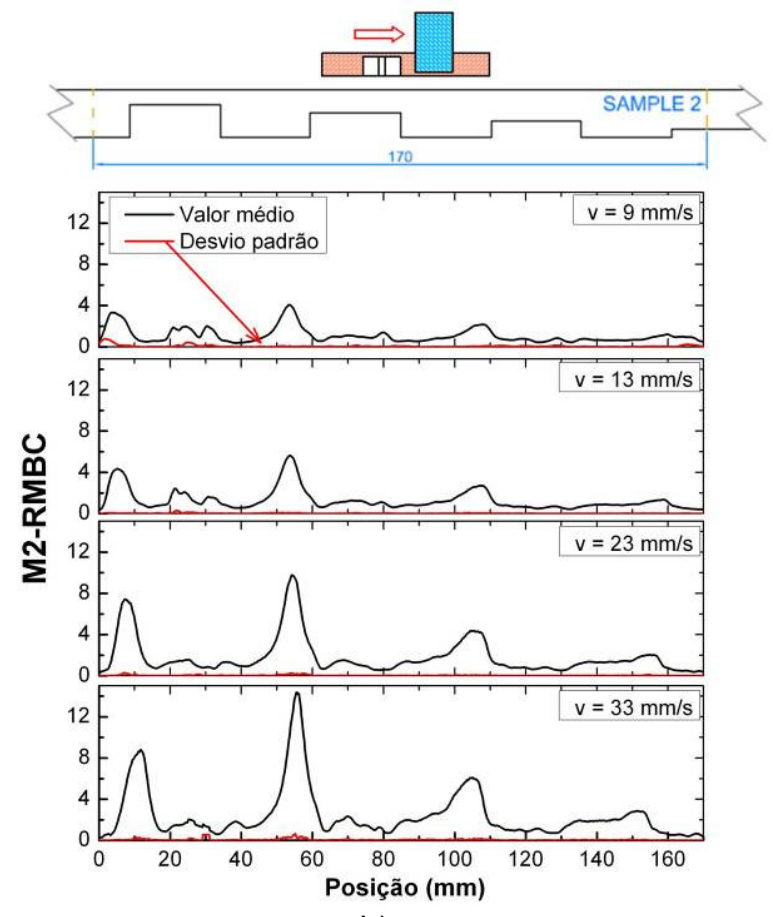

b)

Figura 5.24 - Variação do parâmetro M2-RMBC do sinal medido na amostra 2, com uma banda de freqüência de análise de 1-100 kHz. a) Bobina leitora na frente dos ímãs, b) Bobina leitora atrás dos ímãs.

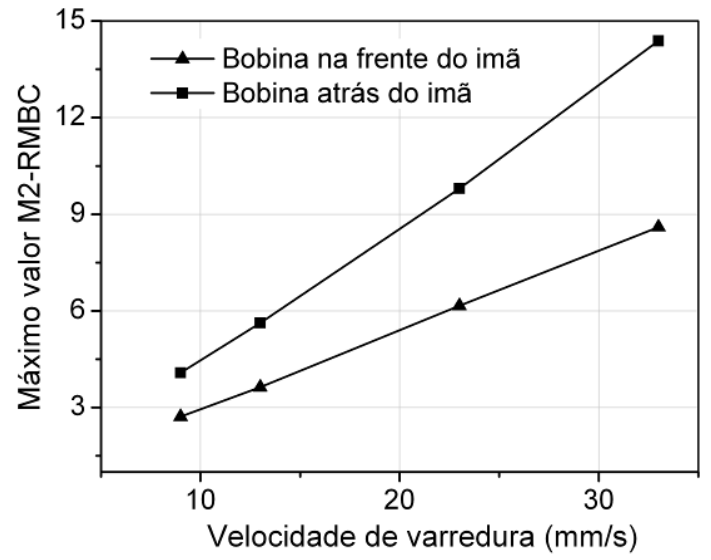

Figura 5.25 - Variação da amplitude máxima do parâmetro M2-RMBC com relação a velocidade da sonda sobre a amostra 2. 
$\mathrm{Na}$ Figura 5.22 e Figura 5.24, é possível notar que o sinal RMBC contém informações sobre a presença das ranhuras nas amostras. No entanto, a posição de início e final de cada ranhura, bem como a sua profundidade, não é claramente perceptível. Em compensação, uma melhora significativa na detecção e classificação das ranhuras pode ser obtida utilizando um procedimento de processamento de sinal adequado, descrito a seguir.
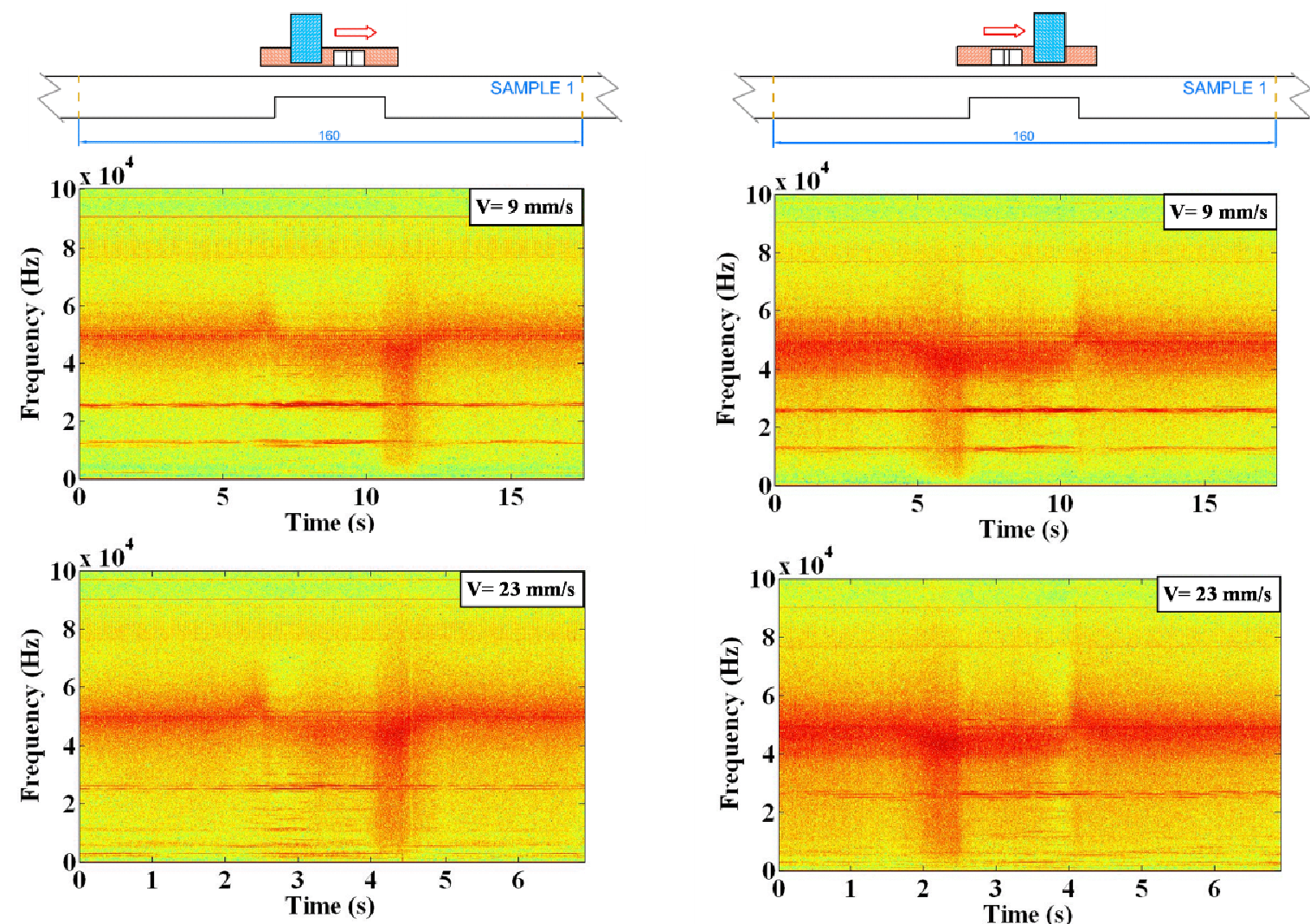

a)

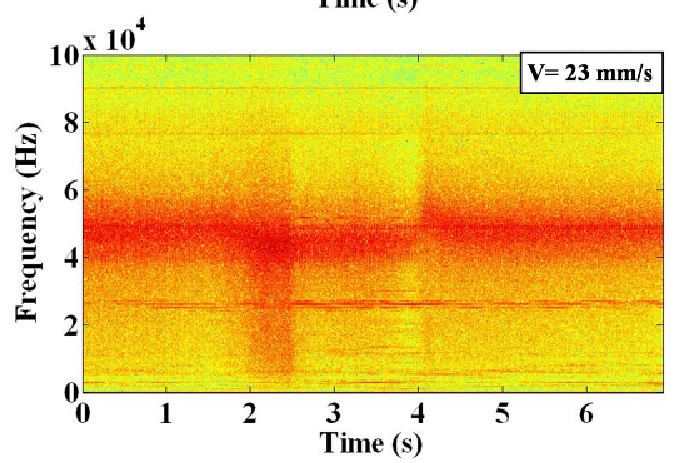

b)

Figura 5.26 - Espectrograma do sinal de RMBC medidos na amostra 1. a) Bobina leitora na frente dos ímãs, b) Bobina leitora atrás dos ímãs.

A Figura 5.26 e Figura 5.27 apresentam os espectrogramas dos sinais de RMBC medidos sobre amostras 1 e 2 . Dois padrões tempo-espectral pode ser observados nestas figuras. As estreitas faixas de freqüências fixas, perto de 10, 25 e $90 \mathrm{kHz}$ são interferências eletromagnéticas detectadas pela bobina leitora ou pelos equipamentos eletrônicos, e não estão relacionados com a emissão de Barkhausen. O segundo padrão está relacionado com o sinal de $\mathrm{RMBC}$ e é observado como uma 
banda larga centrada em $50 \mathrm{kHz}$. Nesses sinais, é possível ver com boa precisão, flutuações de freqüência em determinados instantes de tempo correspondente com a passagem da bobina leitora sobre as bordas das ranhuras. Isto é mais bem visto na banda de freqüência de 10 - $100 \mathrm{kHz}$, na Figura 5.27b.
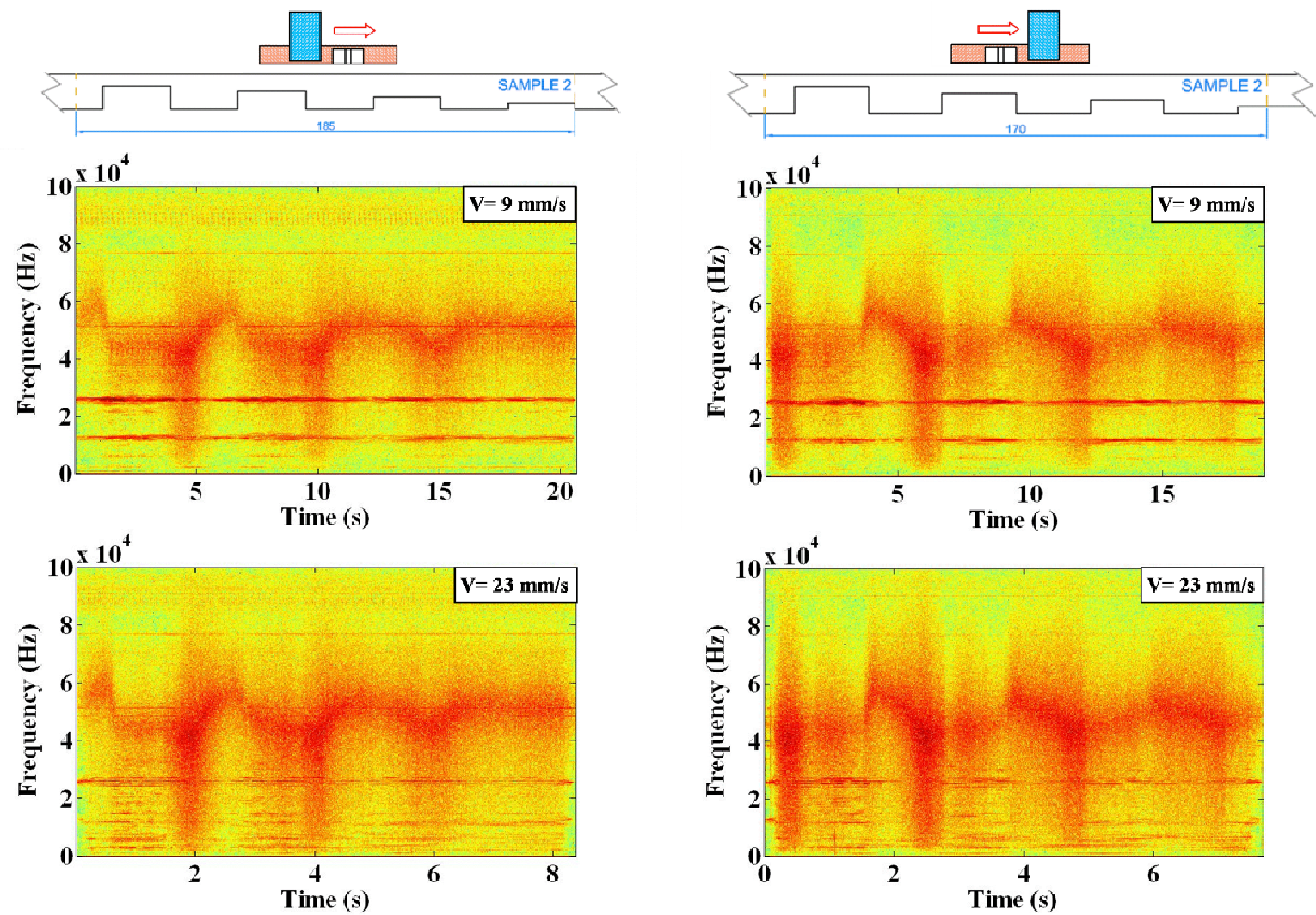

a)

b)

Figura 5.27 - Espectrograma do sinal de RMBC medidos na amostra 2. (a) Bobina leitora na frente dos ímãs, (b) Bobina leitora atrás dos ímãs.

Emissões de RMBC são produzidas por gradientes de fluxo magnético e, como mencionado anteriormente (Figura 5.8), o comportamento magnético do sensor induz um gradiente no material monitorado. Além disso, maiores gradientes de fluxo são produzidos nas transições de espessura da amostra. Acredita-se que em dependência das amplitudes desses gradientes são geradas modulações no sinal de RMBC em bandas diferenciadas de freqüência. Gradientes fortes geram intensas modulações em bandas de freqüência relativamente baixa, enquanto gradientes baixos geram pequenas modulações em bandas de freqüência altas. 
Assim, na Figura 5.26, e principalmente na Figura 5.27, é possível observar que as modulações fortes ocorrem nas bordas das ranhuras (1-60 kHz, aproximadamente), enquanto as pequenas são produzidas em uma faixa de freqüência acima de $60 \mathrm{kHz}$ (que coincidem com as regiões de espessura da amostra).

Até agora, o parâmetro M2-RMBC foi calculado para a banda de freqüência completa dos sinais RMBC. No entanto, se o sinal de RMBC é filtrado numa banda de freqüência 60-100 kHz, e o parâmetro M2-RMBC é calculada para o sinal filtrado, obtém-se os sinais mostrados na Figura 5.28 e Figura 5.29, para as amostras 1 e 2 respectivamente.

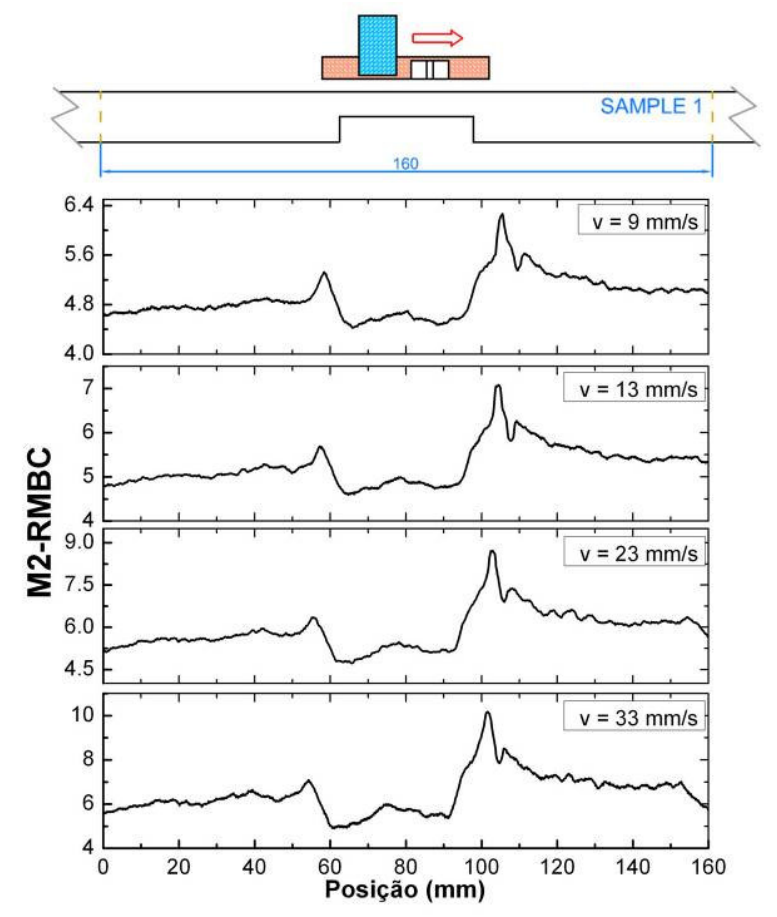

a)

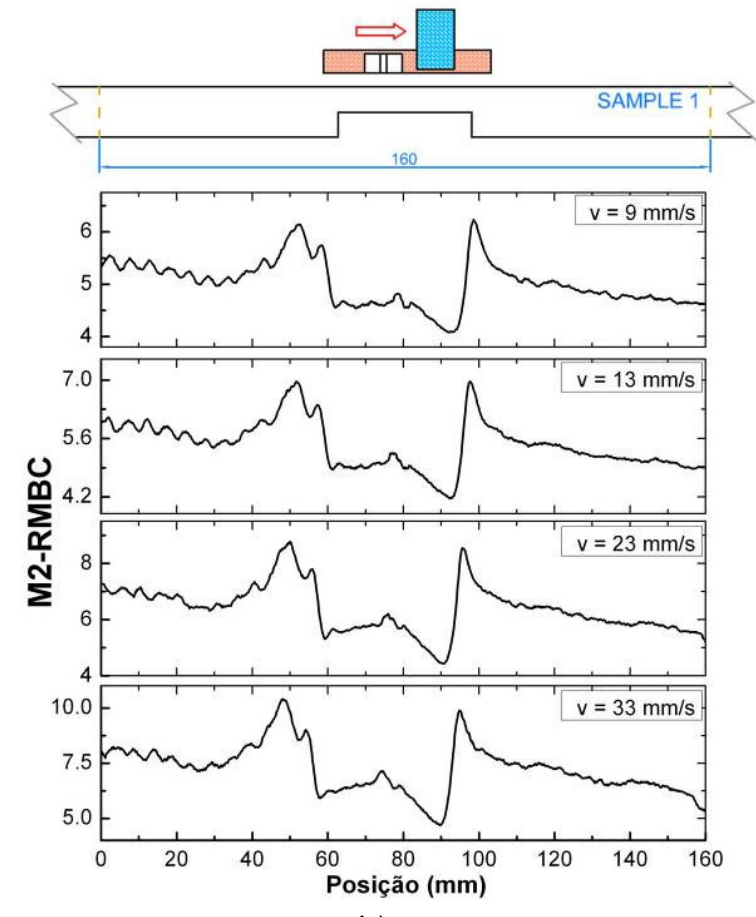

b)

Figura 5.28 Variação do parâmetro M2RMBC na amostra 1, com uma banda de freqüência de análise de $60-100 \mathrm{kHz}$. (a) Bobina leitora na frente dos ímãs, (b) Bobina leitora atrás dos ímãs. 


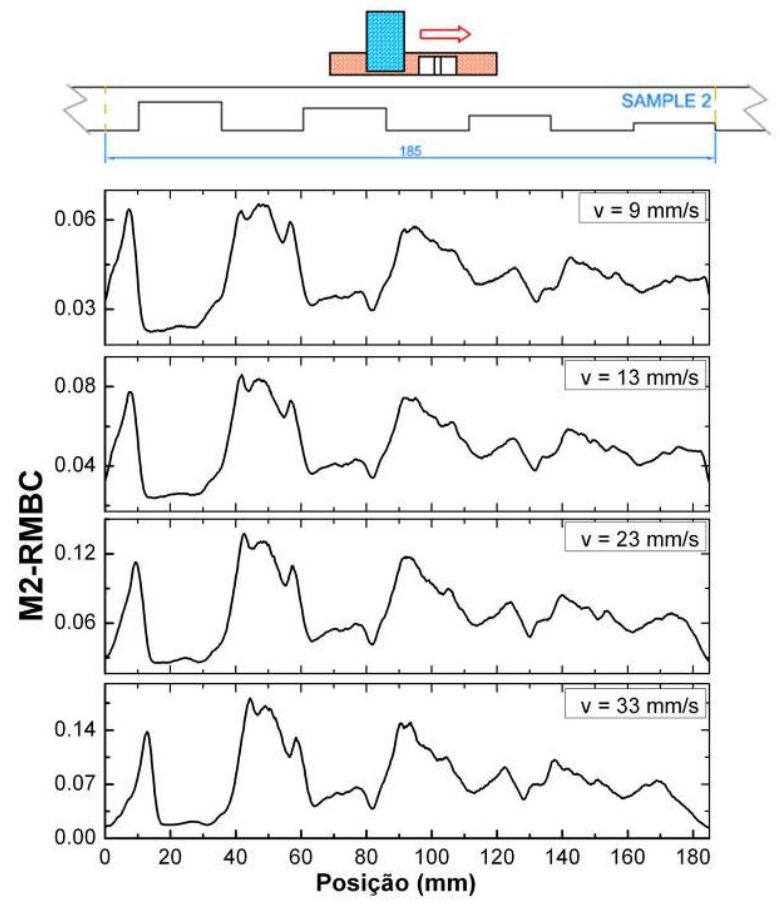

a)

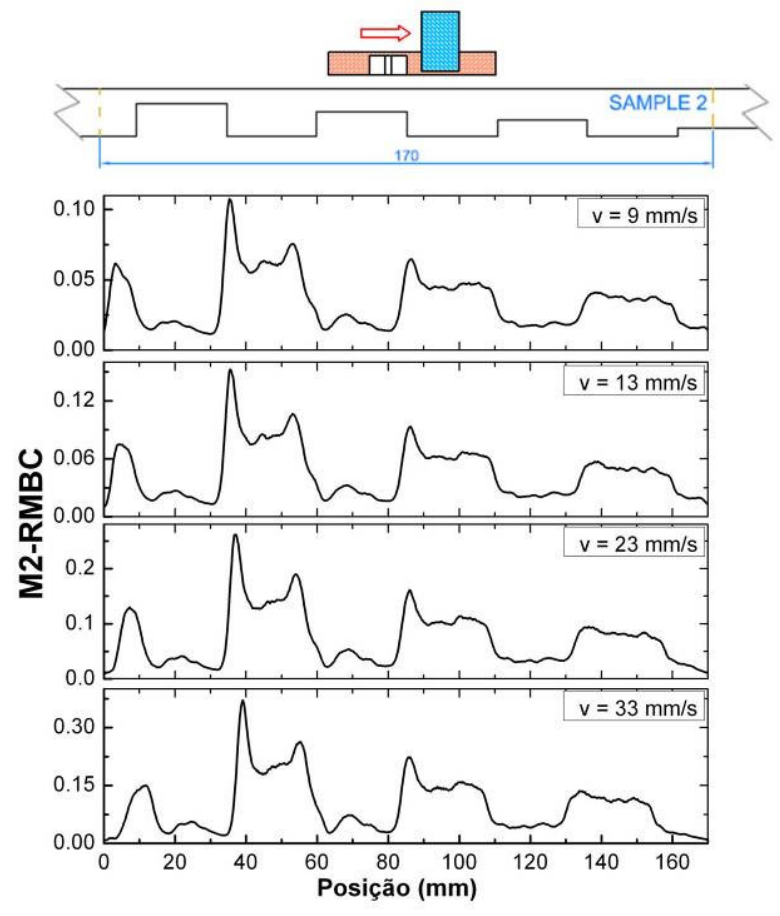

b)

Figura 5.29 Variação do parametro M2RMBC na amostra 2, com uma banda de freqüência de análise de $60-100 \mathrm{kHz}$. (a) Bobina leitora na frente dos ímãs, (b) Bobina leitora atrás dos ímãs.

Observa-se na Figura 5.28 e Figura 5.29, como a identificação das bordas das ranhuras em cada uma das amostras é significativamente aumentada. Além disso, no caso da amostra 2, é possível identificar melhor a profundidade das diferentes ranhuras. A amplitude do parâmetro $\mathrm{M} 2-\mathrm{RMBC}$, sobre as ranhuras, mantém o mesmo nível, menor do que sobre a espessura da parede normal. Em contrapartida, o nível do valor médio M2-RMBC, após a passagem da sonda sobre a ranhura, depende da espessura da parede remanescente. Essa amplitude é maior quando a espessura da parede remanescente é inferior. Isso indica que este nível médio de M2-RMBC após a passagem da ranhura pode ser utilizado como parâmetro para avaliar a espessura da parede remanescente.

Também pode ser visto que a configuração da sonda tem influência neste último aspecto mencionado. $\mathrm{O}$ ímã na frente do sensor dá resultados melhores do que o contrário. Este comportamento está relacionado com a gradiente de fluxo magnético produzido pela aproximação ou afastamento da sonda a partir da borda do sulco, o que aumenta a produção do RMB. A posição relativa do sensor é uma variável que afeta de maneira importante a geração e medida das emissões Barkhausen, e 
portanto irão influenciar a qualidade da detecção. Há várias questões sobre a configuração da sonda, tamanho e geometria de falha, tipo de borda, intensidade do fluxo magnético, resposta em freqüência do sensor, e velocidade de varredura que ainda precisam ser estudada mais a fundo, para melhorar a compreensão e utilização da técnica.

É interessante observar que o parâmetro M2-RMBC dos sinais filtrados no intervalo de $60-100 \mathrm{kHz}$, como mostrado na Figura 5.28 e Figura 5.29, mantêm a mesma forma para diferentes velocidades de varredura. Este parâmetro tem apenas um efeito de amplificação do sinal. Finalmente, na Figura 5.29, é possível notar a influência das configurações da sonda nos sinais de RMBC. Colocando a bobina atrás do ímã, com respeito ao movimento, se consegue um aumento na qualidade da deteç̧ão.

\subsection{MEDIÇÕES DE RMBC EM UMA AMOSTRA COM DEFORMAÇÕES PLÁSTICAS LOCALIZADAS}

\subsubsection{Materiais e métodos}

A amostra é de aço AISI -1070, com geometria $27 \times 240 \mathrm{~mm} \mathrm{~mm} \mathrm{e} 3 \mathrm{~mm}$ de espessura. Para eliminar possíveis tensões residuais, foi feito um tratamento térmico de revenido $\left(850^{\circ} \mathrm{C}, 4\right.$ horas, atmosfera controlada). Seguidamente foram induzidas duas deformações plásticas localizadas aplicando cargas de compressão. A peça usada como endentador para produzir as deformações foi um cilindro de aço com diâmetro de $65 \mathrm{~mm}$. Na Figura 5.30 são indicados os carregamentos utilizados para produzir cada uma das deformações e suas posições na amostra. 


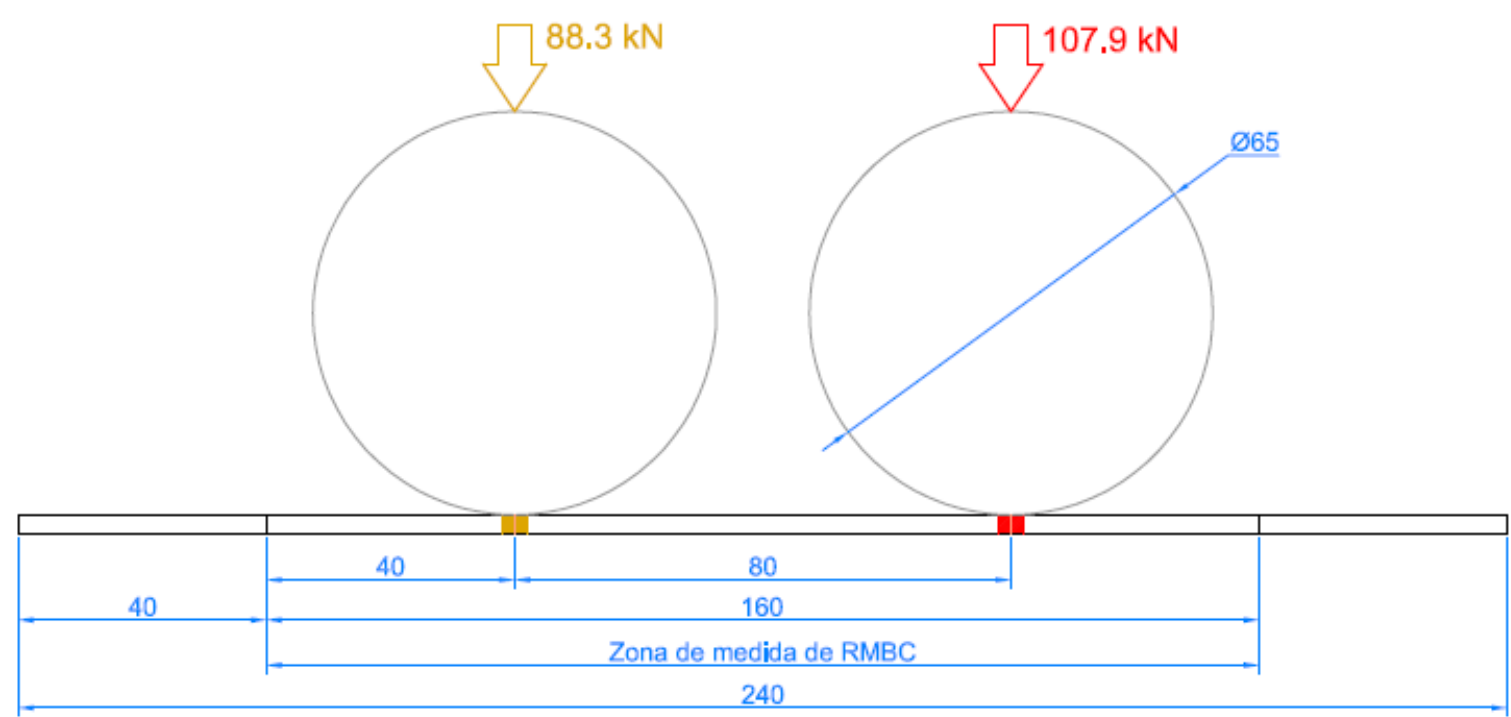

Figura 5.30 - Posição das deformações plásticas na amostra. Medidas em mm.

Os esmagamentos produzidos geraram uma variação na espessura. Dita variação aumenta a densidade de Fluxo magnético nessas regiões ao passar a sonda de RMBC, e conseqüentemente gera erros nas medições. Portanto, decidiu-se, com um procedimento de retífica e alto nível de refrigeração, eliminar as depressões geradas. Assim, a amostra ficou com uma espessura final constante de $2.75 \mathrm{~mm}$.

Nas medições de RMBC foram testadas as bobinas leitoras A, B, C e D. Amplitude do campo aplicado, velocidades de varredura, e orientação da sonda também foram analisados. Para cada condição de medida, foram feitas 4 medições.

\subsubsection{Resultados}

\subsubsection{Influência do campo aplicado}

Apresentam-se resultados de medições feitas com a bobina leitora A, posicionada atrás dos ímãs e utilizando uma velocidade de $33 \mathrm{~mm} / \mathrm{s}$. Usaram-se campos produzidos por 1, 2, 3 e 4 ímãs. A Figura 5.31 mostra os resultados da influência do campo aplicado na resposta do RMBC. 


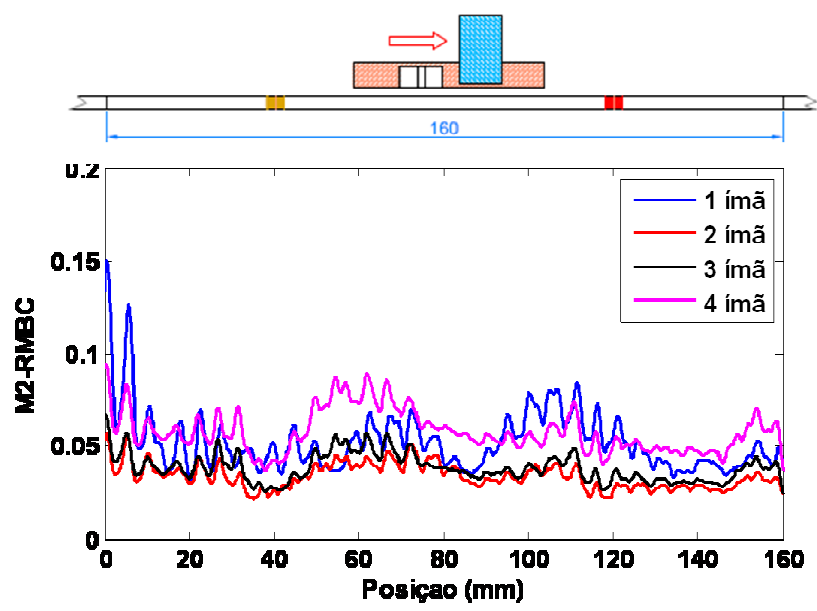

Figura 5.31 - Influência do campo aplicado na resposta do RMBC. Variação do parâmetro M2-RMBC calculado em uma banda de freqüência de análise $1-100 \mathrm{kHz}$.
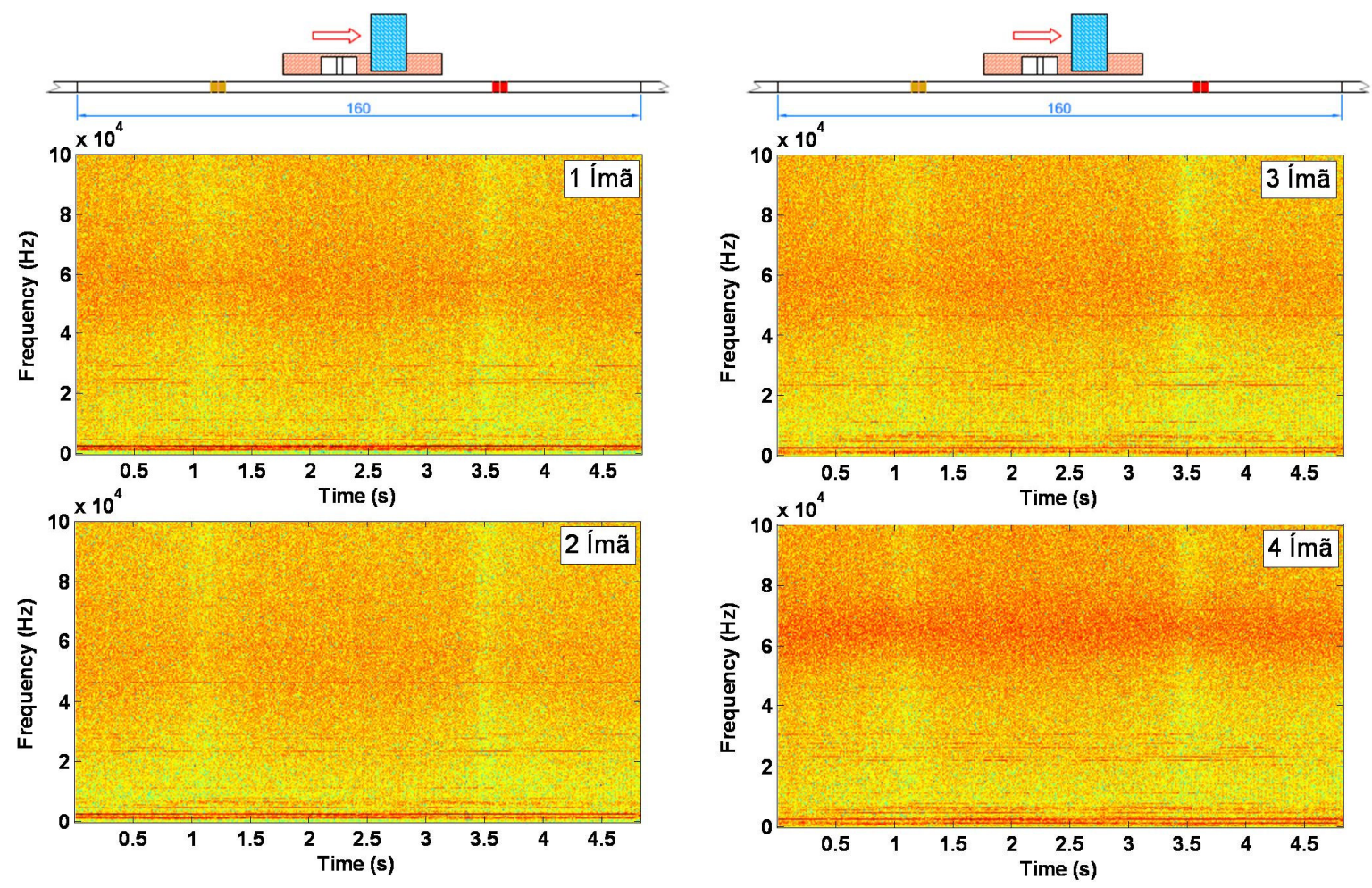

Figura 5.32 - Espectrograma do sinal. Influência do campo aplicado.

Observa-se na Figura 5.31, como, quando calculado o parâmetro M2-RMBC na banda completa de análise do sinal $(0-100 \mathrm{kHz})$, não se conseguem obter correspondências entre a o perfil gerado, e o dano inspecionado. Esse fato acontece para as 4 condições de medida. Por outro lado nos espectrogramas mostrados na 
Figura 5.32, e acima dos $30 \mathrm{kHz}$, são diferenciadas claramente bandas temporais que indicam o posicionamento das deformações geradas. O seja, são identificadas bandas verticais em cor mais claro, que indicam uma diminuição da amplitude do sinal de Barkhausen.O comportamento é similar nos 4 gráficos da Figura 5.32. Aparentemente, a resposta deficiente mostrada na Figura 5.31 é gerada por sinais de baixa freqüência $(1-30 \mathrm{kHz})$.

A Figura 5.33 mostra a variação do parâmetro $M 2-R M B C_{\text {normalizado }}$ do sinal filtrado numa banda de freqüência de análise de $30-100 \mathrm{kHz}$. Nessa condição de análise, a resposta da técnica melhora substancialmente. Consegue-se identificar a posição das duas deformações, assim com diferenciar suas amplitudes. O perfil do parâmetro M2-RMBC mostra como o sinal de Barkhausen diminui com o aumento da deformação plástica, o qual é uma resposta típica em medições de RMBE. A alta densidade de discordâncias presentes nessas zonas do material dificulta 0 movimento das paredes de domínio. Observa-se também, como a influência do campo aplicado é mínima. Obtiveram-se pequenas melhoras na resposta, quando utilizados 2 e 3 ímãs, Em geral, o grau de detecção foi similar para os 4 casos estudados.

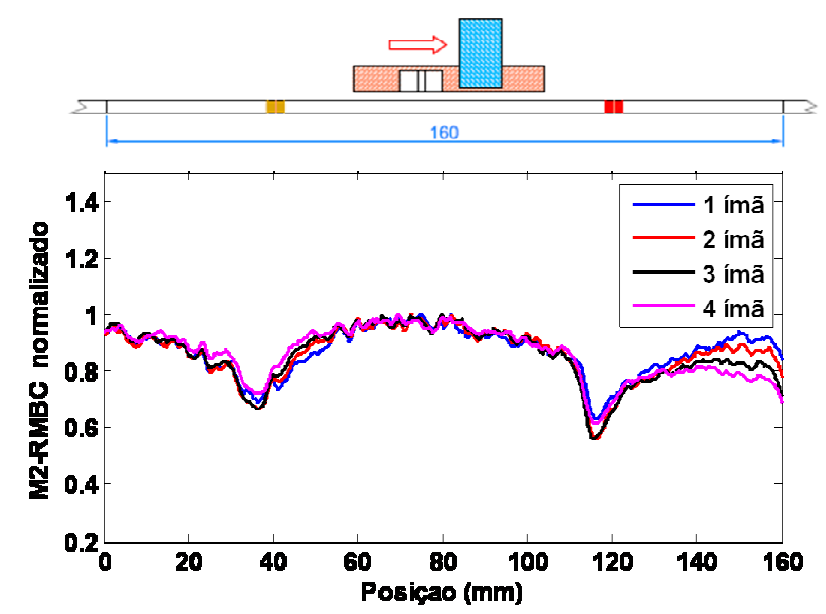

Figura 5.33 - Variação do parâmetro $\mathrm{M} 2-\mathrm{RMBC}_{\text {normalizado }}$ do sinal filtrado numa banda de freqüência de análise de $30-100 \mathrm{kHz}$. 


\subsubsection{Influência da Bobina leitora}

A Figura 5.34 mostra os resultados dos sinais obtidos com as diferentes bobinas leitoras quando é utilizado o campo magnético produzido por um ímã. Manteve-se as bobinas sempre atrás do ímã, com relação ao sentido do movimento. A velocidade utilizada foi de $33 \mathrm{~mm} / \mathrm{s}$. Observa-se nesta Figura, que nenhuma das bobinas mostrou resultados aceitáveis, quando considerada a banda completa de freqüência de análise do sinal $(1-100 \mathrm{kHz})$.

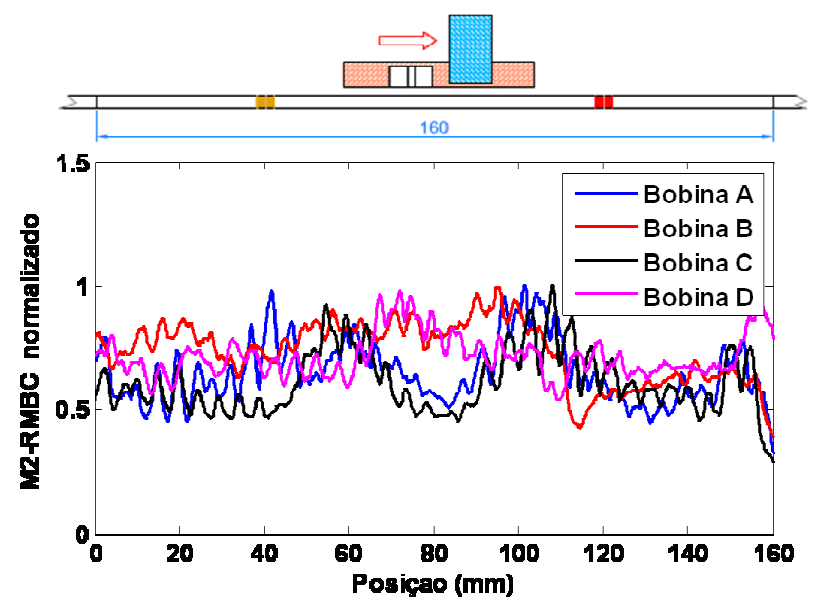

Figura 5.34 - Influência da Bobina leitora na resposta do RMBC medido. Variação do parâmetro M2RMBC na banda de freqüência de análise $1-100 \mathrm{kHz}$.

No gráfico dos espectrogramas (Figura 5.35) é observado que a melhor resposta é fornecida pela Bobina A. Nos resultados das outras bobinas, não são identificados, claramente, transientes nos gráficos tempo-frequência que correspondam com a posição das deformações plásticas geradas. Observa-se que apesar da Bobina $D$ tem maior numero de espiras (4000) que a Bobina $A(1250$ espiras), e portanto uma maior sensibilidade, ela fornece resultados piores. As bobinas são sistemas dinâmicos de $2^{\mathrm{a}}$ ordem e possuem frequência de ressonância relacionada com o número de espiras. Essa ressonância podem ser observadas pela intensidade do sinal: a bobina $B$ tem frequência de ressonância por volta de $75 \mathrm{kHz}$, a $\mathrm{C}$ em torno de $58 \mathrm{kHz}$ e a $\mathrm{D}$ em torno de $25 \mathrm{kHz}$. A bobina $A$ possui frequência de ressonância acima da banda de medição. Nos casos estudados até agora, são os sinais de 
RMBC de alta freqüência, acima dos $40 \mathrm{kHz}$, os que melhor tem identificado os tipos de danos gerados. Abaixo desse nível, geralmente tem sido registrados sinais não diretamente relacionados com as falhas estudadas.
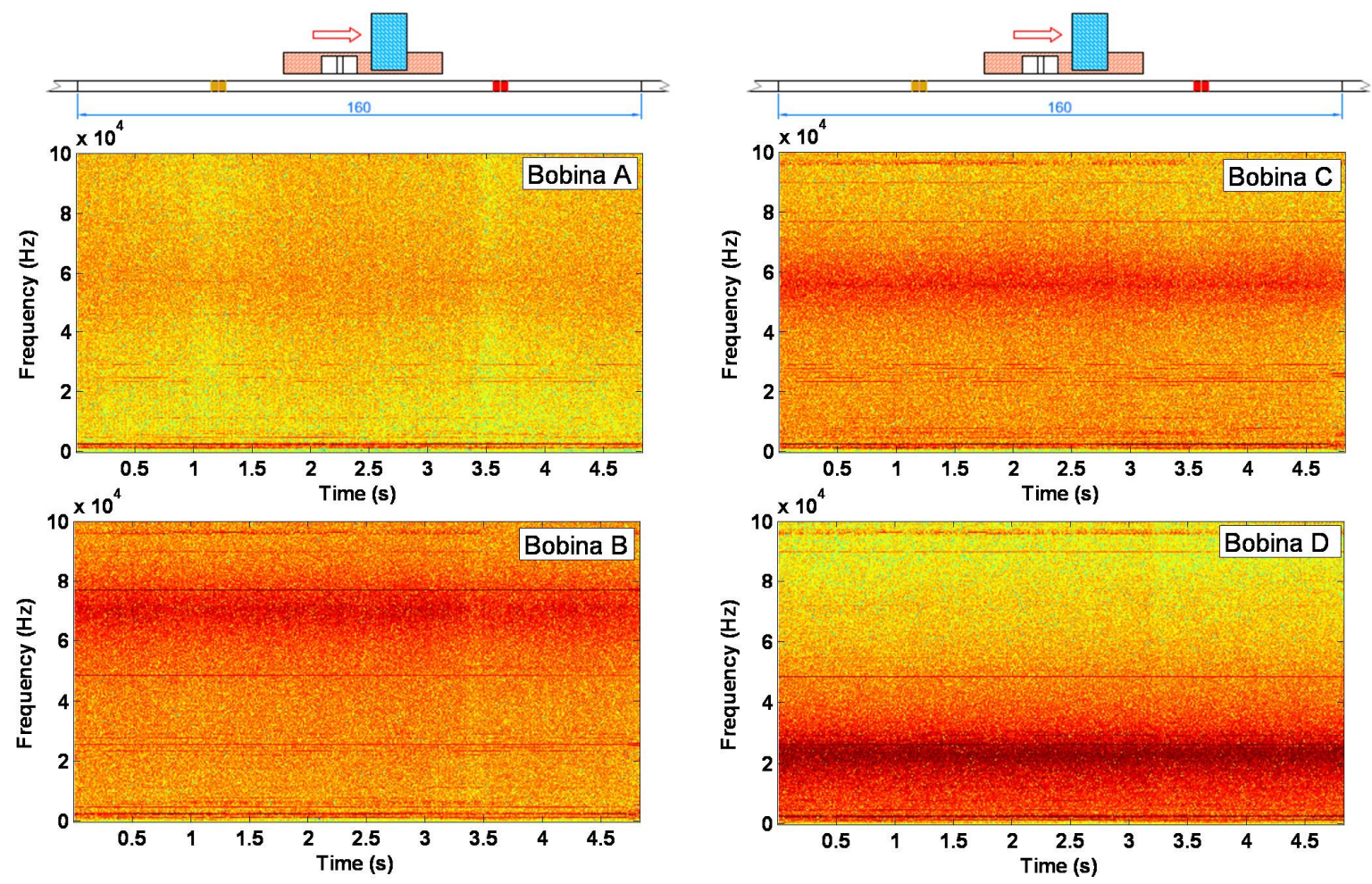

Figura 5.35 - Espectrograma do sinal. Influência da bobina leitora.

Baseados nos gráficos dos espectogramas, e procurando melhorar os resultados obtidos, foi feita uma filtragem nos sinais em determinadas bandas de freqüência de análise para cada uma das bobinas. Os resultados são amostrados na Figura 5.36.

Observa-se na Figura 5.36, nos sinais obtidos pela bobina leitora B e C, uma pequena melhoria no grau de detecção da falha. Ainda assim, a sensibilidade da bobina leitora $A$ é notoriamente superior.

Convém observar que, as características construtivas das bobinas leitoras de RMBC apresentam um alto grau de influência nos resultados das medições. Pequenas variações construtivas produzem mudanças importantes nos sinais obtidos. 


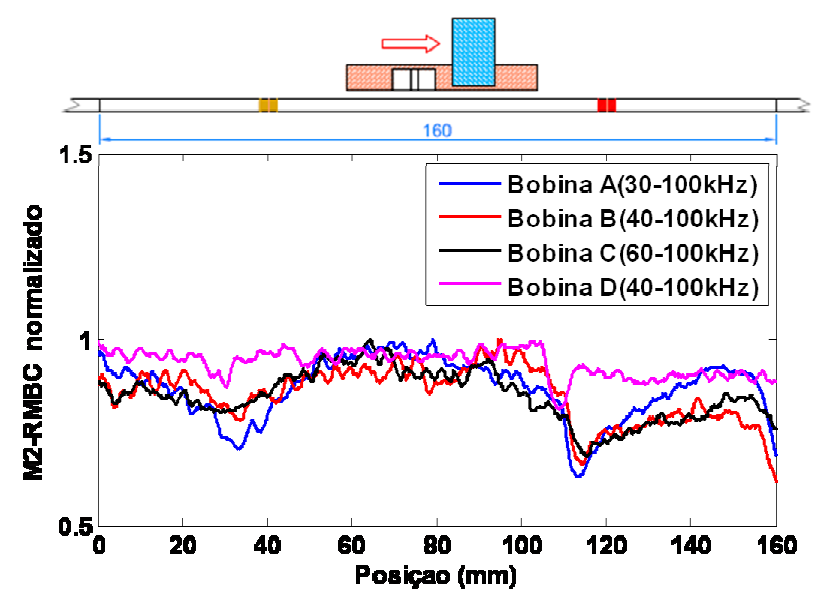

Figura 5.36 - Variação do parâmetro M2RMBC do sinal filtrado numa banda de freqüência de análise de $60-100 \mathrm{kHz}$. Respostas da bobinas leitoras B e C.

\subsubsection{Influência da velocidade e orientação da sonda}

A seguir são mostrados resultados de ensaios realizados com as seguintes condições: 4 velocidades de varredura $(9,13,23$ e $33 \mathrm{~mm} / \mathrm{s})$; bobina leitora $A$ : duas orientações da sonda (movimento com bobina atrás, e na frente do ímã). A Figura 5.37 mostra a variação do parâmetro M2-RMBC do sinal, usando quatro velocidades de varredura. Banda de freqüência de análise, $30-100 \mathrm{kHz}$.

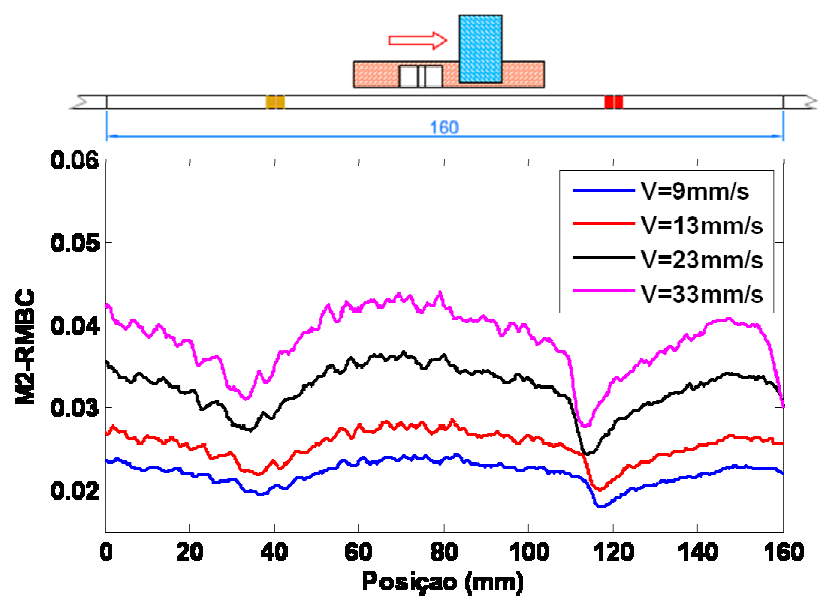

Figura 5.37 - Variação do parâmetro M2-RMBC do sinal medido. Banda de freqüência de análise $30-100 \mathrm{kHz}$.

$\mathrm{Na}$ Figura 5.37 é observado que com as 4 velocidades utilizadas, a técnica consegue detectar a localização e os níveis de deformação plástica. Além disso, é 
percebido como a amplitude do sinal é levemente amplificado com o aumento da velocidade da sonda. Um aumento na velocidade de varredura gera um aumento proporcional nas variações temporais de amplitude e direção do fluxo magnético no interior da amostra. Condições que aumentam os sinais de RMBC gerados.

A Figura 5.38 mostra os resultados da Figura 5.37 depois de fazer uma normalização em relação aos valores máximos de cada perfil gerado do parâmetro M2-RMBC. É observado nessa figura, que o nível de detecção do dano estudado, aumenta com o aumento da velocidade de varredura. $O$ que resulta numa vantagem da técnica, quando se considerar a sua aplicação na área industrial.

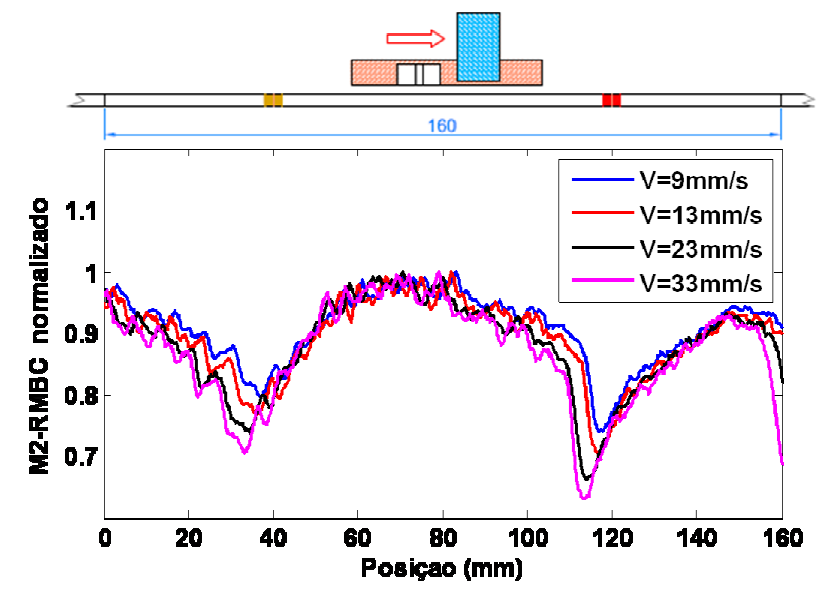

Figura 5.38 - Variação do parâmetro M2-RMBCnormalizado do sinal medido. Banda de freqüência de análise $30-100 \mathrm{kHz}$.

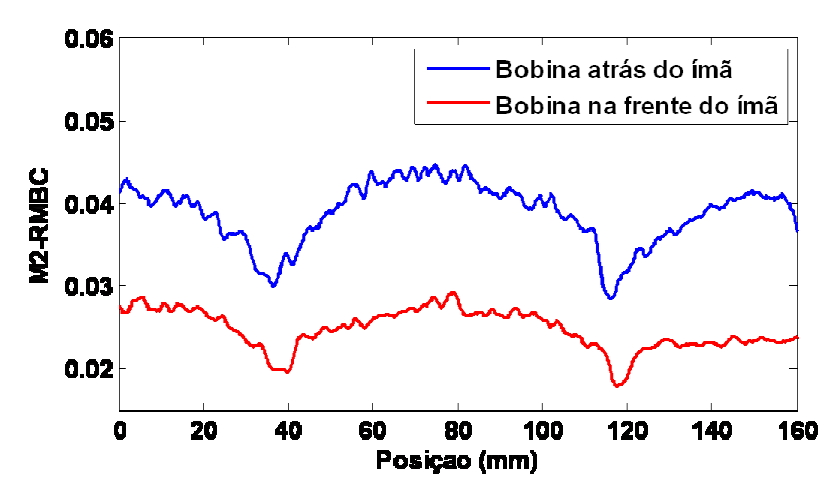

Figura 5.39 - Variação do parâmetro M2-RMBC. Banda de freqüência de análise de $30-100 \mathrm{kHz}$. Efeito da orientação a sonda.

Na Figura 5.39 são comparados os resultados obtidos, quando utilizada a sonda com a bobina atrás e na frente do ímã. Como observado nas análises anteriores, 
posicionar a bobina atrás do ímã, em relação ao sentido do movimento da sonda, gera melhores resultados (maior nível de detecção e amplitude do sinal) que quando colocada na frente.

\subsubsection{Resultados adicionais}

Com o objetivo de verificar a sensibilidade da técnica para menores níveis de deformação e em aço em estado de entrega (sem tratamento térmico de revenido), foram feitas medições de RMBC em uma segunda amostra.

Foi cortada uma amostra de 30x220X3 mm de uma lâmina de aço AISI -1070. Os carregamentos utilizados para a geração das deformações, e suas posições na amostra, são mostrados na Figura 5.40. Da mesma forma que na primeira amostra, com um procedimento de retifica, foi eliminada a variação de espessura gerada pelos esmagamentos produzidos. Variação que não superou $1 / 10 \mathrm{de} \mathrm{mm}$, o que indica o baixo nível de deformação plástica gerado. Assim, a amostra ficou com uma espessura constante final de $2.91 \mathrm{~mm}$.

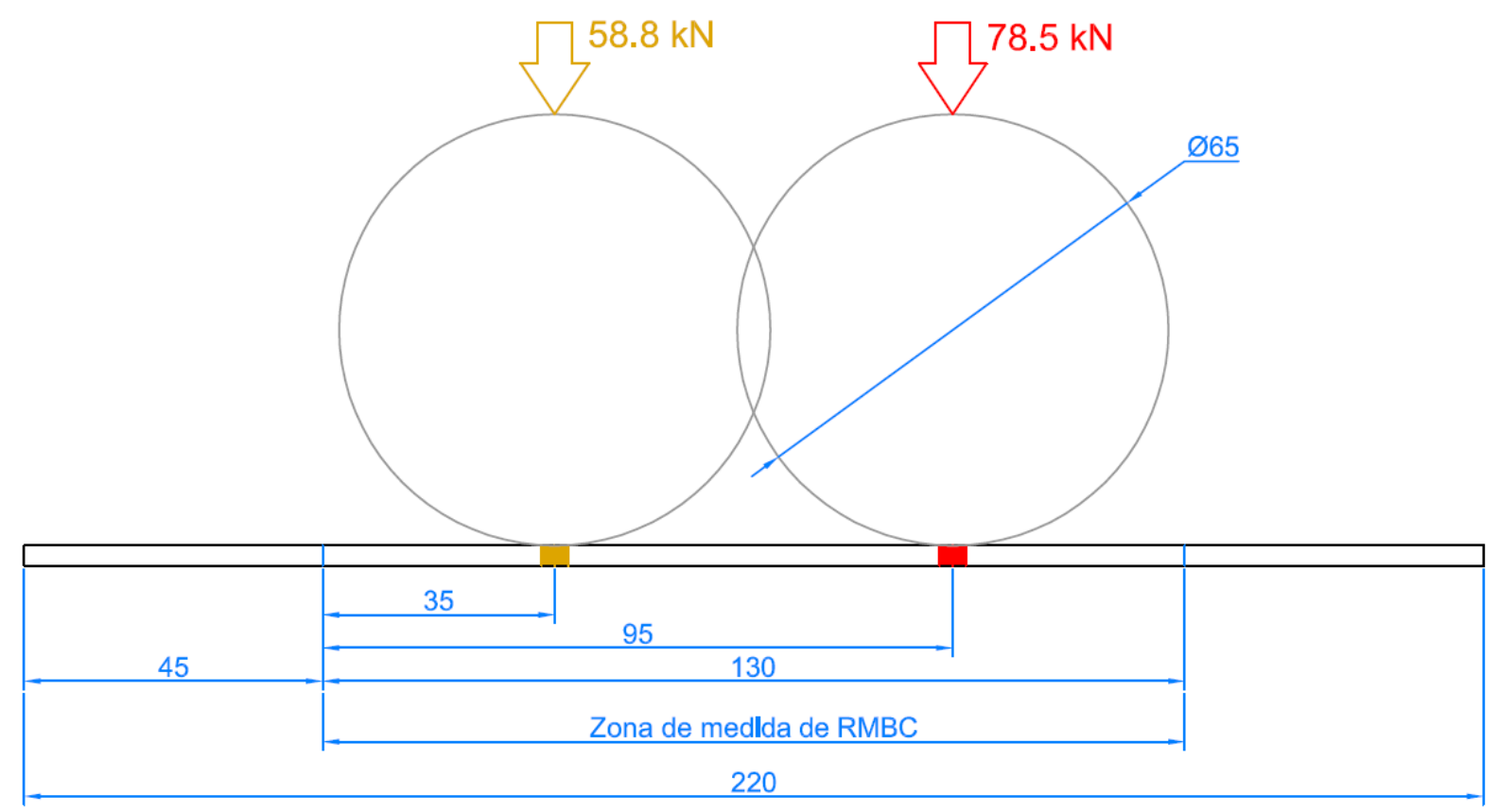

Figura 5.40 - Posição das deformações plásticas na amostra 2. Medidas em mm. 
Resultados satisfatórios são mostrados na Figura 5.41, onde se pode observar a identificação de cada uma das zonas deformadas, como a variação de intensidade dessas deformações. A sonda de RMBC foi utilizada com a bobina leitora A, 1 ímã, e velocidade de varredura de $33 \mathrm{~mm} / \mathrm{s}$. A medição foi feita colocando a bobina atrás do ímã.

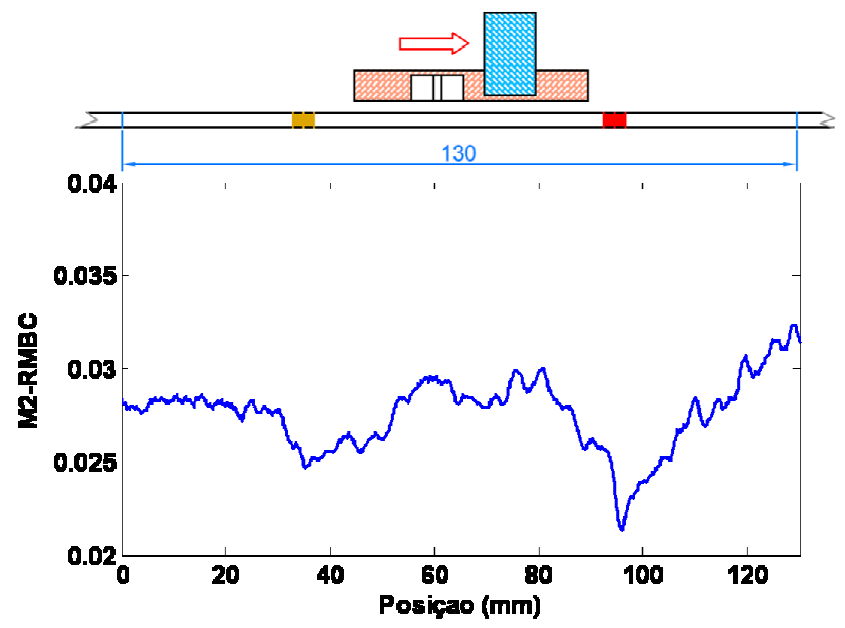

Figura 5.41 - Variação do parâmetro M2-RMBC. Banda de freqüência de análise de 30-100kHz. Amostra em estado de entrega.

\subsection{MEDIÇÕES DE RMBC EM AMOSTRAS COM TENSÃO APLICADA}

Nos casos estudados anteriormente via RMBC, tem-se utilizado casos com mudanças relativamente grandes na microestrutura do material, tais como, defeitos volumétricos, variação na composição química e deformação plástica. $\mathrm{O}$ caso estudado a seguir é mais complexo, já que as mudanças microestruturais produzidas são mínimas: deformação elástica gerada na rede cristalina, devida a tensão mecânica. Neste item são apresentados resultado de medidas de RMBC, de gradientes superficiais de tensão produzidas por flexão. 


\subsubsection{Materiais e métodos}

De uma chapa de aço AISI -1070 (Limite de escoamento, $\sigma_{e}=500 \mathrm{MPa}$ ) de $3 \mathrm{~mm}$ de espessura foram cortadas amostras de $27 \times 240 \mathrm{~mm}$. Seguidamente foi feito um tratamento térmico de revenido $\left(850^{\circ} \mathrm{C}, 4\right.$ horas, atmosfera controlada), com o objetivo de eliminar possíveis tensões residuais presentes no material. O novo limite de escoamento do material revenido, foi determinado em um ensaio de tração, $\sigma_{\mathrm{e}}=310 \mathrm{MPa}$. As amostras foram submetidas à flexão segundo o esquema mostrado na Figura 5.42. Em cada um dos extremos da amostra foi produzida uma deflexão de $4 \mathrm{~mm}$. Esta montagem gera no ponto médio uma tensão máxima de 250MPa, e uma tensão mínima nos extremos de OMPa (Cálculos teóricos). O perfil de tensão gerado e a posição da zona de medida de RMBC são mostrados na Figura 5.43. As tensões, portanto, são produzidas na faixa elástica da curva TensãoDeformação do material.

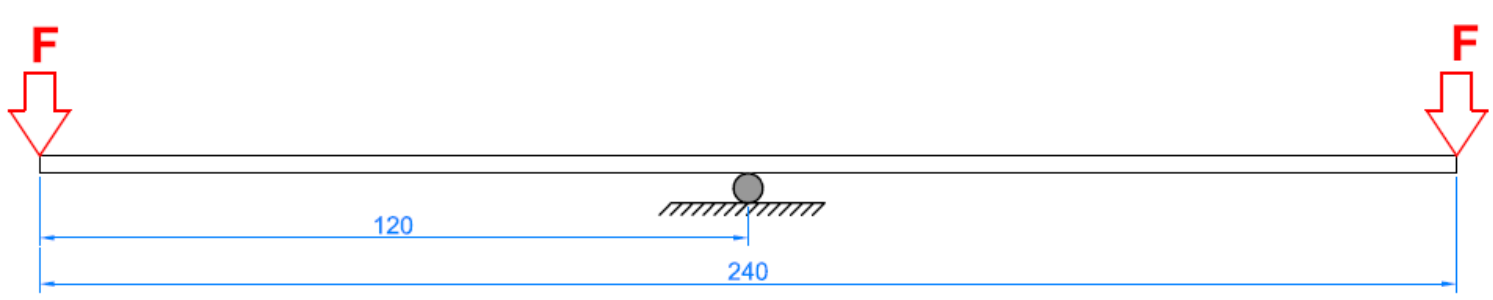

Figura 5.42 - Montagem da amostra com tensão aplicada. Medidas em mm.

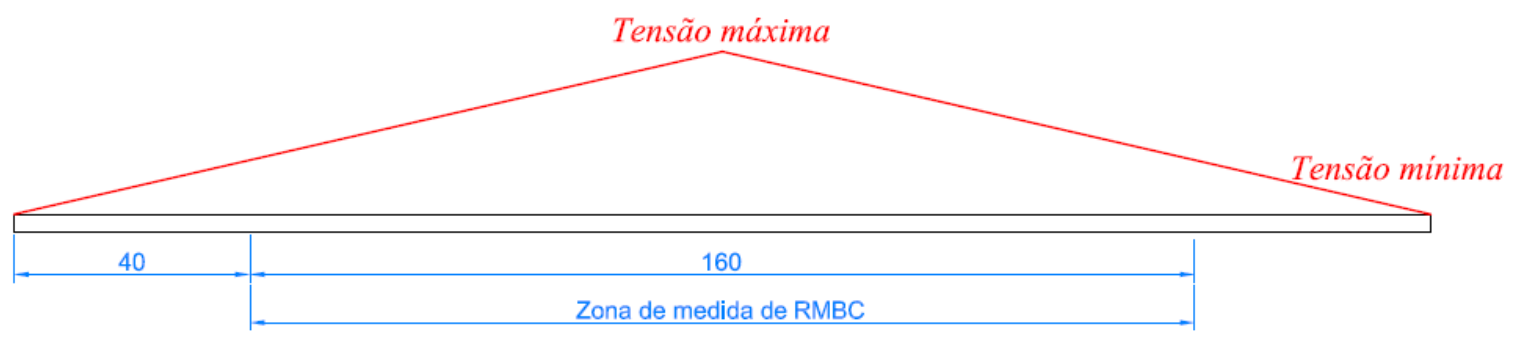

Figura 5.43 - Perfil de tensão gerado na amostra. Medidas em mm.

Foram utilizadas nas medições as bobinas leitoras $A, B$ e $C$, campos magnéticos gerados por 1, 2, 3 e 4 ímãs, e 4 velocidades de varredura $(9,13,23$ e $33 \mathrm{~mm} / \mathrm{s})$. 
Em todos os ensaios a bobina leitora foi mantida atrás do ímã, e para cada condição de medida, foram registradas 6 repetições.

\subsubsection{Resultados}

A Figura 5.44 mostra a influência do campo aplicado e a velocidade de varredura na variação do parâmetro M2-RMBC. Nesse caso, foi utilizada a bobina leitora A. Os cálculos foram obtidos tomando a banda completa de freqüência de análise do sinal $(1-100 \mathrm{kHz})$. O efeito da velocidade, foi analisado utilizando o campo magnético produzido por 1 ímã, e o efeito do campo, utilizando uma velocidade de varredura de $23 \mathrm{~mm} / \mathrm{s}$.

a)
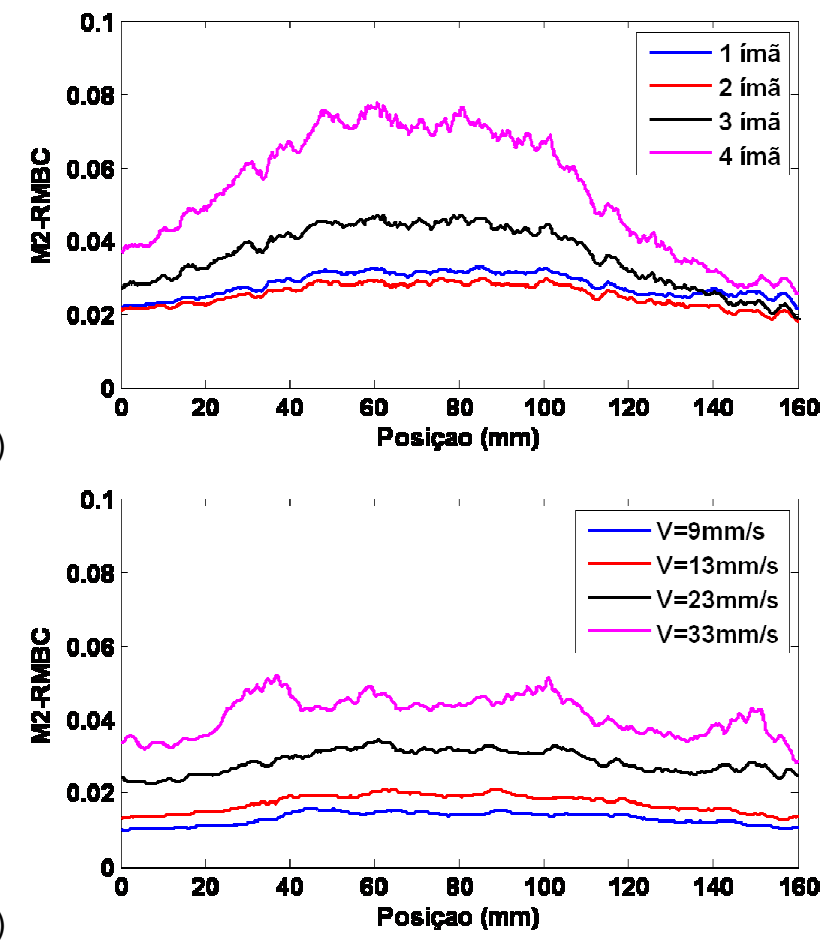

Figura 5.44 - Variação do parâmetro M2-RMBC. Resposta da bobina leitora A numa banda de freqüência de análise $1-100 \mathrm{kHz}$. a) Influência do campo aplicado, utilizando $V=23 \mathrm{~mm} / \mathrm{s}$, b) Influência da velocidade de varredura utilizando 1 ímã.

Observa-se na Figura 5.44, e sem utilizar nenhuma filtragem no sinal, uma boa correspondência entre os sinais obtidos e o perfil de tensão gerado na amostra. Os sinais de Barkhausen aumentam com 0 aumento da tensão aplicada, 
comportamento que tem sido encontrado em vários estudos realizados com RMBE, bem como nos resultados mostrados no Capitulo 3. Tensões de tração alinham os domínios magnéticos na direção da tensão, a quantidade de paredes de domínio aumenta, e conseqüentemente o RMB gerado cresce.

A Figura 5.45 mostra os espectogramas do sinal para o caso de dois campos magnéticos e velocidades utilizados. Zonas obscuras do gráficos são relacionadas a emissões Barkhausen de maior amplitude, e para o caso estudado, zonas na amostra com tensões de tração relativamente altas. Nesses gráficos observa-se como essas zonas obscuras distribuídas no centro, se atenuam para zonas mais claras nos extremos. O contraste na distribuição de cores, é amplificado com o aumento da campo magnético aplicado e a velocidade de varredura, sendo mais perceptível no gráfico referente a 4 ímãs e $V=33 \mathrm{~mm} / \mathrm{s}$.
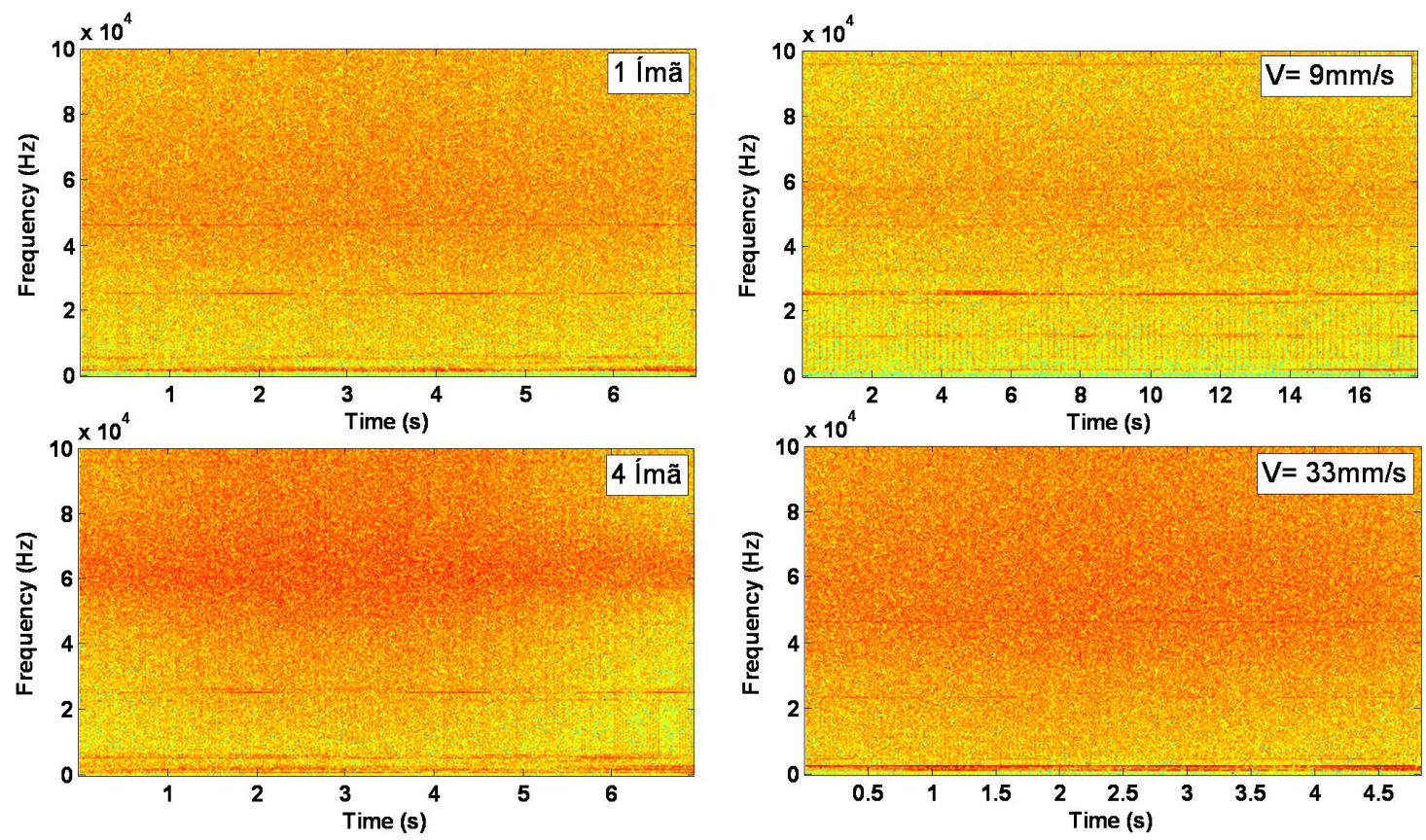

Figura 5.45 - Espectrograma do sinal. Influência do campo aplicado e velocidade de varredura.

Baseado na análise dessas imagens tempo-frequência, foi feita uma filtragem no sinal, para eliminar bandas de baixa freqüência. A Figura 5.46 mostra as distribuições do parâmetro M2-RMBC numa banda de freqüência de análise do sinal de $30-100 \mathrm{kHz}$. Nessa figura, é confirmado novamente como os sinais de RMBC de alta freqüência apresenta melhores correspondências com as tensões mecânicas. Também é observado, como o efeito do campo, além de aumentar a amplitude do 
sinal, aumenta o grau de detecção do dano. Por outro lado a velocidade tem efeito só de amplificação do sinal, a sensibilidade é minimamente afetada.

a)

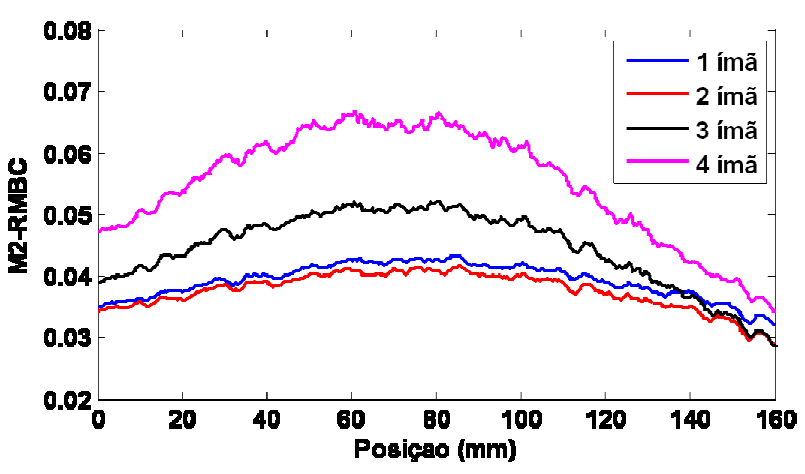

b)

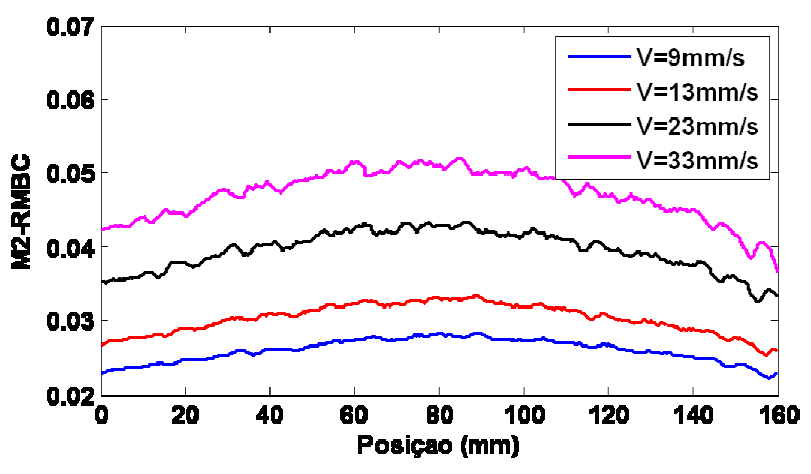

Figura 5.46 - Variação do parâmetro M2-RMBC. Resposta da bobina leitora A em uma banda de freqüência de análise $30-100 \mathrm{kHz}$. a) Influência do campo aplicado, utilizando $V=23 \mathrm{~mm} / \mathrm{s}$, b) Influência da velocidade de varredura, utilizando 1 ímã.

A Figura 5.47 mostra o efeito das características da bobina leitora, nos gráficos de

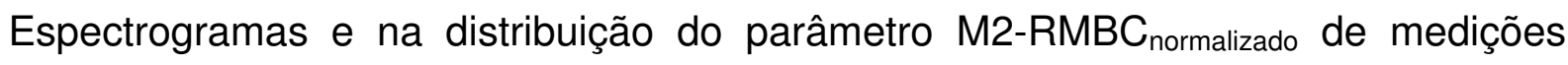
feitas na amostra com tensão aplicada.

Nos gráficos de espectrograma, é observado como as freqüências de ressonância das bobinas $\mathrm{B}$ (2000 espiras) e $\mathrm{C}$ (2500 espiras), estão localizadas respectivamente, ao redor dos 70 e $60 \mathrm{kHz}$. Já a bobina $A(1250$ espiras) tem dita freqüência bem acima da freqüência máxima de análise do sinal (100kHz). Na Figura 5.47, e para os espectogramas das bobinas B e C, é evidenciada uma banda horizontal com amplitude constante no tempo, e localizada em uma freqüência ao redor dos $33 \mathrm{kHz}$. Essa banda correspondente a um ruído externo não relacionado com o RMB. Este ruído não foi registrado (ou teve interferência mínima) nos sinais obtidos pela bobina A. 
O fato de que a resposta da bobina leitora tenha uma freqüência de ressonância dentro da banda de freqüência de análise (neste caso $1-100 \mathrm{kHz}$ ), faz com que a bobina amplifique com maior intensidade tanto, os sinais de RMB como outros ruídos não intrínsecos do material localizados perto de ditas freqüências. Essa interferência gera uma diminuição na qualidade da resposta. Ainda realizando uma filtragem seletiva para cada um dos sinais, não é possível obter resultados relevantes com as bobinas $B$ e $C$. Não entanto a bobina $A$, mostrou excelentes

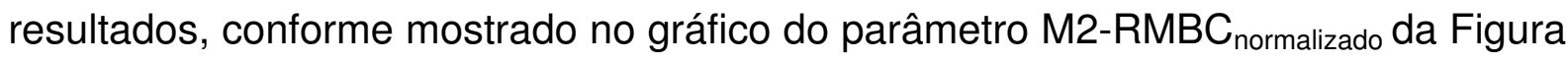
5.47 .
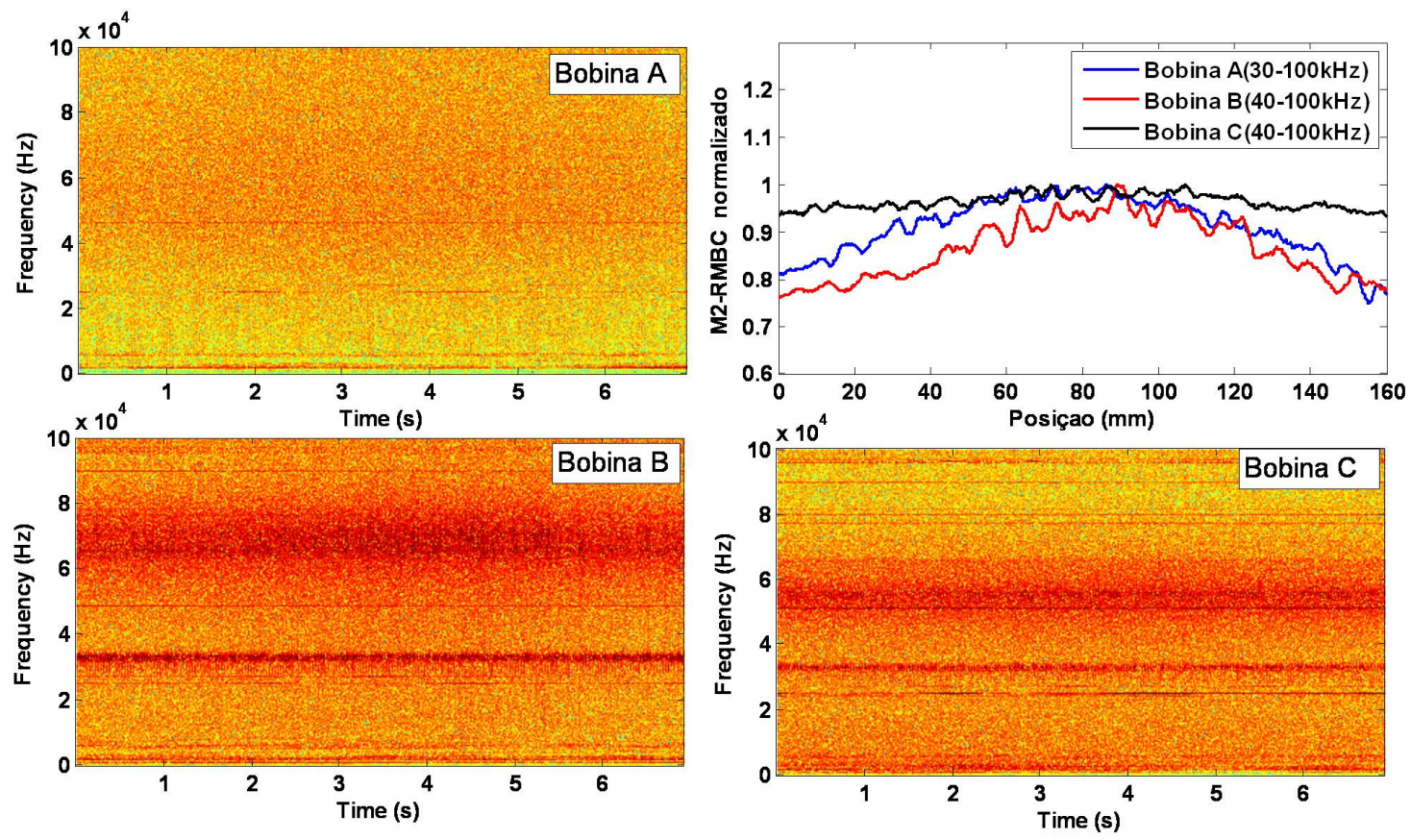

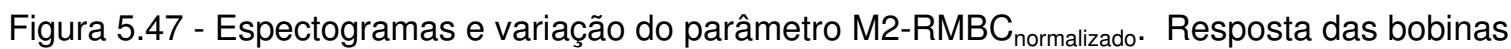
leitoras $A, B$ e C, em diferentes bandas de freqüência de análise. $V=23 \mathrm{~mm} / \mathrm{s}$. Campo magnético produzido por 1 ímã.

Com a finalidade de ratificar a capacidade da técnica de RMBC na identificação de perfis de tensão, gerados em superfícies, foi feita uma segunda montagem experimental. $O$ apoio, que na primeira montagem (Figura 5.42) estava localizado no meio da vão, esta vez foi deslocado $40 \mathrm{~mm}$ para a esquerda. As deflexões produzidas nos extremos da viga foram calculadas de tal maneira de gerar um perfil assimétrico de tensão, com tensão máxima na superfície, similar à gerada na 
primeira montagem. Assim, foram geradas deflexões nos extremos de $3.5 \mathrm{~mm}$, produzindo uma tensão máxima na posição do apoio, de 246MPa. Na Figura 5.48 são mostrados os perfis de tensão gerados nas duas montagens utilizadas.

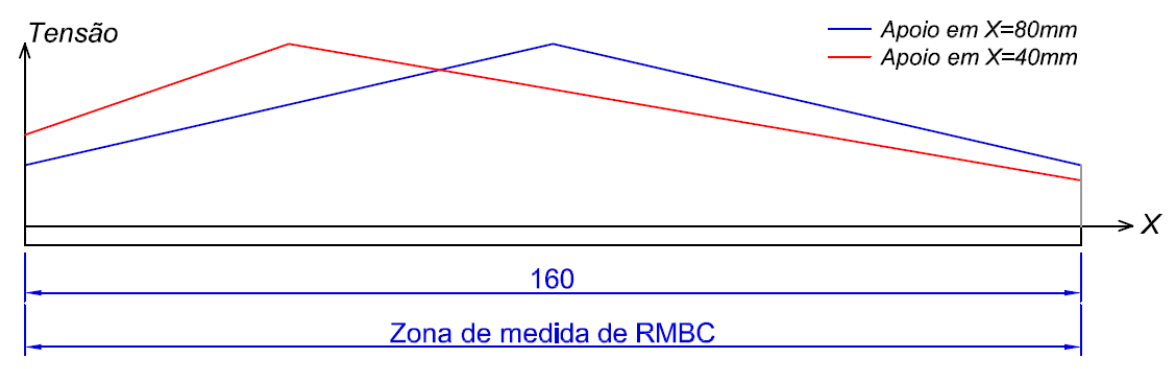

Figura 5.48 - Perfis de tensão gerados por flexão, na zona de medida de RMBC. Linha vermelha, localização do apoio em $X=80 \mathrm{~mm}$. Linha azul, localização do apoio em $X=40 \mathrm{~mm}$.

Medições de RMBC foram feitas nas duas montagens, utilizando a bobina leitora $A$, 1 Imã e velocidade de varredura de $23 \mathrm{~mm} / \mathrm{s}$. A variação do parâmetro M2-RMBC calculado numa banda de freqüência de análise de $30-100 \mathrm{kHz}$, é mostrado na Figura 5.49, para os dois casos.

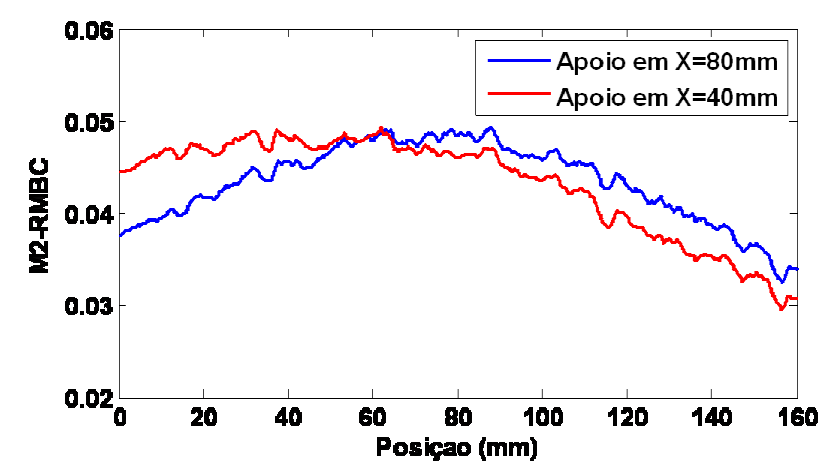

Figura 5.49 - Variação do parâmetro M2-RMBC na detecção de dois diferentes perfis de tensão gerados por flexão. Banda de freqüência de análise, $30-100 \mathrm{kHz}$. Linha vermelha, localização do apoio em $X=80 \mathrm{~mm}$. Linha azul, localização do apoio em X=40mm.

Comparando os resultados obtidos na Figura 5.49 e na Figura 5.48 é observado que a técnica de RMBC detecta, e diferencia claramente os dois perfis de tensão medidos. A posição e amplitude das tensões geradas, correspondem com o perfil de amplitude obtido do parâmetro M2-RMBC, nos dois casos. 


\subsection{CONCLUSÕES}

- Este capítulo descreve uma nova abordagem para END de inspeção de superfície, com base no conceito de Ruído Magnético de Barkhausen Continuo.

- Realizaram-se análises do comportamento magnético da sonda de RMBC por meio de simulações de elementos finitos, utilizando o software ANSYS. Os resultados mostraram que ao colocar ferrites de alta permeabilidade magnética no núcleo da bobina leitora, são geradas variações no comportamento do fluxo magnético induzido no material, justo embaixo do sensor de RMBC, favorecendo a produção e medida do RMBC no material.

- Dois métodos de processamento de sinal são apresentados a fim de estudar o sinal RMBC: uma técnica de alisamento de sinal e um método tempofreqüência. É mostrado que ao utilizar um filtro passa-banda no sinal bruto, na faixa de freqüência de $60-100 \mathrm{kHz}$, antes do alisamento do sinal, aumenta a qualidade de detecção para todas as velocidades de varredura empregadas.

- O método de RMBC foi utilizado na avaliação de diferentes amostras:

$\checkmark$ Amostra com materiais diferentes: Se conseguiu diferenciar cada um dos materiais utilizados na fabricação da amostra. Os resultados finais das medidas de RMBC foram comparados com medições de RMBE. Os resultados das duas técnicas foram similares.

$\checkmark$ Amostra com diferentes porcentagens de descarbonetação: Os resultados foram similares aos obtidos na amostra com materiais diferentes.

$\checkmark$ Detecção do tamanho e espessuras de ranhuras artificialmente produzidas: Os resultados mostram que é possível detectar o início e o fim das ranhuras geradas nas amostras, bem como a espessura da parede remanescente. 
$\checkmark$ Detecção de deformações plásticas produzidas por tensões de esmagamento: Foram detectados e diferenciados diferentes graus de deformação plástica, gerados em amostras revenidas e em estado de entrega.

$\checkmark$ Detecção de perfil superficial de tensões aplicadas: Foram identificados claramente diferentes perfis de tensão gerados na superfície de uma viga, submetida a tensões de flexão.

- A influência da configuração da sonda, velocidade de varredura, amplitude do campo magnético aplicado e análise de banda de freqüência, na qualidade de detecção, também foi estudada.

$\checkmark$ As configurações de sensores, colocando a bobina leitora atrás do ímã mostram melhores resultados.

$\checkmark$ É mostrado que a qualidade do diagnóstico, na maioria dos casos estudados, não depende da velocidade de varredura. Esse fator tem apenas um efeito de amplificação. Só no caso de medições de deformações plásticas, foi observado uma pequena melhoria no grau de detecção do dano, como o aumento da velocidade.

$\checkmark$ Um aumento na amplitude do campo gera aumentos, nas amplitudes dos sinais de RMBC, e na qualidade do diagnostico.

$\checkmark$ Em todos os casos estudados, uma análise dos sinais em bandas de alta freqüência (acima dos $30 \mathrm{kHz}$ ), mostraram os melhores resultados. 


\section{CONCLUSÕES.}

Nesta tese resultados inovadores foram apresentados e discutidos referente à aplicação da técnica de medição do Ruído Magnético de Barkhausen na inspeção de falhas em aços. Estudos relacionados com a medição de tensões de flexão e avaliação de dureza foram realizados utilizando a técnica tradicional do RMB. Além disso, aportes importantes foram realizados no desenvolvimento da nova técnica de medição do RMB, Barkhausen Continuo, onde foram estudadas 5 aplicações diferentes de mapeamento de falhas. Das análises feitas em cada um dos casos estudados, foram tiradas as seguintes conclusões.

\section{MEDIÇÕES DE TENSÕES DE FLEXÃO VIA RMB.}

- A correspondência entre diferentes parâmetros de análise do sinal de RMB e os valores de tensão aplicada, foi analisada. Foram calculados os parâmetros, Amplitude pico, Posição pico, $\mathrm{RMB}_{\text {rms }}$ e $\mathrm{RMB}_{\text {energy. Os parâmetros calculados a }}$ partir dos gráficos de envelope, Posição pico e Amplitude pico, apresentaram maiores desvios e menores correlações na medição de tensão, que os parametros $R M B_{\text {rms }}$ e $R M B_{\text {energy. }}$ Na medição de tensões elásticas via $R M B$, o parâmetro que mostra o melhor comportamento é o $\mathrm{RMB}_{\text {energy. }}$.

- A resposta de diferentes faixas temporais e de amplitude do sinal de RMB, na medição de tensão, não apresenta vantagens em relação à análise do sinal completo.

- Diferentes amplitudes de correntes e freqüências de excitação foram aplicadas na sonda de RMB. Encontrou-se que a resposta do sinal de RMB melhora, quando utilizados valores baixos nesses parâmetros de medida.

- Para o material estudado, aço SAE-1070, a amplitude do parâmetro RMB energy calculado a partir medidas de RMB paralelas a tensão aplicada, aumenta com a 
tensão, enquanto $\circ \mathrm{RMB}_{\text {energy }}$ de medições de $\mathrm{RMB}$ transversais, diminuem. $\mathrm{O}$ comportamento sempre e o mesmo, e independe do ângulo em que seja aplicada a tensão em relação à direção de laminação.

\section{UTILIZAÇÃO DO RMB NA AVALIAÇÃO DE DUREZA EM AÇOS.}

Medições do RMB foram realizadas para caracterizar gradientes de microestruturas geradas em amostras de SAE-4140 e SAE-6150, por tratamentos térmicos de ensaio Jominy.

- As análises metalograficas das amostras dos dois materiais ensaiados apresentaram uma variação continua de densidade de defeitos cristalinos (principalmente discordâncias) ao longo da superfície submetida a diferentes taxas de resfriamento. Na medida em que aumenta a taxa de resfriamento, a microestrutura muda de martensita a bainita inferior e finalmente a bainita superior.

- Em regiões próximas da superfície temperada foram geradas baixas emissões de $\mathrm{RMB}$, e os parâmetros calculados, Amplitude pico e $\mathrm{RMB}_{\mathrm{rms}}$ apresentaram amplitudes baixas. Por outro lado a posição da amplitude máxima do envelope do RMB, parâmetro "Posição pico", esteve localizado em correntes de excitação relativamente altos. Já, nas medições feitas em posições afastadas da superfície temperada, as emissões de RMB aumentaram e o comportamento de todos os parâmetros foi inverso.

- Os parâmetros calculados dos sinais de RMB acompanharam a gradiente microestrutural gerado. Foram encontrados bons coeficientes de correlação lineares entre os diferentes parâmetros calculados do RMB e as medidas de dureza.

- Um aumento da freqüência de excitação (de $5 \mathrm{~Hz}$ para $20 \mathrm{~Hz}$ ) gera uma leve diminuição nos coeficientes de correlação linear entre os diferentes parâmetros calculados do RMB e às amplitudes de dureza. 


\section{BARKHAUSEN CONTÍNUO.}

Foi descrita uma nova abordagem para END de inspeção de superfície, com base no conceito de Ruído Magnético de Barkhausen Continuo.

- Através de uma análise de simulação por elementos finitos, foi verificado que ao colocar ferrites de alta permeabilidade magnética no núcleo da bobina leitora da sonda do RMBC, são geradas variações no comportamento do fluxo magnético induzido no material, justo embaixo do sensor, favorecendo a produção e medida do RMBC no material.

- Dois métodos de processamento de sinal são apresentados a fim de estudar o sinal RMBC: uma técnica de alisamento de sinal e um método tempo-freqüência. É mostrado que ao utilizar um filtro passa-banda no sinal bruto, na faixa de freqüência de $30-100 \mathrm{kHz}$, antes do alisamento do sinal, aumenta a qualidade de detecção para todas as velocidades de varredura empregadas.

- O método de RMBC foi utilizado na avaliação de diferentes falhas:

$\checkmark$ Em amostra com materiais diferentes, foi possível diferenciar cada um dos materiais utilizados na fabricação da amostra. Em outro caso similar, foram identificados materiais com e sem descarbonetação.

$\checkmark$ Em amostras tipo chapa, è possível detectar o início e o fim de ranhuras artificialmente produzidas na faze oposta da chapa, bem como a espessura da parede remanescente.

$\checkmark$ São detectados e diferenciados diferentes graus de deformação plástica produzidas por tensões de esmagamento.

$\checkmark$ Perfis superficiais de tensão aplicada, gerada por flexão, foram identificados com boa precisão.

- A influência da configuração da sonda, velocidade de varredura e amplitude do campo magnético aplicado, na qualidade de deteç̧ão, também foram estudadas. 
$\checkmark$ As configurações de sensores, colocando a bobina leitora atrás do ímã mostram melhores resultados.

$\checkmark$ É mostrado que a qualidade do diagnóstico, na maioria dos casos estudados, não depende da velocidade de varredura. Esse fator tem apenas um efeito de amplificação.

$\checkmark$ Um aumento na amplitude do campo geram aumentos nas amplitudes dos sinais de RMBC, e na qualidade do diagnostico.

\section{TRABALHOS FUTUROS.}

Ainda há inúmeras aplicações que aguardam maiores desenvolvimentos, envolvendo o Ruído Magnético de Barkhausen, tanto na sua configuração estática e, sobretudo, na configuração contínua.

Particularmente citamos:

- Examinar a possibilidade de realizar mapeamento de tensões na profundidade do material.

- Estudar procedimentos de medida e análise dos sinais, em mapeamento de tensões biaxial.

- Analisar o efeito de deformações plásticas, na medição de tensões elásticas via RMB.

- Avaliar a Influência, da presença de freqüências de ressonância, da bobina leitora, dentro da banda de freqüência de análise dos sinais, na qualidade da resposta do RMB, analisando medições de tensão e dureza.

- Estudar a influência da magnitude do campo magnético aplicado, na utilização do RMB para medição de dureza em aços.

- Mesmo que os resultados apresentados neste trabalho indicam a viabilidade do uso do RMBC, a fim de inspecionar diferentes tipos de falhas, há muitas questões que permanecem abertas. Entre elas, estudar a influência de diversos fatores na qualidade de detecção, como: mudança de velocidade da sonda, distância entre a sonda e a superfície inspecionada, e configurações geométricas diferentes de ímãs. 


\section{REFERÊNCIAS}

ALFRED E. CROUCH, THOMAS BEUKER. In-line stress measurement by the continuous barkhausen method. International Pipeline Conference, Calgary, Alberta, Canadá, 2004.

ANGLADA-RIVERA, J. et al. Magnetic Barkhausen Noise and hysteresis loop in commercial carbon steel: influence of applied tensile stress and grain size. Journal of Magnetism and Magnetic Materials, v. 231, n. 2-3, p. 299-306, 2001.

ARAGONESES, P. et al. Dynamic coercive field of bistable amorphous FeSiB wires. Journal of Physics D-Applied Physics, v. 31, n. 5, p. 494-497, 1998.

ASTM - AMERICAN STANDARD FOR TESTING MATERIALS. A 255-02. Standar Test Methods for Determining Hardenability of Steel. June 1999.

ASTM Handbook, Metallography and Microstructure, Ninth Edition, vol. 9, 1985.

BABBAR, V. et al. Mechanical damage detection with magnetic flux leakage tools: Modeling the effect of localized residual stresses. leee Transactions on Magnetics, $v$. 40, n. 1, p. 43-49, 2004.

BABBAR, V.; CLAPHAM, L. Residual magnetic flux leakage: A possible tool for studying pipeline defects. Journal of Nondestructive Evaluation, v. 22, n. 4, p. 117-125, 2003.

BARKHAUSEN, $\mathrm{H}$. Two with help of new repeating rediscovered appearances by $\mathrm{H}$ Barkhausen - The silence during unmagnetising of iron. Physikalische Zeitschrift, v. 20, p. 401-403, 1919.

BLAOW, M. et al. Effect of deformation in bending on magnetic Barkhausen noise in low alloy steel. Materials Science and Engineering a-Structural Materials Properties Microstructure and Processing, v. 386, n. 1-2, p. 74-80, 2004.

et al. Effect of hardness and composition gradients on Barkhausen emission in case hardened steel. Journal of Magnetism and Magnetic Materials, v. 303, n. 1, p. 153-159, 2006.

. et al. Magnetic Barkhausen noise: the influence of microstructure and deformation in bending. Acta Materialia, v. 53, n. 2, p. 279-287, 2005.

BOZORTH, R.M. Ferromagnetism. 2 ed. New York: D. Van Nostrand Company Inc., 1951. 
CALLISTER. W. D. Materials Science and Engineering. An introduction. 7 ed. John Wiley \& Sons, Inc. 2007.

CAMPOS, M. A. et al. Characterization of the elastic-plastic region in AISI/SAE 1070 steel by the magnetic barkhausen noise. Ndt \& E International, v. 41, n. 8, p. 656-659, 2008.

CAPO-SANCHEZ, J. et al. Analysis of the stress dependent magnetic easy axis in ASTM 36 steel by the magnetic Barkhausen noise. Ndt \& E International, v. 40, n. 2, p. 168-172, 2007.

et al. Magnetic Barkhausen measurements for evaluating the formation of Luders bands in carbon steel. Ndt \& E International, v. 40, n. 7, p. 520-524, 2007.

, PADOVESE, L. Magnetic Barkhausen noise measurement by resonant coil method. Journal of Magnetism and Magnetic Materials, v. 321, n. 18, p. L57-L62, 2009.

CHIKAZUMI, S. Physics of Magnetism, 2 ed. New York: John Wiley \& Sons, Inc, 1966.

COHEN L.; Time Frequency Analysis: Theory and Applications; Prentice Hall, 1994.

CULLITY, B.D; GRAHAM C. D. Introduction to Magnetic Materials, 2 ed, IEEE PRESS, Published by John Wiley \& Sons, Inc., 2009.

DAVUT, K.; GUR, C. H. Monitoring the microstructural changes during tempering of quenched SAE 5140 steel by magnetic barkhausen noise. Journal of Nondestructive Evaluation, v. 26, p. 107-113, 2007.

DHAR, A. et al. Influence of Luders bands on magnetic Barkhausen noise and magnetic flux leakage signals. Journal of Materials Science [S.I.], v. 37, n. 12, p. 2441-2446, 2002.

. et al. Influence of uniaxial plastic deformation on magnetic Barkhausen noise in steel. Ndt \& E International, v. 34, n. 8, p. 507-514, 2001.

FRANCO, F. A.; PADOVESE, L. R. NDT flaw mapping of steel surfaces by continuous magnetic Barkhausen noise: Volumetric flaw detection case. Ndt \& E International, v. 42, n. 8, p. 721-728, 2009.

GUR, C. H.; CAM, I. Comparison of magnetic Barkhausen noise and ultrasonic velocity measurements for microstructure evaluation of SAE 1040 and SAE 4140 steels. Materials Characterization, v. 58, n. 5, p. 447-454, 2007. 
HALLER, T. R.; KRAMER, J. J. OBSERVATION OF DYNAMIC DOMAIN SIZE VARIATION IN A SILICON-IRON ALLOY. Journal of Applied Physics, v. 41, n. 3, p. 1034-\&, 1970.

HIGUCHI, T. Magnetizing frequency-dependence of magnetic domain size in 50 percent nickel-iron alloy deduced from a statistical-analysis of core noise. Journal of Physics DApplied Physics, v. 7, n. 17, p. 2379-2385, 1974.

HWANG, D. G.; KIM, H. C. The influence of plastic-deformation on barkhausen effects and magnetic-properties in mild-steel. Journal of Physics D-Applied Physics, v. 21, n. 12, p. 1807-1813, 1988.

JILES D. C. Introduction to magnetism and magnetic materials. Chapman and Hall, New York, 1994.

. Dynamics of domain magnetization and the Barkhausen effect. Czechoslovak Journal of Physics, v. 50, n. 8, p. 893-924, 2000.

The effect of stress on magnetic barkhausen activity in ferromagnetic steels. leee Transactions on Magnetics, v. 25, n. 5, p. 3455-3457, 1989.

KAPLAN, M. et al. Characterization of dual-phase steels using magnetic barkhausen noise technique. Journal of Nondestructive Evaluation, v. 26, p. 79-87, 2007.

KINSER, E. R. et al. Modeling microstructural effects on Barkhausen emission in surface-modified magnetic materials. leee Transactions on Magnetics , v. 41, n. 10, p. 3292-3294, 2005.

KLEBER, $X$. et al. Ferrite-martensite steels characterization using magnetic Barkhausen noise measurements. Isij International, v. 44, n. 6, p. 1033-1039, 2004.

KRAUSE, T. W. et al. Characterization of the magnetic easy-axis in pipeline steel using magnetic barkhausen noise. Journal of Applied Physics, v. 75, n. 12, p. 7983-7988, 1994.

et al. Investigation of the stress-dependent magnetic easy axis in steel using magnetic Barkhausen noise. Journal of Applied Physics, v. 79, n. 8, p. 4242-4252, 1996.

LO, C. C. H. Depth profiling of magnetic properties of surface-modified materials by model-assisted multi-frequency analysis of Barkhausen effect signals. Journal of Applied Physics [S.I.], v. 103, n. 7, 2008.

- et al. Development of a magnetic NDE imaging system using magnetoresistive devices. Review of Progress in Quantitative Nondestructive Evaluation, Vols 22a and 22b, v. 20, p. 931-938, 2003. 
MANDACHE, C. et al. Investigation of optimum field amplitude for stress dependence of magnetic barkhausen noise. leee Transactions on Magnetics, v. 43, p. 3976-3983, 2007.

MANDAL, K. et al. The effects of defect depth and bonding stress on magnetic Barkhausen noise and flux-leakage signals. Journal of Physics D-Applied Physics, v. 30, n. 14, p. 1976-1983, 1997.

. Use of Magnetic Barkhausen noise and magnetic flux leakage signals for analysis of defects in pipeline steel. leee Transactions on Magnetics, v. 35, n. 3, p. 2007-2017, 1999.

MITRA, A.; JILES, D. C. Magnetic Barkhausen emissions in as-quenched Fe-Si-B amorphous alloy. Journal of Magnetism and Magnetic Materials, v. 168, n. 1-2, p. 169176, 1997.

MOORTHY, V. et al. Effect of tensile deformation on micromagnetic parameters in $0.2 \%$ carbon steel and 2.25Cr-1Mo steel. Acta Materialia, v. 47, n. 6, p. 1869-1878, 1999.

. et al. Evaluation of applied and residual stresses in case-carburised En36 steel subjected to bending using the magnetic Barkhausen emission technique. Acta Materialia, v. 52, n. 7, p. 1927-1936, 2004.

. et al. Magnetic Barkhausen emission technique for detecting the overstressing during bending fatigue in case-carburised En36 steel. Ndt \& E International, v. 38, n. 2, p. 159-166, 2005.

. et al. Magnetic Barkhausen emission technique for evaluation of residual stress alteration by grinding in case-carburised En36 steel. Acta Materialia, v. 53, n. 19, p. 4997-5006, 2005.

. et al. Surface and subsurface stress evaluation in case-carburised steel using high and low frequency magnetic Barkhausen emission measurements. Journal of Magnetism and Magnetic Materials, v. 299, n. 2, p. 362-375, 2006.

PADOVESE, L. R. et al. Time-frequency and time-scale analysis of Barkhausen noise signals. Proceedings of the Institution of Mechanical Engineers Part G-Journal of Aerospace Engineering, v. 223, n. G5, p. 577-588, 2009.

PALA, J.; BYDZOVSKY, J. Dependence of Barkhausen noise in plastically deformed steel on frequency and nonlinearity of magnetizing field. Acta Physica Polonica A, v. 113, n. 1, p. 23-26, 2008.

PALMA, E. S. et al. Fatigue damage assessment in AISI 8620 steel using Barkhausen noise. International Journal of Fatigue, v. 27, n. 6, p. 659-665, 2005. 
PEREZ-BENITEZ, J. A. et al. A study of plastic deformation around a defect using the magnetic Barkhausen noise in ASTM 36 steel. Ndt \& E International, v. 41, n. 1, p. 5358, 2008.

. et al. Characterization of angular dependence of macroscopic magnetic properties in ASTM 36 steel using magnetic Barkhausen noise. Ndt \& E International, v. 40, n. 4, p. 284-288, 2007.

QI, X. et al. Research on the Relation Between Magnetic Barkhausen Noise and Ferromagnetic Materials with Different Heat Treatments. Journal of Testing and Evaluation, v. 36, n. 6, p. 525-533, 2008.

STEFANITA, C. G. et al. Plastic versus elastic deformation effects on magnetic Barkhausen noise in steel. Acta Materialia, v. 48, n. 13, p. 3545-3551, 2000.

STUPAKOV, O. et al. Governing conditions of repeatable Barkhausen noise response. Journal of Magnetism and Magnetic Materials, v. 321, n. 18, p. 2956-2962, 2009.

SZCZYGLOWSKI, J. Influence of eddy currents on magnetic hysteresis loops in soft magnetic materials. Journal of Magnetism and Magnetic Materials, v. 223, n. 1, p. 97102, 2001.

TUMANSKI, S. Induction coil sensors - a review. Measurement Science \& Technology, v. 18, n. 3, p. R31-R46, 2007.

U. HOFMANN et al. Non-destructive evaluation (NDE) of quality characteristics of heavy plates. Luxembourg: European Commission, technical steel research, 2005. (Final report. Contract No 7210-PR/248 1 July 2000 to 30 June 2003). Disponível em: < http://bookshop.europa.eu/eubookshop/download.action?fileName=KINA21436ENS 00 2.pdf\&eubphfUid=155838\&catalogNbr=KI-NA-21436-EN-S..$>$. 